\title{
Making leadership cases impactful: a comparison of teaching methods
}

\author{
SAM YOUNG
}

A thesis submitted in fulfilment of the requirements for the degree of Master of Commerce in Management and International Business, The University of Auckland, 2014. 
In New Zealand, tertiary educators tend to use teaching cases as a tool to teach management subjects, including leadership. Teaching cases are usually delivered in a lecturer-led combination theory lecture/case discussion pattern; the 'Hybrid' approach. In contrast, the "Case in Point" method delivers cases in a student-led, solely discussion-based way. This thesis aimed to compare these two methods to find which provided the most effective leadership learning.

The research design was based on retroductive grounded theory seeking to answer whether students make sense of leadership teaching cases differently when they are delivered using different methods. Using the same teaching plans, resources and teaching cases to teach the same sub-topics, two sets of 'Hybrid' and "Case in Point" sessions were run in Leadership classes, with students undertaking a Bachelor of Sport and Recreation degree at three AUT campuses: on the North Shore, in Manukau and in Nelson. Overall, 42 students took part. Methods of observations, interviews, questionnaires and focus-groups were used to collect qualitative data from the participants, coded for effective teaching characteristics and analysed using the CAQDAS software, QDA Miner Lite.

The results indicate that students do make sense of leadership teaching cases differently when they are delivered using different methods. Effective learning of leadership is enhanced when teaching with cases which have impact. More effective learning takes place in the "Case in Point" sessions, discussion was student-led and the learning had more longevity for the participants. The "Case in Point" method of teaching appears to be a more effective delivery method for leadership learning than the 'Hybrid' method. The evidence, however, is not entirely clear due to difficulties in ensuring consistency in teaching approach and session delivery between campuses, and differences in impact between the cases used.

In this thesis, the clarification of the factors which comprise impactful cases will assist the writers of cases, and those who seek to teach with them. The solutions proposed to avoid the difficulties encountered in this research will be useful to future researchers seeking to compare the "Case in Point" and 'Hybrid' approaches.

Keywords: Case study | Case method | Management education | Leadership | Teaching case typology | Teaching case selection | Case structure and inclusions | Teaching note structure and inclusions 
Like so many students before me, I owe a debt of gratitude to those who have shared my learning; to those who have assisted me through crises of confidence, time, knowledge and life balance.

I need to acknowledge the contribution of my initial supervisor, Professor Brad Jackson. He was remarkable for his uncanny ability to ask pointed and pertinent questions; in guiding yet not giving me the answer; and in holding up a mirror so that eventually I could see what he saw. His knowledge and understanding of both leadership and education added a great deal of depth to my research. Heartfelt thanks.

I was lucky enough to have two supervisors. I need to also thank Dr. Liliana Eraković of the University of Auckland's Business School, for providing background information on the mechanics of her strategic management teaching using the Case in Point method and for baby-sitting me so helpfully and tirelessly through the Research Ethics application and thesis editing process.

A huge vote of thanks has to go to my three teaching colleagues; Dr. Lynn Kidman and Gaye Bryham from AUT, and Nic John from NMIT. Without their selfless help in carrying out the Approach A and Approach B sessions, I could not have been able to undertake this research.

This research was also undertaken with the support of Dr. Henry Duncan, Head of School, Sport and Recreation at AUT, and Claire Dallison, my Nelson Programme Leader.

Many academics also unstintingly provided papers, and additional clarifications around the basis of their work, including Professor Bruce Kimball (Department of Educational Studies, Ohio State University, USA), Professor Laurence Lynn Jr (Lyndon B. Johnson School of Public Affairs, The University of Texas at Austin, USA), Professor Steve Kempster (Lancaster University, UK), Assistant Professor Jen Katz-Buonincontro (School of Education, Drexel University, USA), and Dr. Kathleen T Ross (Executive Vice President, Leadership Development, Healthy Companies International, USA).

I also want to thank my husband, Jan Kuwilsky, who has coped with being short-changed in my attentions for two years in order to allow me to complete this piece of work. He has proof-read most of the script and is due an especial vote of thanks for attempting to persuade me into functional English usage. Additionally, my colleague and Communications lecturer, Ellie Fijn, proofed the close to final version. I ignored them at my peril, thus any mistakes which follow are entirely my responsibility. 


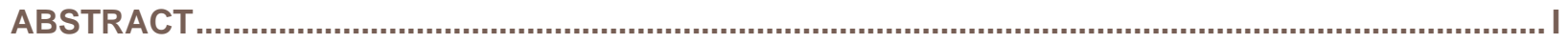

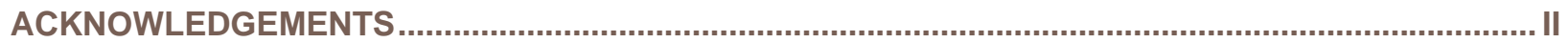

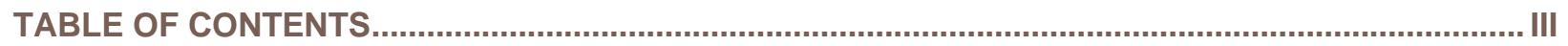

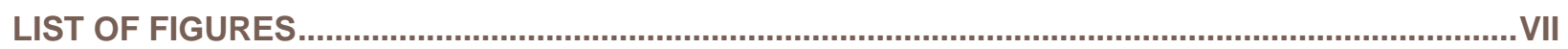

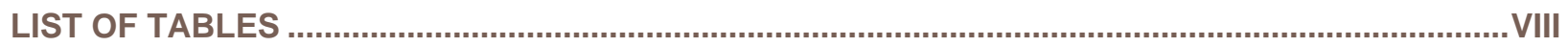

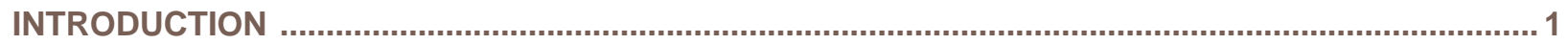

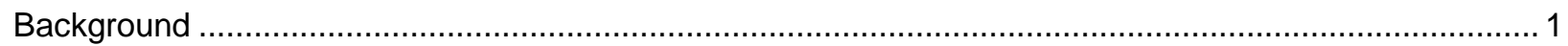

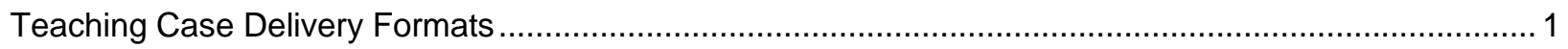

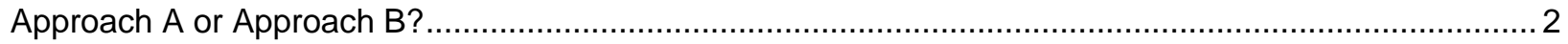

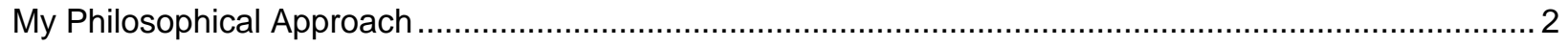

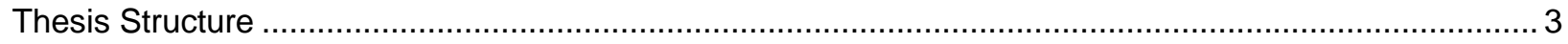

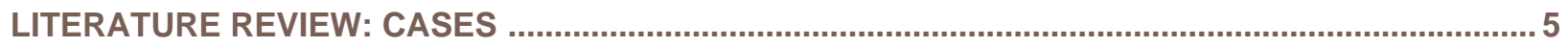

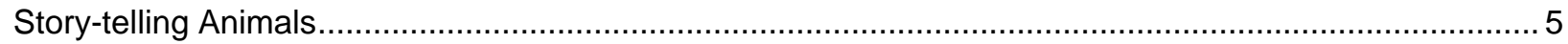

The Case as a Story

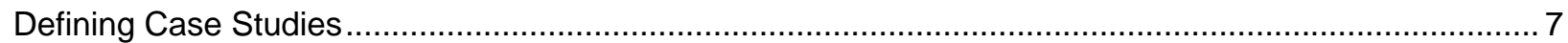

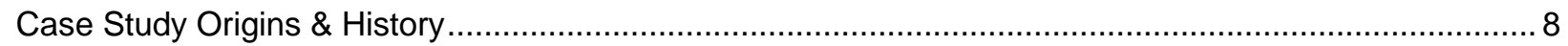

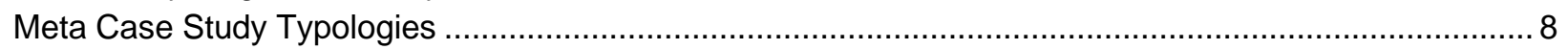

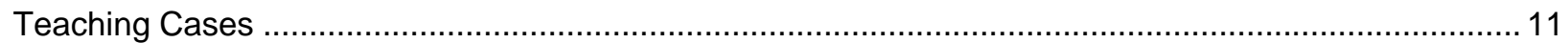

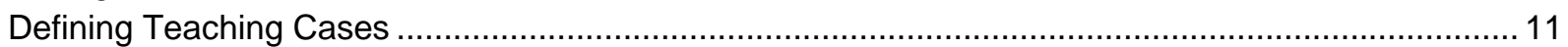

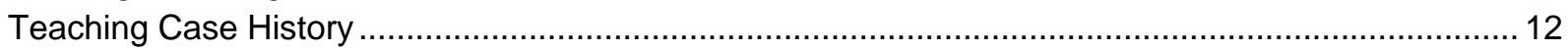

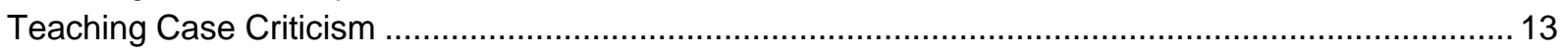

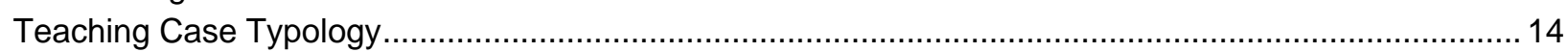

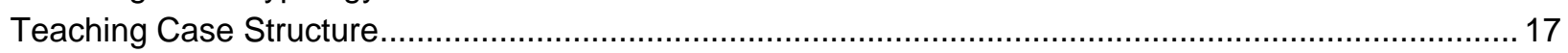

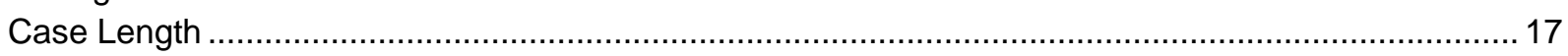

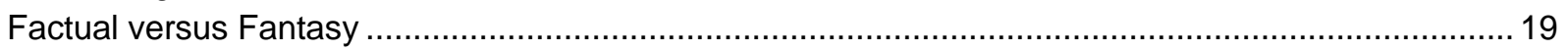

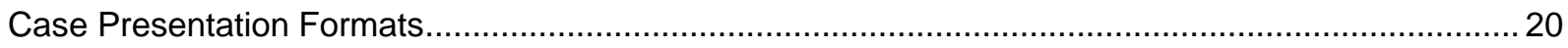

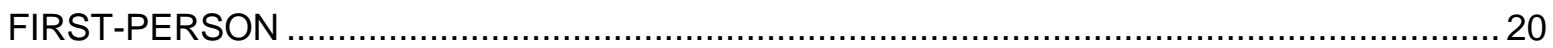

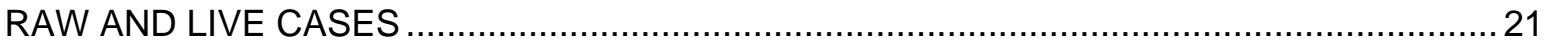

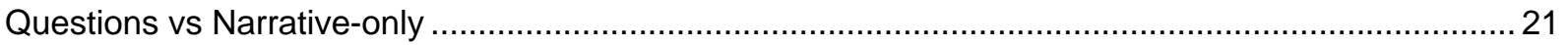

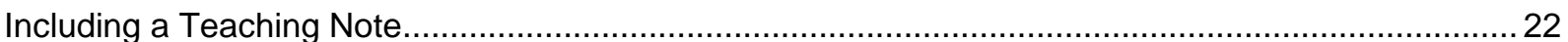

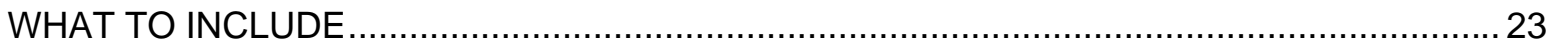

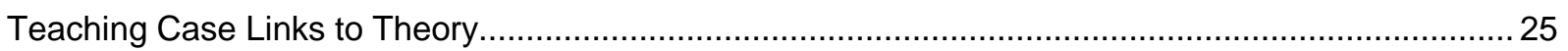

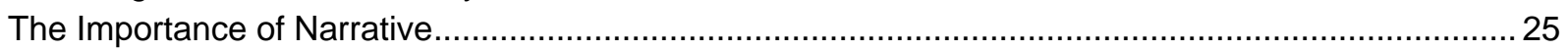

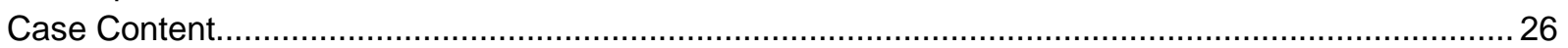

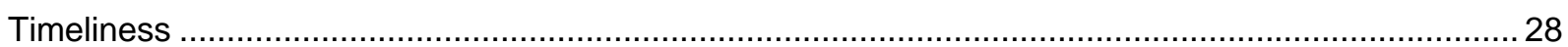

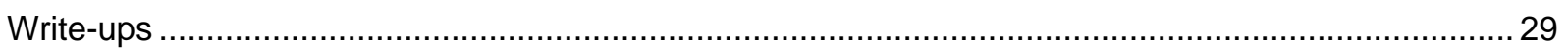

What is Different About Leadership Teaching Cases? ................................................................ 30

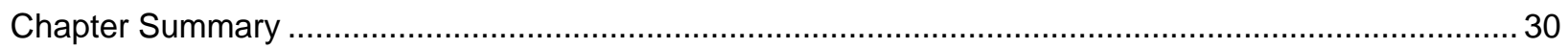

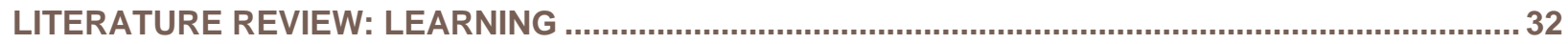

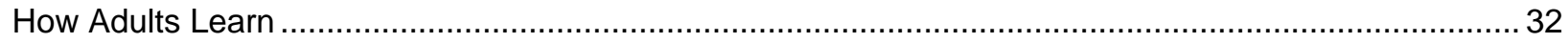

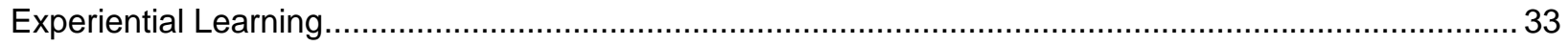

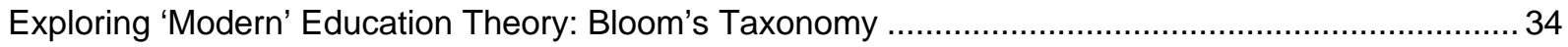

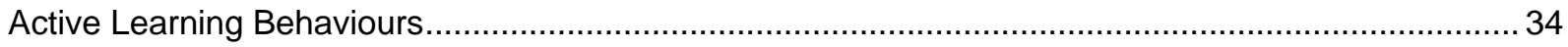




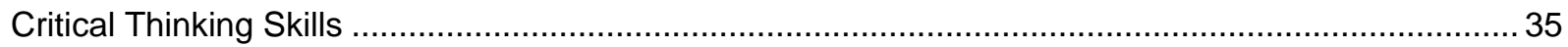

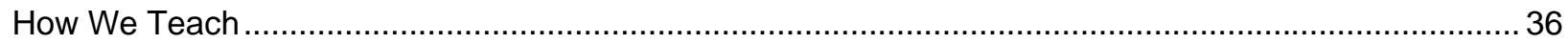

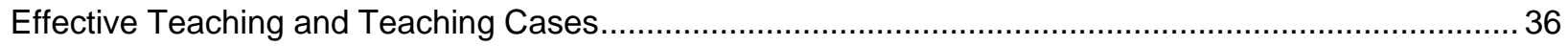

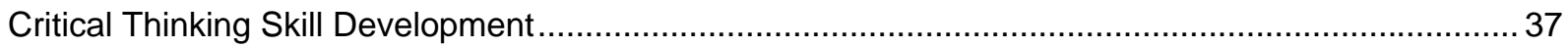

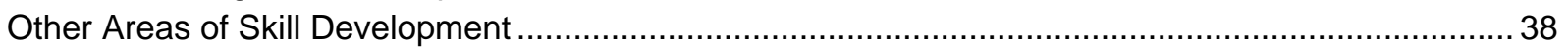

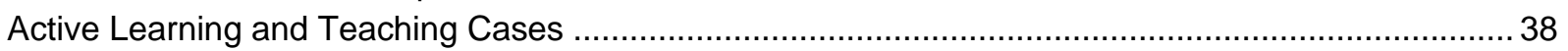

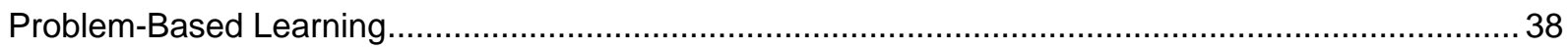

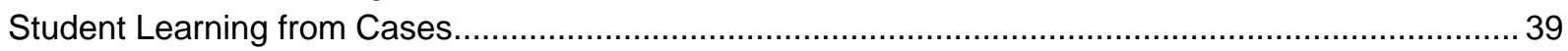

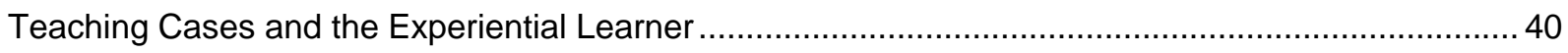

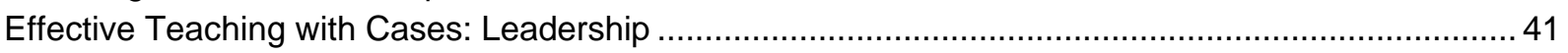

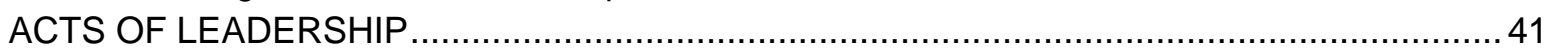

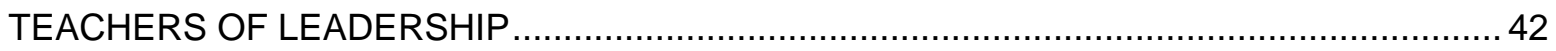

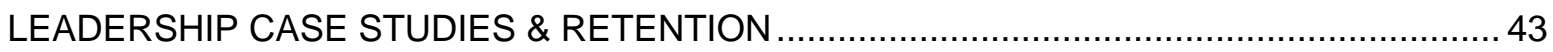

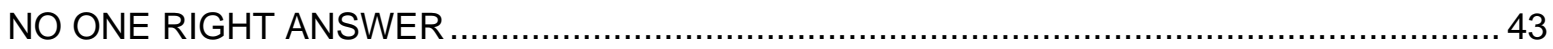

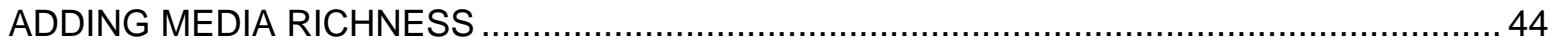

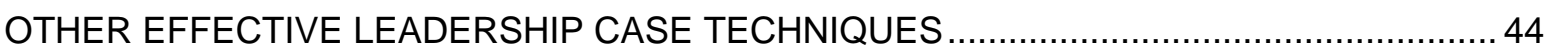

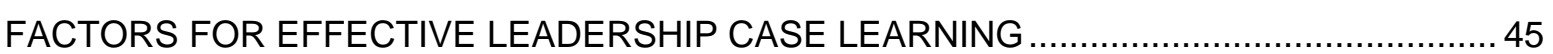

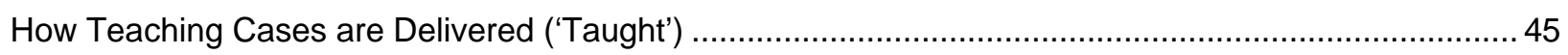

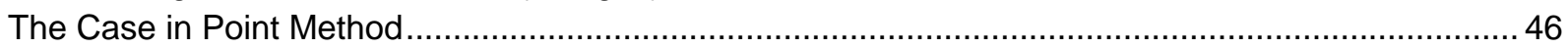

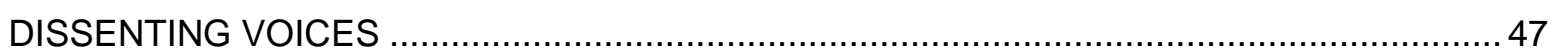

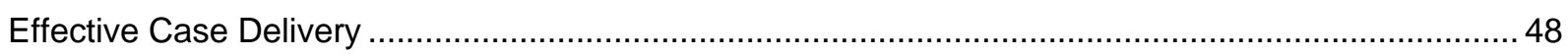

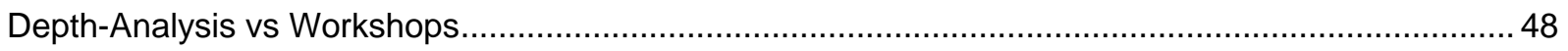

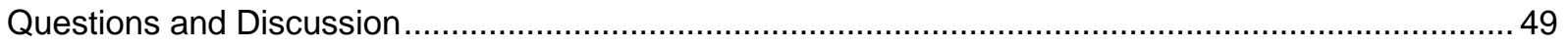

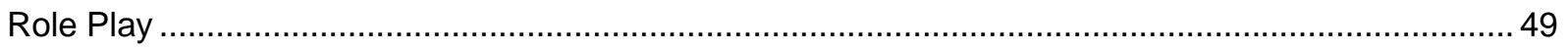

Leadership Theory Relevant to Effective Leadership Case Learning ................................................ 50

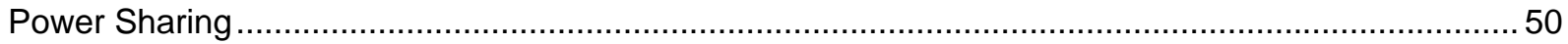

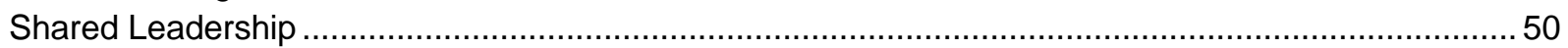

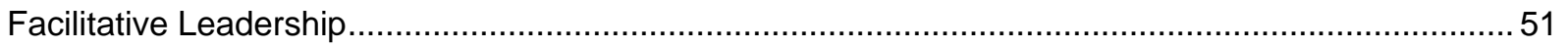

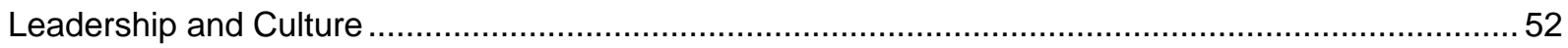

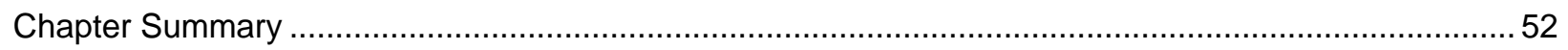

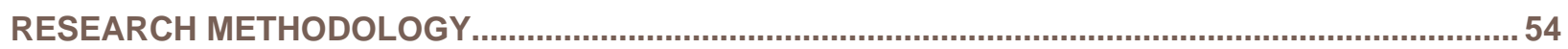

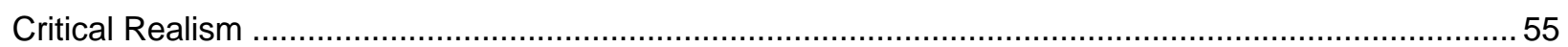

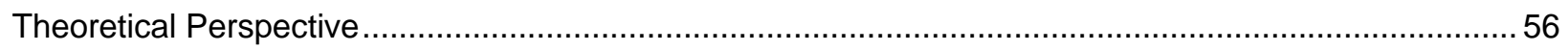

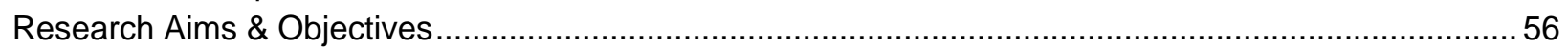

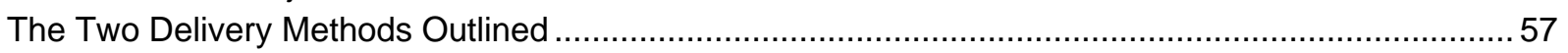

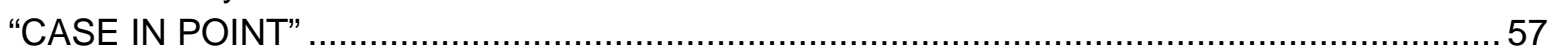

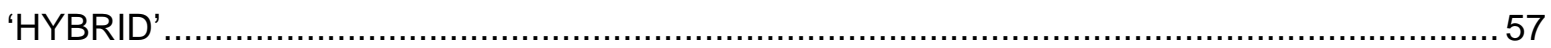

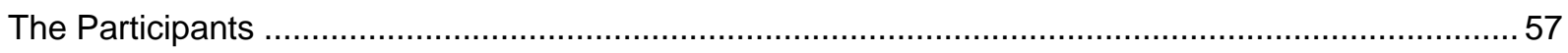

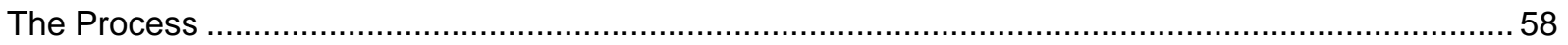

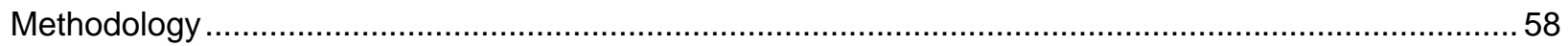

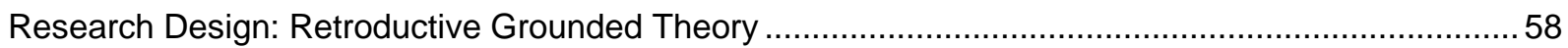

Methods

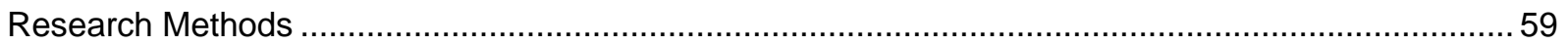

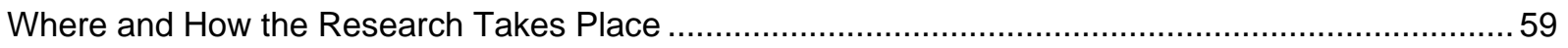

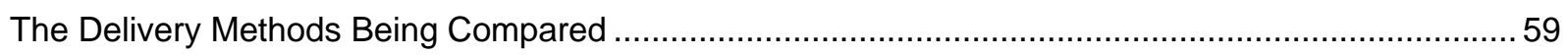

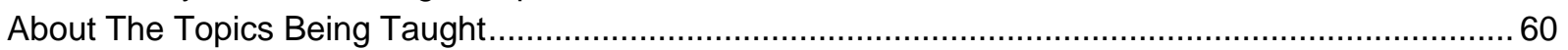

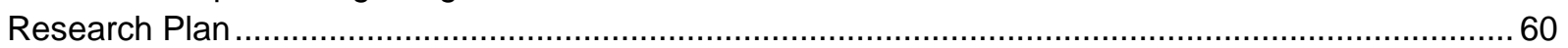

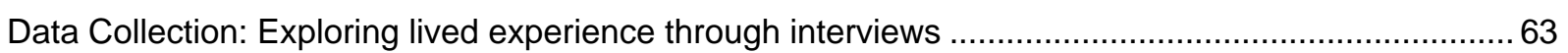

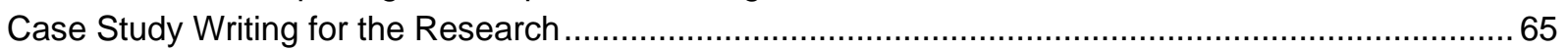

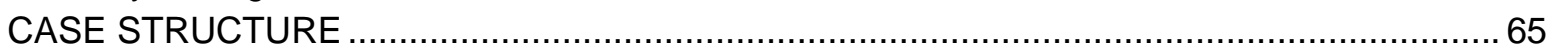

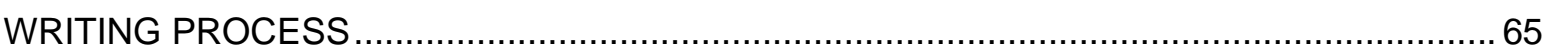




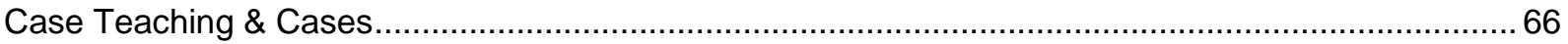

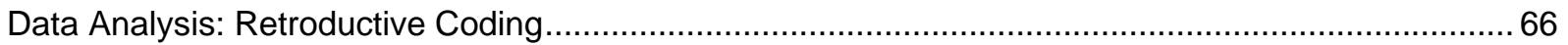

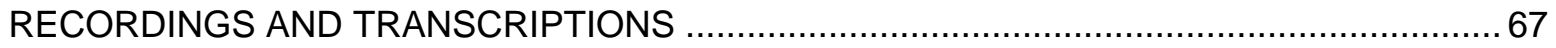

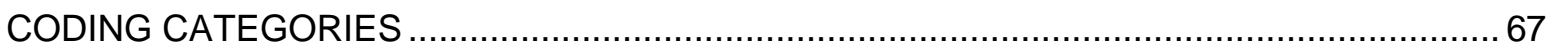

THE CODING PROCESS

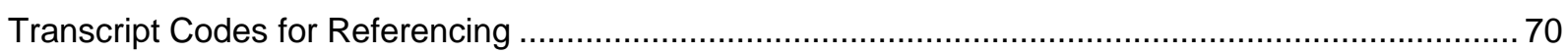

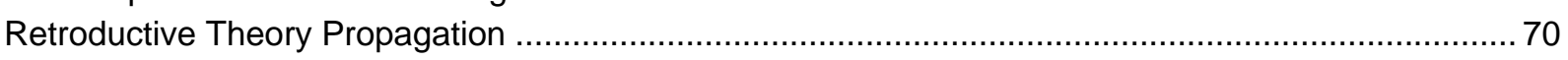

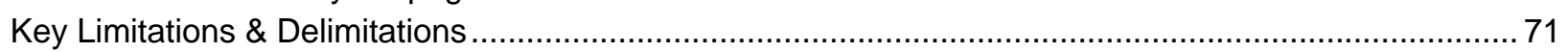

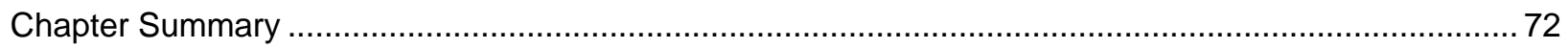

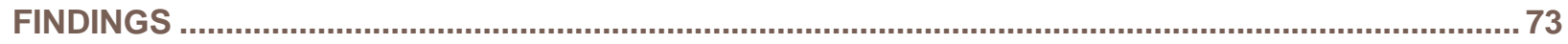

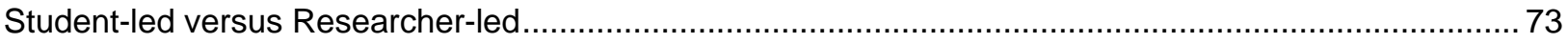

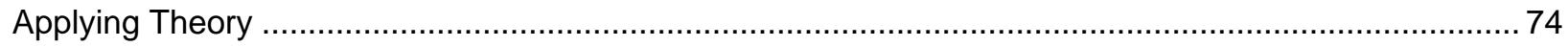

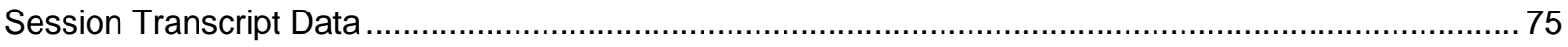

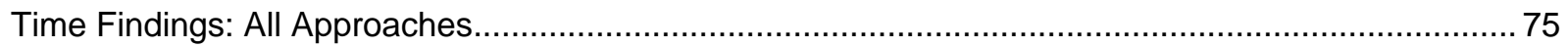

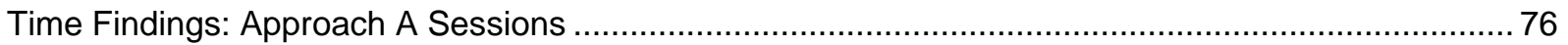

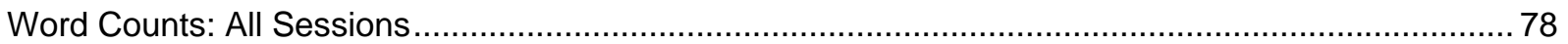

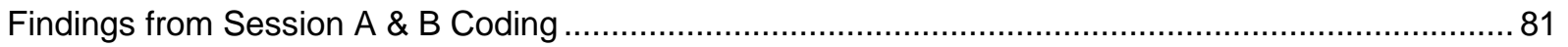

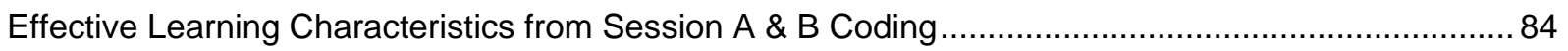

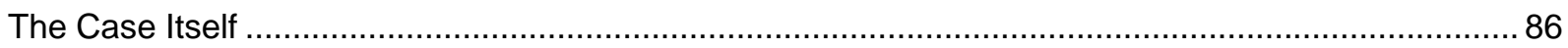

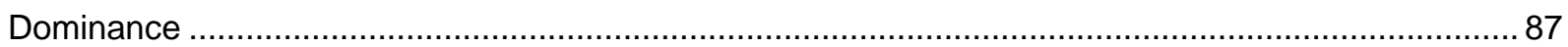

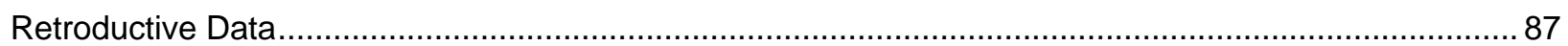

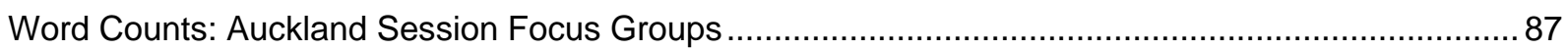

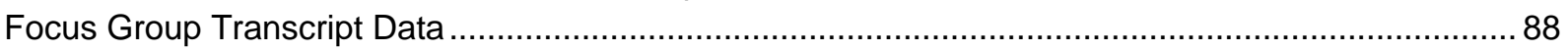

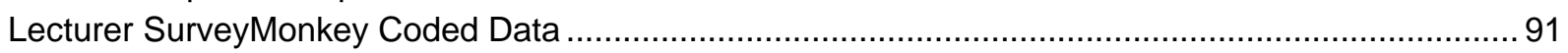

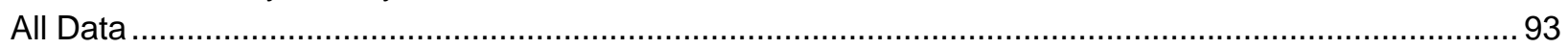

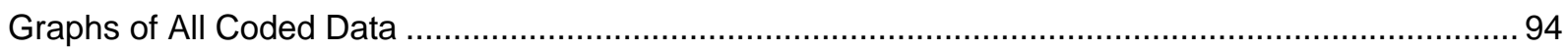

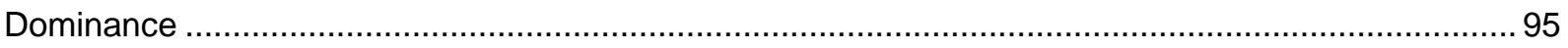

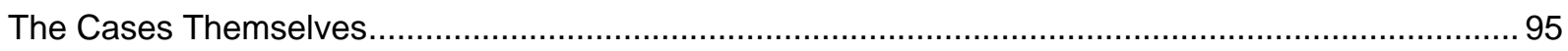

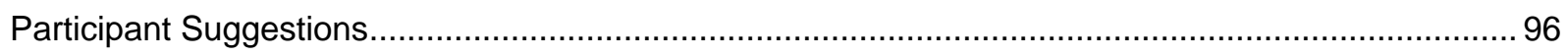

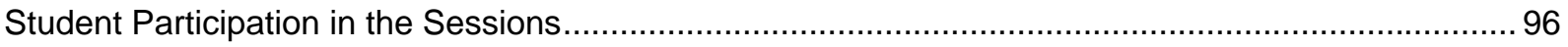

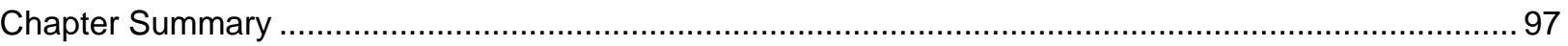

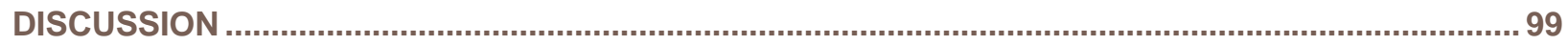

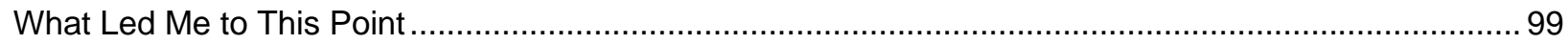

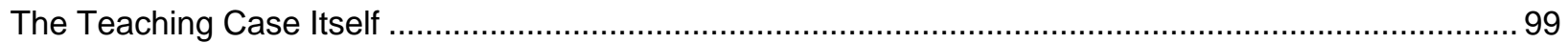

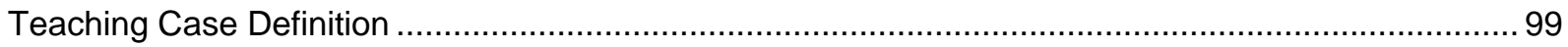

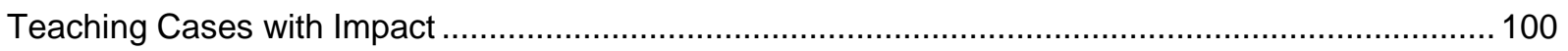

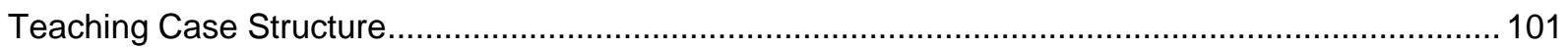

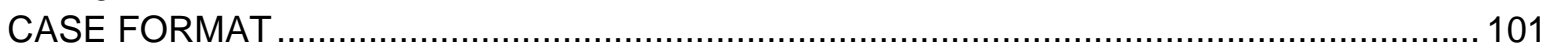

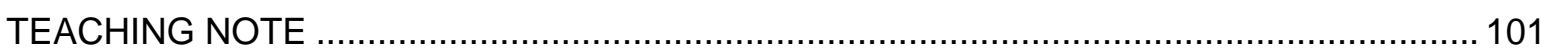

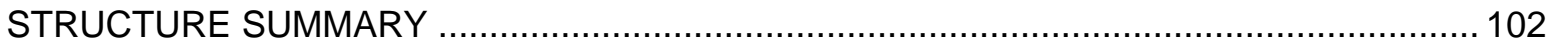

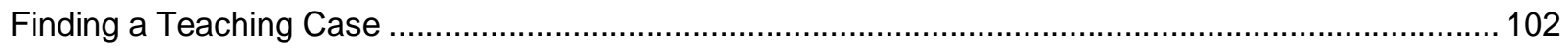

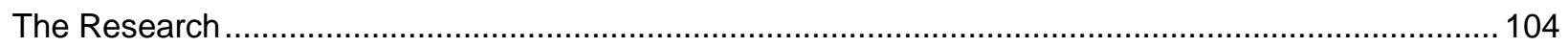

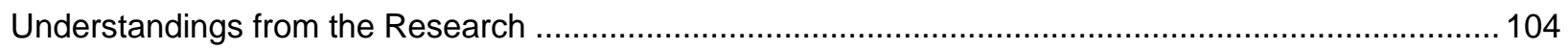

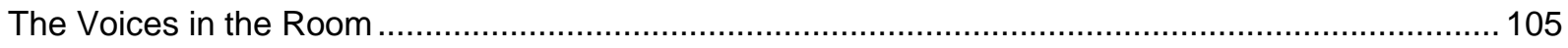

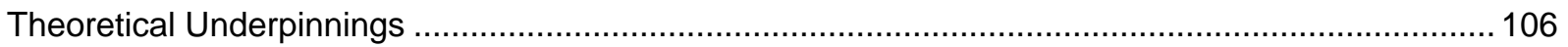

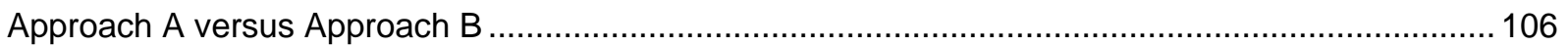

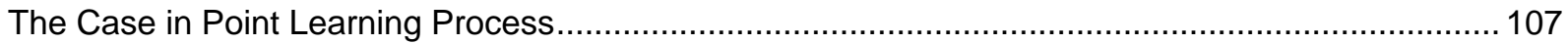

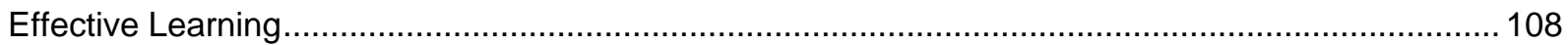

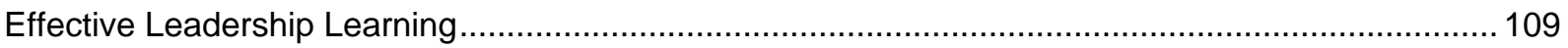

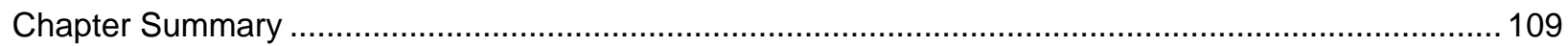


CONCLUSIONS

Sensing Differently

Limitations 112

Future Research. 113

BIBLIOGRAPHY . 114

APPENDICES 133

Appendix One

(a): Field Research Case Study Types 133

Appendix One (b): Teaching Case Study Types 135

Appendix One (c): Tabled Authors' Areas of Topic Expertise.. 137

Appendix Two (a): Research Project Plan | July 2012 to June 2014. 140 Appendix Two (b): CAQDAS Research Categories \& Code Definitions..... 142 Appendix Three (a): Ethics Application Approval Letter 144

Appendix Three (b): Ethics Application Participant Information Sheet .............................................. 146

Appendix Three (c): Ethics Application Student Consent Form .................................................... 148

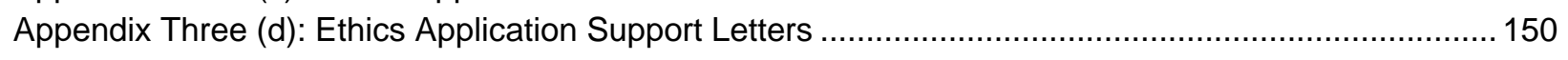

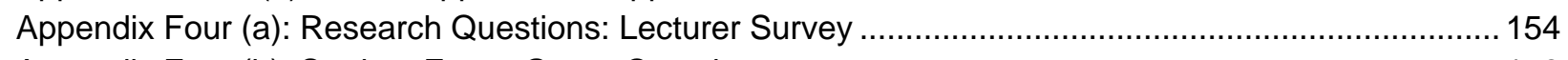

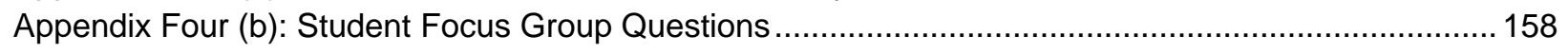

Appendix Five (a): Instructor Briefing Pack - Lesson Plans ............................................................. 159

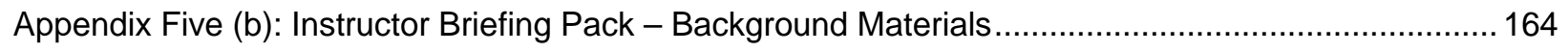

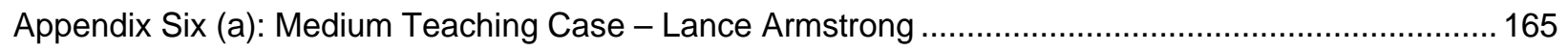

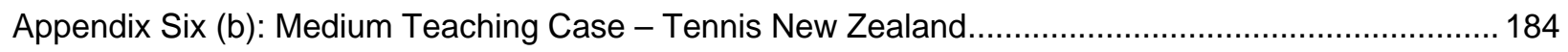

Appendix Six (c): Short Teaching Case (case only) - Lance Armstrong ..............................................203

Appendix Six (d): Short Teaching Case (case only) - Tennis NZ .......................................................... 205 


\section{List of Figures}

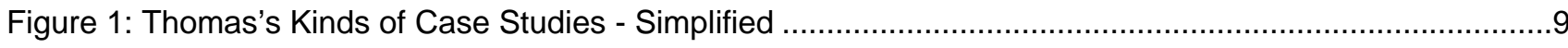

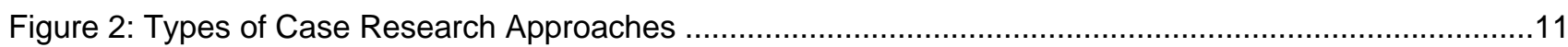

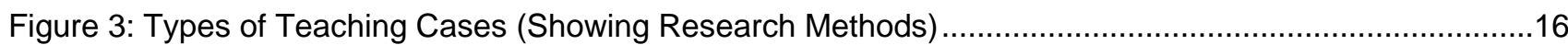

Figure 4: Types of Case Learning From Teaching Cases (Including Learning Outcomes) ..........................16

Figure 5: Experiential Learning Cycle \& Basic Learning Styles .............................................................33

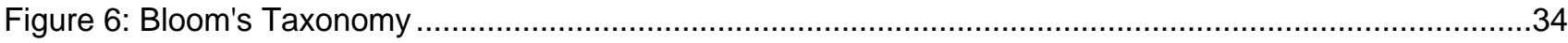

Figure 7: The Leadership Continuum adapted to a Lecturer/Student-led Case Delivery Continuum ..............46

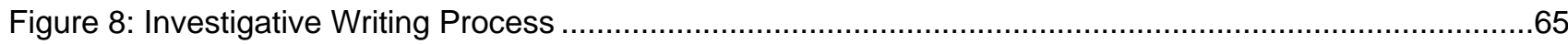

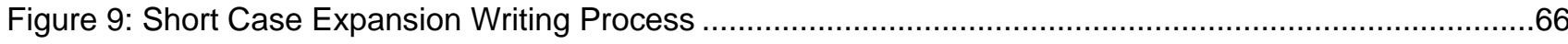

Figure 10: The Leadership Continuum Adapted to a Lecturer/Student-Led Learning Continuum..................73

Figure 11: Approach A Summary Data (by Campus By Session Activity Category in Percentage of Minutes) 77

Figure 12: Approach B Summary Data (by Campus Session Activity Category in Percentage of Minutes)......77

Figure 13: Auckland Campus Approach A and B Summary Data (Session Activity Category in Percentage of Minutes)

Figure 14: Nelson Campus Approach A \& B Summary Data (Session Activity Category in Percentage of Minutes)

Figure 15: Average Word Count for approach B Sessions (by Speaker Type By Campus in Percentages).....79

Figure 16: Average Word Count for Approach A Sessions (by Speaker Type by Campus in Percentages).....80

Figure 17: Average Word Count for Auckland Campus Approach A Sessions (by Speaker Type in Number of

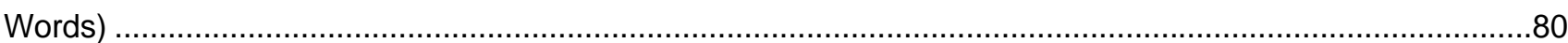

Figure 18: Effective Learning Code Counts (All Campuses by Approach A and Approach B) ..........................

Figure 19: Ineffective Learning Code Counts (All Campuses by Approach A and Approach B) ...................95

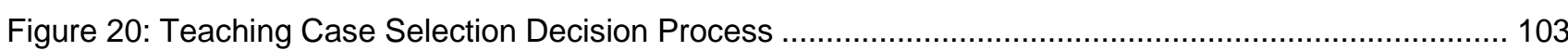


Table 1: Case Length Summary .18

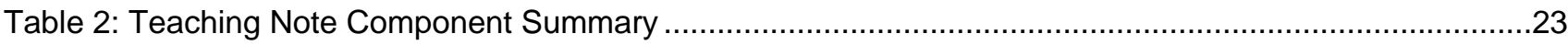

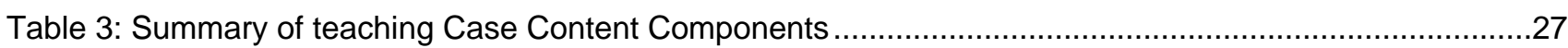

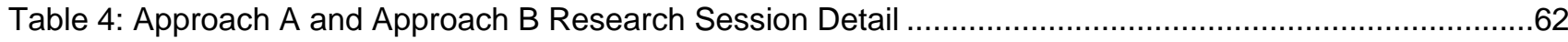

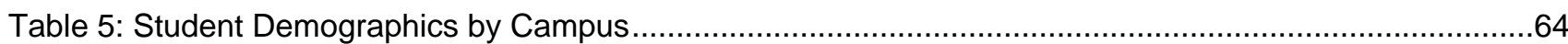

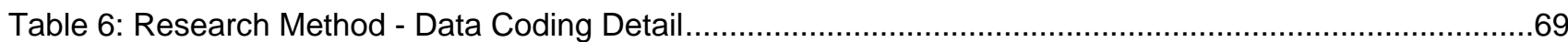

Table 7: Approach A \& B Session Activity Categories (All Campuses by Session Activity Category

Percentages)

Table 8: Approach A and Approach B Session Activity Categories (by Campus By Session Activity Category in Minutes) .75

Table 9: Approach A and Approach B Session Activity Categories (by Campus By Session Activity Category in

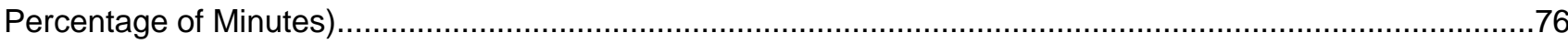

Table 10: Average Word Counts per Contribution (by Approach A \& B, All Campuses) ..................................79

Table 11: Average Word Counts Per Contribution by Speaker Type (by Approach A \& B by Campus) ...........79

Table 12: Summary of Category and Code incidence counts (All campuses by approach a \& B) ...................81

Table 13: Summary of Effectiveness Category \& Code Incidence Counts (Auckland Campuses by Approach A \& B) .83

Table 14: Summary of Effectiveness Category \& Code Incidence Counts (Case By City By Approach A \& B)86 Table 15: Average Word Count By speaker type (Focus group sessions at Auckland Campuses) .88

Table 16: Summary of Category and Code Incidence Counts (All focus groups by Approach A and Approach B) .88

Table 17: Summary of Effectiveness Category and Code Incidence Counts (Case by City Focus Group) ......90 Table 18: Summary of Category and Code Incidence Counts (All Lecturer Surveys by Approach A \&B) ........92 Table 19: Summary of Category and Code Incidence Counts (All Auckland Lecturer Surveys by Approach A and Approach B). .92

Table 20: Proposed Industry Standard for Teaching Case Inclusions 102 


\section{Background}

Since 2007, I have taught management papers at Nelson Marlborough Institute of Technology (NMIT) and Auckland University of Technology (AUT) on the NMIT B.Com and AUT B.Sport \& Recreation degrees. Across the two degrees, the paper that I teach in common is Leadership, at year two on the B.Com, and year three on the B.Sport \& Recreation.

In my short history of teaching leadership to undergraduate students from both programmes, I have noticed an apparent causal relationship: that if theory teaching is immediately illustrated by the exploration of a targeted, factual case study, both the B.Com and B. Sport \& Recreation students appear to retain more of the theory, and seem better able to apply both the theory and the learning to different situations.

The case studies seem to become a theory 'anchor', with the theory itself apparently becoming a tool that graduates can apply repeatedly to workplace situations.

Additionally, my students appear to respond positively in workshop situations to cases which are under two pages in length, are factual, tell a story, create a situation that they can relate to and in which they can see themselves as one or more of the characters in the story. Long cases are too unwieldy to read in class, and would require more preparation time.

I began my leadership case research journey exploring the format of teaching cases. However, the more I read, the more another question started to grow: whether or not the "Case in Point" method initially developed and used by Harvard was an effective way of teaching leadership cases to undergraduates.

\section{Teaching Case Delivery Formats}

I teach leadership using what I call a 'hybrid' case delivery format; a combination of lecture and workshop. We cover relevant theory in class, students then read a short case and discuss, in small groups, the case questions; finally sharing ideas in a class debrief. This takes about twenty minutes.

"Case in Point" is a more staged delivery process, often used in post-graduate education, particularly on MBA courses. Students receive hefty discussion cases just ahead of class, independently reading and researching, writing up their ideas, relevant theory, issues and problems. Before the class, students discuss their findings in small groups, collectively determining issues and solutions. In class, the lecturer provides minimal input aside from directly asking the first person to answer the lecturer's first question. From this point, the lecturer lightly referees and guides discussion; drawing out issues, 
ensuring diversity in voice and view, and providing an effective summary at the close of the two hour session (McNair, 1954; Towl, 1969; Christensen \& Hansen, 1987; Roberts, 1997; Rangan, 1995; Parks, 2005; Gill, 2011).

The "Case in Point" method intrigued me. If my students pre-read the cases and analysed them before class, we would have more time to dissect far more complicated and layered leadership situations.

However, I had three key concerns. Firstly, that my undergraduate leadership students might not yet have enough theory in their toolkit to learn effectively from leadership cases delivered this way; that they may lack the structure to self-direct and explore both theory and new research. Secondly, that they may well lack the discipline to prepare properly for the case classes. Thirdly, that, as this would be a new way of teaching, students would need some capacity-building.

\section{Approach A or Approach B?}

The issues gnawed at me as I researched case formats. I sought "Case in Point"/'Hybrid' comparative studies in the literature, and found none. In a conversation with my supervisor, Brad Jackson, he asked me what my burning question was. My immediate, ungoverned response was "is the "Case in Point" method 'better' than the 'Hybrid'?"

I had many questions. Why had no one tried this before? Who was I to test this? What was 'better'? How would I know 'better' when I saw it? And how could I test the two methods?

I determined to simplify things by simply comparing the two case delivery methods and consider the differences that arose from those two sessions:

1. Approach A: have the students analyse a medium-length case of around three thousand words, explore applicable theory, write it up, then discuss their ideas, and

2. Approach B: teach the theory first, then anchor it with a work-shopped short case, read in class.

Is student learning different when they are taught leadership entirely by case workshops (Approach A), or by our more normal lecture/workshop combination (Approach B)?

This research project has gathered some evidence.

\section{My Philosophicall Approach}

My philosophical approach to learning is a cyclic one: to quote Sinatra, "do be do be do" (Precht, 2011, p. 248). I take a recursive deductive and inductive approach, whereby I learn the theory, test my world for fit to it, then recheck and readjust the theory for sense based on my experience and my perception of the world. As Ross says, "the body of knowledge regarding management is always in flux; constantly emerging from the dynamic interplay between theory and practice" (1998, p. 102). 
My preferred research model is relationship-focused; more on understanding how organizations impact individuals and society over organisational effectiveness and efficiency. I favour mid-range or substantive contingency approaches, usually utilising both deductive and inductive methods and using both quantitative and qualitative data (Bryman \& Bell, 2006). While I hold some affinity for using theory to structure observed data (i.e., an empiricist's approach), this research project will require a phenomenological approach; collectively forming a critical realist perspective on the process.

With regard to "the how" versus "the what" of knowledge, I take Polanyi's (1966) - constructivist epistemology - view: when riding a bicycle, in order to keep one's balance, a practical knowledge of how to ride is superior to a theoretical knowledge of physics; although understanding both the application and the physics will aid us as learners. As such I tend to trust hunches for "the how", tempered by researching "the what" in a continuous feedback loop.

\section{Thesis Structure}

This thesis is structured as follows:

- In Chapter 1: Introduction (this chapter), I outline my teaching background; the development of my research question and the search for better ways to teach leadership cases; and my approach to my research question.

- In Chapter 2: Literature Review - Cases, I consult research and teaching case experts on the history and development of case studies as a teaching tool, I define what a teaching case is, I explore case typologies, case structure, what makes an engaging case, teaching notes and how cases are used.

- In Chapter 3: Literature Review - Learning, I explore adult learning theory, andragogy, and consult adult teaching and learning experts on the use of experiential and active learning, critical thinking, the use of cases in conveying narrative knowledge, and delivery methods. I explore research into effective teaching cases to adults, and the leadership theory - shared leadership, acts of leadership and power sharing - which links my own teaching and research practice with teaching case delivery.

- In Chapter 4: Methodology, I explain the research design with which I attempted compare my two chosen teaching methods of the "Case in Point" and 'Hybrid' delivery methods. I detail my research ontology and epistemology as a critical realist, and explain the process and detail of the research methodology and methods I have constructed to answer my research question: do students make sense of leadership cases differently when they are delivered using different methods?

- In Chapter 5: Findings, I explore my Approach A and B recordings. Using my session, focus group and survey transcripts, I assign categories to my data, and analyse codes using CAQDAS software and review the incidence of my chosen codes and word counts in Excel. I 
find flaws in my research methods but find other ways of obtaining useful results from my research.

- In Chapter 6: Discussion, I compare and reinterpret my findings in light of expert views on case type, structure and selection. I propose a teaching case definition, and a teaching case typology. I summarise key elements which provide impact in cases. I outline a possible 'industry standard' for case structure, and a process for seeking new cases. I consider aspects of teaching delivery and effective learning, and guardedly conclude that the "Case in Point" delivery method as an effective learning tool.

- In the final chapter, Chapter 7: Conclusions, I summarise whether or not students made sense of leadership teaching cases differently when they are delivered using different methods, what the limitations of my research was, and detail what further questions and decisions this provokes. 


\section{Literature Review: Cases}

\section{WHAT OTHER PEOPLE SAY ABOUT CASE STRUCTURE}

I sense that using case studies makes learning 'sticky'; that cases aid student learning. The starting place for my investigative journey was into the 'where', the 'what' and the 'how' of case studies; where the idea of cases came from, what defines them, what their components are and how they are constructed.

\section{Story-telling Animals}

Man, according to Swift (1992, p. 53) "is a story-telling animal". Schank and Abelson (1995, p. 2) state that human "knowledge is encoded as stories". Green (2004) cites an Indian proverb "Tell me a fact and I'll learn. Tell me the truth and I'll believe. But tell me a story and it will live in my heart forever" ( $p$. $1)$.

Story-telling and memory are inextricably entwined within us, according to Schank and Abelson (1995). In adding to our own human knowledge, we use the story scripts that we already know to anchor new stories to, and do our best to fit the new story facts to our existing structure. Anything that does not fit, we leave in limbo until resolved, or forgotten. Stories aid memory. Schank and Abelson report that "Telling is remembering. Everything else, what we fail to tell, gets forgotten" (1995, p. 25). Gudmundsdottir (1991) proposes that humans tell stories to give our experiences meaning. Storytelling appears to be a basic human behaviour.

That imposition of meaning leads us to use existing structures and knowledge in our telling. Schank and Abelson also say that we "speak in generalizations that our listener can understand" and that the "index of the story is what is held in memory, not the particular words that comprise the story itself" (1995, p. 46). They go on to discuss three steps that all humans take in making sense of new data. Firstly we match "indices for story retrieval", then we add "aspects of a new story to empty slots in an old one", and lastly, we seek "further evidence" for those that we aren't sure we quite understand (1995, p. 17). Further, they say that we do not learn directly from the stories of others: our own storyschema is triggered and we are distracted into rehearsing our own, richer stories. Unless storytellers are good, and the new story builds on or adds evidence to our existing schema, we stay in our own memory and ignore the new.

This aspect of storytelling is repeated in many ways. Green notes that journal writers "are often advised to make their findings into 'a good story"' (2004, p. 1). She goes on to say that the "case study method, frequently used in business schools, is a popular means of introducing stories into the classroom". Gudmundsdottir (1991, p. 6) states that "Good stories are memorable, functional and entertaining". Naumes and Naumes (1999, p. 2) discuss the power of storytelling, and how important they are in transmitting inter-generational history, knowledge and culture. Good storytellers "weave 
spells with words" and the best use "message, details and style" to weave that spell. They also state that "case writing, like storytelling, has elements of art", "drawing in the [...] reader to make scenes vivid and the characters live".

\section{The Case as a Story}

Many experts in this area have written about the storytelling aspects of cases. Remenyi (2012, p. 18) suggests that teaching case studies should be written as an "engaging mystery story". Case narratives "circumscribe and structure how cases tell stories" (Kenney, 2001, p. 347).

Teachers are people who guide others. Gudmundsdottir (1991) suggests that teachers' tools include recreating the past through stories, as "narrative knowledge" which consists of "case histories and narrative explanations" (p. 4). She explores the convergence of researching and teaching, noting that:

"Teachers live in stories. They tell their students about some of the things they know. Researchers offer themselves to teachers as sympathetic listeners. Their presence calls forth stories from teachers about who they are, what they know, and their world in the classroom. In the telling, the teacher's stories are simultaneously produced and revised. As researchers probe and guide with their questions, the teachers' stories inevitably become jointly produced. It is a dynamic process because past experience is not buried in the ground like archaeological treasures waiting to be recovered and studied. Rather, the past is recreated through the telling" (Gudmundsdottir, 1991, p. 4).

Extending on pure narrative, Gudmundsdottir (1991, p. 2) defines a story by it having "beginning, middle and end phases". This structure, or meta framework, is what a story fits within, and could take the form of curricula, research or a teacher's ontological beliefs. Vega $(2011$, p. 1) considers cases to be stories with "a beginning, a middle, and an ending. It must involve narrative description, and often benefits from dialogue and human interaction. A case needs to be interesting to engage the reader on an emotional as well as an intellectual level".

Until the scientific method was developed, Becker, Dawson, Devine, Hannum, Hill, Leydens, Matuskevich, Traver and Palmquist argue that "naturalistic inquiry" in the form of case studies was our primary research tool (2005). Flyvbjerg (2011) concurs. Further to the modern use of cases in law, Becker et al (2005) highlight the role of Robert Park in defining case use for journalistic and writing purposes through the 1920s, noting that, in Park's view, case study looked at "laws of becoming with a constant possibility of change" (emphasis added).

Caulley and Dowdy (1979, p. 41) say that for those who wish "to examine the real, practical application of recorded case histories to novel, unresolved problems, the common law legal tradition offers a superlative paradigm". They go on to note that in the legal profession, lawyers have two main uses for cases: one is in seeking "value-neutral" (p. 9) information with which to educate themselves and advise clients, and the other as a single-minded, justifying and adversarial client advocate. In acting as client advocates, lawyers from each side in a dispute present their evidence to impartial adjudicators, who determine admissibility of facts, mitigating factors, relevant law and actions, and 
then make a determination based on the quality of argument presented. The bones of the matter - the evidence, mitigating factors, law, rulings and obiter dicta - then become a legal "case", and add to the body of professional knowledge. Even though this is a very formalised style, legal cases still tell a story.

\section{Defining Case Studies}

The Collins English Dictionary (1994, p. 250) offers eighteen definitions of case, with five being pertinent to this study: "1. a single instance, occurrence, or example of something. 2 . an instance of disease, injury, hardship, etc. 3. a question or matter for discussion: the case before the committee. 4. a specific condition or state of affairs; situation. 5. a set of arguments supporting a particular action, cause etc". It goes on to define 'case study' (1994, p. 250) as "the act or an instance of analysing one or more particular cases or case histories with a view to making generalizations [sic]".

Morra and Friedlander (2009 p. 1) define a case study as "a method for learning about a complex instance, based on a comprehensive understanding of that instance obtained through extensive description and analysis of that instance taken as a whole and in its context".

The notion of context is further explored by Flyvbjerg (2011), who defines a case study by saying that the choice of what to study and determining boundaries were key issues for its 'casing'. He stresses that cases are set "in time, often as a string of concrete and interrelated events that occur 'at such a time, in such a place' and that constitute the case when seen as a whole" (p. 301). He also notes that "case studies focus on 'relation to environment', that is, context" (p. 301).

In addition, Stake (1995, p. 133) regards a case as "a special something to be studied, a student, a classroom, a committee, a program, perhaps, but not a problem, a relationship, or a theme. The case to be studied probably has problems and relationships, and the report of the case is likely to have a theme, but the case is an entity. The case, in some ways, has a unique life". The case, according to Stake, becomes a 'thing' in its own right.

Paraphrasing Beauchamp (2004), Hegan (2011, p. 37) summarised a case definition as "real life business issues that organisations have experienced and involves students analysing these cases in order to identify such issues, and provide solutions to how these concerns can be overcome".

Taken collectively then, a case study can be treated as a unique entity created to assist learning. It may encompass a number of base histories, but has discrete and definable boundaries. Cases should be about a real situation, and must explore and encompass situational context. Cases must also be based on scholarship and sound research methods, with data being collected over a period of time and sources triangulated as much as possible to provide generalisability.

They are future-focused tools created to guide, teach, anchor theory and illuminate decisions. They are created from scholarly, triangulated, generalisable, logically-structured research which reflects society's changing mores and the time they were written in (Christensen \& Hansen, 1987; Creswell, 1994; Merriam, 1988; Stake, 1995; Yin, 1989). 


\section{Case Study Origins \& History}

In his 2003 serialised article "Case development in Europe - An historical perspective" Kenneth Roberts also states that humans are storytellers. Further he proposes Herodotus as the first case writer, saying "Herodotus (called the father of history) probably also deserves the title of the world's first case writer. There is much in his book The Histories which parallels the work of modem case writers." (2003, p. 6). The Histories was constructed between 450-420BC.

In addition to the legal field, the structure and purpose of formalised case writing in Roberts's view has been significantly influenced by the use of cases to pass on medical practice. Roberts details the mid$17^{\text {th }}$ century Parisian use of the pharmacology cases of $13^{\text {th }}$ century writer, Nicholas Myrepos; whose work was "in turn based on a $7^{\text {th }}$ century text, The Epitome by Paul of Aegina, originally written in about 107AD" (2003, p. 7; FreeDictionary, 2012).

Roberts also acknowledges the use of cases for military purposes, talking of Julius Caesar, Pliny and Tacticus providing "vivid accounts of life" $(2003$, p. 6) which contextualises life in their times, providing us insight into problems and illuminating decisions. When Sandhurst, the first of the 'modern' military Academies, was founded in England in 1811, the writings of many early generals were drawn on to teach practice, tactics and decision-making.

Military analyses are recognisable as "case studies appeared [in England] about 1900, largely logistics-based exercises about three or four pages long" (Roberts, 2003, p. 8). However, cases in a recognisable format appeared much earlier, at Harvard. They were the brainchild of Dane Professor of Law and Dean of the Law Faculty, Christopher Columbus Langdell, who compiled a book of cases in 1870 (Kimball, 1995). Langdell is arguably the creator of case studies in their 'modern' format, and also the founder of Harvard's 'case method' of teaching (now known as "Case in Point").

\section{Meta Case Study Typologies}

Investigating the types of cases is an education in itself. There appears to be no typology consensus, aside perhaps from the terms a 'field research case' and a 'teaching case' (Harling \& Misser, 1998; Heath, 2006; Remenyi, 2011; Vedpuriswar, 2001; Yin, 2009). However, within that, there are many ideas as to how to categorise case studies, depending on which perspective you take.

Various authors' views of field case study typology are tabled by Thomas (2011), to which I added Thomas' own typology (2011), Lijphart (1971, as cited by Parrodo, 2008), Stenhouse (1985, as cited by Bassey, 1999), Merriam (1988), Eisenhardt (1989), Stake (1995), Bassey (1999), Naumes and Naumes (1999), De Vaus (2001), Bennett (2001, citing Eckstein, 1975), Yin (2004 \& 2009), Seawright and Gerring (2008), Dul and Hak (2008), Andrews, Hull and Donahue (2009), and Remenyi (2011) (see Appendix One(a) for the completed table).

In compiling the table, I noted several themes. It appears that some case writers classify by the research method (Merriam 1988; Stake, 1995), others by the case source material (Lijphart, 1971; Yin, 2009; Thomas, 2001), others by how they fit with other cases in a series (De Vaus, 2001; 
Seawright \& Gerring, 2008), others by the type of solution required (Heath, 2006; Ellet, 2007) and others by a combination of approaches (Lijphart, 1971).

Grünbaum (2007) thoughtfully compared the field research case typologies of Yin (2003), Merriam (1988), Stake (1995), and Eisenhardt (1989), and determined that Merriam, Stake and Eisenhardt were based in a relativistic ontology, whereas Yin is more of an empiricist, thus creating an underlying difference in their approaches to typology.

Further, Grünbaum (2007, p. 83) suggests that case studies are "qualitative and the objective can be descriptive, exploratory and/or explanatory, that is, they can be theory generating or contribute to modifications of theory" (emphasis added).

After tabulating other authors' case typographies, Thomas (2011, p. 93) instead suggests a series of four hierarchical considerations for structuring cases. He proposes first determining the 'subject' (ie the style of story the case tells). Following this, the purpose - the research methodology - of the case should be determined. This will then lead to the author deciding on an approach, which appears to relate to methods for storytelling, and a process, which also appears method-driven, but is more related to time.

\section{Kinds of Case Studies - simplified (Thomas, 2011)}

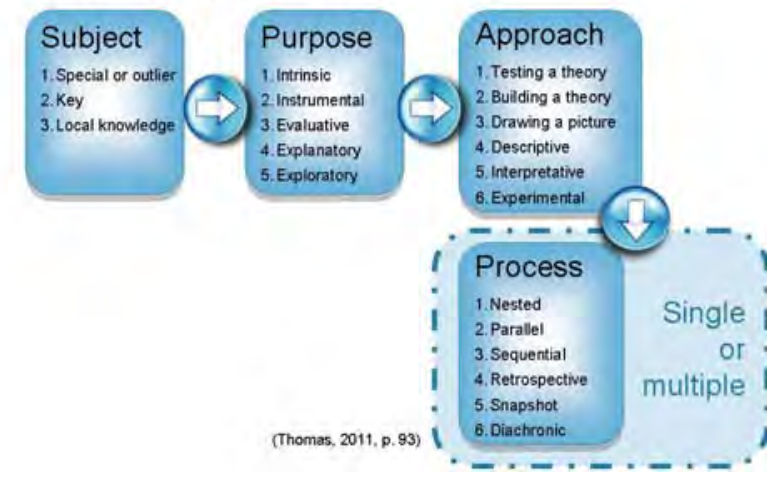

FIGURE 1: THOMAS'S KINDS OF CASE STUDIES - SIMPLIFIED

In reviewing Thomas' (2011) case structure I was struck by two points. Firstly - despite the title - it does not appear overly simplified. Secondly it appears to be coloured by case field research, and is more closely related to the methodological thought process.

Taken collectively - see Appendix One(b) - it appears that the 'how' and the 'why' of field case typologies have often become confused with the 'what'. In my summary table, the results of the case, such as 'outlier', 'critical', 'instrumental' and 'influential' all appear to be saying the same thing: this case is unusual (and to be a unique contribution to the field, this is as it should be). The case typologies that are focused on mechanisms, such as the format (single, multiple or case series), the type of source data (local knowledge), the research method (holistic, embedded, retrospective, longitudinal or observer) or the process followed (individual field case), are, I believe, unhelpful in determining my composite typology, so I have excluded them. 
Bassey (1999, p. 3), as mentioned by Thomas (2011), cites Stenhouse (1985, p. 50) as having identified four research case typologies:

1. Ethnographic: a single case, where careful, deep observation seeks underlying causal factors, to illuminate decisions made or the participants' circumstances;

2. Evaluative: a case or cases explored to provide a value judgement on the soundness of the participants' or evaluators' processes, resourcing or organisations;

3. Educational: cases used to develop theory or practice, to provoke discussion and reflection, and enhance the participants' development;

4. Action research: a case or cases which provide continuous improvement feedback.

When considering cases, action research in my opinion seems more aligned to the research method, as opposed to being a research approach, very similar to both (2) and (3) above.

Additionally, Bassey explores the typologies of Yin (exploratory, descriptive and explanatory), Stake (intrinsic and instrumental) and Adelman (issue/hypothesis and bounded system), examining their research typology definitions, their fields and their research philosophies (1999, pp. 29-30). He then synthesised his own educational case study typology of three:

1. Theory-seeking/theory-testing: illustrating and providing "fuzzy propositions [...] or fuzzy generalizations" (Stenhouse, 1985, p. 50, as cited by Bassey, 1999, p. 27)

2. Storytelling/picture-drawing: carefully analysed descriptions of situations, processes or organisations;

3. Evaluative: providing a value judgement on the soundness of the participants' or evaluators' processes, resourcing or organisations.

In their work on the theory and hypothetical foundations of storytelling in teaching, Andrews, Hull and Donahue (2009) suggested four case types, those of "case-based, scenario-based, narrative-based, and problem-based instruction" (p. 7).

From analysing the abstracts of close to 700 published case research articles, Dul and Hak (2008) kept it simple, taking the view that there were only three types of cases: theory-building, where the authors formulate a new theory; theory-testing, where existing knowledge is put under the spotlight, and - by far the largest group - practice-oriented cases, which describe an intervention process and the systems and tools used.

In reviewing this material, there appear to be common themes, which I believe can be grouped into four areas: descriptive (carefully analysed stories); explanatory (causal explanations); theory-oriented ("fuzzy propositions [...] or fuzzy generalizations"; Bassey, 1999, p. 27) and evaluative (a value judgement on soundness). 


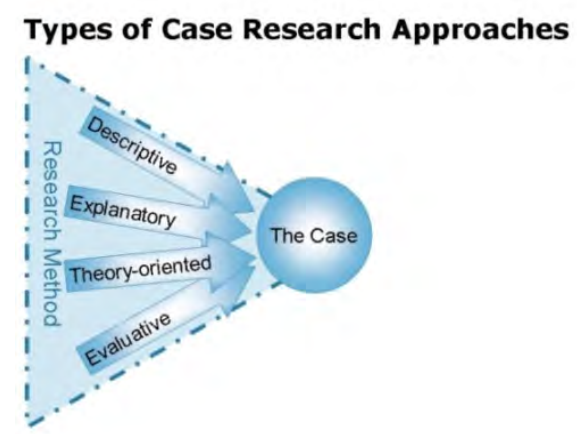

FIGURE 2: TYPES OF CASE RESEARCH APPROACHES

The authors examined thus far have research case expertise. As Lynn (1999, p. 10) noted, while research cases could show normal, good or "exemplary decision-making", because of their alreadyconcluded nature, their use does not develop critical thinking. In the next section I turn my attention to those who have teaching case expertise.

\section{Teaching Cases}

\section{Defining Teaching Cases}

The experts in teaching cases present a range of views as to what teaching cases are for; their meaning, their definition. Some writers consider that their purpose is to provoke dialogue and thinking. McDade (1995, p. 9) states that teaching cases are carefully written to "support intensive discussion and detailed analysis". Vega (2011) also highlights the point that teaching cases should encourage both discussion and analysis.

It has been a long-held view that teaching cases illustrate problem-solving and develop problemsolving skills. Fisher (1972, p. 9 citing Bauer, 1955, p. 31) cites Bauer's definition of the case study as a "written record of human experience centered in a problem or issue faced by a person, a group of persons, or an organization". Kimball too highlights problem-solving, citing Dewey; "cases are 'problems' to be solved" (1995, p. 12).

In considering from where teaching cases first came, Caulley and Dowdy (1979) draw a distinction between common law and "evaluation case histories", noting common law cases are the law, whereas evaluative cases are linked to "prevailing social mores" which evolve (p. 37). The authors also echo Dewey (Kimball, 1995), suggesting business cases pose "a problem to be solved rather than a solved problem" (p. 37). Despite their work being largely related to the legal area, it is still drawn upon by experts in other research fields, including Yin (2009). However, Roberts (2003; also Lynn, 1999) observes that the fundamental difference between management and law cases is that legal case results are already fixed, so any argument is moot.

Other writers focus on the decision-making uses (Vega, 2011). Morra and Friedlander (2009) view teaching case studies as a sub-set of research case studies, suggesting that teaching cases set out to show us why choices were made, creating engagement and provoking us to solve them. 
Salo takes a slightly broader approach, but still focuses decision-making. He suggests some unwritten assumptions - his 'rules of the game' - which include: data and evidence; the protagonists' authentic dialogue and views, questions and implicit "underlying issues"; with the emphasis on next steps (2007, p. 7).

An interesting alternative defining idea is proposed by Vissak. He cites Simon et al (2010, p. 372), suggesting that case studies "bridge the gap" between theory and practice.

Relating back to Schank and Abelson's indices (1995), Greenhalgh proposes that teaching cases are incomplete stories so are open to many interpretations (2007). Tower (in Golich et al, 2000, p. 12) considers that content need not be famous or infamous, but may contain many lessons, and many approaches ("multi-layered problems seen from multiple perspectives") from ordinary life.

Summarising these perspectives, I suggest that teaching cases should support intensive discussion and detailed analysis, contain multi-layered problems seen from multiple perspectives, and be created to guide, teach, anchor theory and illuminate decisions.

\section{Teaching Case History}

Teaching, using case studies in law, started before 1870 (Kimball, 1995). Harvard tried the case method in their medical school from 1900-10, but it fizzled out in the wake of a US government report - the 1910 Flexner Report calling for education reform which apparently resulted in a medical funding 'deluge' - and the case method lecturers moving on. The first documented use of cases was in the just-founded Harvard Business School in 1908, on their business management programme (Roberts, 2004, p. 6; Kimball, 1995). Within a decade cases were being used in Finance, Policy and Sales. Kimball relates that initially Harvard case books were designed like law casebooks, "with a citation system modeled upon legal citations" (1995, p. 11).

In the 1920 s a shift took place. Harvard law cases were - and continue to be - based on the Baconianist model: that of empirical observation, careful data collection, followed by data classification according to inducted laws. Educators found that business was too amorphous, too unpredictable, and too likely to change for this model to serve well. Kimball reports that the business educators turned to John Dewey, who proscribed "1) that the interest of students must be stimulated in order for learning to occur; 2) that direct experience is a prerequisite of learning; 3) that knowledge is dynamic and dependent upon context; 4) that process more than content is to be learned; and, most significant; 5) that learning comes through purposeful reflection upon 'problems', such that the teacher is a problem-poser, and cases are 'problems' to be solved" (1995, p. 12).

In 1927, due to the demand from both within Harvard and other schools, Harvard held a summer school teaching the case method. During the summer school, they discussed the writing of 'headnotes', which Roberts proposes may be "early teaching notes" (2004, p. 6).

Harvard has played a key role in conceptualising, promoting and spreading the case approach to teaching. The teaching cases, more or less as we know them today, spread to Europe, firstly to 
France in 1929, then - probably - to the UK around 1930; both channels via Harvard MBA graduates (Roberts, 2004, p. 7).

\section{Teaching Case Criticism}

Despite being written more than thirty years ago, some questions which Allen posed about the writing of cases still appear to be largely unanswered $(1981$, p. 8):

"What should be the criteria for distinguishing whether a case is good or poor? Will these criteria be generally accepted by the academic community? Are cases prepared from field gathered data to be preferred over ones prepared from library obtained data? Are student- or research-assistant-prepared cases to be treated equal to cases prepared by academic professionals? Are longer cases preferable to shorter ones? Are teaching notes to be required? If so, should there be a standard format? Since a good case activity involves students in the process of learning, should the case be required to promote such involvement or can it be allowed to present information merely as the author sees fit?"

The last question which Allen poses; "Are teaching notes to be required?"(1981, p. 8) can now be answered with a firm 'yes' by case database organisations. Teaching notes are usually a requirement for acceptance (see "Including a Teaching Note" for details).

There is some criticism (Booth et al, 2000; Argyris, 1980) of case proponents developing an overly strong decision-making focus in cases, a trait that has apparently grown since the 1970s. Lundberg, Rainsford, Shay and Young wrote a paper about case reviewer comments in 2001, saying that there is a presumption that 'ideal' cases are written with the primary purpose of making management decisions. They propose that this is "inadvertently forsaking the range of educational opportunities" that case teaching provides, and are teaching too narrowly because of it (2001, p. 451).

Further, O'Shannassy, Kemp and Booth (2010) consider that teaching cases add value to students' soft skills, but note that cases must not only focus on the solutions but also the process. They identify these issues a clear risk with cases. This is both in the hands of the lecturer choosing the case, and in the lecturer ensuring that students work in teams to develop "meaningful practice at being a manager" and to smooth the path wisely through team conflict (2010, p. 478).

Additionally, there is criticism that the cases used in the case method are too rationalistic. Swiercz and Ross suggest that cases do not reflect the changing, irrational nature of business (2003). They make a valid point: we must ensure that the cases we use fit our times and our environmental complexity.

Further, Liang and Wang (2004) find in their research that the case method's oft-stated purpose of 'bringing a chunk of reality' into classrooms did not match the actual themes being delivered within cases. They consider there is a significant bias towards rational approaches in management cases, determining five themes common to both the US and China: "rationalistic framework, undersocialized protagonist, strategy-driven organization, manager-as-analyst, and naive and biased politics" (p. 397). 
Echoing Swiercz and Ross (2003), they note that the decision-focused cases examined in their study appeared more "rationalistic" than did descriptive cases (p. 411).

Part of the issue, according to Liang and Wang (2004), are the case publishers themselves. With the high demand for decision-forcing cases, and the large amounts of rationalistic research, the management area is in danger of becoming a 'one trick pony'. They consider that it is hard for alternative views and philosophies to get published.

However, Liang and Wang (2004) offer some solutions. They suggest that, to avoid the biases inherent in the 'published' cases, the case teachers could access public-domain information - provide what is essentially raw source material - either instead of cases, or to supplement rationalistic case examples. They also suggest that case teachers provide cases which utilise a range of philosophical approaches.

Both Swiercz and Ross (2003) and Liang and Wang (2004) raise a valid issue of simplicity versus complexity. If cases are being taught as illustrators of simple problems with single answers when we operate in an increasingly complex world, then they are a less relevant tool.

While there is criticism, much of what I have explored appears less to be criticism than to be unanswered questions. It appears - particularly from the work of Allen (1981) - that some issues still require research:

1. What makes a good case?

2. Which is better; field cases or secondary research cases?

3. Which is better; student-prepared cases or professorial-prepared ones?

4. Which is better? Longer cases or shorter ones?

5. Are management cases too decision-focused? If so, is this detrimental to learning?

6. Do management cases contain too narrow a cultural or epistemological focus?

In this work I have developed answers to questions one and four.

\section{Teaching Case Typology}

Categorising teaching cases is an even more confused area than field research case typology. There appears to be little agreement, with almost all experts fielding their own unique selection. Adler, Whiting and Wynn-Williams cite Barrows (1986) who proposes six types "lecture-based cases, casebased lectures, case method, modified case-based, problem-based, and reflective problem-based" (2006, p. 216). Barrows categories appear to focus more on the teaching method than on the case source or the learner-orientation.

Heath (2006) also proposes six case types: incident; background; exercise; situation; complex; and decision cases. He conceptualises cases from the teaching perspective. He thinks about what tool he wants to create by writing the case. His background cases seem to have parallels with descriptive field research cases. His situation cases appear similar to theory-oriented field research; his decision and complex cases are similar to explanatory research. 
Aligning with a narrower typology view, Adler et al also cite Kimmel (1995) who suggests three case types, structured on the expertise of the user "basic, intermediate, and advanced" (2006, p. 217). Even narrower still, Golich, Boyer, Franko and Lamy (2000) propose only two types of cases: a retrospective or narrative case which provides a complete problem history including the actual outcome; and a decision-forcing case which stops short of the outcome, leaving decisions to the student. Golich et al's view appears more learner-oriented than Adler et al.

Harking back somewhat to field research, Lynn (1999) suggests five teaching case types: decisionforcing; policy-making; problem-defining; concept-application and illustrative. Lynn's policy and concept cases appear somewhat similar to theory-oriented field research cases. His decision-forcing case type appears largely linked with explanatory field research. Problem-defining cases appear similar to evaluative field research. His illustrative cases are closely aligned with descriptive field research cases. Lynn's typology appears to harmonise largely with field case typology.

Vega (2011) too seems to echo field case typology, considering decision-making cases while noting descriptive approaches "factual description of a real situation" and cases solely prepared "for students to develop their analytical and evaluative skills" (p. 2).

Suggesting nine types of cases, Lundberg et al (2001) aim to promote variety of teaching case use. They are concerned that cases are becoming too dominated by decision-making or problem-solving cases, resulting in student critical thinking being channelled too narrowly. They note that breadth in the case types being taught may help to ensure depth and range in our graduates. I find their approach overly complicated, and see the field more simplistically.

In considering the writing of teaching cases, there are a number of reputable authors in the field, and, following Thomas' (2011) field research example discussed earlier, they have been tabulated in order to cross-compare in Appendix One(b): Gentile (1990), Johnson (1990), Sykes and Bird (1992), McQueen (1995, based on Corey, 1980), Lynn (1995), Golich, Boyer, Franko and Lamy (2000), Roberts (2001), Lundberg, Rainsford, Shay, and Young (2001), Richards and Gorman (2004), Zimmerman (2005), Heath (2006), Ellet (2007), Graham (2009), Gill (2011), Vega (2011) and Yemen (2012).

Overall, there is little agreement between the sixteen authors: only one common thread of "Descriptive" teaching cases, with $69 \%$ of writers mentioning some version of this. The next closest are decision-making cases, mentioned by $50 \%$. If I combine decision-making authors with those who mention problem-orientation, this category would then total $63 \%$.

Having completed this substantial literature review of case expert views, I believe that what case writers are referring to as the 'type of case' may in reality be the format when the case is written up for use in the classroom. For example, a case which has been researched to identify issues in a company is an 'issue-identifying' case type, which can be presented in the format of a practice case, a case series, a longitudinal case, or a decision-making case. 
Harmonising teaching case typology with field case typology allows transferability between the disciplines. Additionally, many teaching cases are researched as field cases, so the creation of an additional typology is superfluous, pointless, wasteful and inefficient.

The types of cases, which I consider sum-up teaching case typology, are described briefly as:

1. Descriptive/Storytelling/Slice of life: a teaching case that simply explains a situation without overt elements of judgement or clues as to what the case aims to illustrate

2. Issue-identifying: a teaching case that builds student strengths in identifying the broad range of issues that may or may not be a causal factor in the case

3. Idea-generating: a teaching case designed to spark new and alternative ideas, provoke paradigm shifts, refine models or merely challenge the status quo

4. Problem-solving: a teaching case where the student is focused on seeking and solving the problem posed by the case. This category includes decision-making or -forcing cases.

This typology can be easily paired with the research method typology as follows:

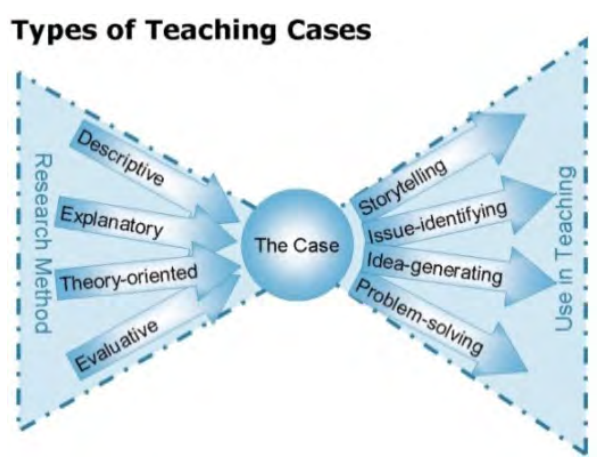

\section{FIGURE 3: TYPES OF TEACHING CASES (SHOWING RESEARCH METHODS)}

However, in formulating these teaching uses, there is still the student's resulting learning outcomes to consider. The learning outcome for a storytelling case is most likely to be the understanding of the context; issue-identifying cases to be the application of theory; idea-generating to be the formulation of our own theories; and problem-solving to lead to growing and honing problem-identification skills.

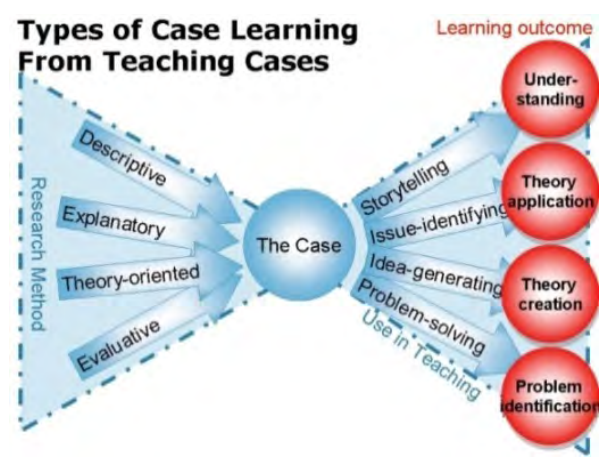

FIGURE 4: TYPES OF CASE LEARNING FROM TEACHING CASES (INCLUDING LEARNING OUTCOMES)

I believe that having a clear teaching case typology, which takes in the research base and is linked to the learning outcomes, allows for a more structured and thoughtful creative case writing process. 


\section{Teaching Case Structure}

Following on from typology, how cases are structured is another area containing varied expert opinions. Caulley and Dowdy (1979) report that legal cases follow a logical, time-oriented, factual structure, which clearly lays out relevant issues and principles based on common law and relating to the matter at hand, along with the case outcomes. Caulley and Dowdy appear to propose time as a structure to present the case facts around.

At the other extreme, Salo (2007) states that the teaching case is made up of the story and the exhibits which support the story, apparently suggesting that case structure is the data it contains.

More recently, Griffin (2009) points to a new development in case teaching: that of unstructured "raw" cases, where cases are presented solely online as a summary page leading off via hyperlinks to the source data which will lead the reader onward. Aside from a very short scene-setting introduction, students are left to self-discover a great deal of uninterpreted data. Raw cases - versus those which are written, or "cooked" - appear thus far to be more engaging for tech-savvy students, more realistic, and, surprisingly, much more data are explored. Griffin reports that students have mined links to more and more remote connections; becoming much more involved and active in their research of the case. Some draw-backs with raw cases would be the timeliness both of data and links.

To allow for such an unstructured approach to structure, perhaps a guideline-oriented approach may work well. Forman and Rymer (1999b) when analysing student's written analysis of cases (created pre-discussion) on a "highly selective MBA program at a public university" (p. 107), asked what they termed "four fundamental questions" (p. 104):

- "What is the overall purpose of the case write-up in business classes?"

- "What is the recurring situation to which the case write-up responds?"

- "What actions do students perform in preparing a case write-up?"

- "What accounts for the write-up's coherence for instructors and students?"

I consider that Forman and Rymer's (1999b) questions could equally assist case writers to create, use and assess the content and structure of case studies, with a little rewording:

1. Purpose: what is the overall purpose of this case?

2. Situation: what is the recurring situation that this case is responding to?

3. Preparation: what do teachers and learners need to do to prepare for this case?

4. Hook: what accounts for this case's coherence for teachers and learners?

These questions would form a useful checklist to structure teaching cases.

\section{Case Length}

Having examined case structure, we now turn our thoughts to how long a case should be. Many authors specify a length, with some proposing that cases should be short (Erskine \& Leenders, 1989; Wright, 1996; Herreid 2005; Gill 2011), some mid-length (Fisher, 1972; Allen, 1981, citing Bennett \& 
Chakravarthy, 1978; Abell, 1997; Golich, Boyer, Franco and Lamy, 2000), and some almost any length (Merseth, 1991; McQueen, 1995; Remenyi, 2012):

\begin{tabular}{|c|c|c|c|c|c|c|c|c|c|c|c|}
\hline $\begin{array}{l}\text { Case } \\
\text { Length }\end{array}$ & 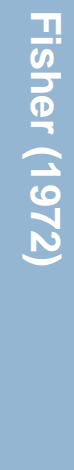 & 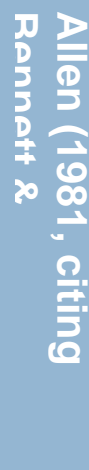 & 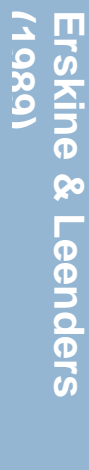 & 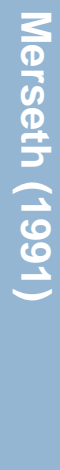 & 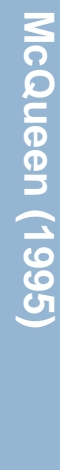 & 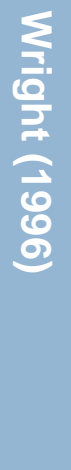 & 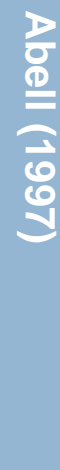 & 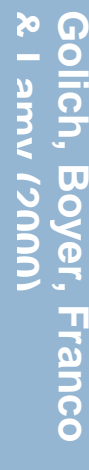 & $\frac{1}{\frac{1}{10}} \frac{1}{\frac{1}{2}}$ & 5 & 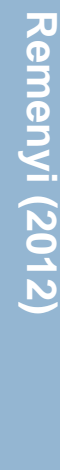 \\
\hline Starting from & 3 & 8 & 5 & 4 & 2 & 0.3 & 5 & 3 & 1 & 2 & 1 \\
\hline Ending at & 8 & 15 & 5 & 35 & 60 & 1 & 10 & 7 & 4 & & 60 \\
\hline
\end{tabular}

Writing for the Harvard Business School Bulletin, it is likely that Allen, Bennett and Chakravarthy taught post-graduate cases by the "Case in Point" method, so eight to 15 pages of text may be a standard Harvard length.

Another centre of "Case in Point" teaching is Canada's Richard Ivey School of Business. Ivey Professors Erskine and Leenders (1989) provide lecturer commentary that the maximum time that any lecturer can expect for student "Case in Point" preparation is three hours, which should drive case length. Golich, Boyer, Franco and Lamy note that the shorter times of undergraduate classes require shorter cases (2000). Wright questioned his undergraduate HR students using Likert Scales on their case learning, and found that students preferred micro cases of just a few paragraphs in length (1996).

Secondary teachers appear to prefer a case length of a few paragraphs (judging by cases contained in student texts), under-graduate, one to four pages (Herreid, 2005; Wright 1996), and post-graduate quite a lot longer (Allen, 1981; Wrage, 1994; Lynn, 1999).

Leenders \& Erskine (1989) suggest that keeping a student-focus helps to keep cases short. Wright found in his research that length influences how students perceive learning effectiveness versus their effort (1996; also Charan, 1976).

A sound determinant of case length could derive from good storytelling; tell them enough to keep them wanting more, but not so much as to satisfy their desire to listen (Gill, 2011). Lynn (1999, p. 112) sums up the tensions in case length beautifully, with lecturers having the "inherent tension between an almost universal student preference for cases that are 'not too long' and the necessity of including enough [... realistic detail] to facilitate [...] analysis of issues". Abell (1997), Gill (2011) and Wrage (1994) concur. 
With so many opinions, it is hard to chart a clear path. Kenny (2001, p. 349) considers that cases need "to be short for students to 'inhabit' them quickly". As a tentative summary, perhaps undergraduate teaching cases, which students can 'inhabit' quickly, should be no more than four pages in length.

\section{Factual versus Fantasy}

There are many arguments for factual writing in teaching cases. Ellet states that cases should "represent reality" (2007, p. 3), mirroring real-world complexity, untidiness, relevance and irrelevance.

Anecdotal student feedback indicates that students prefer case studies to be factual. 'True' case studies "convey wisdom gleaned from successes and failures and compensate for students' lack of real-world experience" (Kenny, 2001, p. 347) and have benefits in "bringing to life dilemmas of real people" (p. 346). Fisher (1972, p. 9) too appears to support factual cases, as they provide "simulation" of real-world activities. These views are upheld by Yadav, Lundeberg, Deschryver, Dirkin, Schiller, Maier and Herreid (2007).

The factual nature of cases provides reassurance to graduates that the solutions contained within are 'tried and tested', with real-world solutions having perceived generalisability, reliability and validity. The effectiveness of case studies in teaching science by Andersson, Hussénius and Gustafsson is seen as bringing practice closer to theory, better readying students for the workplace (2009).

Undergraduates generally lack experience of working in their field, so realistic cases can fill that gap. Harling and Misser believe that teaching cases have the unique quality of simulating "an actual managerial situation", enabling students to have "first-hand observation of real-life situations" (1998, p. 120-121). This is echoed by Hativa (2001). Remenyi (2012, p. 3) also discusses the idea of 'real life', suggesting that case research should cover areas that the researcher cannot affect. Additionally, 'real' situations appear to give students more confidence that the learning that results will be a replicable tool. As learning is experiential and based on real-life events, "it tends to 'stick' with the student in a way that poring over texts and memorizing rules cannot" (Bonoma \& Krosnik, 1989, p. 3). Lynn (1999) and Vega (2011) have also observed that students like realism in cases.

Following the maxim, 'when all else fails, ask', Wright (1996, p. 22) surveyed his Human Resource undergraduate students. $72 \%$ of his respondents agreed that factual cases were more engaging than fictional ones.

If a case is presented as being real, it gains an element of validity. Naumes and Naumes write of field cases as factual, unbiasedly reported, evidenced teaching storytelling, which allows students to rehearse reality $(1999$, p. 7). They emphasise the importance of reality of the case context, while noting that superficial elements may be disguised without adverse effects.

Students, Naumes and Naumes (1999) found, when given fictitious cases, spent more time analysing where and why the case was not real, than seeking the issues the case presented. Hansen (1997) concurs. 
Data to create the case study should come from a variety of sources. Morra and Friedlander cite the World Bank saying cases should contain multiple data sources: such as observations, surveys, statistics, interviews, financial data and document review; primary and secondary data; and should use appropriate research methodologies and sound analysis methods. They also note the importance of maintaining "a chain of evidence" $(2009$, p. 3). It seems academically prudent that we research widely and reflect that research professionalism in our cases. Caulley and Dowdy (1979, p. 9) point out the need for a "value-neutral" approach in cases.

Researcher and writer bias are a consideration with cases. Naumes and Naumes (1999), Vega (2011) and Fisher (1972) all note the importance of considering bias, ensuring objectivity and relying on evidence in preparing teaching cases. We must be careful to prepare cases to academic standards.

Even with the best of intentions, however, our opinion pervades what we select and what we leave out. Gudmundsdottir cautions us, noting that cases "are not mere copies of the world, like photographic images; they are [the writer's] interpretations" (1991, p. 63).

It appears that students prefer - and are more interested in - factual teaching cases, researched and written to academic standards.

\section{Case Presentation Formats}

Lynn (1999) considers three techniques for cases, which he calls 'formats'. They are:

1. Relationship to time: i.e., whether being told prospectively or retrospectively

2. Number of chapters: i.e., one part, multi-part or additional reading/resource cases (NB: some one-part cases have an epilogue)

3. Organisation of the case materials: i.e., how well planned and laid out the case is; the quality of support materials; and the quality of the accompanying resources.

Lynn's idea of time - i.e., of a case being able to be set in the future or the past - appears to be in conflict with Vega's (2011) concept of tense and time: Vega suggests that, if cases were yet to take place, they would effectively be fiction. However, what Lynn is suggesting is a storytelling mechanism. Images too are important. Merriam (1988; Becker, 2005) suggests that images will enhance and embed learning; that a picture does indeed 'tell a thousand words'. A carefully chosen image will set the tone for a case very quickly for the reader, and help them to quickly "inhabit" the case (Foran, 2001, p. 45).

\section{First-Person}

Hansen explained Harvard's character-centric or first-person writing style as "[g]rabbing the reader and hanging on" (Christensen \& Hansen, 1994, p. 268). By this Hansen meant that writing should be punchy, direct, use the active voice, be evocative and let the 'owner' of the voice be heard, felt, seen and pictured. Hansen suggests that the central characters in our cases should be seen as people, 
with personalities, tone and feel consistent with the words and images we portray in the case. We should use their voice where possible.

Naumes and Naumes (1999, p. 7) add the rider that when interviewing participants for a case study there is a risk of introduced bias when paraphrasing. They suggest it is "always best to let the words of the people providing the information speak for themselves" (p. 15), giving the participant their true voice, and let the reader decide what connotation to put on it.

This first-person writing style is also used by Ivey (Leenders, Mauffette-Leenders \& Erskine, 2001). This type of writing tends to draw the reader in. Further, students have a very positive reaction to the inclusion of dialogue. Wright (1996, p. 23) found that $86 \%$ of his students strongly disagreed with his questionnaire statement "I find the use of dialogue in a case incident unnecessary - the technique doesn't add anything to the learning experience". Hearing the voice of those in the case added to the engagement of the learners.

\section{Raw and Live Cases}

There are two other types of case formats, which are more difficult to define: 'raw' cases, and 'live' cases.

Raw cases (Griffin, 2009) are a case which is merely a paragraph on a webpage, with a mass of hyperlinks, a question or position statement, and a "Information that came to light after [ $x$ date], should NOT inform your work" (p. 707). Students take a more organic approach, reading more material, exploring further and becoming more engaged with the material.

Live cases are where there is a live participant in the classroom who can be questioned; for example, a guest speaker from industry (Cameron, Trudel, Titah \& Léger, 2012). They are "dynamic rather than static" learning experience, requiring students to be highly engaged and participative (lowa State University, 2010, p. 19). Briefing materials, often including video, will have been provided to the students before the live case session (O'Connell, McCarthy \& Hall et al, 2004; Iowa State University, 2010).

The study completed by O'Connell et al (2004) on the use of video \& live participants to extend leadership cases found that the "choice of media really does make a difference, in the level of engagement, the focus of attention, and lessons learned through the case method" (p. 310) and students more thoughtful responses with the increase through written to video to CEO (p. 309). Wilier (1995, citing Zorn, 1991, p. 219) also supports the views of O'Connell et al (2004), adding that today's students are more attuned to video, and that the richness - the profusion of detail, the pleasant depth and breadth supplied (OED, 2009) - of the information being conveyed on film far exceeds that of a written case.

\section{Questions vs Narrative-only}

Most case databases require questions to be provided before teaching case can be successfully submitted (see "Including a Teaching Note"). The quality of questions provided is equally as important 
as to whether to supply them or not. Wassermann's (1992) trainee case teachers fed back on what they looked for in case questions, reporting that good questions are: answerable in many words; student-relevant; part of a pattern; open-ended; clearly formulated; and structured to examine 'big ideas'. Good questions should also require a student perspective and the ability to look at wider and personal case aspects.

Remenyi suggests that teaching cases should include questions, but mentions the Harvard habit of not including questions in their case studies, reporting that Harvard justify this lack by saying that their students should be competent enough to seek out an analyse the key points (2012; also Garvin, 2003). Harvard students independently analyse cases and determine the issues and solutions.

In a debate hosted by Lundberg and Winn (2005), two case experts debated whether or not questions should be included with the case. Arguments against included overly-constraining the lecturer, and making the lecturer's job too easy. It was implied that lecturers would be seduced into blindly following rather than thinking for themselves. Arguments for including questions suggested that the questions proposed would give insight into creator's mind, add cohesion between the case and the supporting materials, assist in our understanding of the reason that the case was written, and provide questions that the lecturer may not have thought of themselves.

Acceptance of a case into a case database is a form of publication. Most lecturers are under 'research conditions' within their institutions, making publication a desirable outcome; assisting lecturers to meet their key performance indicators. Because acceptance into case databases require questions and answers to be provided, lecturers will now provide them. However, questions are often included only within the teaching note which allows the lecturer to draw on them, while not channelling the students toward any particular solution or topic area.

\section{Including a Teaching Note}

Cases with a teaching note can be quickly and efficiently searched for, usually via synopses and teaching objectives. Most case databases (Darden, Cranford University's Case Centre, the Australia and New Zealand School of Government (ANZSOG), the North American Case Research Association (NACRA), and even Harvard) request - if not require - teaching notes from case writers. The US Association to Advance Collegiate Schools of Business (AACSB) treats refereed cases with teaching notes as publications (Lundberg \& Winn, 2005), as do most learning institutions in New Zealand.

There are many reasons to prepare a teaching note, the key benefits being that the note: is what lecturers search on; guides the writer; improves case quality as the note informs the case; helps lecturers to teach cases; and harmonises course delivery where there are multiple instructors (Hansen, 1997; Lundberg \& Winn, 2005; Rotch, 1985). The latter is true of my AUT Sports Leadership course.

There has been some controversy as to whether teaching notes should or should not be included with case studies, with Harvard being a long-time critiquer. Teaching note opposers ask what evidence there is that case quality is improved; a possibly valid point as I found no research in this area. Others 
suggest that a teaching note may limit lecturer creativity (Lundberg \& Winn, 2005). However, Ó Cinnéide (2006) suggests lecturers will read a note when evaluating new cases and will adopt, amend or discard it depending on cultural fit. However, opposing argument is fading.

Many lecturers simply prepare the case to teach, and never get around to preparing a teaching note. This reduces a case's transferability, limiting other users' understanding of the deeper meanings in the case. Leenders and Erskine (1989) interviewed a number of case writers. Respondent feedback was that a note was a boring bit of administration that they might get around to - if they had to. One day.

\section{What to Include}

From 22 respected case experts, I have compiled a table of teaching note components, as follows:

TABLE 2: TEACHING NOTE COMPONENT SUMMARY

\begin{tabular}{|c|c|c|c|c|c|c|c|c|c|c|c|c|c|c|c|c|c|c|c|c|c|c|}
\hline$\frac{\bar{\Phi}}{3}$ & 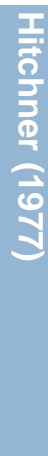 & 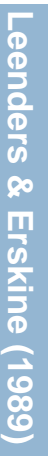 & 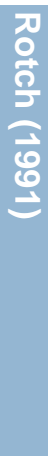 & 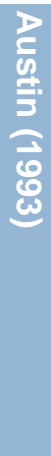 & 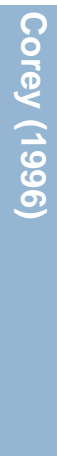 & 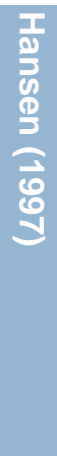 & 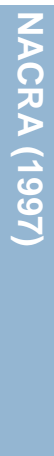 & 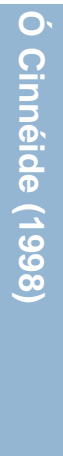 & 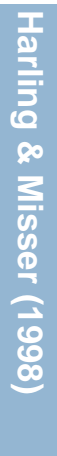 & 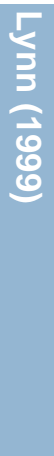 & 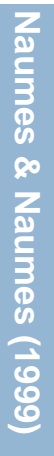 & 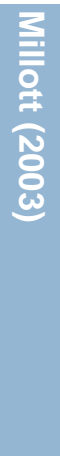 & 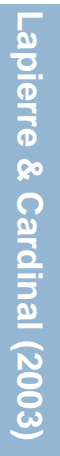 & 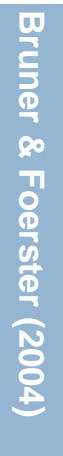 & 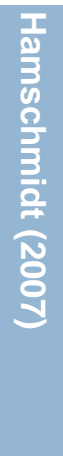 & 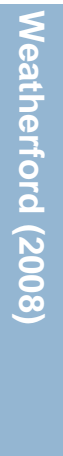 & 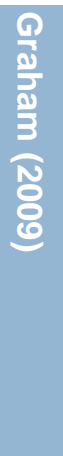 & $\begin{array}{l}\frac{\Gamma}{8} \\
\stackrel{D}{N} \\
\stackrel{0}{0}\end{array}$ & 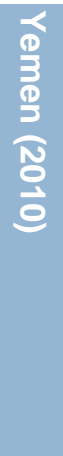 & 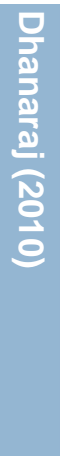 & 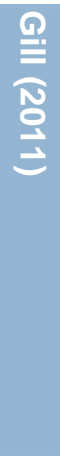 & $\frac{\substack{0 \\
\frac{1}{6}}}{3}$ \\
\hline Synopsis & $x$ & & & & $x$ & $x$ & $x$ & & $x$ & $x$ & $x$ & $x$ & $x$ & $x$ & $x$ & $x$ & $x$ & $x$ & $x$ & $x$ & $X$ & $X$ \\
\hline Scope & & $x$ & $X$ & $x$ & & $x$ & $x$ & & $x$ & $x$ & $x$ & & $x$ & & $x$ & $x$ & $x$ & $x$ & $x$ & & & $x$ \\
\hline $\begin{array}{l}\text { Teaching } \\
\text { objectives }\end{array}$ & $x$ & $X$ & $x$ & $x$ & $x$ & $x$ & $x$ & & $x$ & $X$ & $x$ & $x$ & $x$ & $x$ & $x$ & $x$ & $x$ & $x$ & $x$ & $x$ & $x$ & $X$ \\
\hline $\begin{array}{l}\text { Teaching } \\
\text { Plan }\end{array}$ & $x$ & $x$ & $x$ & $X$ & $x$ & & & $x$ & $x$ & $x$ & $X$ & & $x$ & $x$ & $x$ & $x$ & $x$ & & $X$ & $x$ & $x$ & $X$ \\
\hline $\begin{array}{l}\text { Discussion } \\
\text { questions } \\
\& \text { answers }\end{array}$ & $x$ & $x$ & $x$ & $x$ & $x$ & $x$ & $x$ & $x$ & $x$ & $x$ & $x$ & $x$ & $x$ & $x$ & $x$ & $x$ & $x$ & $x$ & $x$ & $x$ & $x$ & $x$ \\
\hline $\begin{array}{l}\text { Specifically } \\
\text {-mentioned } \\
\text { issues } \\
\text { analysis }\end{array}$ & $x$ & $x$ & & $x$ & & $x$ & $x$ & $x$ & & & $x$ & $x$ & & $x$ & & & & & & & & \\
\hline $\begin{array}{l}\text { Specifically } \\
\text {-mentioned } \\
\text { theories }\end{array}$ & & & & & & $x$ & & & & & $x$ & & $x$ & & $x$ & & & & & & & $X$ \\
\hline $\begin{array}{l}\text { Extension } \\
\text { materials/ }\end{array}$ & $x$ & $x$ & $x$ & $x$ & $x$ & $x$ & $x$ & $x$ & $x$ & $x$ & $x$ & $x$ & $x$ & $x$ & $x$ & $X$ & & $x$ & $x$ & $x$ & $x$ & $x$ \\
\hline
\end{tabular}




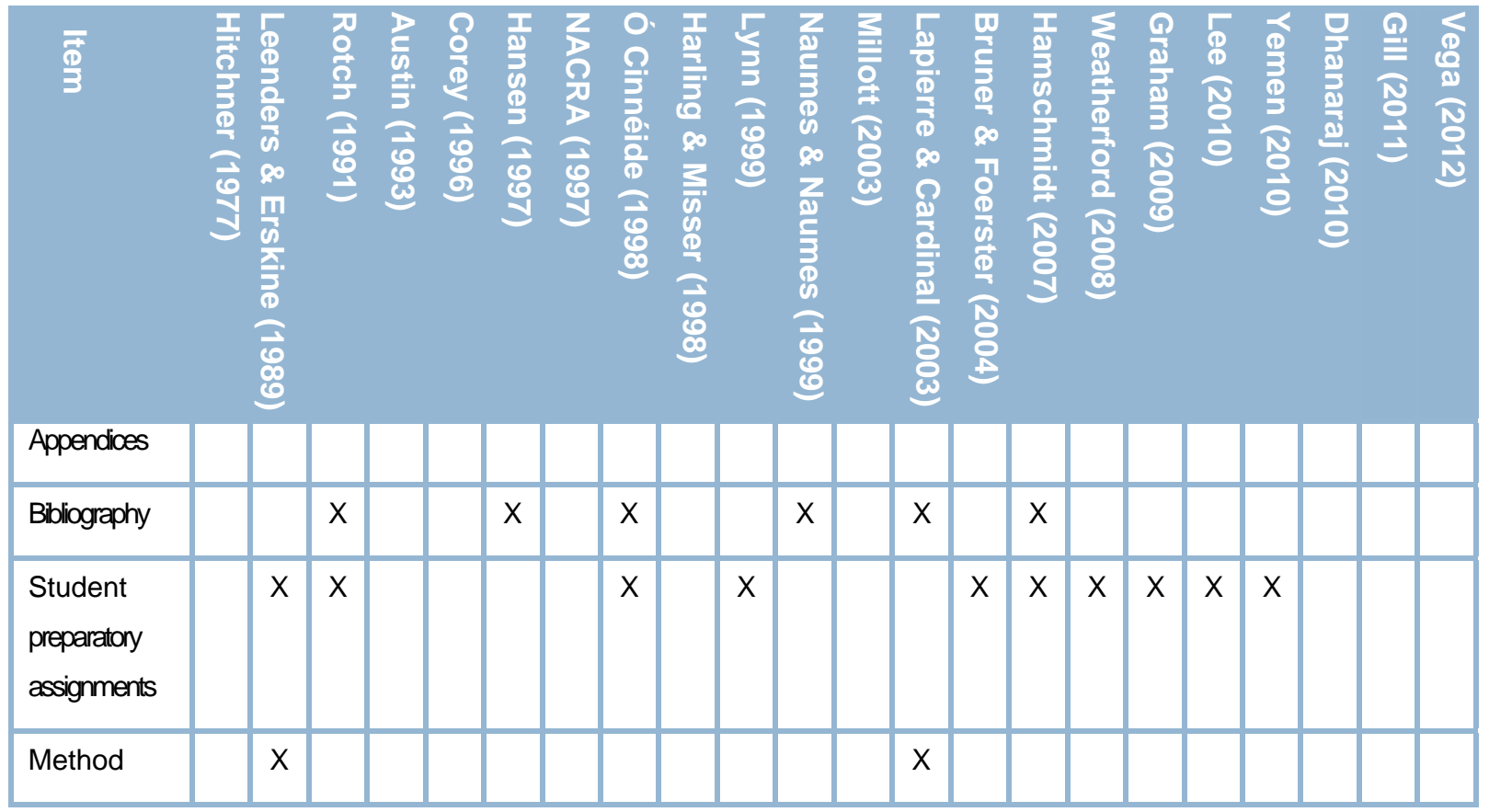

Consensus from the case experts would indicate that a teaching note should include a synopsis (82\%), a scoping statement (68\%), teaching objectives (95\%); questions (100\%) \& answers (95\%, often implied but not specified), a suggested teaching plan (82\%); and some form of extension materials (95\%), which may include audio visual material, links and references.

When undertaking any type of academic writing, we reference all work from others. We include a bibliography in order to show that our work is robust and can be relied upon; to demonstrate our own knowledge of our field; to provide a map for the reader back to the source; to honour others' effort and ideas; and to guard against distortion, avoid misrepresentation and prevent plagiarism (Curtin, 2010; Doroja, 2004; Manaeva, 2009). Yet only $27 \%$ propose a teaching note bibliography. Despite almost three quarters of the consulted experts neglecting sources, I believe that a bibliography must be included for academic integrity, so is an essential teaching note component.

With regard to the teaching plan, of the 22 case authors consulted in Table 2: five do not list teaching plans as a necessary inclusion for teaching notes; nine $-41 \%$ - mention the much 'softer' teaching suggestions or tips; and six suggest what appear to be quite structured teaching instructions.

In conclusion, a teaching note is becoming more a standard inclusion, driven largely by case database publication requirements.

A proposed 'standard' for teaching note components would include: a synopsis; scope; teaching objectives; questions \& answers; extension materials; and bibliography.

When it comes to teaching plans, I would stop short of suggesting a teaching plan as a requirement. Due to the different epistemological approaches of educators, I consider a teaching plan may be construed as overly prescriptive and often - if not mostly - disregarded. Teaching suggestions, however, would be useful, and, for the case user, would give more insight as to the thought processes 
of the writer. Not having previously written a teaching suggestion section, I will now start including these in the cases I construct.

Thus I would propose a good quality teaching note be constructed including: synopsis; scope; teaching objectives; questions \& answers; teaching suggestions; extension materials; and bibliography.

\section{Teaching Case Links to Theory}

A theory can be defined as "A supposition or a system of ideas intended to explain something, especially one based on general principles independent of the thing to be explained" (OED, 2014). It is a framework or scaffold for us to understand the components or characteristics of a situation. Theories guide us in tackling new situations; we can apply an already established process based on a theory. Bruner states that theory not only helps us understand, it aids us in recall (1977).

Some cases illustrate theories; some do not, depending on the case research, typology and teaching outcomes. Robyn (1986), from the Kennedy School of Government, focuses on the teaching value of cases noting a fellow lecturer's maxim "Every case needs a theory" (p. 1).

Including theory should enhance thoughtfulness, not focus learners on seeking the 'right' formula. Polito, Berry and Watson note in their monograph on teaching leadership that many customers (i.e., researchers and businesses) of business school outputs considered the focus to be too theoryoriented, lacking real-world application, suggesting that "Instead of leaders, B[usiness]-schools had generally produced 'Lone Ranger' managers with quantitative decision making skills" (2001, p. 2).

Yet business schools using the "Case in Point" method usually teach without supplying specific theory. The founder of the method, CC Langdell, is paraphrased by Kimball (1995), suggesting that students each "recreates or rediscovers" theory or argument during the "Case in Point" analysis and debrief process. The implication is that theory is induced from the learning process. This may work well at post-graduate level, but may be too much of a stretch for undergraduate students who may not yet have accumulated a toolkit of theories to draw on.

\section{The Importance of Narrative}

The telling of the case story is the stuff of narrative; not formal and arms-length, but informal and direct. In preparing a case teaching guide for secondary school ICT teachers, Rasco (2008, p. 5) suggests that case teaching "implies a shift in emphasis from theories to practices and a shift in genre from exposition to narrative". Lewis (2011) further explores this idea by proposing more of a shift to narrative as an acceptable social science research form.

Contrariwise, narrative is defined by the Collins English Dictionary (1994, p. 547) as "an account, report or process of narrating" and "a narrated account or story"; or as a "construct created in a suitable medium (speech, writing, images) that describes a sequence of fictional or non-fictional events" (NationMaster (n.d.b). From Latin, narrative has been defined by Gudmundsdottir as a "structure, knowledge and skill [with telling]" (1991, p. 1) and "works like a 'root metaphor' (Sarbin, 
1986)". By 'root metaphor', Gudmundsdottir means an organisation process - a context we can understand and relate to - to convey meaning.

Narratives draw us into another's world. Bruner (1990, p. 43) states that stories are comprised of "a unique sequence of events", and that 'sequentiality' is a key factor in human storytelling. The implication is that our world-view and our wants combine to seek a logical chain of events which we can relate to: we may not want to take these actions ourselves, but we can see why others, based on how we know them, made those choices. Bruner suggests that human nature itself leads us to storytelling. Lewis (2011) concurs.

Bruner's work implies there must also be an inherent logic in narratives, that the reader can determine from the sequentiality the steps and decisions that the protagonists took.

Within our cultures, we create 'negotiated meanings', or, as Bruner (1990, p. 47) terms it, the "expectable and/or the usual in the human condition". Where we have situations that do not fit our negotiated meanings, stories make deviations comprehensible.

Narratives have some key components. Bruner (1990) goes on to cite Burke (1945), whose concept 'dramatism' is made up of a pentad; the actor, action, goal, scene, and instrument ; to which is added trouble, which creates the necessary drama for good storytelling through pentad component imbalance. For example, where an actor does not fit their action, we know there will be trouble soon enough.

Great stories push the boundaries of what Bruner terms 'legitimacy'; where stories work out in a lifelike way, with "Trouble morally explicated if not redressed" (Bruner, 1990, p. 50).

We like our stories to have a suitable and satisfactory ending, or at least arrive at Vollendung ('fulfilment', to quote Heidegger, as cited by Lewis, 2011, p. 206). Bruner cites Ricoeur (who in turn has paraphrased Gallie) in explaining that the conclusion is the culmination of our thoughts, feelings and actions on the predicaments hidden and revealed in the story (1990).

While Bruner (1990, p. 44) considers that stories can be factual or fictional, for case studies I believe this does not hold true ( $c f$ "Factual versus Fantasy"; Bonoma \& Krosnik, 1989; Lynn, 1999; Kenney, 2001; Andersson, Hussénius \& Gustafsson, 2009; Vega, 2011; Remenyi, 2012). The concept of reliability has a part to play here, tying in with Bruner's idea of legitimacy: for users to rely on a case as a tool, it needs the veracity of having worked previously.

In summary, a good narrative has sequentiality and logic, which creates a negotiated meaning, where any deviations are comprehensible; there is dramatism (which includes 'trouble') and leads us to a conclusion.

\section{Case Content}

The content of case studies influences how effective they are as teaching tools. From 10 respected case experts, I have compiled a table of 'good case' content components: 


\begin{tabular}{|l|c|c|c|c|c|c|c|c|c|c|}
\hline & & & \\
\hline
\end{tabular}

Drawing on Bruner (1990), it is clear that 'trouble' is a key ingredient for good case content, with 90\% of experts consulted listing clearly mentioning aspects of Bruner's pentad (only Wasserman, 1992, does not).

The other 'big hitters' in this area are $80 \%$ agree on 'thought-provoking' being a key ingredient; $70 \%$ think well-written and good story are key; $60 \%$ believe generalisability and relevance are a key case ingredient; and $50 \%$ consider focus or purpose is necessary. We already know that cases should be realistic (see "Factual versus Fantasy"). The rest of the expert opinion is fairly fragmented. 
Curiosity is defined as "A strong desire to know or learn something" (OED, 2014a). This relates well to the concept of a case being thought-provoking: it provokes us to want to learn more. Bruner (1990) discusses the human desire for a 'good' ending; for legitimacy, sequentiality and conclusion (see "The Importance of Narrative").

So, to summarise, a good case should definitely include 'trouble'; be thought-provoking, be wellwritten, real and a good story. Secondary criteria include that the case is relevant, is generalisable and has a clear focus or purpose.

\section{Timeliness}

The relevance of cases to today's work environment is also a key factor. Allen (1981), citing Bennett and Chakravarthy's (1978) post-MBA survey results, found that a good case less than five years old.

Drawing attention to case timeliness, Polito, Berry and Watson (2001), comment that cases are often old, with business students being taught cases which their lecturers had learned from twenty years previously. Polito et al go on to suggest that, as leadership issues themselves are largely timeless, a solution is to use historic figures, both actual and fictional, in writing leadership teaching cases. In their monograph they cited several case series created from literature, from film, and from ancient and modern history; including Attila the Hun, Shakespeare's plays and Martin Luther King Junior.

Cases need not only be set in the present or the far distant past. Hansen (1997, p. 400) notes that when cases contain currently relevant issues and an understandable context, timeliness need not be a factor. She illustrates this descriptively, telling of a teacher who "still tortures herself for embarrassing a student in class by calling his original dialogue 'sexist"', a situation which could have arisen at any time in the past fifty years.

There are a number of writers who consider timeliness is an issue, however. Hamschmidt (2007) believes that excellent cases are based on recent events, in order to model current challenges that will engage students. While Hamschmidt's cases are written on sustainability, an area which is changing quickly, the point about increased student engagement is valid.

However, another aspect of case timing is that they must always be set in the past. Vega (2011) states that cases, when written, have already taken place. If they were yet to take place, or were taking place this minute, written cases would effectively be fiction. She notes that students must evaluate on results, otherwise it is "guesswork, and education is not based on guesswork. It is based on application of theories and analytical perspectives to past situations" (p. 1).

From my own experience in delivering teaching cases in workshops, I believe that my students respond best when they can "inhabit' them quickly" (Kenny, 2001, p. 349). An understanding of the context and culture, having lived in the world with the story at hand, aids my students to 'inhabit' the case. As we are generally examining modern leadership practice, my students are less likely to engage quickly and fully with historic cases. 
In addition, Polito, Berry and Watson discuss the need to avoid the older universalistic style of leadership, such as hero leadership and trait theory in cases (2001). Leadership cases can date quite quickly by demonstrating old paradigm context, content or culture.

So, unless cases contain timeless issues, those written in the past five years are probably most useful in management and leadership.

\section{Write-ups}

In general, long teaching cases require pre-discussion preparation by the learner, where they read, analyse and tease out what each learner considers to be the key issues in the case. With the case study method developed by Harvard, and on many MBA programmes, this pre-discussion analysis is completed in writing, and handed in either before or after the group discussion.

Forman and Rymer discuss the value of the "write-up" which students perform using the case study method developed by Harvard Business School (1999a, p. 383). Write-ups (also known as casereports, -memos, -responses or "WAC - written analysis of a case", p. 381) are a structure to aid students in case analysis, preparing them for group and class discussions. Write-ups have epistemic functions, with learners creating knowledge through the process of writing (Forman \& Rymer, 1999b).

Write-ups, done well, encourage learners to take the decision-maker's role, in determining their own position prior to group case discussion and to anticipate their engagement with the lecturer in the debrief session (Forman \& Rymer, 1999a, p. 384). The aim is for learners to sharpen their ideas and challenge the status quo based on their own experience and staged insight.

There are down-sides to case study method write-ups, which Forman and Rymer (1999a; 1999b) identify as taking a subordinate role to the discussion; the lack of focus on the writing itself; the lack of consistency in structure, presentation or form; the lack of translation into a known business writing form; and the lack of publication to business or academic audiences (presumably in an effort to keep the cases 'fresh' for future learners).

Furthermore, many students who were interviewed by Forman and Rymer (1999a) expressed anxiety about the public scrutiny their analysis received, writing solely for the debrief session and potentially leaving out issues that may be controversial or difficult to evidence. Additionally, many leaners, asked by their lecturers to write as if they were the main character in the case, either ignore the instruction or take it on only superficially; effectively becoming "consultants outside the case situation" (p. 391). The value potential from immersion in the protagonist's situation is greatly reduced, contrary to the lecturer's intent. While learners understand the lecturer's motivation in doing this, they instead take on "analytical roles for the instructor" in readiness for the group discussion session (p. 391).

Write-ups appear to often be used in "Case in Point" teaching, often at MBA level. It may be that they are too advanced a tool to be truly useful in undergraduate teaching. However, I believe that the completion of a simple write-up prior to a case debrief session could be useful as a formative assessment for students. 


\section{What is Different About Leadership Teaching Cases?}

Interestingly, there is not a lot of information demonstrating difference with case structure or content for leadership cases. Heifetz (1994), the noted Harvard Leadership Professor, talks about leadership cases in terms of "engagement with real problems" (p. 7) and to "illustrate theory and enrich speculation about how individuals might think about leadership in a variety of settings" (p. 8).

Polito, Berry and Watson call for the need for a qualitative, action- and relationship-oriented focus in teaching leadership which has real-world relevance, and will produce leadership and leaders, not "'Lone Ranger' managers with quantitative decision making skills" (2001, p. 2). They also note the need for timeliness in cases (they comment on the dated nature of many business school cases), and the need to avoid the older universalistic style of leadership, such as hero leadership and trait theory in cases (Polito et al, 2001). It is true when looking through many of the cases listed in the Harvard and Darden databases that a great number of cases were written well over a decade ago.

Ensuring use of current leadership cases with multiple solutions and varied settings should meet the needs of students well.

\section{Chapter Summary}

In this chapter we have examined case definitions, history, typology, structure, length, realism, sources, questions, format, teaching notes, the inclusion of theory, storytelling, content, timeliness, write-ups and teaching case uses and leadership case differences.

We now understand how research case typology relates to teaching case typology and learning outcomes proposing: (a) four research method - descriptive, explanatory, theory-oriented and evaluative; leading to (b) four corresponding teaching uses - storytelling, issue-identifying, ideagenerating and problem-solving; resulting in (c) four learning outcomes - understanding, theory application, theory creation and problem-identification. We have some ideas about what defines a teaching case, and some useful items with which to structure teaching cases, including: determining the case purpose; identifying the recurring case situation; detailing the required case preparation; and understanding the case's hook for the learners. We have a guide of one to four pages as an undergraduate case length.

We know that cases are best if they are 'real', and that there are a number of formats but that case characters need their own 'voice'. Questions and answers should be included in cases (usually in the teaching note), and a good quality teaching note should contain the following: synopsis; scope; teaching objectives; questions \& answers; teaching plan; extension materials; and bibliography.

The requirements for a good narrative are sequentiality; logic; creating negotiated meaning, where deviations are comprehensible; dramatism which leads to; a conclusion. A case works well when it includes 'trouble', is thought-provoking, is well-written, and is a good story. 
We have some understanding of what is different about leadership cases, including that they work best if they are recently written or if they contain timeless issues. Additionally, we know that simply structured write-ups have potential as a useful assessment tool.

In the coming chapter, we explore how we learn actively, as engaged adult learners, what that means for teaching with cases, and what leadership theory fits within this work. 
Having explored what cases are, my attention now turns to the learning process: I understand the tool, now I must know how best to use it to aid my students' learning. In this chapter I explore adult learning theory, andragogy, experiential learning, how to teach cases to adults effectively, and the leadership theory which links my own teaching and research practice with teaching case delivery.

\section{How Adults Learn}

Much of the field of learning theory is based around pedagogy. The term is Greek in origin, a composite of 'child' and 'lead' or 'guide'; pedagogical learning then is leading or guiding the child (Papatheodorou \& Moyles, 2009, p. 4). Pedagogical learning is closely linked to human psychological, physical and emotional development from early childhood to the end of adolescence, as children grow from dependence to independence.

Child development and instruction is a central focus of pedagogy. Originally being taken to mean "the art and science of teaching", a core ideal of pedagogy is that the "teacher is responsible for learning" (McNamara, 2002, p. 6). McNamara further worries that pedagogy has drifted from this central idea, becoming negatively flavoured with "pedantry, dogmatism, or severity" (2002, p. 6) and needs to come back to a positive authority model of teachers.

For adult learning, pedagogy may be perceived as too autocratic, too instructional, too centred on the educator as a parent figure. Like the old paradigm of leadership (Daft, 2008), pedagogy can be seen to be about control, sameness, focused around the leader-teacher, and not on the needs of the learner-followers.

An alternative approach is to focus the learning approach around the fully-developed adult learner. Andragogy, "the art and science of helping adults learn," was first formalised by Knowles (1968, cited by Knowles, 1980, p. 43), where learners move from a point of dependency (pedagogy) to selfdirectedness in their learning (andragogy). Building on Knowles' work, Amrein-Beardsley \& Haladyna suggest that andragogy is active, inquiry-oriented, and learner-centred, not instructor-led. Andragogy is "internally motivated learning", "piqued by a curiosity, task, or problem-based orientation" (2012, p. 18). This is very similar to the new paradigm of leadership, built on ideals of collaboration, difference, change and empowerment (Daft, 2008).

Interestingly, education appears to have originally been adult-oriented. Knowles (1977, p. 202) provides a wonderful tour of adult education history by reminding us that the early Classical thinkers such as Socrates, Euclid, Confucius, the Hebrew prophets and Lao-Tze were teachers of adults. Their educational approach was andragogical, not pedagogical. Knowles then points out that, because 
delivery in those earlier times was an active, learner-centred process of enquiry, our early educators were case teachers. The Socratic method, that of "engaging the learner in a process of dialogue, an active process of enquiry" is largely how the "Case in Point" method is delivered today. Gill (2011), however, disputes the alignment of the "Case in Point" method with the Socratic method, preferring to align it to the 'dialoguing' style.

Knowles places the learner in the central role: emphasising that the learner is the one who is expected to change, in thought, in affection and in action (Knowles, Holton \& Swanson, 2005, citing Boyd, Apps \& Associates, 1980). For deep learning to take place, Mintzes and Quinn (2007, p. 303) suggest that education should focus on restructuring the learner's knowledge and creating "meaningful learning"; a learner-centred approach, not one that is teaching-oriented.

Andragogy requires teaching and learning to be learner-centric; a new paradigm relationship of collaboration, empowerment and discovery.

\section{Experientiall Learning}

Taking a fully-developed, learner-centric, andragogical approach, in 1984 Kolb developed an experiential learning model. Kolb's model provides a process linking education, work, and personal development, which proposes that all learners move through four learning stages: firstly experience, secondly reflection, thirdly abstraction, and lastly active testing (cited by Adler, Whiting \& Williams, 2004, p. 215; Barrett, 2005; Engbers, 2006; Stedman, Rutherford \& Roberts, 2006; Clawson, 1997).

The two axes of Kolb's model are, north to south, prehension; and east to west, transformation. Prehension is the placement of the learner from apprehension to comprehension. Transformation is the learner's location from active experimentation to reflective observation (Kreber, 2001).

\section{Experiential Learning Cycle \& Basic Learning Styles}

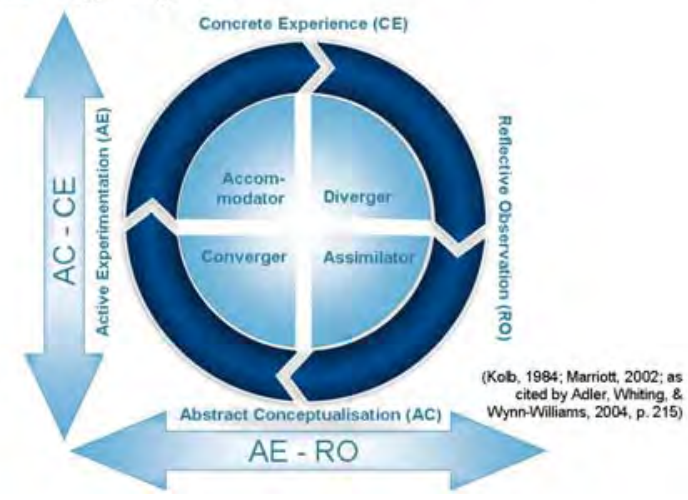

FIGURE 5: EXPERIENTIAL LEARNING CYCLE \& BASIC LEARNING STYLES

Concrete experience is the learning that takes place from doing; reflective observation active reflection on those practical learning experiences; abstract conceptualisation is the creation of mental models from the reflection; and active experimentation is the application of reflection and mental models with new experiences; effectively learning a new process (Engbers, 2006). 
Within this cycle, most of us have a preferred learning style, which comes most easily to us and that we gravitate to. It is thought that business and accounting students tend towards 'converger' as a preferred style (Adler et al, 2004), often only lightly covering the other stages, or skipping stages altogether. This can undermine the effectiveness of learning.

The reflective aspects of Kolb's model, and the developmental and staged approach it allows us to take to our own learning, fits well with my personal approach to research and learning.

\section{Exploring ‘Modern' Education Theory: Bloom's Taxonomy}

We also need to examine the depth of learning which takes place. Forehand (2010) outlines Bloom's Taxonomy, used since the 1950s in education, as a multi-levelled model which classifies how we learn in six "cognitive levels of complexity". We firstly remember - recall or recognise; then understand - or construct meaning using interpretation; then apply - or execute and implement; then analyse - or take apart and reassemble, differentiate or attribute; then evaluate - or make judgements and critique; then create - or recombine or reorganise elements into a coherent pattern, generate or plan (Forehand 2010). Forehand (2010) diagrams Bloom's taxonomy (1956), as updated by Anderson, \& Krathwohl, 2001:

\section{Bloom's Taxonomy (revised 2001)}

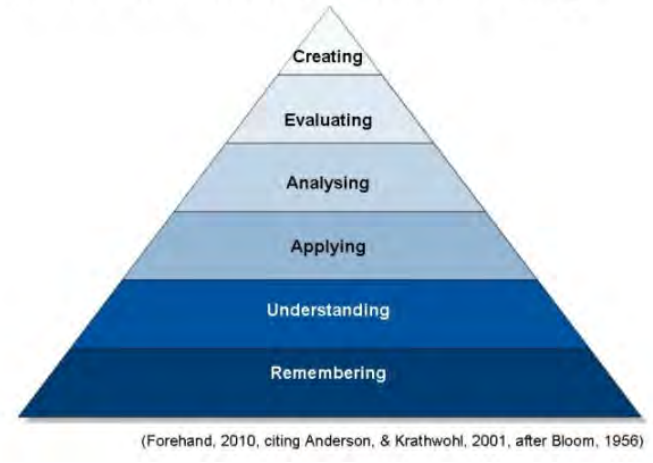

FIGURE 6: BLOOM'S TAXONOMY

Bloom's taxonomy stages the depth of learning very clearly. The beginner learner starts at recall, then moves through the stages to the top, with the ability to reconstruct their field as they reach expertise. Like Kolb's Learning Cycle, this too is a staged process, and needs to suit the level of the learner, and ensure our delivery is structured in a way that assists our learners to transition between levels. The requirements, delivery, teaching expertise and learner readiness to move from recall to understanding will be different to the transition needs between evaluating and creating.

As we become more expert, our learning is deeper.

\section{Active Learning Behaviours}

We have accumulated some tools for learning to take place. We understand the stages of learning, we can consider our delivery order, we understand there are different levels of learning depth, which 
will need to suit our learner's readiness level. However, because our adult learners are central to learning, they must lead the process.

Learner-centric andragogy requires active learning behaviours. Stanger-Hall in her 2012 work on multi-choice exam questions and lack of fit with critical thinking skill development, lists some student cognitively passive and active learning behaviours. Passive learning, or cognitively passive learning behaviour, includes "I came to class" and "I read the text". This learning approach does not include practice, application or reflection. Active learning on the other hand, or cognitively active learning behaviours, includes practice, application or reflection. The statements "I compared and contrasted" and "I closed my notes and tested how much I remembered" (Stanger-Hall, 2012) align to all four aspects of Kolb's Experiential Learning Model (1984) and the hierarchy of Bloom's Taxonomy (1956).

We now have a range of considerations: the stages of the learning cycle, learning depth and learner readiness, and active learning behaviours. Together these provide our adult learners with a learning environment for our modern world: one that develops critical thinking.

\section{Critical Thinking Skills}

Critical thinking is key to adult learning. Without developing critical thinking skills, we are still passive learners; Kolb's Learning Cycle has no reflective observation or abstract conceptualisation.

Critical thinking has been defined by Ennis (1993) as the top three layers of Blooms' taxonomy: that is, analysing; evaluating; and creating. Research into critical thinking by McBride (1996) found that students who actively participate in their learning make the greatest critical thinking gains. He notes that where active learning does not take place, it is the teachers who need to adjust their strategies. Stanger-Hall (2012, p. 295) cites Arum and Roksa (2011) who report that, in their first two years at US universities, $46 \%$ of students did not develop critical-thinking skills, and further, that after four years $36 \%$ had still not developed them. From these results, we can see that learners may be passive, educators may not be always using the right tools and techniques, or we together are not creating the right environment for effective adult learning to take place.

However, an environment that builds critical thinking skills must be deliberately developed. Developing learners' critical thinking skills requires an environment which encourages questioning, listening, identifying assumptions and challenging them, evaluating argument and evidence, and reasoning (Mason, 2008; Thomas, Davis \& Kazlauskas, 2007; Brookfield, 1991). We encourage these behaviours with group work, discussion, reflection and assessments. Additionally, as they are learning critical thinking skills, learners need positive reinforcement, mirroring and modelling from their teachers (Brookfield, 1991).

The learning cycle, learning depth, active learning and critical thinking have been examined. My next steps are to consider teaching that ensures that adult learners learn. 


\section{How We Teach}

There are barriers to creating an environment where active, critical learning can take place for our adult learners, a key barrier being the quality of teaching itself. From discussions I have had with other educators, many lecturers come to teaching though being expert in their teaching area; not by being expert teachers. Many of us only start to learn to teach well after we start teaching. Researchers such as Gudmundsdottir reflect this, suggesting that understanding teaching is a "practical way of knowing subject matter. It is learned mostly on the job from trying things out and observing, talking or working with other teachers" (1991, p. 3).

In discussing the pedagogical epistemological development of secondary school teachers, Gudmundsdottir (1991, p. 3), compares a trainee's way of knowing which starts naively as a reflection of themselves and their own classroom learning experiences, to an experienced teacher who understands the complexity of learning through practice, where they know "150 different approaches".

As tertiary educators, many of us begin teaching adult learners without having considered what our learners need from us to learn well.

\section{Effective Teaching and Teaching Cases}

Effective teaching can be considered to be teaching that is fit for purpose. Weimer (2013; Feldman, 1988; Layne, 2012) defines the characteristics of effective teaching as stimulating student interest in subject and material; cultivating thinking skills; being approachable; creating clarity through their knowledge, presentation and elocutionary skills and the need to create an environment where students can motivate themselves to learn.

Surveying 117 training directors selected from Fortune 500 organisations with the highest employee count, Carroll, Paine and Ivancevich (1972) had respondents rate the effectiveness of a number of different training delivery methods, matched to a range of participant learning outcomes. The training delivery methods used were case studies, discussions, lectures with questions, business games, films, programmed instruction, role playing, sensitivity training and TV. The learning outcomes measured were knowledge acquisition, changing attitudes, problem-solving, interpersonal skills, participant acceptance and knowledge retention. Case studies, in the opinion of the training directors, performed the best overall. Additionally, case studies were scored as the top performing method in developing problem-solving skills.

Cases used in educator training, Kleinfeld (1988, p. 4) considers, provide trainee teachers with "vicarious experience" of teaching problems; providing a view of how an expert teacher frames issues and reflects upon them afterwards; illustrating strategies and tools; and to illustrate that teaching is "an inherently ambiguous activity". Additionally, Kleinfeld (1988) considers that cases help teachers to prepare emotionally for teaching roles, as well as intellectually; that cases enable trainees to model 'thinking like a teacher'. When we do not know how we should think as a professional in our field, teaching cases can provide that insight for us. 
It is not just in learning to think like a member of our profession where cases can aid us as an effective teaching tool. In their research, Adler, Whiting and Wynn-Williams (2004) discovered that accounting students are being taught more via case study. They found this increased use of cases encourages learning through curiosity; analysis, evaluation and creativity; and learning to "apply general concepts to specific situations" (p. 214). These aspects of curiosity, judgement, application and thoughtfulness relate well to Bloom's taxonomy (see "Bloom's Taxonomy").

Developing higher order cognitive skills relating to Bloom's taxonomy is one of the four advantages of case study teaching that Kuntz and Hessler (1998) summarise. The other three are that cases ground the student in society and reality; cases provide learnings which extend past the classroom and into the student's future career; and they encourage students to question underlying assumptions, see other perspectives and amend theory.

It appears that cases build critical thinking skills.

\section{Critical Thinking Skill Development}

Critical thinking skills align with Bloom's taxonomy levels of analysing, evaluating and creating (Ennis, 1993). Wasserman (1993) suggests that learning with cases allows students to increase their analytical and reflective-thinking skills; to hone decision-making skills; to reflect on their own values and beliefs; to improve problem-solving abilities; and to listen to and discuss the ideas of those around them. Strange \& Mumford (2005) found case-based knowledge is used by leaders in problemsolving. Wassermann (1992) cites Christensen (1987) stating that it is only by students' own efforts in really engaging with problems to find their own solutions that they think, and develop to independent then interdependent learners. If they do not develop these skills, learning does not take place, whether they can "recite some correct answer with 100\% accuracy" or not (Christensen, 1987, p. 24, as cited by Wassermann, 1992, p. 797).

Bruner (2001) states that case teaching is effective and develops critical thinking capacity. Cases help learners test the likely outcomes of their analysis and solutions, and to provide recommendations. The discussion itself motivates students to keep applying themselves. He also finds that students model the "inductive learning-from-experience" process (p. 3) that they will use once they are in the workplace.

A survey of 152 US and Canadian science lecturers was conducted by Yadav, Lundeberg, Deschryver, Dirkin, Schiller, Maier and Herreid (2007; also cited by Herreid, 2011). The respondents had all been science case teaching workshop attendees within ten years of the survey. When it came to critical thinking, while noting that this is possibly a 'preaching to the converted' audience, $91 \%$ of respondents found that students developed multiple perspectives from cases; $90 \%$ believed students gained a deeper conceptual understanding; $89 \%$ that students had stronger critical thinking skills; and $82 \%$ that students made better connections between subject areas. When it came to participation with cases, $95 \%$ considered students were more active; $94 \%$ that students were more engaged; $91 \%$ that students had more practical application. Of course, this is from the lecturer point of view: we have no indication from this research whether students agree. 
Regardless, teaching cases appears to be powerful tools. Adler et al (2004) note that when using cases, teachers can modify the how active student learning was. In their 2008 study of 286 year three business students at three Irish universities, Ballantine, Duff and Larres found that cases motivated students to take a "deep approach to learning" (p. 189); in particular, improved relating of ideas and the increased use of evidence in the students' work during the academic year. This idea of deep learning links both to critical thinking and to active learning behaviours.

\section{Other Areas of Skill Development}

Technique and communication skills are also honed by case teaching. Adler et al state in their conclusions that business cases simultaneously develop students' intra-and interpersonal skills alongside their technical abilities (2004). They go on to say that cases specifically build capacity in "critical analysis, creative thinking, teamwork, negotiation, and communication" (2004, p. 226).

William Rotch, a Darden Business School case teacher, suggests five key skill areas honed by using cases (1981). They are knowledge acquisition; application of analysis; building good analysis habits; development of a manager's perspective; and active, reflective self-development. Rotch also suggests that case teaching develops leadership, assertiveness and internal locus of control.

These skills positively assist our students' work readiness, and build good active learning habits.

\section{Active Learning and Teaching Cases}

Effective learning links strongly to active learning behaviours. Fulmer (1997) extends effective learning from passive through critical thinking to action-oriented learning; from 'ivory tower to factory floor', where challenges come in processing and applying solutions to real life situations.

In addition, active deep learning is enhanced by the use of teaching cases. Adler et al (2004, p. 216), citing Christensen (1987, p. 3) and Mauffette-Leenders et al (1997, p. 3), suggest that teaching cases "encourage students to take a deeper and more thoughtful approach to their learning". Ardalan (2006, p. 368) found that teaching aims using case studies are move students from passive receptors of lecturer wisdom to active, engaged learners. Bauer, writing in 1955, cited Donham (1931, p. 12) in highlighting case teaching as "an instrument of great power" because it arouses interest and engages students actively (p. 37). Gill compares the cognitive passive and cognitive active, highlighting the active learning that the "Case in Point" method and dialoguing cases can provide (2011).

Cases help us to learn effectively through interaction, reflection and application. So passive learning, or cognitively passive learning behaviour, would equal "I read the case". Active learning, or cognitively active learning behaviours equates to "I presented the key issues I saw, participated in the discussion and argued my points"; interaction, reflection and application.

Active learning in turn links to our ability to problem-solve.

\section{Problem-Based Learning}

Problem-based learning (PBL) is defined by Sockalingam and Schmidt as "situations or phenomena set in real-life contexts, which require students to explain or resolve the presenting issues" (2011, p. 6, 
citing Hmelo-Silver, 2004). Bridges and Hallinger (1997) consider that case teaching is teachercentred and PBL is learner-centred. While hybrid methods are more likely to be somewhat teachercentred, the "Case in Point" method is definitely learner-centred. Schmidt (1993, p. 429-430) outlines the research-underpinned benefits of PBL for students as:

1. "Activation of prior knowledge": small-group problem analysis situations ensure students draw hard on what they already know

2. "Effects of prior knowledge activation on the processing of new information": trying to fit what is already known into the analysis of a new problem in small groups enables students to better understand and remember the new material, regardless of how correct the prior knowledge is

3. "Contribution of group discussion to the effect of problem-based learning": analysis in small groups greatly improved student recall of the case, discussion, theories and materials

4. "Evidence for elaboration and restructuring processes": students adapt and test what they already know to fit new problems, as organic mesh rather than bolted scaffolds

5. "Effects of problem-based learning on epistemic curiosity": students are more likely to seek out further information on problems presented after PBL sessions

While PBL is not the same as case teaching, case studies are a useful PBL tool. I found this list of characteristics from Bridges and Hallinger particularly interesting, as I could see the potential use of these characteristics for my own research, as effective learning behaviour components to seek in my data (1997).

\section{Student Learning from Cases}

As we have seen, students learn from cases in many ways. Boehrer and Linksy (1990) summarise these as: that learning is purposeful, resulting from pursuing a case solution; secondly, that the case discussion environment approximates the workplace, so mimics the 'real world'; thirdly, that student learning and experience each 'unlock' the other, forming a virtuous cycle; and lastly that students learn from one another. Further, Hutchings (1993) proposes that, because discussion participants start listening to each other and thinking together, a "community intelligence evolves" (p. 16), presumably increasing the group's collective intelligence, and thus the expertise of society at large. This idea is also endorsed by Kuntz and Hessler (1998).

Additionally, Corey (1980, as cited by McQueen, 1995, p. 186) suggests that students learn in four ways from case studies: via discovery; from probing; through practice; and by contrast and comparison. Denny (1978, p. 4) also believes a key benefit of case studies is that they "allow readers 'elbow room' to draw conclusions other than those presented directly by the writer".

Drawing on studies by Hassall et al (1998) and Weil et al (2001), Weil, Oyelere and Rainsbury (2004) explored students' perceptions of the benefits of learning with teaching cases. The study by Hassall et al (1998) had students to rank the development of ten skills when learning with cases. The 
top five were (1) negotiation skills; (2) group work skills; (3) presentation ability; (4) applying and integrating subject and knowledge skills; and (5) questioning assumptions and listening to rationale. $85 \%$ of "students agreed that case studies were the most appropriate teaching tool for developing knowledge; $90 \%$ agreed in respect of skills and 62\%, personal qualities" (p. 142).

Surveying 68 students over three collaboratively-taught, third year IT capstone classes, Harper, Lamb and Buffington (2008, p. 414) surveyed students on teaching case delivery, developing a set of eight 'effectiveness' characteristics returning scores between agree (2) strongly agree (1) on a Likert five factor scale. These characteristics are (in order of most effective to effective):

1. "Applying $[\ldots]$ principles to real world situations"

2. "Brought out important points about [the topic]"

3. "Provid[ing ...] a good opportunity to synthesize; [i.e.], identifying potential solutions to a case problem and choosing the most appropriate solution"

4. "Increas[ing] the likelihood of student participation in class discussion"

5. "Provid[ing...] a good opportunity to exercise evaluation skills, (i.e., appraising the extent to which particulars are accurate, effective, economic, or satisfying)"

6. "Writing the case report aided in understanding the case principles"

7. "Prefer[ring...] student teams [being] assigned the responsibility of presenting a particular case"

8. "Good [...for] teaching "soft skills"; [i.e.], interpersonal [..\&] management skills"

As these have previously been used as determinants and measures of case effectiveness, I will use these to draw from when coding my own research data.

In their student survey evaluating the effectiveness of case study, Carlson and Schodt (1995) found that students were very engaged, with student comments including the usefulness of cases as tools, deepening the connection between theory and practice, increasing student problem-solving skills and being able to virtually explore their future field. Hativa (2001) also suggests that case teaching increases student motivation through student engagement and contextualised learning.

\section{Teaching Cases and the Experiential Learner}

Teaching cases allow us the vicarious rehearsal of theory: we can 'try before we buy'. For example, Wall suggests that teaching cases permit "the examination of an instance in action" (2006, p.12, citing Walker, 1980, p. 33), and in Wall's view, is extremely useful in training.

Bonoma and Krosnik (1989, p. 2) illustrate perfectly the experiential learning that students gain from case studies; they learn about, for example, electricity, not purely from theory, but by "moisten[ing] a finger and insert[ing] it in an electrical socket". Case learning in a controlled environment equates using "small sockets and controlled experiences", avoiding the equivalent of live practice on a 'substation'. 
Rehearsed realism is an idea also explored by Fisher (1972), who compared it to the idea of apprenticeship. He highlights that cases provide learners with "reality testing", "the simulated exploration of alternative decisions", "new concepts, useful generalizations, guiding principles and valuable insights" (p. 50). Fisher adds that learners learn "through a process approximating 'selfdiscovery' in real life" (1972, p. 67). He also says that cases are "the closest thing to apprenticeship that exists", "bridging the gap between the classroom and the real world" (1972, p. 50 citing Bauer, 1955, p. 40). Gorman, Mehalik \& Werhane, in their textbook, Ethical and Environmental Challenges to Engineering, said that cases "constitute a kind of virtual apprenticeship, in which students can apply ethical principles to actual situations and discuss the outcomes with each other and with a faculty mentor" (2000, p. 2).

Suggesting is a four stage similarity in how students experience cases, Schoen and Sprague detail "an initial reaction of frustration, an arousal of curiosity, a development of insight and a final achievement of administrative power" (in McNair, 1954, p. 79). Schoen and Sprague's process aligns well to Kolb's Learning Cycle. Additionally, with business students, Adler et al consider that the use of cases helps to develop experiential learning styles other than Kolb's Learning Cycle converger stage (2004) (see Figure 7: Experiential Learning Cycle \& Basic Learning Styles). Case teaching appears to help students develop a more balanced approach to learning.

There is good evidence supporting effective teaching and learning for experiential learners using teaching cases. We next turn our attention to the finer detail of how we teach leadership with cases.

\section{Effective Teaching with Cases: Leadership}

\section{Acts of Leadership}

Jackson and Parry note that leadership "is a process that goes on between all people and that all people can be involved in leadership, almost in spite of their formal position" (2008, p. 83). A leadership act takes place when, in the words of Marie Corelli, "Seize this very minute. Whatever you can do, or dream you can begin it; Boldness has genius, power, magic in it" (misattributing Goethe, 1905 , p. 31). In a leadership vacuum, we can choose to take leadership action, even though we are not the 'official' or acknowledged leader. Phil Dourado tells us that acts of leadership can be taken anywhere, at any time, by any person in an organisation (2007), and that "a vibrant organization is full of acts of leadership" (2007, p. 164). Great results "depend [...] on the capacities of individuals (who may be located in a wide variety of positions)" (Dourado, 2007, p. 165, citing Flowers, 2005), and this capacity is even more critical when learning and undergoing transformation.

Often students have the view that they have paid to come to hear from the expert (the lecturer); that they want leaders who provide all the answers. It can be a shock for them to find that good learning requires active participation. They can find it hard to accept that sharing the space is a necessary part of the transformational process. Leading them to developing our shared voice in the classroom is always a pleasure. All participants should understand that the 'buck stops' with them; exactly the requirements for acts of leadership and learning (Moxley, 2000; Dourado, 2007). 


\section{Teachers of Leadership}

When considering management cases, there is not a great deal of difference from the broader pool of effective case research already explored. However, Fisher's study, while old - 1972 - highlights a few differences due to the similarity of Fisher's approach to my research intentions. In his research, Fisher surveyed two groups of academic leaders, with one taught via case method and the other via readings and workshops, seeking to find whether case studies had a greater impact on learners, and was therefore more effective (1972). He found that cases are a more effective teaching/learning method, with respondents having a positive attitude change almost five times more than the readings/workshop group. He considers that cases build self-analysis and decision-making skills. In addition, older group members appear more positively affected by using cases than younger ones; i.e., teaching case use is likely to be more effective in teaching older learners (Fisher, 1972).

Leadership is primarily taught through reading and discussing theories. Bridges and Hallinger (1997) explored criticism for this type of traditional leadership education programme. They consider that the traditional approach fails on two fronts: firstly that the learning is not linked to the learner's future context, and secondly that it provides no experience in "what leaders actually do and what it feels like to be a leader" (p. 131). Cases provide realistic rehearsal for the workplace (O'Connell, McCarthy \& Hall, 2004).

Effective teaching of leadership cases includes linking theory and practice. Corey's six factors (those of discovery; skilful probing; continual practice; contrast \& comparison; involvement; motivation) are highlighted in leadership cases to two effective case learning outcomes: the real discovery of facts, and opinion formulation involvement. These factors form a "strong precursor to learning" (O'Connell, McCarthy \& Hall, 2004, p. 296, citing Corey, 1980). In writing about leadership cases, Armandi, Oppedisano and Sherman (2003, p. 1087) noted that "through case analysis, learners can develop the foundation for bridging the gap between leadership theory and practice".

Not all researchers think that leadership cases are the most effective tool, however. Bridges and Hallinger (1997, p. 135) discount teaching cases as being too teacher-centred, in favour of the broader PBL, which they consider to be more student-centred (obviously not realising that the "Case in Point" method fits the PBL definition). They summarise PBL's learning outcomes for leadership as:

1. "Acquiring new knowledge and learning how to apply it"

2. "Developing skills in self-directed learning"

3. "Developing skills in running meetings, resolving conflict, and using group problem solving and decision tools"

4. "Acquiring insight into the emotional aspects of leadership".

Greenhalgh takes a succession focus with students, as future leaders, proposing that they must develop the skills to "anticipate and respond" to organisational challenges in both a logical, linear manner and in a more organic and innovative way (2007, pp. 181-182). She believes that good case teaching fulfils both these perspectives of 'science' and 'art'. 
Story-telling is a large part of leadership: conveying vision, mission, values and goals in acts of leadership throughout our organisations. Gardner (1995, pp. 41) writes that effective leadership uses story-creation and -telling as "a fundamental part of the leader's vocation". Good case teaching provides "acculturation in which students learn how to frame and resolve business issues in accordance with prevailing [business] values", but Greenhalgh also suggests students use lenses such as Morgan's Metaphors (2007, citing Morgan, 1997) to analyse cases; using this type of more artistic, metaphoric frame to balance scientific models. Greenhalgh also notes that the scientific approach aligns more with management, art with leadership.

Parks (2005) concurs, saying that "we need a more spacious myth of leadership, grounded in more adequate metaphors that can embrace the complexity [...that] leadership now demands" (pp. 4-5). Parks cites Heifetz and Linksy (2002, p. 73; Parks, 2005, p. 8), referring to leadership as an "improvisational art", where when teaching cases we aim as teachers, through conflict, and through waiting, to have students develop insight, move to re-patterning, then on to interpretation, 'testimony' and testing. Through the process, they will have developed what Parks terms "the artistry of adaptive leadership" (2005, p. 26).

For effective leadership student learning, Greenhalgh sets case writing assignments where students research and explore a chosen situation and write up a suggested change programme. She notes that these assessments are very rewarding, as they "inspire leadership and change" (2007, p. 190), reaching the top level of Bloom's taxonomy, synthesis and evaluation. This theme is echoed by Greenstein \& Hall (1996) with regard using student-generated cases for accounting education.

\section{Leadership Case Studies \& Retention}

Cases help us remember leadership information. Connelly et al (2007, p. 235) found that "participants retain information from case studies better than information from principle-based training, and that the application of skills to a new problem is similar in both conditions". Principle-based training is more or less textbook learning (written theory with examples).

Anchoring concepts in our memory make later recall and use easier. This is especially important in leadership where there is a variety of options, strategies, decisions and answers.

\section{No One Right Answer}

While management cases are often apparently channelled as a single 'best practice' learner solution, in my personal teaching experience, leadership cases provoke a much broader range of responses, processes and outcomes from students. Learners' development appears less channelled, with cases more distinctive in the situational complexity each one presents.

From teaching, and from reading the views of others, leadership cases appear to provoke a broader range of responses, processes and outcomes from students. Learners' development appears less channelled, with cases more distinctive in the situational complexity each one presents, with outcomes focused on individuals dealing with situational complexity and a multiplicity of solutions. As Connelly, Allen and Waples put it: "reliance on convergent thinking can weaken [case learning's] 
effectiveness" (2007, p. 219). Therefore cases work best where multiple viewpoints are desired. Leadership lends itself to multiple viewpoints.

\section{Adding Media Richness}

Based on lecturer reflection \& secondary research, Blanchard and Donaghue (2007) create a "realistic experiential learning environment" using case study, simulations and role playing, visiting CEOs and a number of other mechanisms in their MPA (Policy Administration) programme. While their paper and conclusions are not specific to cases, they consider that their programme structure provides "effective instruction that helps students develop leadership skills and attributes" (p. 461).

The leadership case research conducted by O'Connell, McCarthy and Hall (2004, p. 294; also Blank, 1985) finds that the "leader's presence, even through video, significantly affects student engagement and can substantially enhance impressions of leadership effectiveness" for the students participating in the case session.

\section{Other Effective Leadership Case Techniques}

Innovative presentation formats also assist learning; variety being the spice of life. Armandi, Oppedisano and Sherman (2003, p. 1080) suggest that case studies provide a "slice of life" enquiry into organisational problems or decisions. They cite Willings (who wrote on using case studies as a training tool to teach decision-making, published in 1968), reiterating Willings's view that cases are effective as a decision-making training tool. They themselves present their leadership case, 'Ted Shade' where a summary of leadership theory is provided, followed by the case itself which details the situation from a number of different viewpoints, then finally by the case analysis. This process takes theory, then case, then blends the two; an interesting construction, and a structure which I have not seen used elsewhere in teaching cases.

In many ways this formulation used by Armandi et al (2003) echoes that of the hybrid case method; teach some theory, have the students complete a short case; then analyse the facts and link the theory to the case facts where there is a 'fit'. While, Armandi et al provide no rationale nor evidence for their chosen case structure, the editor of Management Decision provides a note explaining that the theory was included for non-expert information; the different viewpoints give insight into the manager's mental models, leadership style, self- and other-perception; and that cases enhance teaching leadership decision-making (2003, p. 1076).

Lecturers are not the only useful writers of cases. Swiercz and Ross consider that having students write leadership cases - called SWIF (student-written Instructor-Facilitated case learning) - was a powerful tool for helping students become active and engaged (2000). It is likely that raw cases (Griffin, 2009) may also work well for leadership cases, although there is no research yet into this area.

As with every aspect of leadership learning, there are a number of approaches that will work well for teaching and learning. 


\section{Factors for Effective Leadership Case Learning}

Summarising the requirements for effective leadership cases learning, we should include:

- A 'good' story - slice of life - which provides experience in "what leaders actually do and what it feels like to be a leader" (Bridges \& Hallinger, 1997, p. 131)

- A teaching process which allows student conflict, reflection, insight, re-patterning, interpretation, 'testimony' and testing (Heifetz \& Linksy, 2002; Parks, 2005)

- Real discovery of facts and opinion formulation (O'Connell, McCarthy \& Hall, 2004)

- Cases with multiple answers (Connelly, Allen \& Waples, 2007)

- Media richness: video, live and raw materials (Blanchard \& Donaghue, 2007; O'Connell, McCarthy \& Hall, 2004; Griffin, 2009), and being open to other ways of constructing cases

Having explored effective teaching with cases, we will now consider how we deliver them.

\section{How Teaching Cases are Delivered ('Taught")}

Writing for Cranfield University's Case Centre, Roberts (1997) argues that a good case lecturer exchanges a "dispenser of wisdom" role for that of a group-learning manager (p. 4). Teaching substantially with cases requires the lecturer to find or write 'big idea' cases which will deliver the major concepts required, and ensure they have accumulated enough evidence for the students to mine the relevant issues (Wassermann, 1992; Christensen \& Hansen, 1987; Roberts, 1997).

For best results, students read and research the materials before coming to classes, familiarising themselves thoroughly with the case, and in some instances, writing some form of briefing note (Roberts, 1997; Christensen \& Hansen; 1987).

When in their class, they work in small groups, discussing either preparatory questions (if provided), or the issues they have identified in their briefing note work. Wasserman states that "Students are held responsible for expanding their knowledge base as they examine the issues and concepts, lest their discussions lead to distorted and immature conclusions. They acquire information not from the teacher's lectures but from reading and gathering documentary material" (1992, p. 796). Their analysis is expanded and balanced by discussion.

Cases are an academic input-output model; the transformation gain comes only from the amount each student contributes to analysis and discussion (Roberts, 1985). Unless students "take part in the classroom discussion it is unlikely that [they] will receive any positive contribution" (p. 2). Ertmer and Stepich (2002, p. 6) reiterate this succinctly; "Powerful as they may be, 'cases, even with commentaries, do not teach themselves' (Shulman, 1996, p. 155). While a case narrative can serve as an anchor for the development of situated knowledge, it is the case discussion that encourages participants to develop new perspectives and ideas (Lundeberg, Levin, \& Harrington, 1999)".

There are a number of aspects to consider in teaching case delivery, and we will briefly examine a selection. 
A number of researchers have considered teaching case delivery methods. Rangan (1995) considers there are several ways to teach a case. Rangan proposes four delivery methods: lecturing; theorising; illustrating; and choreographing. In a very similar vein, Gill (2011) suggests five approaches: lecturing, theorising, illustrating, and - splitting Rangan's choreographing in two - dialoguing and choreographing. Gill's delivery methods transition from lecturer-led to student-led teaching and learning, and could be placed on a continuum following Tannenbaum \& Schmidt's (1973, p. 165) Leadership Continuum model:

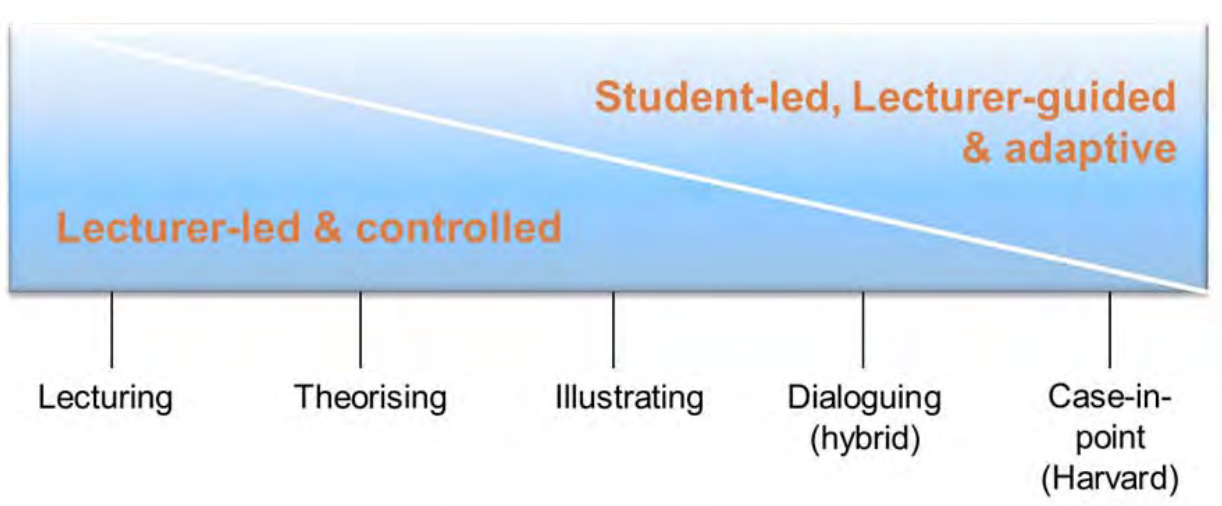

FIGURE 7: THE LEADERSHIP CONTINUUM ADAPTED TO A LECTURER/STUDENT-LED CASE DELIVERY CONTINUUM

The methods that I am concerned with are: the dialoguing style, which I believe aligns with the 'Hybrid' lecturer-led delivery; and the 'choreographing' style.

The 'hybrid', 'dialoguing', Socratic (Gill, 2011) or 'instructor-led' approach (Roberts, 1985) is where the instructor forms the focal point, controlling session flow through choice of students and selection of questions. The instructor starts, guides and leads discussion with an introduction to the case, asking the questions, usually of the whole class. Students do not tend to build on each other's contributions without direct instructor involvement. The questions are likely to be provided with the case itself, and the case may be read in class time. The case debrief session is very interactive and may take place alongside the theory session in a workshop (Gill, 2001; Roberts, 1985). Ideas are usually banked on a whiteboard and recapped at the end of the discussion.

We next define the "Case in Point" method.

\section{The Case in Point Method}

The "Case in Point" method is also known as the Harvard or the 'choreographing' (Gill, 2011) method. This is syndicate-based learning where the students have, in small groups, unpacked and analysed the case data and determined a view (Roberts, 1985; Christensen \& Hansen, 1987; Parks, 2005).

Once the small group analysis is complete, the class comes together for a full group discussion and exploration on the identified issues, which should suggest avenues for further study (Wassermann, 1992; Roberts, 1997; Roberts, 1985; Christensen \& Hansen; 1987). The case teacher facilitates the dialogue between groups, framing, guiding and prompting discussion (McNair, 1954; Towl, 1969; 
Roberts, 1985; Christensen \& Hansen, 1987; Rangan, 1995; Golich et al, 2000; Parks, 2005; Gill, 2011).

Using this method, students build on each other's contributions, usually without direct instructor involvement (Gill, 2011). The instructor may or may not be available for group consultations (Roberts, 1985). Questions are generally not supplied with the case (Harvard and Ivey generally do not).

In the debrief sessions, the instructor usually does not need to control the flow of the session unless the discussion stalls or a key issue is missed. Ideas are usually banked on a whiteboard as the session progresses, are critiqued by anyone during the session, amended where necessary, and are summarised and recapped at the end of the session by the instructor (Christensen \& Hansen, 1987; Parks, 2005).

\section{Dissenting Voices}

There are some dissenting voices with regard to the "Case in Point" method. Resistance from teachers when the idea of teaching via the case method is introduced is explored by Wassermann (1992) as: (a) cases are lengthy and curricula would suffer; (b) teachers are student informationproviders; (c) students would not be exam-ready; (d) students were not independent learners so needed more direction; (e) students were not responsible team members, would not be on-task so would cause conflict.

Countering these arguments, Wasserman (1992, p. 796-797, citing Christensen, 1987, p. 24-25) states that "Case in Point": (a) is an efficient teaching method; (b) encourages lecturers to research their subject and hone their delivery; (c) allows for industry practice feedback, change, research and innovation; (d) teaches students to understand theory AND to act; (e) allows learners to work at the higher levels of Bloom's Taxonomy; and (f) stimulates lecturers' and faculty thought processes.

Additionally, Shugan (2006) has some specific reservations of the "Case in Point" method. These include that: the Socratic method is inferior to the scientific method; it weakens classroom/research links; it surrenders teaching to students; and may build false confidence in students. Gill (2011) suggests Shugan is taking a more pedagogical view; where the learner is the child who must be led, and refutes many of Shugan's statements, to wit: Socratic method is the "Hybrid" method; cases are based on academically research; no proof that student-led classes are better or worse than lecturerled; and vigorous debate usually exposes puffery. In considering Gill's answers, I wonder if Gill presumes that Shugan believes there is a 'right answer' to cases. If so, then I agree with Gill. When exploring cases, I think it is the discussion, the sifting and the honing of our thinking and cognition skills that has value.

Forman and Rymer (1999a) too suggest that cases can make students arrogant and too command and control-oriented when delivering their verdict in "Case in Point" debrief sessions; that they can adopt a "dominating voice" (p. 392). This confrontational and somewhat aggressive style tends to lock out those students - often women - who prefer a more collaborative, questioning or humble approach. 


\section{Effective Case Delivery}

For ensuring effectiveness, Rangan (1995) suggests four key elements for case delivery:

1. Decision orientation: students ask themselves, as the central character 'what would you do?'; to be action-oriented and apply judgement despite not having 'enough' data to make a fully reasoned decision (just as in the 'real world'), and to trade-off evidence, values and priorities.

2. Themes/analyses: to limit the class to three or four thematic areas and their relationship to each other. It is the instructor's job to ensure the themes work, build on each other and provide clarity and keep momentum in the class.

3. Structure: there are two main components: time and trapping session themes and ideas. The instructor keeps an eye on the time, pushes on when discussion is flagging or cuts overexplored ideas. They also record the class ideas on the whiteboard in such a way that the students know where the discussion has been and where it may still need to go.

4. Closing: concluding with a summary which reflects the themes and their developmental argument, shows the transitions between themes and details alternatives, where alternatives existed.

Furthermore, Hativa (2001) suggests five pauses in case delivery:

1. Two or three times (for a couple minutes each) to allow students to reflect, develop questions and consolidate notes

2. Give students time to reflect and present and answer their own or instructor questions or to present their own questions

3. For pair work with students working in pairs to discuss key points, organize ideas and develop questions

4. Explicitly assign thinking, note-taking and reflecting tasks; solo or in pairs

5. Summarising; whether lecturer- or student-led; or both

These techniques will help structure small group work, deepen discussions, improve student case analysis, provoke more learning points and round off a debrief session by closing the learning cycle. Taken together, the two previous sections form a valuable checklist for case lecturers.

\section{Depth-Analysis vs Workshops}

Using the "Case in Point" approach to teaching cases, there is equal focus on the discussion and the analysis. In a case workshop using hybrid delivery, students generally read the case in class, discuss the issues in small groups, then they report back for a full class discussion, or debrief.

Hativa (2001) outlines the lecturer's case teaching duties as selecting appropriate cases to suit the course needs; guiding and summarising discussion; and leading students to ensure comprehension, synthesis and evaluation of the intended principles. She notes that lecturers who fail to summarise may leave their students feeling adrift and wondering if any learning has occurred. 
Interestingly, Fulmer (1992) suggests that the "Case in Point" method is not the most efficient way of conveying content. However, he notes that the process learning which takes place using the Harvard approach is extremely valuable. Using a hybrid method where there have been a mix of lectures and cases, the analysis itself may only be limited to the time taken in small group reading, discussion and reporting back.

In hybrid methods, the ability of the lecturer to direct discussion is probably even more crucial than with the "Case in Point" method. Hativa refers to the positive correlation between student discussion participation and "learning, motivation and problem-solving ability" demonstrated by research (2001, p. 112, citing Nunn, 1996). Socratic questioning methods are also a sound approach. Additionally, she suggests that "recitation", quick-fire question exchange controlled by the lecturer, promotes more student learning than methods that avoid lecturer questioning (eg "Case in Point" method), and the more questions asked and answered, the more effective the learning (2001, p. 101, citing Gall \& Artero-Boname, 1995).

This aspect of questioning needs a little more exploration.

\section{Questions and Discussion}

For learning to be effective, lecturers must lead case discussions and ask the right questions. Winston (2000, p. 159) states in case delivery, the instructor acts as guide, anticipating blocks and smoothing the way, modelling acceptable culture and asking questions, with the outcome of 'mutual understanding". Thus case teachers can provide leadership as good 'askers of questions' (Daft \& Pirola-Merlo, 2009).

Ertmer and Stepich (2002) propose that there are four approaches that lecturers can use to frame and ensure robust discussion. They are to model expert - or devil's advocate - responses or questions; to link to issues or underlying principles; to select contributors so all are heard; and to draw connections to reinforce theory or concepts. These 'tips' also add value to the case lecturer's toolkit.

\section{Role Play}

Foran (2001, p. 45) uses role play, letting students "enter the discussion comfortably, followed by a lively role play, in which they 'inhabit' the case" then discuss the issue at hand. Foran uses cases to promote discussion and debate in his classes which ensures that more than half of his group will have contributed at each 75 minute session, including using a 'one-word essay' summation of each case, which is collated and related back to the group at the commencement of the next class (2001, p. 47).

We have examined a number of techniques for teaching leadership cases, but have not yet considered what leadership theory might be useful both in teaching, and in undertaking this research project. 


\section{Leadership Theory Relevant to Effective Leadership Case}

\section{Learning}

In the classroom I aim to create a teaching environment where we all have a voice. I encourage students to have the confidence to bring resources, to share their experiences and insights. I prefer a climate of equality, honesty and respect to support discussion and debate. Like Marshall (1984), I aim to use power with and through others.

As a teacher of leadership, I am constantly reminded of leadership theory, of our structures which make it easier for ourselves to view and understand the leadership actions of ourselves and of others. In this work, I too need to consider what theory is relevant to developing and coming to my own conclusions in my investigative process.

Leadership theory that has relevance for my classroom practice, and so too for my research, includes acts of leadership (already mentioned), shared leadership, and power sharing.

\section{Power Sharing}

Power is the capacity to influence others, whereas influence is our capability to change others' actions (DuBrin, 2013; Pfeffer, 1992; Yukl, 2006). DuBrin (2013) notes that influence increases in importance when we do not have formal authority. Informal authority, or 'person power', is made up of 'expert' power (i.e., professional knowledge), and 'referent' power (i.e., character) (French \& Raven, 1959).

Students generally do not possess much power. They have generally little to no position power (i.e., legitimate, reward, coercive power sources; French \& Raven, 1959). Of their personal powers, students are often an unknown quantity with regard to referent power until we are well into a semester. With regard to expert power, lecturers also may assume that students have little simply by dint of them taking the course.

Whereas when we are able to give students a voice in the classroom, we usually find that they have many deep veins of expertise that we can mine, drawing forth a range of valid and fascinating perspectives that add to the learner journey of the cohort.

While power sharing can be a challenge to create in the classroom, it is easy to establish this with peers in undertaking research. Power and knowledge sharing throughout this project has been egalitarian, and based on personal power.

\section{Shared Leadership}

Shared leadership is a model of responsibility, collaboration, respect and purpose. Pearce \& Conger define shared leadership as "A dynamic, interactive influence process [where participants ...] lead one another to the achievement of group [...] goals" (2003, p. 1). Allen, Morton and Li define it as "the cocreation of an environment by a group [...] to accomplish a common vision and collaborative goals" (2003, p. 4). 
The components of shared leadership are defined by Moxley (2000) as a: balance of power; shared purpose; shared responsibility; mutual respect; commitment. For shared leadership to work, an egalitarian balance of power is needed, using participants' personal power to co-create positive outcomes. Group members should not use coercive power or the power of their position, but remain equal partners, empowering one other. Creating a true balance of power is likely the hardest aspect of a shared leadership model (Moxley, 2000, p. 96), and fits well with the classroom where the focus is on learning and with working with other lecturers to achieve collective goals.

The element of shared purpose must be lived by every member of the leadership group, with individual's divergent opinions and agendas subsumed for the group goal (Moxley, 2000). This too is a factor that fits well with teaching and learning. Responsibility and accountability for partnership work is also essential. This cannot be an 'us and them' model; "it can only be us. There is no waiting for someone else to act" (Moxley, 2000, p. 76), with every role in the organisation being where the "buck stops'. Respect and commitment are led by the lecturer in creating the class culture. These concepts fit well with active and engaged learning and with a geographically diverse research project.

When Moxley's requirements are met, relationships transform into a partnership, inspiring a feel and tone of increased vitality and energy (2000). The research portion of this project was invigorating due to the sense of partnership that I gained from the students and lecturers who so willingly took part.

\section{Facilitative Leadership}

Facilitative leadership is a values-based model developed by Roger Schwarz (2002), a trainer and teacher. It is a supportive philosophy suited to mentoring and developing adults. Moore (2004, 231, citing Rees, 1998, p. 18) in defining it as involving "followers as much as possible in creating the group's vision and purpose, carrying out the vision and purpose, and building a productive and cohesive team".

Schwarz (2002) notes that facilitative leaders can be informal leaders in the group; that position power is not a defining requirement of the style (akin to Dorado's Acts of Leadership, 2007). There are four underpinning values which need to be met for this leadership style: "valid information, free and informed choice, internal commitment and compassion" (Moore, 2004, p. 230):

1. "Valid information" is where access to information is open to all participants. In my classes I encourage students to bring alternative views for open-minded discussion

2. "Free and informed choice" is enabled by access to the best information available, within known constraints. Students are taught to gather evidence to develop sound arguments

3. "Internal commitment" is the next step; that with the best information, the "best' decisions can be made. As a result, participants commit to the outcome. This is when learning happens.

4. "Compassion" in this model is open-mindedness, the ability to suspend judgment and listen to ideas. This too is a necessary requirement for learning.

The facilitative leadership style sits well with teaching. 


\section{Leadership and Culture}

Culture has been economically defined by Deal and Kennedy as "the way we do things around here" (Bolman \& Deal, 2008, p. 269, citing Deal \& Kennedy, 1982, p. 4). Culture is the intangible method that humans have, by action, emotions and thought, of defining environments, groups and things.

Edgar Schein stated that "one of the most decisive functions of leadership may well be the [management] of culture", that culture and leadership "are two sides of the same coin" followed by "the only thing of real importance that leaders do is to create and manage culture" (1990, p. 2). Jackson and Parry (2008, p. 63) ascribe leadership as "essentially a cultural activity".

The 'new' leadership paradigm, that of transformational leadership, leaders are considered to be "managers of meaning" (Jackson \& Parry, 2008, p. 28, citing Smircich \& Morgan, 1982). If leadership is a 'cultural activity', then teachers too are 'managers of meaning'.

Culture in a leadership classroom is modelled by the lecturer.

\section{Chapter Summary}

In this chapter we understand from research and learning theory that adults learn differently to children; that an 'andragogical' approach requires teaching and learning to be learner-centric, in a new paradigm relationship of collaboration, empowerment and discovery. We have examined teaching and learning - refining as we have progressed - and know now what constitutes effective teaching active learning behaviour; problem-based learning, and the development of critical thinking skills. Cases also constitute rehearsal for students; serve effectively as apprenticeship learning. Collectively these skills enable students to be flexible in meeting the workplace problems they will encounter after graduation.

Leadership teaching cases have been studied by researchers who show us that realistic workplace rehearsal which links theory and practice is a key outcome; that leadership requires good storytelling skills which then helps anchor our leadership learning; and that leadership issues require adaptive, reflective practice as there is usually not 'one right answer'. We also find that using a range of media reading, video and CEO visits - positively affects student engagement, as does having students write their own cases. We know how we deliver cases is important because we can use tools which are too decision-focused and that students may lack confidence to speak up in discussions. There are arguments regarding the lack of resourcing to prepare cases and little evidence supporting the idea that case teaching improves learning or decision-making. This latter view, however, is inconsistent with the evidence shown elsewhere.

We have examined delivery and know that there are a range of case delivery methods and considerations, including analysis, questioning and discussion. We have detailed the difference between the "Case in Point" method and the hybrid method, which we will further explore in the research itself. In addition we have found a range of techniques which we can use in the classroom to improve case delivery efficiency and effectiveness. 
Lastly in this chapter we have explored leadership theory relating to my own views on teaching, learning and research; those of power sharing, shared leadership, facilitative leadership and culture.

In the coming chapter, we explore the research bases, design and methods which attempt a comparison of the "Case in Point" and the hybrid case delivery methods. 
Having determined what constitutes the effective learning of leadership cases, in this chapter I now explain the research design with which I attempted compare my two chosen teaching methods of the "Case in Point" and 'Hybrid' delivery methods. I detail my research ontology and epistemology as a critical realist, and explain the process and detail of the research methodology and methods I have constructed to answer my research question: do students make sense of leadership cases differently when they are delivered using different methods?

Using cases on real situations to teach leadership provides 'authentic simulation' (O'Connell, McCarthy \& Hall, 2004) in a field where much of our learning comes from modelling, practice and apprenticeship (Kempster, 2006). A safe way to practice leadership before we have to 'do it for real' is to be embraced.

Having now completed a lot of reading about field and teaching cases, there appear to be two recurrent case teaching models arising from the literature: the 'Hybrid'; and the "Case in Point".

The "Case in Point" method, taught for over a hundred years at Harvard, is where an entire course is delivered through medium to long teaching cases. Students read, analyse, write up an analysis, and discuss their case findings with a peer study group before class, then are called on as individuals to present their solutions in class where the whole topic is debriefed in a two hour session. Aside from calling on individual students, the instructor only facilitates the exploration; the students are the true explorers (Christensen \& Hansen, 1987; Mauffette-Leenders, Erskine \& Leenders, 2001; Parks, 2005).

The 'Hybrid' method is a mixture of workshop and lecture, with the key topic theories being delivered for a topic, followed by application via a short teaching cases, often read in class, and discussed in small groups, backed up by a full class discussion.

As yet I have not found research specifically comparing the "Case in Point" and the 'Hybrid' case methods, so it appeared clear that I should seek some answers myself. Lynn (1999, p. 12) cites Behn (1993, p. 53), who notes that the case researchers “...'will never be able to prove they are right. They will not even be able to prove that their work is helpful, for even the testimony of managers who find the insights of case analyses useful does not constitute proof. But at least those engaged in caseanalysis research will know that they are asking important questions' about what values are at stake". I am interested in exploring the different learning that these two models might provide students, and the differences that instructors might note in delivering them. I will compare Approach A ("Case in Point") and Approach B ('Hybrid'), to observe what differences there are in students' leadership case sense-making with the two delivery methods. 


\section{Critical Realism}

Spencer has observed that "for any theory that we have about what knowledge is, we must have a presupposition about what the world is like. That is, we must assume that the world exists in such a way that it makes our theory of knowledge possible. There is no escaping having a theory of ontology" (2000, p. 1). Ontology is defined by Bryman and Bell as "social entities [...] that have a reality external to social actors" (2010, p. 22). Ponterotto states that ontology is the "form and nature of reality, and what can be known about that reality" (2005, p. 5, emphasis added). Ontologically-speaking (i.e., being) while I do consider that each of us experiences our own reality, I am neither a relativist nor a positivist, but a realist. I do not have the reserve and uncompromising objectivity of a true positivist, nor do I have the only one - of seven billion realities - subjectivity of a confirmed relativist. While I believe that in teaching we have generalisable best practice methods and techniques, and that refinement of these can be meaningfully applied across our teaching organisations to the benefit of all participants, these methods will not suit everyone to the same extent. Observing "the empirical and discover[ing] by a 'mixture of theoretical reasoning and experimentation"' (Outhwaite, 1983, p. 332, as cited by Krauss, 2005, p. 4) suits my personal approach to exploring new theories and research. I explore, then field test it to see if, despite supplied evidence, these new ideas truly meet my needs and can be built into my practice.

I am seeking to know more about case delivery methods and what student impressions are of learning leadership theory. Understanding more about the delivery of leadership learning to my students would benefit me; enabling me to help students learn as much as possible, with learning that will stay with them and be useful in their future work and mentoring roles.

Epistemology is defined by Bryman and Bell as what is "regarded as acceptable knowledge in a discipline" (2010, p. 16). Ponterotto (2005, p. 6) clarifies this by saying epistemology "is concerned with the relationship between the 'knower' (the research participant) and the 'would-be knower' (the researcher)." Epistemologically (i.e., knowing), I want to know how to become a better teacher of leadership. What I currently know about teaching and learning leadership is from practice, coaching, mentoring, survey feedback from students and formal and informal self-development. What will count as new knowledge are structures, methods, ideas and processes from the research participants which will further refine how I currently teach, write and workshop leadership cases with my students in the future, and that can be applied across the teaching organisations participating in this process.

In taking a critical realist's view of epistemology, that there can legitimately be multiple perspectives of single realities (Healy \& Perry, 2000, as cited by Krauss, 2005), I believe both qualitative and quantitative research are mutually complementary. Quantitative studies provide background, guidance and underpinnings for qualitative research, and qualitative studies provide theories, phenomena and grounding for quantitative work.

Furthermore, critical realism takes account of the values of our human systems and of the researchers who research them; thus my worldview has determined the questions I am seeking to answer; that 'l' am mostly indivisible from 'my research'. Both myself and my participants will co- 
construct the research findings from "interactive dialogue and interpretation" (Ponterotto, 2005, p. 129).

\section{Theoretical Perspective}

A theoretical perspective provides an explanation - a 'working' model - for a certain viewpoint, with three main qualitative research schools of thought: post-positivist; interpretative; and critical (HesseBiber \& Leavy, 2011).

My theoretical framework springs from comparing case delivery methods to determine if students make sense of leadership cases differently when they are delivered using different methods. In undertaking this research comparison, I will gain insight into what makes leadership cases impactful.

A key issue is that I am unaware as yet of any other research which compares the "Case in Point" to the 'Hybrid' case delivery method. The closest research I have found to my intentions is Fisher's (1972) research in evaluating the case study method for effectiveness. He surveyed 36 newlyappointed academic deans and vice presidents from across America, at the University of Chicago's 1971 'Institute for Academic Deans'. He divided his participants into two evenly-represented and similar attitudinal groups of 18 , with one group taught via case method and the other via readings and workshops (with the case swapped out for a position paper on the same topic). Both groups were taught using the same materials, and were evaluated with pre- and post-experimental session surveys using an attitudinal questionnaire. Fisher's hypothesis was "that the case study experience has greater impact on most learners, as measured by positive attitude change, and thus may be a more effective teaching/learning method than the more traditional reading-discussion approach" (1972, p. 109).

While Fisher's work is dated, it deals with the issue of comparing the "Case in Point" method with another (although, instead of lecture, I compare the 'Hybrid' method). He matched his materials carefully to ensure the course content was as similar as possible. I too have written the cases so they are very similar for the different case delivery sessions.

However, Fisher appears to be more of a qualitative empiricist than I, so his actual methods are less suitable for my epistemological approach. I am taking a qualitative, critical realist perspective, and want to observe what happens with my lecturers and students in their individual social construction, allowing the data to emerge.

\section{Research Aims \& Objectives}

WHAT THE PROBLEM IS

\section{Do students make sense of leadership cases differently when they are delivered using different methods?}

I set out to test how teaching an undergraduate level leadership topic using the "Case in Point" method works, as compared to the 'Hybrid' method which I currently use in my teaching. I wanted to 
know if students' sense making of the material was different when their lecturers used different delivery methods.

\section{The Two Delivery Methods Outlined}

"Case in Point"

The "Case in Point" method is usually an entire course which is delivered using teaching cases. Students (a) read each case and (b) analyse it solo outside class, self-sourcing relevant theory, identifying drivers, analysing costs, budgets and any other exhibits, then (c) discuss their findings with a peer study group before class, then (d) are called on as individuals to present their solutions in class where the whole topic is debriefed in a two hour session. Aside from calling on individual students, the lecturer only facilitates the exploration; the students are the true explorers.

For the purposes of this research comparison, I determined to teach one sub-topic using the "Case in Point" method. Thus students: (a) read the case; and (b) analysed it individually, self-sourcing relevant theory, identifying drivers and analysing exhibits, then completed a short, written case analysis; then (c) discussed their individual findings with a peer study group in a two hour tutorial session where they could also ask questions, get guidance on theory from the lecturer or complete their own analysis; then (d) presented their conclusions in two hour, student-led case debrief session. The total case reading, exploration, discussion and debrief time would total three and a half hours.

\section{'Hybrid'}

The 'Hybrid' method is where the case may be read - often in class time - and the students form their initial ideas as they read. Students then get into small groups and discuss their impressions. Once the groups have explored enough ideas, the instructor initiates, guides and leads an entire class discussion, asking questions (usually provided with the case itself). While the instructor forms the focal point, controlling session flow through choice of students and selection of questions, the debrief session is interactive and often takes place after or before a related theory session.

For the purposes of this research comparison, I determined to teach the same sub-topic using the 'Hybrid' method, in my normal style of delivery. Thus students (a) read the case in class and (b) analysed it individually briefly during the class, applying theory just taught and identifying drivers, then (c) discussed their individual findings in small groups briefly during the class time, then (d) the lecturer led the discussion, asking the supplied case questions and drawing out student conclusions in a short debrief session. The total case reading, exploration, discussion and debrief time was 20 minutes. Relevant theory was taught bracketing the case delivery and the other activities which made the time up to the three and a half hours of normal delivery on this sub-topic.

\section{The Participants}

There were three groups of participants at three AUT campuses (North Shore, Manukau \& Nelson). The participants were all AUT Bachelor of Sport \& Recreation Year 3 students. 
The two Auckland courses are taught by Dr. Lynn Kidman. I teach the Nelson course. However, to allow myself to be an observer in the process and so I was not directly involved, one of my NMIT colleagues in the Applied Business School in Nelson, Nic John, agreed to take my class for the duration of the two sub-topics, and for the focus group.

Thus the two leadership instructors for the purposes of the study were: Dr. Lynn Kidman (Auckland's North Shore and Manukau campuses) \& Nic John (Nelson campus).

\section{The Process}

In determining if students' leadership learning was different when they are taught leadership entirely by case workshops, which I will call Approach A, or by our more normal lecture/workshop combination (which I will call Approach B), I recorded two sets of delivery sessions - one set of Approach A sessions, one set of Approach B sessions - for each of our three cohort groups at Nelson, North Shore \& Manukau.

I then held a student focus group for each cohort and looked for arising themes, which the lecturers attended.

The lecturers (Dr. Kidman in Auckland; and Nic John) undertook a brief online survey after each session.

I assumed that the "Case in Point" method may be too much of a stretch: that students would not yet have enough theory at their command to be able to seek out and apply appropriate theory. However, I was aware of the possibility that I could have been underestimating my students, and may have found them utterly capable of learning this way.

From the outset I was prepared to change my delivery method if my students found the "Case in Point" method more impactful. My case delivery methods may: broaden to adding in the "Case in Point" method for use sometimes; change to often using the "Case in Point" method, or; shift to rewriting the course to deliver leadership only using the "Case in Point" method.

\section{Methodology}

\section{Research Design: Retroductive Grounded Theory}

My research design was based on qualitative retroductive grounded theory, with data collection methods of (a) exploring lived experience through observation and interviews (b) retroductive analysis and explanation and (c) discussion with respondents prior to theory propagation (Kempster \& Parry, forthcoming 2014).

In reading the contribution of Harry Woolcott to Kileff and Pendelton's Urban Man in Southern Africa, Woolcott (1975, p. 122) highlights the complex influences that feedback plays in research. He comments that "feedback is predicated on the idea of controlling and correcting what happens next by feeding back information about what happened already. The terms predicating and adjusting help translate the process into the realm of human behaviour (cf Tustin, 1972)". He warns that 
researchers must remain alert to the ways that interpersonal feedback can "exert subtle and unexpected influences" on research. I have attempted to remain alert to undue influences through the feedback process.

My data sources were both secondary (literature and research review), and primary (recordings, lecturer survey and anecdotal student feedback).

Information gathering techniques both within New Zealand and internationally included literature review materials; self-reflection \& own observation; colleagues' (other lecturer) observations; analysis of students' experiential data and the analysis of lecturers' experiential data.

\section{Methods}

\section{Research Methods}

My research methods included:

- Observations: recording two 1 hour and 45 minute workshops at each participating campus.

- Interviews: as a half hour semi-structured interview with the instructors, on their reflections on completion of the entire process.

- Questionnaires: Instructors taking each workshop records their impressions via a SurveyMonkey survey as soon as possible after each workshop.

- Focus-groups, as a half hour semi-structured debrief sessions conducted by myself as researcher, with all student and instructor participants at each campus.

\section{Where and How the Research Takes Place}

The research procedures took place during the students' normal Sports Leadership lecture rooms at AUT North Shore and Manukau campuses and at NMIT's Nelson campus, with a sound recording device (in-room microphone - Manukau; laptop - North Shore; camcorder - Nelson).

The sound recorded case and focus group sessions took place in late August and early September 2013. Only normal class time was used for the recorded sessions and the focus groups (two 1 hour and 45 minute workshops, student preparation and writing time for the written case analysis - built into the assignment marks for the course, plus a half hour focus group session.

\section{The Delivery Methods Being Compared}

The details of the two delivery methods are:

1. Approach A: This was a three step process. Firstly, students read and analyse the case individually, completing a one page analysis (later submitted for course credit). Secondly, students discuss the case in groups before the recorded case class, coming to a group view. Thirdly, students come to the two hour session and are called on by the instructor to present their own and their group's ideas. The entire session is a case debrief class, on what theories 
the students consider are relevant, and on how they have applied those to come up with potential solutions for the case. The theory should have been learned through the one page preparation process.

2. Approach B: the topic is taught as usual, walking students through theory, applying using a short case which is discussed in small groups, then debriefed by talking through the questions provided. Some students will volunteer information, some will be called on, as the instructor determines. Case discussions usually take 20 minutes of 'Hybrid' lecture/workshop time.

\section{About The Topics Being Taught}

I determined to teach two adjacent sub-topics, at the end of our second course topic, Conceptual Frameworks. I chose this topic and sub-topics for several reasons:

1. Cohesion: enough course time had passed for students to be well rehearsed with using cases via the 'Hybrid' method; they were 'performing' (Tuckman, 1965)

2. Size: the sub-topics at the topic end were both standalone areas; they would fit into the time available without needing any changes

3. Staging: the sub-topics were far enough ahead in the semester for me to prepare the necessary materials; write the cases; gain academic approval; and brief the participants

4. Timing: all campuses would be able to undertake the sessions reasonably close together without the study break unduly impacting on student and lecturer feedback

5. Expediency: I already had a short case (Tennis New Zealand), so effectively I only needed to write one other case and edit it; and expand the short case.

From Topic Two: Conceptual Frameworks, the two sub-topics were:

- Shared Leadership: encompassing shared leadership models and theory and examining governance with a sports issues focus. The case written for this topic was Tennis New Zealand - unify, lead and strengthen (see Appendix Six(b))

- Power and Ethics in Leadership: exploring power and influence models and theory, ethical, stewardship, and servant leadership and personal development and ethics models. The case written for this topic was Lance Armstrong - Everybody's doing it (see Appendix Six(a)).

\section{Research Plan}

My research plan was as follows:

1. Writing a medium-length case (i.e., 2,000 words or four pages) for the sub-topic being taught (in fact, I wrote one case this way; starting with the medium case and editing. The other case I expanded from a two page case). I then reduced the medium length case down to a short version of 950 words or 2 pages (See Appendix 6 for both cases, both lengths).

2. Briefing all students on the two Approaches and why I was interested in learning more about different learning impressions between the two methods. I obtained student permission for 
research participation. I ensured those who opted out were able to complete the two sub-topics using online materials already prepared.

3. Posting guidelines online so students could successfully undertake the case analyses and were prepared for the group participation component, including preparing an online tutorial with a case, its analysis and the exemplars, to be posted online with the other course materials for next semester.

4. Organising the materials and teaching plan for the two sub-topics (Shared Leadership, and Power \& Ethics in Leadership) to be delivered, each two ways, as follows:

\section{a. Approach A:}

i. Using the 'normal' lecture time of 1 hour and 45 minutes hours for group discovery session for the case (not recorded), where the case materials were explored and group discussions took place with the instructor present

ii. Session of 1 hour and 45 minutes hours formally discussing the case as "case-inpoint" (recorded)

b. Approach B:

i. Lecture/workshop of 1 hour and 45 minutes hours not containing the case (not recorded)

ii. Lecture/workshop of 1 hour and 45 minutes hours containing the case (recorded)

5. Uploading student versions of the medium and short cases to NMIT/AUT Online and making them available to the students online prior to the beginning of the topics.

6. Ensuring all students, whether participating in the recorded Approach A case debrief session or not, submitted a one page case analysis assignment to TurnltIn as part of their scheduled assignment work. This assessment was part of the regular course assessment schedule, which was planned at the beginning of the year between AUT and NMIT. This regular assessment was not used for any data gathering. As this assessment was related to the Approach A sessions, Dr. Lynn Kidman marked this work to eliminate any possibility of my having a conflicting power relationship with the students, or being able to influence the results in any way.

7. Arranging to have the workshop in which the instructors taught the short case using the Approach B method recorded; and the session debriefing the case using the Approach A was recorded. AUT Auckland (Manukau \& North Shore) taught Power \& Ethics using Approach A while NMIT/AUT in Nelson taught Shared Leadership using Approach A. After each session, the instructor filled in the SurveyMonkey instrument. In the first week of teaching available following the Power \& Ethics lecture, I interviewed the student groups. The timeline and details follow: 


\begin{tabular}{|c|c|c|c|}
\hline Items & Nelson & North Shore & Manukau \\
\hline \multicolumn{4}{|c|}{ Ethics approval received } \\
\hline Briefings & Nic 20 August & Lynn 21 August & Lynn 21 August \\
\hline $\begin{array}{l}\text { Sub-topic } 2 d \\
\text { Shared Leadership } \\
\text { Session } 1\end{array}$ & $\begin{array}{l}30 \text { August } \\
\text { Nelson, Approach A } \\
\text { (discovery of TNZ short } \\
\text { case) } \\
\text { Student self-directed } \\
\text { learning session } \\
\text { No recording }\end{array}$ & $\begin{array}{l}26 \text { August } \\
\text { North Shore, Approach } \\
\text { B (TNZ short case) } \\
\text { Normal hybrid approach } \\
\text { (workshop) } \\
\text { No recording }\end{array}$ & $\begin{array}{l}27 \text { August } \\
\text { Manukau, Approach B } \\
\text { (TNZ short case) } \\
\text { Normal hybrid approach } \\
\text { Recorded to end of TNZ } \\
\text { case }\end{array}$ \\
\hline $\begin{array}{l}\text { Sub-topic } 2 d \\
\text { Shared Leadership } \\
\text { Session } 2\end{array}$ & $\begin{array}{l}3 \text { September } \\
\text { Nelson, Approach A } \\
\text { (discussion of TNZ short } \\
\text { case) } \\
\text { Harvard case debrief } \\
\text { session } \\
\text { Recorded }\end{array}$ & $\begin{array}{l}28 \text { August } \\
\text { North Shore, Approach } \\
\text { B (TNZ short case) } \\
\text { Normal hybrid approach } \\
\text { (lecture) } \\
\text { Recorded }\end{array}$ & $\begin{array}{l}27 \text { August } \\
\text { Manukau, Approach B } \\
\text { (TNZ short case) } \\
\text { Continue normal } \\
\text { teaching of this topic } \\
\text { until end of session. } \\
\text { No recording }\end{array}$ \\
\hline SurveyMonkey & Fill in online reflection & Fill in online reflection & Fill in online reflection \\
\hline $\begin{array}{l}\text { Sub-topic 2e Power } \\
\text { \& Ethics } \\
\text { Session } 1\end{array}$ & $\begin{array}{l}6 \text { September } \\
\text { Nelson, Approach B } \\
\text { (Lance Armstrong short } \\
\text { case) } \\
\text { Normal hybrid approach } \\
\text { Recorded to end of } \\
\text { Lance Armstrong case }\end{array}$ & $\begin{array}{l}3 \text { September } \\
\text { North Shore, Approach } \\
\text { A (discovery of Lance } \\
\text { Armstrong medium } \\
\text { case) } \\
\text { Student self-directed } \\
\text { learning session in } \\
\text { workshop sessions } \\
\text { No recording }\end{array}$ & $\begin{array}{l}4 \text { September } \\
\text { Manukau, Approach A } \\
\text { (discovery of Lance } \\
\text { Armstrong medium } \\
\text { case) } \\
\text { Student self-directed } \\
\text { learning session } \\
\text { No recording }\end{array}$ \\
\hline $\begin{array}{l}\text { Sub-topic 2e Power } \\
\text { \& Ethics } \\
\text { Session } 2\end{array}$ & $\begin{array}{l}10 \text { September } \\
\text { Continue normal } \\
\text { teaching of this topic } \\
\text { until end of this lecture. } \\
\text { No recording }\end{array}$ & $\begin{array}{l}4 \text { September } \\
\text { North Shore, Approach } \\
\text { A (discussion of Lance } \\
\text { Armstrong medium } \\
\text { case) } \\
\text { Harvard case debrief } \\
\text { session } \\
\text { Recorded }\end{array}$ & $\begin{array}{l}4 \text { September } \\
\text { Manukau, Approach A } \\
\text { (discussion of Lance } \\
\text { Armstrong medium } \\
\text { case) } \\
\text { Harvard case debrief } \\
\text { session } \\
\text { Recorded }\end{array}$ \\
\hline SurveyMonkey & Lecturer online reflection & Lecturer online reflection & Lecturer online reflection \\
\hline Focus groups & $\begin{array}{l}13 \text { September } \\
\text { Nic, Nelson 11am } \\
20 \text { minutes, as per focus } \\
\text { group questions } \\
\text { No recording Mind maps } \\
\text { on the white board }\end{array}$ & $\begin{array}{l}24 \text { September } \\
\text { Lynn, North Shore, } \\
\text { group 1, 9am } \\
\text { Lynn, North Shore, } \\
\text { group 2, 10.30am } \\
20 \text { minutes, as per focus } \\
\text { group questions } \\
\text { Recorded }\end{array}$ & $\begin{array}{l}25 \text { September } \\
\text { Lynn, Manukau 10.30am } \\
20 \text { minutes, as per focus } \\
\text { group questions } \\
\text { Recorded }\end{array}$ \\
\hline Lecturer debrief & $\begin{array}{l}\text { Email question on why } A \\
\text { made }\end{array}$ & 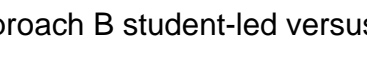 & lecturer-led choice was \\
\hline
\end{tabular}




\begin{tabular}{|c|c|c|}
\hline Items & North Shore & Manukau \\
\hline $\begin{array}{l}\text { Summary findings } \\
\text { to students }\end{array}$ & By August 2014, via emails provided & \\
\hline $\begin{array}{l}\text { Finalised research } \\
\text { to lecturers }\end{array}$ & By September 2014, finalised thesis emailed. & \\
\hline
\end{tabular}

8. Arranging to record and receive the sound recordings by Nic John at NMIT/AUT Nelson (camera on sound only), and by Dr. Lynn Kidman at AUT in Manukau \& North Shore (CDs).

9. Storing all the sound recordings together on one removable pass-worded hard-drive.

10. Transcribing all the recordings, using Saldaña (2009) and Kvale's (2007) to guide this process. No participants, aside from myself, were named in the transcripts.

11. Importing the transcriptions into a CAQDAS software project file.

12. Storing all transcripts, along with the CAQDAS project file, on a secure PC.

13. Ensuring instructor impressions, arising during the sessions and in reflection immediately afterwards, were recorded via a SurveyMonkey questionnaire which lecturers completed after each session. The SurveyMonkey instrument data was downloaded, and imported into the CAQDAS project file. The data was stored along with the transcripts. The instructors also attended the student focus group sessions, and provided additional reflections to those already supplied via the SurveyMonkey instrument.

14. Reviewing the resulting materials for themes, essences and 'causal powers' (Kempster \& Parry, forthcoming 2014). The codes I developed and their definitions are contained in Appendix Two (b) of this document. Once all the recordings and transcripts were completed, I had hoped to review the preliminary themes with the students wishing to be further involved in the project before the end of the semester via email. Unfortunately the transcription took significantly more time than I had planned for, with the end of the tertiary year arriving before I was able to revisit themes or meanings arising with the students (to ascertain what their impressions are of the results and the process; i.e., taking a retroductive approach). This has meant that my original impressions and themes do not have the benefit of thematic retroduction, only that of initial impressions (i.e., focus group feedback).

\section{Data Collection: Exploring lived experience through interviews}

Kempster and Parry suggest that interviews need to be "[d]esigned to assist respondents to elicit recollections". I am aware that the respondents are likely to have "limited awareness of causal powers in the actual and real stratified levels" (forthcoming 2014, p. 83). Lundeberg, Levin and Harrington (1999, p. 237-239) demand explicitness in describing the experimental process of observation. All participating students gave their permission for me to use their words as recorded. The list of transcripts and summary details are contained in Appendix Four of this document.

I interviewed the participants, and: 
1. Had the lecturers delivering to both sessions answer a survey after each delivery, to capture their impressions on the day, via SurveyMonkey. The survey questions asked are contained in Appendix Four (a) of this document.

2. Debriefed each student groups informally (either via Skype or in-person) after the last of the sub-topics, with the lecturers present. The interview questions asked are contained in Appendix Four (b) of this document.

3. The lecturers considered their impressions were accurately recorded via the SurveyMonkey instruments and from their contributions at the focus groups.

4. If the students had had any further reflections that they wanted to share with me after the sessions, I asked them during the focus groups to contact me via their lecturers (none did).

All student sessions - the two Approaches and the debrief sessions - were recorded and transcribed without naming any of the participants, so as to not focus on any individual student identity, but to focus instead on the ideas they presented. Individuals were not identified in any transcribed, coded or analysed data.

While all individual participants remained anonymous, I presented student summary group data as those who were registered on the course and those who attended the recorded sessions in order to show the attendee make-up, and to confirm the groups were reasonably representative of our 'normal' student groups at all campuses:

TABLE 5: STUDENT DEMOGRAPHICS BY CAMPUS

\begin{tabular}{|c|c|c|c|c|}
\hline $\begin{array}{l}\text { Campus (registered \& attended } \\
\text { groups) }\end{array}$ & $\begin{array}{l}\text { Age } \\
\text { Range }\end{array}$ & $\begin{array}{l}\text { Average } \\
\text { Age }\end{array}$ & Gender & $\begin{array}{l}\text { Student Ethnicityl } \\
\text { National Origin }\end{array}$ \\
\hline Nelson NMIT Campus & $20-30$ & 23 & $\begin{array}{l}\text { Men 54\% } \\
\text { Women } \\
46 \%\end{array}$ & $\begin{array}{l}\text { NZ/Pakeha 93\% } \\
\text { NZ Maori 7\% } \\
\text { Pasifika 0\% } \\
\text { Internationals 0\% }\end{array}$ \\
\hline $\begin{array}{l}\text { AUT Campuses (North Shore \& } \\
\text { Manukau campuses are collectively } \\
\text { reported) } \\
\text { NB: The North Shore classes } \\
\text { attended the sessions contained } \\
\text { proportionally more international } \\
\text { students }\end{array}$ & $18-50+$ & 23 & $\begin{array}{l}\text { Men } 58 \% \\
\text { Women } \\
42 \%\end{array}$ & $\begin{array}{l}\text { NZ/Pakeha } 56 \% \\
\text { NZ Maori } 22 \% \\
\text { Pasifika } 10 \% \\
\text { Asian } 4 \% \\
\text { Internationals/Othe } \\
\text { r } 6 \%\end{array}$ \\
\hline
\end{tabular}

I ensured that all resources were made available for all participants, whether attending or not attending the Research Approach A or Approach B sessions (i.e., short or medium case for the appropriate group, lecture film clips, readings). The full case and teaching note were made available online for all students once their small case assessment had been submitted. Students were able to use this as a resource for both theoretical development and for ideas to further analyse their cases in their final portfolio, and to record and further reflect upon their own experiences on the course. 


\section{Case Study Writing for the Research}

In preparing for this research, I wrote two medium length cases (circa 2,500 words) and two short cases (950 words). Each version was broad enough to cover the learning outcomes for each of the Shared Leadership and the Power \& Ethics sub-topics.

\section{Case structure}

Based on my own experience and my preliminary literature review, the structure I used for both cases was as follows:

1) The case (Short $\approx 950$ words; Medium $\approx 2,000$ words)
a. Brief Introduction/scene setting
b. Image to cue the reader
c. Case body
d. Three broad questions including a video link (if the case possessed video)

2) The teaching note
a. Synopsis
b. Information about the intended audience
c. Teaching Objectives
d. Questions \& answers from the case, with appropriate theoretical support, plus two extension questions and answers
e. Bibliography
f. Appendices

3) A teaching plan was supplied, but was not included in the case.

\section{Writing Process}

My process in preparing and writing these two cases was quite different, however: With the Lance Armstrong - Everybody's doing it case (sub-topic, Power \& Ethics, see Appendix Six (a)), I began with my usual search for an issue which would illustrate the ethics theory I needed to teach. I conducted a broad trawl for materials once I had settled on Lance Armstrong as a potential topical subject, as the recapitulation of his wrongdoing denials were still echoing in the media. The medium case was built then, from the bottom up, with an investigative approach, using all secondary data. It was purpose-built to 2,550 words with aspects researched and included specifically and purposefully to illustrate the desired theory, ideas and issues. Once the medium length case was complete, the short case was cut from the whole cloth. The process for the short case then, was an edit. The Tennis New Zealand - unify, lead and strengthen (TNZ) case (sub-topic, Shared Leadership, see Appendix Six (b)) was based on researcher Dr. Lesley

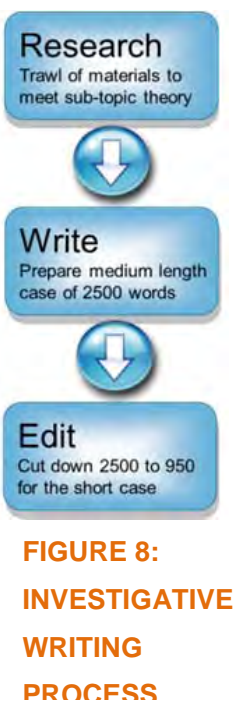

Ferkins's Doctoral Thesis as well as on several papers which Dr. Ferkins has co-authored with Professor David Shilbury as both follow-ups and in further investigation. I had previously prepared a 
short case (circa 950 words) from Dr. Ferkins's work to illustrate how the shared leadership model

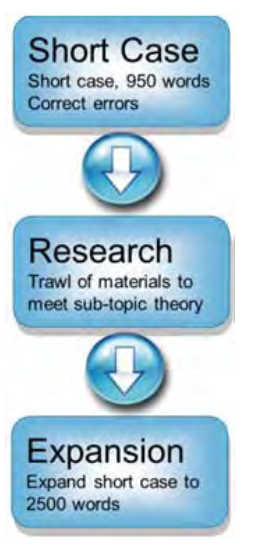

FIGURE 9:

SHORT CASE

EXPANSION operated at TNZ, which I had taught before. For my research purposes, I retro-fitted the short case to encompass all the sub-topic Shared Leadership theory, and created the medium length-case from the base of the short case, correcting any errors introduced by myself with the help of Dr. Ferkins. Dr. Ferkins had made herself available for clarification and proofing (for which I am very grateful!). I also had access to published papers and those currently being prepared for publication by Professor Shilbury and Dr. Ferkins. The process for the medium case, then, was an expansion.

The interesting thing was that the writing for the Lance Armstrong case flowed easily, despite being on a distasteful topic. The editing of this case into the short format was case was also easy. Contrariwise, the TNZ case was a very slow, hard grind. Every word had to be sweated over, every idea teased out carefully, checked and doublechecked, and the process felt more "durance vile" (Burns, 1855, p. 186) than the Lance Armstrong case.

I have reflected since on whether my personal intimacy with the material may be a major contributing issue to the ease or difficulty of construction; due to due to the depth of information I researched for the Lance Armstrong case and the fact that Lesley was the 'owner' and the 'primary experiencer' of the TNZ material. However, while I am sure that ownership also had some bearing, I believe that the primary degree of difficulty I experienced was due more to the process which I followed.

Like building, researching broadly then being able to lay desired cables through to their logical ends is a much 'roomier' and 'open' structure to work within than attempting to rewire a room within the confines and needs of the family who are still living in it.

In my view, the process of researching, writing and editing is immeasurably easier than that of starting with a completed short case, then expanding it.

\section{Case Teaching \& Cases}

My literature review and research findings were then applied across case studies I have already written, refining my current method to better meet the needs of my students when workshop teaching. This includes ensuring all cases have links to video to anchor the case, and that the teaching notes also contain teaching suggestions.

I hope to accumulate enough cases for a possible lecturer's case book for possible publication in 2015, in what I consider is a learner-centric case format for leadership case teaching.

\section{Data Analysis: Retroductive Coding}

In the words of Kempster and Parry (forthcoming 2014, p. 83), I applied "theory to the data to illuminate and /or suggest generative causal powers as well as context specific causal powers" to the lecturer questionnaire data, the student interview data, and analysing for themes. 


\section{Recordings and Transcriptions}

My process of coming to know my data was as follows:

- The Auckland sessions were recorded as mp3s, so did not need conversion. The Nelson files were video (avi) files which I converted to $\mathrm{mp} 3$

- I listened to each data session twice to familiarise myself with it (totalling 11.66 hours of data)

- I then transcribed each session (taking around 12 minutes hours to transcribe each minute of recording, so a transcription project totalling around 140 hours) and recorded each into a separate Word document; one per mp3 file

I determined to use a fairly verbatim account, in plain English as per Saldaña's documented method (2009), but not using Kvale's (2007) more sophisticated linguistic annotations. I established some transcription conventions which I carried through the fourteen recordings I gathered.

To keep track of where in the transcripts the participants had spoken, I used the time and a shortcode for each session, thus the code for "Transcript of Manukau Approach A Session, 1 Sep 2013", 65.02 could be referenced as (MA1, 65.02) in the Findings and Discussion (see "Transcript Codes for Referencing" later in this chapter for details).

Having listened and transcribed each file, I had gained the impression of some possible descriptive codes ("short student replies", "lecturer-dominated", "engaged student-led debate", "engagement" and "free-flowing student-led discussion") which appeared to highlight some differences between the two approaches. While the description of 'what is' was interesting, it did not provide any insight as to what was creating the difference.

\section{Coding Categories}

I returned to my preliminary literature review. In the course of my literature review I had discovered some characteristics which previous researchers had determined were an indicator of effectiveness; a way to measure students sense-making of the case. I noted that some of these characteristics were appearing in some of my data. I decided to use these as my a priori codes. These effectiveness characteristics were:

1. Applying principles: "Applying [...] principles to real world situations" (Harper, Lamb \& Buffington, 2008, p. 414)

2. Important points: "Brought out important points about [the topic]" (Harper, Lamb \& Buffington, 2008, p. 414)

3. Synthesising \& solving: "Provide[d ...] a good opportunity to synthesize; [ie], identifying potential solutions to a case problem and choosing the most appropriate solution" (Harper, Lamb \& Buffington, 2008, p. 414)

4. Student participation: "Increase[d] the likelihood of student participation in class discussion" (Harper, Lamb \& Buffington, 2008, p. 414) 
5. Evaluation skills: "Provide[d...] a good opportunity to exercise evaluation skills, (i.e., appraising the extent to which particulars are accurate, effective, economic, or satisfying)" (Harper, Lamb \& Buffington, 2008, p. 414)

6. Interpersonal skills: "Good [...for] teaching "soft skills"; [ie], interpersonal [...\&] management skills" (Harper, Lamb \& Buffington, 2008, p. 414). Excluded were:

- "writing the case report aided in understanding the case principles" because this having the case analysis submitted before the session not possible at all campuses by the time the Approach A session was delivered; and

- $\quad$ "Prefer[red...] student teams [being] assigned the responsibility of presenting a particular case" as it would be impossible to tell whether this was so due to the anonymous nature of the research.

7. Applying new knowledge: "Acquiring new knowledge and learning how to apply it" (Bridges \& Hallinger, 1997, p. 135)

8. Self-directed learning: "Developing skills in self-directed learning" (Bridges \& Hallinger, 1997, p. 135)

9. Group problem-solving: "Developing skills in running meetings, resolving conflict, and using group problem solving and decision tools" (Bridges \& Hallinger, 1997, p. 135)

10. Leadership emotional insight: "Acquiring insight into the emotional aspects of leadership" (Bridges \& Hallinger, 1997, p. 135)

I considered for some time using Sockalingam and Schmidt's eleven student-rated characteristics of effective learning (2011). However, some aspects of their characteristics were already covered by the ten items I had already selected, and I was unable to identify instances of others (i.e., identifying "Be of suitable format" in the transcripts was inherently difficult and subjective). I determined to continue instead with the ten characteristics I had selected from Harper, Lamb and Buffington (2008), Bridges and Hallinger (1997).

\section{The Coding Process}

From my research in this area and trialling a few packages, I selected the CAQDAS coding freeware, QDA Miner Lite as my coding software for this project. Once I had prepared each Word transcript, I loaded each file into QDA Miner Lite and coded my data using the ten characteristics listed under Coding Categories.

Bruner describes human coding as being "inferred from the nature of antecedent and consequent events" (2006, p. 10); that our construction of meaning is based on what comes before and what came after. Saldaña $(2009$, p. 8) suggests that coding is a "cyclical act".

As I went through the data and coded it, some of the descriptive characteristics I have mentioned earlier kept returning in how much - depending on whether the Approach was type A or B lecturers dominated the sessions, and the pattern of how long a student spoke for in those 
sessions. This pattern of lack of effectiveness gave rise to some emergent (i.e., codes arising from the data; Saldaña, 2009) coding.

One additional category I called "Ineffectiveness", with codes including Lecturer-dominated, Micro-managing, Not connected and Passive (on the part of the students). A second emergent category I called "Teaching Method", with codes including Case in Point positive, Hybrid positive, Small group safety and Suggestion. All codes can be viewed with their definitions in Appendix Two $(d)$.

Using two additional forms of coding: simultaneous - i.e., applying "two or more codes within a single datum" (Saldaña, 2009, p. 5); and pattern - i.e., regular or as varying forms, including similarity, difference, frequency, sequence, correspondence and causation (Saldaña, 2009, p. 6, citing Hatch, 2002, p. 155).

Saldaña (2009, p. 8) cites Charmaz (2006) saying that coding "generates the bones of your analysis.... [1]ntegration will assemble those bones into a working skeleton" (p. 45). The impressions I had gained from the data listening and transcription process were either upheld or negated by the qualitative and quantitative coding and analysis.

I then completed some simple count and summing data on overall word counts, time spent with lecturers talking, students talking, discussion and silence.

\begin{tabular}{|l|l|}
\hline Data analysis tools & Thematic analysis from previous research using \\
\cline { 2 - 2 } Coding data tools & QDA Miner Lite \\
\hline Sorting, grouping \& & Effectiveness \\
ordering data & Applying principles \\
Important points \\
Synthesising \& solving \\
Student participation \\
Evaluation skills \\
Interpersonal skills \\
Applying new knowledge \\
Self-directed learning \\
Group problem-solving \\
Leadership emotional insight \\
Ineffectiveness \\
In group/out group \\
Lecturer-dominated \\
Micro-managing \\
No preparation \\
No theory \\
Not connected \\
Passive \\
\hline
\end{tabular}




\begin{tabular}{|l|l|}
\hline $\begin{array}{l}\text { Teaching Method } \\
\text { Capturing ideas } \\
\text { Case in Point positive } \\
\text { Hybrid positive } \\
\text { Length } \\
\text { Pre-digested } \\
\text { Small group safety } \\
\text { Suggestion } \\
\text { Video }\end{array}$ \\
\hline Quantitative data & $\begin{array}{l}\text { Count of code incidence from within CAQDAS software } \\
\text { analysis }\end{array}$ \\
& Count of minutes of lecturer speaking compared to students \\
& Count of minutes of silence \\
\hline
\end{tabular}

\section{Transcript Codes for Referencing}

When referencing particular sessions in the findings and discussion following, I have used short codes; for example, "MB" for the Manukau Approach B session. This is followed, were appropriate, by a time.

\begin{tabular}{|l|l|}
\hline Transcripted Session Title & $\begin{array}{l}\text { Assigned Short } \\
\text { Code }\end{array}$ \\
\hline Manukau Approach A, 4 September 2013 & MA \\
\hline Manukau Approach B, 28 August 2013 & MB \\
\hline Manukau Focus Group, 25 September 2013 & MF \\
\hline Nelson Approach A, 3 September 2013 & NNA1, NNA2, NNA3 \\
\hline Nelson Approach B, 6 September 2013 & NNB1, NNB2, NNB3 \\
\hline North Shore Approach A, 5 September 2013 & NSA \\
\hline $\begin{array}{l}\text { North Shore Approach B (both groups), 28 August 2013 (NB: run as two } \\
\text { tutorial classes. Combined session data was analysed) }\end{array}$ & NSB1, NSB2 \\
\hline North Shore Focus Groups, 24 September 2013 & NSF1, NSF2 \\
\hline Mind Maps of Nelson Focus Group, 17 September 2013 & NNF \\
\hline Lecturer Surveys TNZ, August-September 2013 & LSTNZ \\
\hline Lecturer Surveys Lance Armstrong, August-September 2013 & LSLA \\
\hline
\end{tabular}

\section{Retroductive Theory Propagation}

Kempster and Parry suggest that "The retroductive explanation needs to be tested with respondents from where it has been derived. Subsequent variation through discussion can then be put forward for researchers to question and test in alternative contexts" (forthcoming 2014, p. 84). I will seek explanations for "generative causal powers that explain leadership learning" and "[c]ontrastive explanations of causal configurations between contexts" to determine which method works, when \& why (p. 83) through participant feedback from the research lecturer surveys and the focus groups. 


\section{Key Limitations \& Delimitations}

\section{WHAT MIGHT HAVE BEEN A PROBLEM \& HOW I AVOIDED IT}

A range of factors need to be explored: what causal powers can be identified before we start; identifying what stratification of issues will remain unobservable; how to generate open-mindedness on the part of the students to the learning opportunity; how to ensure that all participants willingly engage in the case analysis and the group work; how to ensure my Nelson and Manukau lecturers deliver the material in relatively congruent ways.

I was aware from the outset that my research results might indicate that my students would learn more effectively using medium length cases delivered by the Approach A method, which would mean that I would need to alter my teaching methods. I will be doing some additional experimentation to discover if should use this delivery method once my classes have developed some resilience in learning with cases, and only once my group has 'formed, stormed and normed' (Tuckman, 1965).

I do not consider that there were deeper, less observable factors at play during the research, such as the Hawthorn effect (Roethlisburger, 1939, as cited by Mayo, 1945), which has affected the results. The students seemed relaxed, open and candid about their participation and levels of engagement.

It is also possible that, because this research covered only one sub-topic, that the time, subject covered and number of groups is too small an experiment and is thus inherently flawed.

Lundeberg, Levin and Harrington (1999) suggest that one of the greatest risks that a case researcher brings to research is their own biases, including themselves in the classroom. To minimise this, I led none of the case study delivery sessions; I marked no related assessments; and I put systems in place where possible, to avoid 'leading the witness'; i.e., interview processes and structured questionnaires.

To ensure congruence in delivery, I set up a teaching plan for each lecturer, contained in Appendix Five(a). I discussed with the two lecturers an agreed optimal method to deliver the case studies in order to limit individual lecturer bias. To standardise delivery, I wrote the case studies for the research, and prepared the questions that the lecturers asked the class.

Nic John is not a lecturer on the AUT Sport and Recreation programme at NMIT, but has previously taught Leadership in the Business School and has sports credibility. However, he was new to my class, and the lack of time to build rapport may have affected the Nelson results.

Teaching load reorganisations within the Sport and Recreation programme at AUT meant that Dr. Kidman was not actually teaching Leadership at the Manukau Campus when the research was run. However, because she was more familiar with the leadership material, after discussion with the new lecturer, Dr. Gaye Bryman, Dr. Kidman led the class through the research sessions. Dr. Bryman attended the sessions, but Dr. Kidman's lack of rapport with the class may have affected the results at Manukau. 
The four student populations were of similar age, study level and reasons for taking on this particular degree. Each population profile contains ethnic differences and is geographically separate.

\section{Chapter Summary}

As a critical realist, I outlined my viewpoint and explained how this colours my perpetual seeking of 'better ways'. I like to hone what works, and continue to test; so that I can see, with my increasing level of understanding and powers of observation, if there is a better explanation for what I am able to observe and understand.

In this chapter I have explained the process which I followed in my attempt to compare the "Case in Point" method of case delivery with the 'Hybrid' method. I proposed my research question: "Do students make sense of leadership cases differently when they are delivered using different methods?" and introduced my participants: the lecturers, Dr. Lynn Kidman and Nic John; and the students, AUT campus cohorts at Nelson, Auckland North Shore and Auckland Manukau. I explained my methodology - my research design was based on retroductive grounded theory - and my data collection methods consisted of observations, interviews, questionnaires and focus-groups.

Additionally, I have explored my process in developing the two cases which were used in this research, comparing the difficulty I had in expanding a short case into a long case; but the ease with which a long case was edited to a short case.

The schedule of the research and the data collection sessions in August and September 2013 have been explored, and my data recording, handling, analysing and coding process has been outlined. The use of coding software (QDA Miner Lite) and the coding schema which was used (Harper, Lamb \& Buffington, 2008; Bridges \& Hallinger, 1997) have been detailed.

The methodology for the research is complete. In the coming chapter, we explore the research data, to see what learned from the data and the process. 
Having outlined my research standpoint, methodology and methods, in this chapter I explore the data gathered in translating my planned Approach A and Approach B case delivery method comparison into practice. I explore the flaws I found in my research plan. In transcribing my recordings, analysing them CAQDAS software and Excel, I gather some useful information on effective learning, ineffective teaching environments and teaching methods on which to base future teaching decisions.

\section{Student-\|ed versus Researcher-\|ed}

To help limit researcher bias I had another lecturer teach my own class. For a comparison, I had another colleague teaching the same programme with identical materials at a different campus. Both lecturers had been given the same briefing for running the research sessions, and the same background materials (see the Methodology Chapter and Appendix 5). From my knowledge of both lecturers, as teaching practitioners, they are relatively well-aligned philosophically in their preference for active learning approaches and desire for student-leadership in learning.

What I found at first to be devastating, then - once I got over my shock - fascinating, is that in the Approach A sessions, both lecturers took and applied the case session instructions in an entirely different way. Simplifying Tannenbaum and Schmidt's Leadership Continuum (1973, p. 165) and giving it an educational focus, the continuum could be presented to encompass both approaches that the lecturers took: Nic at the lecturer-led end of the continuum, Lynn at the student-led end.

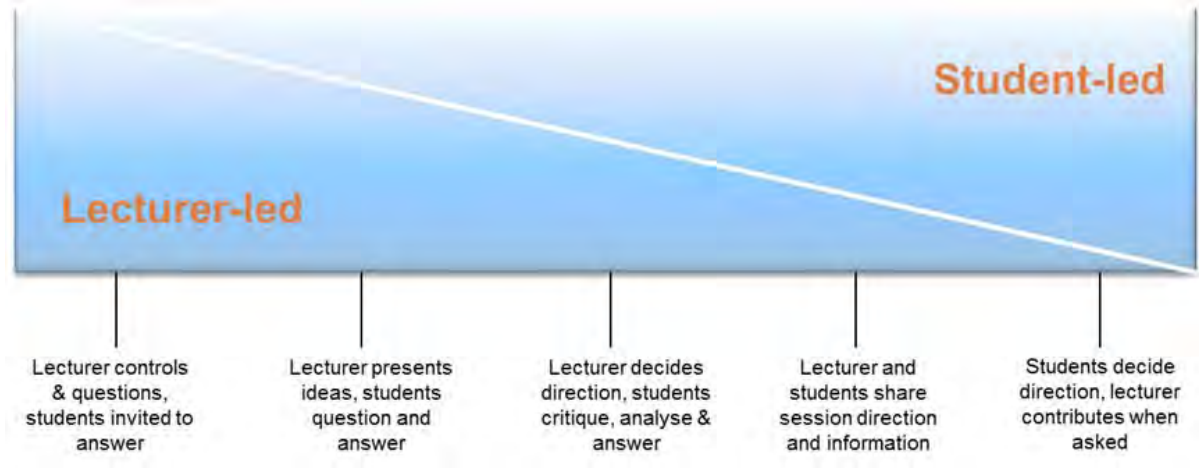

FIGURE 10: THE LEADERSHIP CONTINUUM ADAPTED TO A LECTURERISTUDENT-LED LEARNING CONTINUUM

My intention with this research had been that the lecturers, in both the Approach A and Approach B research sessions, would take a fairly central position of determining direction, while students critiqued, analysed and answered. Then, as the groups developed or proved their competence, I assumed that the lecturers could shift their approach - hand over 'control' - and move more to the student-led end of the continuum. 
Since receiving the recordings for this research in September last year, I have reflected a lot on the drivers which may have affected Lynn and Nic's choices. I have 'assumed' that it was as simple as the lecturers both interpreting my desired outcomes differently. The fact that Nic did not know my class well may have caused him to retain a more controlled approach. He has commented to me that he found the culture of the Sport and Recreation student group difficult to tap into. It may also just have been his interpretation of my goals through my lack of clarity in ensuring mutual understanding. Lynn may have seen an opportunity to stretch her class further which enabled her to take an entirely student-led approach in the Approach A Auckland sessions.

I have asked both of them what led them to run the Approach A sessions as they did. Lynn said, "It's just something I do. You wanted to get them to lead the discussion, so I got them to lead the whole class instead. My pedagogy is student-centred learning, so do as much as I can." (Kidman, 2014). Nic said, "the reason I [thought] the lecture was tutor-led was because I believed that was what you wanted from it, or at least for it to be what I would 'normally' do. Lecture $B$ [he means A] was supposed to be the Harvard method; don't interfere and let them get on with it." (John, 2014).

This comment from Nic brings me to the next issue: adequate briefing of the lecturers. I obviously had not briefed Nic adequately, as Nic juxtaposed the sessions: the $3^{\text {rd }}$ of September session should have been Nelson's Approach A session (Tennis New Zealand as "Case in Point"); Nic delivered this as the Approach B session. A further factor complicating his delivery was that I had given my students a high-level briefing as to what each of the coming sessions with Nic would hold. Because Nic had crossed-over the sessions, the students were effectively being asked to redo the case analysis work which they had already handed in. I suspect this may have made them a little mutinous. I believe this combination of factors contributed to Nic's feeling of the lack of rapport with the group - and, in listening to the recording, the difficulty in getting answers from the group. My class proved hard work to draw out. These were significant contributing factors to the Nelson sessions and its failing to gel.

Additionally, while the outline and intent was extremely clear in my mind from all the reading and class video observations I have done on the "Case in Point" (Approach A) method in undertaking my research, my voluntary research lecturers did not have the benefit of that exposure. Obviously my briefing pack was inadequate to provide enough clear direction to the lecturers (see Appendix 5 and Methodology Chapter for details).

This has highlighted to me the absolute importance of appropriate prior training of instructors in the "Case in Point" method, in order to ensure effective delivery in the classroom.

\section{Applying Theory}

Prior to the class sessions, students needed to complete their write up, exploring and linking what they felt was relevant theory. However, the Auckland case analysis submission deadline did not line up with the Approach A session. Only students who had prepared this work ahead of time would have been fully prepared and able to use the theory and background information. 
Unfortunately, many of the Auckland students had not yet completed and turned this work in at the time of the Approach A sessions. They came to class not yet having done the preparatory work required to be fully able to apply the situations in the cases to the underlying theories.

The Nelson students had completed this work prior to the Approach A session taking place.

\section{Session Transcript Data}

\section{Time Findings: All Approaches}

When transcribing my session data, I put a time notation at the beginning of each line, and preceded each speaker with a designation "[Lecturer]" or "[Student]", and each 'other activity' with a descriptor such as "(silence)" or "(general discussion)". This allowed me to import all my transcript data into Excel and run some simple data counts.

While I did not go so far as to analyse the number and style of questions that the lectures asked (which may be a useful future exercise, but was outside the scope of this research), I calculated an approximate tally of time spent on the different activities in the Approach A and B sessions as follows:

TABLE 7: APPROACH A \& B SESSION ACTIVITY CATEGORIES (ALL CAMPUSES BY SESSION ACTIVITY CATEGORY PERCENTAGES)

\begin{tabular}{l|r|r|} 
& \multicolumn{1}{c}{$\begin{array}{c}\text { All Approach } \\
\text { A session } \%\end{array}$} & $\begin{array}{r}\text { All Approach } \\
\text { B session } \%\end{array}$ \\
\cline { 2 - 3 } Lecturer & $23 \%$ & $59 \%$ \\
\hline Silence & $4 \%$ & $4 \%$ \\
\hline Students & $62 \%$ & $21 \%$ \\
\hline Discussion & $11 \%$ & $13 \%$ \\
\hline Video & $0 \%$ & $2 \%$ \\
\hline Total & $\mathbf{1 0 0 \%}$ & $\mathbf{1 0 0 \%}$ \\
\hline
\end{tabular}

I examined the summary word counts for all the A and B Approaches. I found that students were the dominant contributors overall in the A sessions, but the B sessions were almost reversed, being heavily lecturer-centric. Following this, I then examined each session at each campus, as follows:

TABLE 8: APPROACH A AND APPROACH B SESSION ACTIVITY CATEGORIES (BY CAMPUS BY SESSION ACTIVITY CATEGORY IN MINUTES)

\begin{tabular}{|c|c|c|c|c|c|c|}
\hline Campus & $\begin{array}{r}\text { Manukau } \\
\text { Approach } \\
\text { A }\end{array}$ & $\begin{array}{r}\text { Manukau } \\
\text { Approach } \\
\text { B }\end{array}$ & $\begin{array}{r}\text { Nelson } \\
\text { Approach } \\
\text { A }\end{array}$ & $\begin{array}{r}\text { Nelson } \\
\text { Approach } \\
\text { B }\end{array}$ & $\begin{array}{r}\text { North } \\
\text { Shore } \\
\text { Approach } \\
\text { A }\end{array}$ & $\begin{array}{r}\text { North } \\
\text { Shore } \\
\text { Approach } \\
\text { B }\end{array}$ \\
\hline Lecturer & 4.44 & 37.53 & 52.81 & 77.44 & 4.74 & 78.56 \\
\hline Silence & 2.95 & 8.19 & 3.00 & 1.76 & 3.68 & 3.46 \\
\hline Students & 62.87 & 7.33 & 13.56 & 19.48 & 88.38 & 41.75 \\
\hline Discussion & 0.00 & 11.01 & 21.24 & 5.90 & 9.23 & 26.59 \\
\hline Video & 0.00 & 0.00 & 0.00 & 7.13 & 0.00 & 0.00 \\
\hline
\end{tabular}




\begin{tabular}{rr|r|r|r|r|r|r|} 
& $\begin{array}{r}\text { Manukau } \\
\text { Approach }\end{array}$ & $\begin{array}{r}\text { Manukau } \\
\text { Approach }\end{array}$ & $\begin{array}{r}\text { Nelson } \\
\text { Approach }\end{array}$ & $\begin{array}{r}\text { Nelson } \\
\text { Approach }\end{array}$ & $\begin{array}{r}\text { North } \\
\text { Shore } \\
\text { Approach }\end{array}$ & $\begin{array}{r}\text { North } \\
\text { Shore } \\
\text { Approach }\end{array}$ \\
\hline Total & B & A & B & A & B \\
\hline $\mathbf{7 0 . 2 6}$ & $\mathbf{6 4 . 0 6}$ & $\mathbf{9 0 . 6 1}$ & $\mathbf{1 1 1 . 7 1}$ & $\mathbf{1 0 6 . 0 3}$ & $\mathbf{1 5 0 . 3 6}$ \\
\hline
\end{tabular}

This simple tally data illustrated some clear differences between the session transcripts, between campuses and between lecturers.

What was immediately apparent was the extremely short lecturer activity duration in the Auckland Approach A sessions, as compared to the high lecturer activity duration and low student activity in Nelson. To make the results easier to see, I tabled the data as percentages.

TABLE 9: APPROACH A AND APPROACH B SESSION ACTIVITY CATEGORIES (BY CAMPUS BY SESSION ACTIVITY CATEGORY IN PERCENTAGE OF MINUTES)

\begin{tabular}{|c|c|c|c|c|c|c|}
\hline Campus & $\begin{array}{r}\text { Manukau } \\
\text { Approach } \\
\text { A }\end{array}$ & $\begin{array}{r}\text { Manukau } \\
\text { Approach } \\
\text { B }\end{array}$ & $\begin{array}{r}\text { Nelson } \\
\text { Approach } \\
\text { A }\end{array}$ & $\begin{array}{r}\text { Nelson } \\
\text { Approach } \\
\text { B }\end{array}$ & $\begin{array}{r}\text { North } \\
\text { Shore } \\
\text { Approach } \\
\text { A }\end{array}$ & $\begin{array}{r}\text { North } \\
\text { Shore } \\
\text { Approach } \\
\text { B }\end{array}$ \\
\hline Lecturer & $6 \%$ & $59 \%$ & $58 \%$ & $69 \%$ & $4 \%$ & $52 \%$ \\
\hline Silence & $4 \%$ & $13 \%$ & $3 \%$ & $2 \%$ & $3 \%$ & $2 \%$ \\
\hline Students & $89 \%$ & $11 \%$ & $15 \%$ & $17 \%$ & $83 \%$ & $28 \%$ \\
\hline Discussion & $0 \%$ & $17 \%$ & $23 \%$ & $5 \%$ & $9 \%$ & $18 \%$ \\
\hline Video & $0 \%$ & $0 \%$ & $0 \%$ & $6 \%$ & $0 \%$ & $0 \%$ \\
\hline Total & $100 \%$ & $100 \%$ & $100 \%$ & $100 \%$ & $100 \%$ & $100 \%$ \\
\hline
\end{tabular}

The duration results, when treated as percentages, better illustrated the range in responses. There was a clear and measurable difference in lecturer and student participation, not only between the session Approaches, but also between the Auckland and Nelson campuses.

\section{Time Findings: Approach A Sessions}

At both the Manukau and North Shore campuses, in the Approach A session transcripts, Dr. Kidman asked the first question of the session, then left the students entirely to self-direct the remainder of the class. She was totally silent until the end of the session when she ran a quick debrief with the students. She spoke for under four and a half minutes (6\%) at the Manukau session and four and three quarter minutes (4\%) at North Shore. Students spoke for $89 \%$ and $83 \%$ respectively.

At the Nelson campus, Nic John ran the Approach A session more like a lecture, directing questions and drawing in the theory; very controlled, speaking for almost 53 minutes (half the total time) in what was intended to be a largely student-led content session. Students spoke for $15 \%$ of the time. The time, at all campuses, which the lecturers spent in the leadership role was significantly different in the Approach A sessions. 


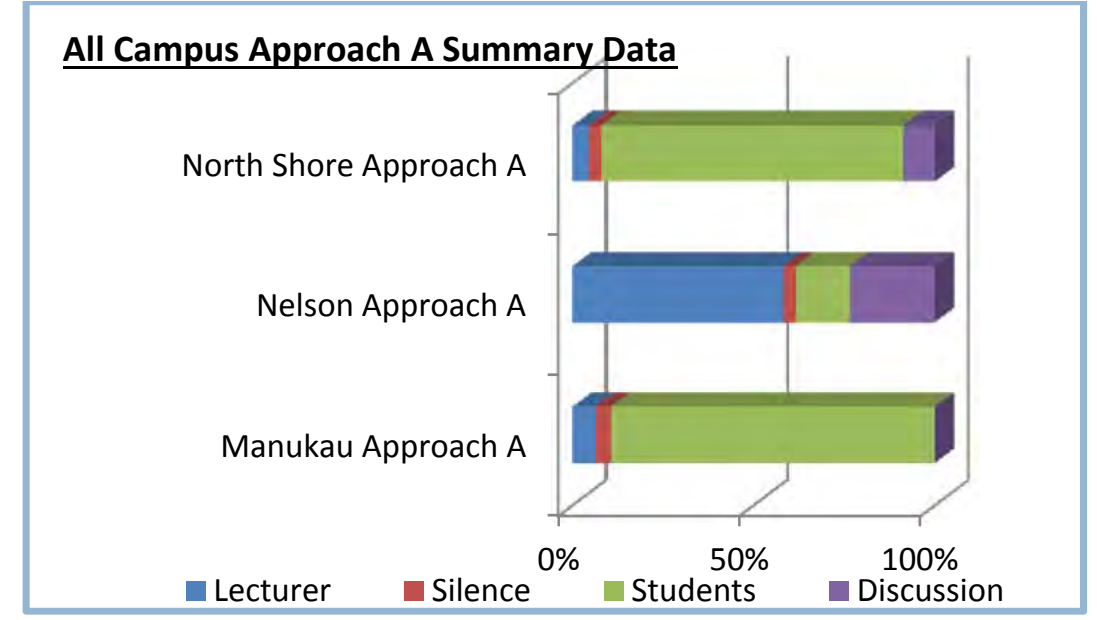

FIGURE 11: APPROACH A SUMMARY DATA (BY CAMPUS BY SESSION ACTIVITY CATEGORY IN PERCENTAGE OF MINUTES)

At both the Manukau and North Shore campuses, in the Approach B sessions, Dr. Kidman ran the session as a hybrid workshop and lecture session. She spoke for roughly half the time in each session, but students at North Shore contributed more freely than at Manukau; Manukau students were silent (in reading or in pauses) for $13 \%$ of the session time compared to $3 \%$ at North Shore. At the Nelson campus, Nic John ran the Approach B session as a hybrid workshop and lecture session, speaking for $69 \%$ of the time. Students spoke for $17 \%$ of the time. Discussion and video took the remainder of the time. The time the lecturers at all campuses spent in the leadership role in the classroom is much closer in the Approach B sessions.

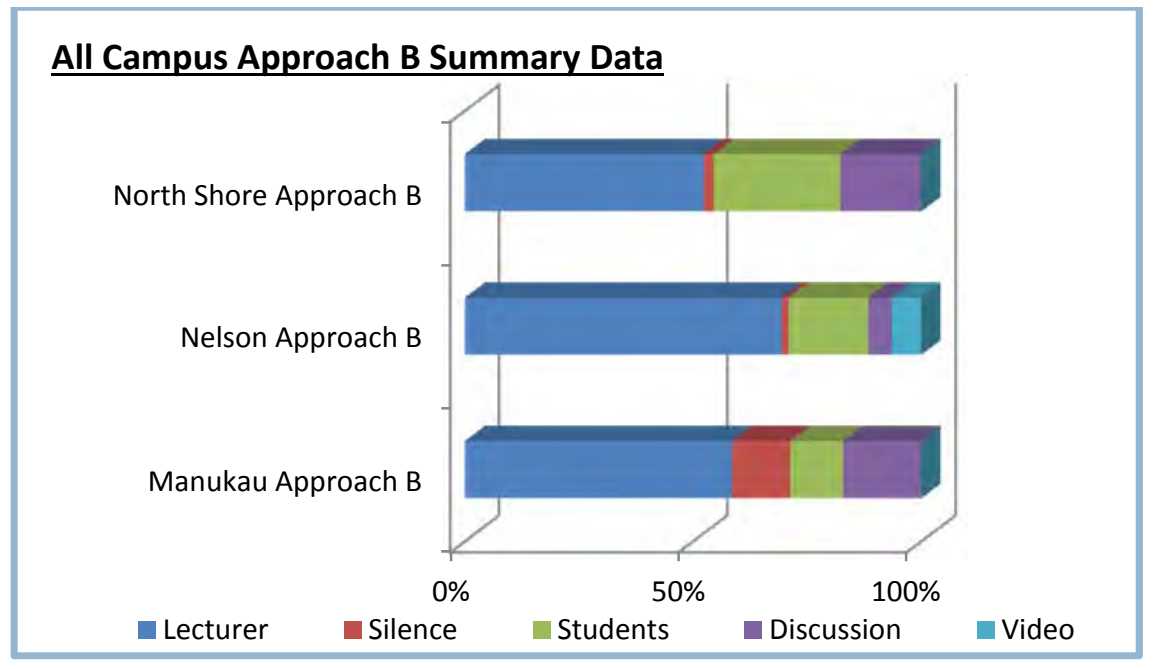

FIGURE 12: APPROACH B SUMMARY DATA (BY CAMPUS SESSION ACTIVITY CATEGORY IN PERCENTAGE OF MINUTES)

In compiling Dr. Kidman's time at both the Manukau and North Shore campuses between Approach A and Approach $B$, it is clear that the activity split at both campuses was largely similar for her Approach A sessions and her Approach B sessions. In the Approach B sessions she effectively had the leadership role; in Approach A, Dr. Kidman passed the leadership role to the students at both campuses. There is a very clear variation illustrated between the Approaches. 


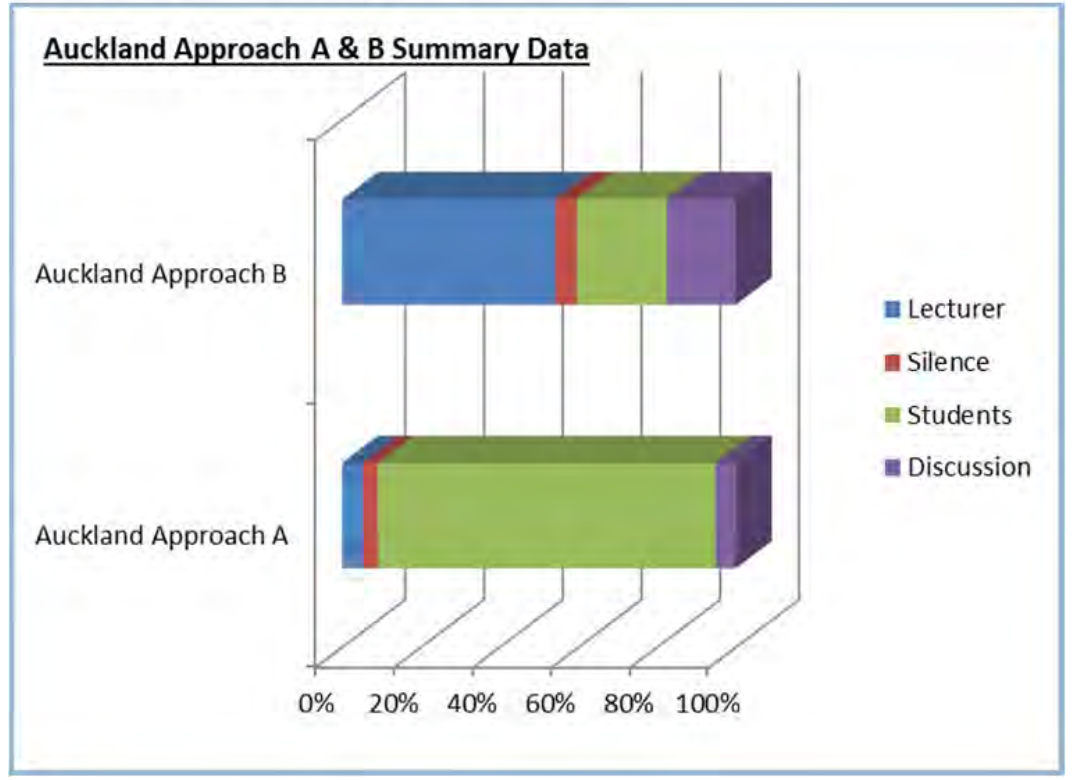

FIGURE 13: AUCKLAND CAMPUS APPROACH A AND B SUMMARY DATA (SESSION ACTIVITY CATEGORY IN PERCENTAGE OF MINUTES)

While being aware that this is only one pair of data points, Nic John's time at the Nelson campus between Approach A and Approach B was less varied. Nic took largely the same approach to both sessions; but was slightly more hands-on in the Approach $B$ session. There is far less variation illustrated between the two Approaches at Nelson than in Auckland.

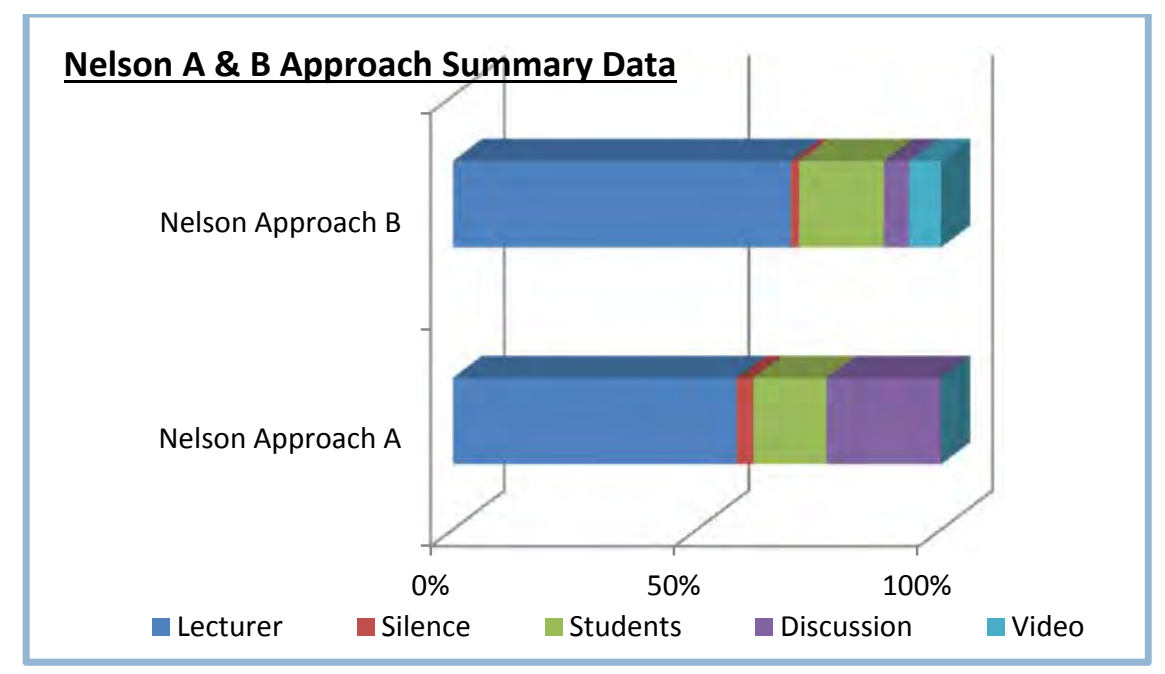

FIGURE 14: NELSON CAMPUS APPROACH A \& B SUMMARY DATA (SESSION ACTIVITY CATEGORY IN PERCENTAGE OF MINUTES)

\section{Word Counts: All Sessions}

I examined the summary word counts for all the A and B Approaches. I found that students and lecturers averaged speaking length overall in the A sessions, but were quite different, being heavily lecturer-centric, in the $B$ sessions. 


\begin{tabular}{|c|c|c|}
\hline & $\begin{array}{l}\text { All } \\
\text { Approach } \\
\text { A session } \\
\text { averages }\end{array}$ & $\begin{array}{l}\text { All } \\
\text { Approach } \\
\text { B session } \\
\text { averages }\end{array}$ \\
\hline Lecturer & 27 & 44 \\
\hline Students & 25 & 16 \\
\hline
\end{tabular}

In the Approach A session transcripts, I also noted that students in their individual responses appeared to speak for a longer time, developing their ideas more. Each response was not merely an 'answer', but a train of thought, an act of persuasion or the linking of case issues to other things. Because of this, I ran some simple counts of the transcript data in Excel, calculating how long that the students and lecturers spoke in each of the session approaches (excluding minute counts for general discussion, silence and video). The results are:

TABLE 11: AVERAGE WORD COUNTS PER CONTRIBUTION BY SPEAKER TYPE (BY APPROACH A \& B BY CAMPUS)

\begin{tabular}{|c|c|c|c|c|c|c|}
\hline Campus & $\begin{array}{r}\text { Manukau } \\
\text { Approach } \\
\text { A }\end{array}$ & $\begin{array}{r}\text { Manukau } \\
\text { Approach } \\
\text { B }\end{array}$ & $\begin{array}{r}\text { Nelson } \\
\text { Approach } \\
\text { A }\end{array}$ & $\begin{array}{r}\text { Nelson } \\
\text { Approach } \\
\text { B }\end{array}$ & $\begin{array}{r}\text { North } \\
\text { Shore } \\
\text { Approach } \\
\text { A }\end{array}$ & $\begin{array}{r}\text { North } \\
\text { Shore } \\
\text { Approach } \\
\text { B }\end{array}$ \\
\hline Lecturer & 28 & 39 & 31 & 45 & 21 & 48 \\
\hline Students & 26 & 12 & 11 & 13 & 39 & 24 \\
\hline
\end{tabular}

In the Approach B session transcripts, lecturers spoke, on average, for significantly longer than the students; the ratio being between 2 times more (North Shore) to 3.5 times more (Nelson). An interesting similarity was the closeness between Nelson and Manukau (at 3.3 and 3.5), where a common factor was a lack of familiarity between the lecturer as session leader, and the students.

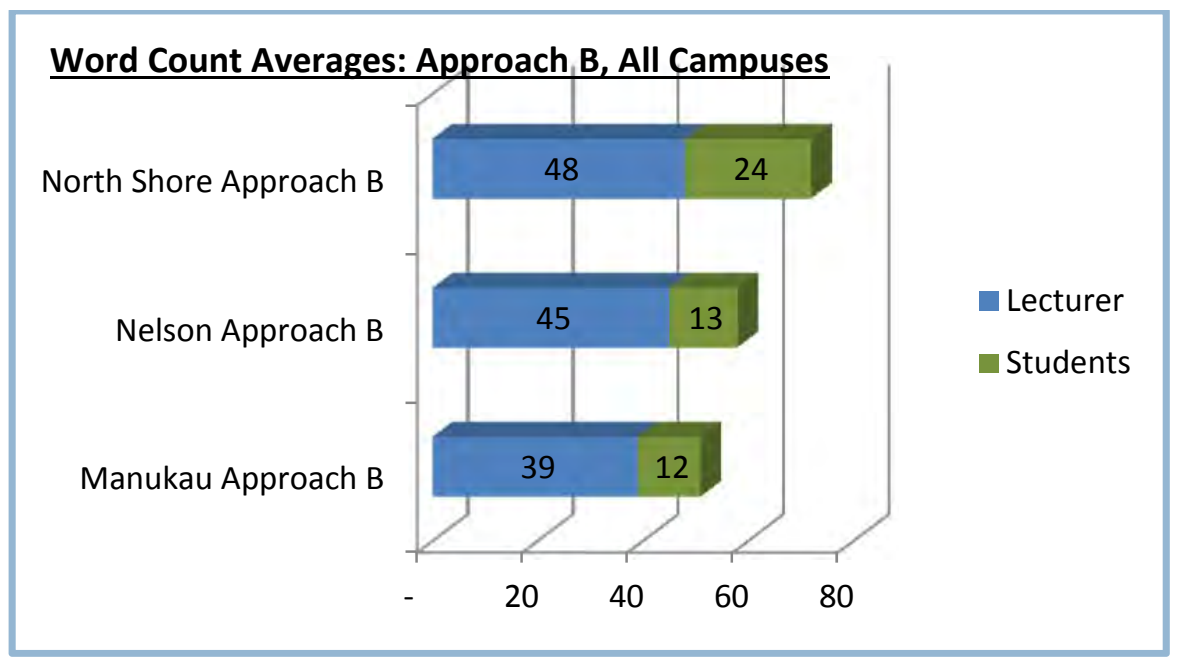

FIGURE 15: AVERAGE WORD COUNT FOR APPROACH B SESSIONS (BY SPEAKER TYPE BY CAMPUS IN PERCENTAGES) 
In the Approach A sessions, lecturers spoke, on average, for both significantly less and for significantly longer than the students; the ratio being between .5 times less (North Shore) to 2.8 times more (Nelson).

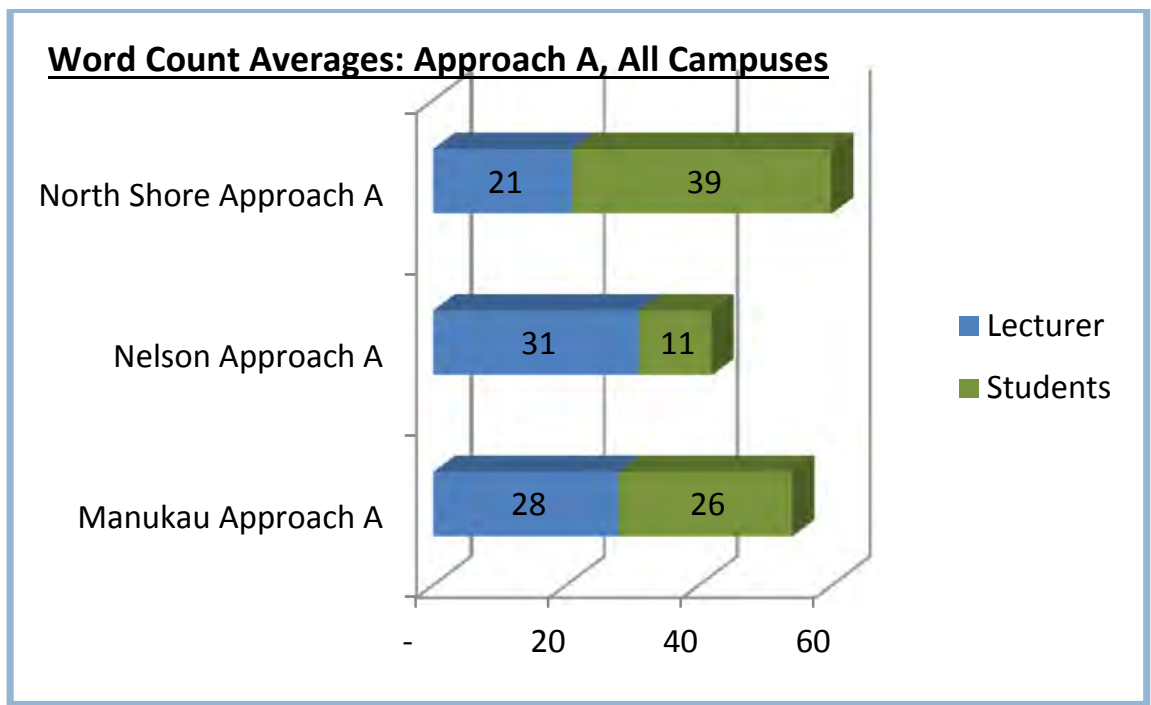

FIGURE 16: AVERAGE WORD COUNT FOR APPROACH A SESSIONS (BY SPEAKER TYPE BY CAMPUS IN PERCENTAGES)

However, taking the Auckland data on its own, in the Approach A sessions, the students spoke for a quarter as long again as the lecturers. The students' voice was the one most heard in the room.

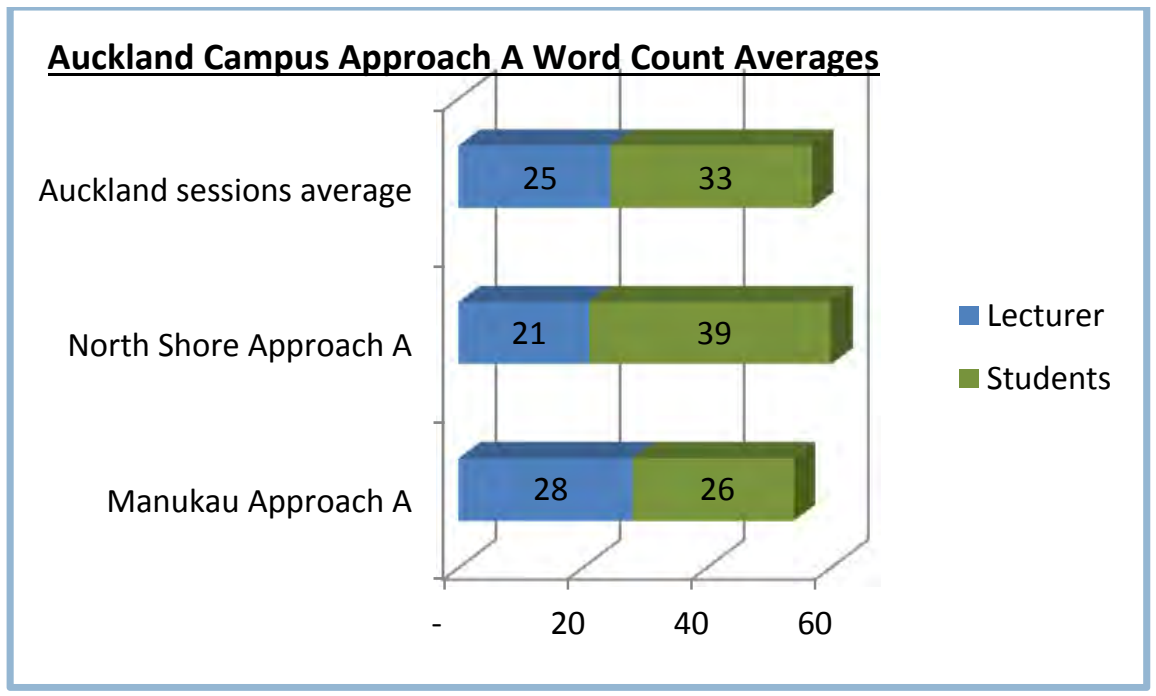

FIGURE 17: AVERAGE WORD COUNT FOR AUCKLAND CAMPUS APPROACH A SESSIONS (BY SPEAKER TYPE IN NUMBER OF WORDS)

On average, then, the data bears out my impression that the students spoke for significantly longer in the Approach A sessions than in the B sessions. Also, the lecturers said less each time they spoke.

The word count averages show that the average Auckland student appeared to take the time to more fully develop their ideas than in the more lecturer-led sessions. This is particularly true of the North Shore Approach A sessions. By weight of the voices being heard in the room, the Approach A 
Auckland sessions appear on the surface to reflect a shared power model, and to have taken more of a shared leadership approach.

\section{Findings from Session A \& B Coding}

I transcribed my Approach A and Approach B session recordings from all the campuses, and I coded the transcripts in QDA Miner Lite, looking for the ten effective teaching categories from Harper, Lamb \& Buffington (2008) and Bridges \& Hallinger (1997) that I had determined to use. While going through the data, I found some emergent codes which I eventually clustered into a category which illustrated poor teaching, termed "Ineffectiveness". The codes within this category tend to limit or inhibit learning, and are aspects such as lecturer-dominance, a lack of preparation, or passivity.

I found another set of emergent characteristics which related strongly to the teaching method, which I categorised as "Teaching Method". The codes within this category include more environmental aspects of the teaching and learning, and include the capturing of ideas, the feeling of safety in small groups, and the desire for pre-digested material.

From the coded data in QDA Miner Lite, I extracted simple frequency counts into Excel and pivottabled the results, organising the data by Approach A and Approach B, summarising all campuses, and both cases, into simple counts as follows:

TABLE 12: SUMMARY OF CATEGORY AND CODE INCIDENCE COUNTS (ALL CAMPUSES BY APPROACH A \& B)

\begin{tabular}{|c|c|c|c|}
\hline Category & Code & $\begin{array}{r}\text { Approach A } \\
\text { Transcript } \\
\text { Counts }\end{array}$ & $\begin{array}{r}\text { Approach B } \\
\text { Transcript } \\
\text { Counts }\end{array}$ \\
\hline \multirow[t]{10}{*}{ Effectiveness } & Applying new knowledge & 11 & 2 \\
\hline & Applying Principles & 57 & \\
\hline & Evaluation skills & 13 & 1 \\
\hline & Group problem-solving & 7 & 2 \\
\hline & Important points & 20 & \\
\hline & Interpersonal skills & 3 & 1 \\
\hline & Leadership emotional insight & 15 & 5 \\
\hline & Self-directed learning & 9 & \\
\hline & Student participation & 6 & 10 \\
\hline & Synthesising \& solving & 17 & 6 \\
\hline \multirow[t]{7}{*}{ Ineffectiveness } & In/Out Group & & \\
\hline & Lecturer-Dominated & 15 & 46 \\
\hline & Micro-managing & 1 & \\
\hline & No Preparation & 2 & \\
\hline & No Theory & 2 & \\
\hline & Not connected & 2 & \\
\hline & Passive & 9 & 10 \\
\hline \multirow[t]{3}{*}{ Teaching Method } & Capturing Ideas & 1 & \\
\hline & Case in Point positive & & \\
\hline & Hybrid positive & 1 & \\
\hline
\end{tabular}




\begin{tabular}{|c|c|c|c|}
\hline Category & Code & $\begin{array}{r}\text { Approach A } \\
\text { Transcript } \\
\text { Counts }\end{array}$ & $\begin{array}{l}\text { Approach B } \\
\text { Transcript } \\
\text { Counts }\end{array}$ \\
\hline & Length & & \\
\hline & Pre-Digested & 4 & \\
\hline & Small Group Safety & 4 & \\
\hline & Suggestion & 4 & \\
\hline & Video & & \\
\hline
\end{tabular}

While I had been transcribing the sessions it seemed to me that there was a much richer - i.e., a profusion of detail, a pleasant depth and breadth supplied (OED, 2009) - quality of discussion among the students taking Approach A in Auckland. I believe this is reasonably well supported by the effectiveness category coded data counts showing a much higher incidence of the students in the Approach A sessions demonstrating that they were applying new knowledge (11 to 0), applying principles (57 to 0 ), showing evaluation skills (13 to 1 ) and group problem-solving (7 to 2 ), that they were raising important points (20 to 0 ), gaining leadership emotional insights (15 to 5), demonstrating self-directed learning (9 to 0 ), and they were synthesising \& solving (17 to 6$)$.

What I did find interesting was that in the sessions themselves, I found more evidence of student participation in Approach B (10 counts) than in Approach A (6), although student participation was evident from listening to the recordings in both sessions. A range of students participated in both sessions. As the groups were small, there was little possibility of 'hiding'. In fact, from listening to the recordings, I suspected that the Approach A sessions should have had more evidence of participation.

At times I noted that the Approach B and the Nelson Approach A sessions were too lecturerdominated. This was based on coding counts as well as tone, density of material conveyed by the lecturer, of lack of student input or questioning over the transcript data. The Approach A sessions were three times less lecturer-dominated than the Approach B sessions (15 to 46); and when considering the Auckland Approach A sessions and 'everyone else' the incidence was 0 to 61 . The incidence of student passivity was roughly the same for both $A$ and $B$ sessions ( 9 and 10), but when considering the Auckland Approach A sessions and 'everyone else' the incidence shifted to 1 to 18 .

Continuing with the ineffectiveness category, in the Auckland-based Approach A sessions, Lynn had specifically asked the students if they had completed their preparation. Most of them had not. Some of the students themselves during the session recap also specifically mentioned the lack of theory and mentioned a lack of connection with some of the material. Some of the issues which I had been initially concerned about - the lack of structure leading to an under-exploration of theory and that the students may well lack the discipline to prepare properly for the classes - seemed to indeed be a concern. For example, the lack of link to theory: "there was some attempt to relate theory into story but it was probably somewhat light in terms of substantiating your comments with academic ...umm... theory" (MA, 65.02) and "I would like to have like to be able to look at it from the academic perspective" (MA, 67.07). I also felt that my third issue, that of students lacking the capacity for a "Case in Point" approach was also evident in comments such as "I just thought it was a pointless 
exercise. That we are going to do something that we can't even do" (NNA1, 03.46), and that the numbers were low, despite the consent forms being filled out, as there were only "Thirteen students here out of seventy" (NSA, 06.43) (see Student Participation later in this section for further details).

Many of the useful comments in this section were trapped because Lynn specifically drew the students out at the end of the session, for which I am very grateful.

During this recap, students made some suggestions and comments centring around wanting material to be more pre-digested "you first read it, and like the readings are so big, and so many of them, it's like you can get lost in all the information. If you have a couple of key points [...] as if the readings were summarised [...] and then discussed it rather than just going off [what is in] our heads" (MA, 65.44) and "if someone sat there and put out on the table the theoretical stuff, the academic stuff and we were able to apply that" (MA, 66.26) and "what I was finding hard is when everyone has different ideas and just putting them together. I think what I am finding hard is running everything together. I just find that a bit challenging" (NSA, 96.10). Some students liked the more hybrid structure "if you went over this PowerPoint present- like this, lectured it beforehand and then we were able to talk about what you said in the lecture and then talked about it in this sort of situation, I probably would have learned a whole bunch more" (MA, 65.02), and completing the case analysis "but if you, like, write it up, and discussed and talk about it, for me, I like understand that better" (MA, 65.34).

On examining the tabled results, I noted a richness - a profusion of detail, the pleasant depth and breadth supplied, (OED, 2009) - to the Approach A data within the effectiveness cluster. Because the lack of clarity and purpose with the Nelson sessions may have been skewing my results, I decided to consider the Auckland lecturer feedback on effectiveness only. The Auckland results were as follows:

TABLE 13: SUMMARY OF EFFECTIVENESS CATEGORY \& CODE INCIDENCE COUNTS (AUCKLAND CAMPUSES BY APPROACH A \& B)

\begin{tabular}{|c|c|c|c|}
\hline Category & Code & $\begin{array}{r}\text { Approach A } \\
\text { Auckland } \\
\text { Transcript } \\
\text { Counts }\end{array}$ & $\begin{array}{r}\text { Approach B } \\
\text { Auckland } \\
\text { Transcript } \\
\text { Counts }\end{array}$ \\
\hline \multirow[t]{10}{*}{ Effectiveness } & Applying new knowledge & 10 & 2 \\
\hline & Applying Principles & 57 & \\
\hline & Evaluation skills & 13 & 1 \\
\hline & Group problem-solving & 7 & 2 \\
\hline & Important points & 20 & \\
\hline & Interpersonal skills & 3 & 1 \\
\hline & Leadership emotional insight & 13 & 5 \\
\hline & Self-directed learning & 9 & \\
\hline & Student participation & 6 & 10 \\
\hline & Synthesising \& solving & 17 & 6 \\
\hline
\end{tabular}

Evidence of student participation became more clearly into focus when I examined the transcripts of the B sessions in Auckland. However, this was evidenced by three students providing feedback on 
their own leadership experiences during the previous week with which each class begins, and was in general not to do with the Approach B sessions themselves.

In this instance, my approach to my coding has limited my ability to highlight the overall impression gained from listening to the Approach A recordings. In those sessions there were many different voices being heard, with students following on from and building on each other's ideas, getting excited and finishing each other's sentences. Student participation was evidenced by the fact that almost all students spoke during the sessions themselves, and spoke for some time.

If I had been more expert in transcript analysis, I could have set up more detailed coding for how things were said (such as coding for excitement, tone of voice and so forth), and cross tabulated this with my existing code categories.

\section{Effective Learning Characteristics from Session A \& B Coding}

I was very heartened to see many incidences of what I would consider to be 'effective' learning demonstrated in the Approach A sessions, particularly in the Auckland student-led sessions.

Of the ten characteristics from Harper, Lamb \& Buffington (2008) and Bridges \& Hallinger (1997), eight of them were evidenced in the Approach A sessions, particularly in the Auckland delivery.

The Approach A sessions demonstrated students applying new knowledge that had arisen during the case discussions with view shifts, application to issues outside the parameters of the case, and consideration of macro-environmental factors. I also noted questioning behaviour, as exemplified by the following: "if they $[\ldots]$ let him compete again, $[\ldots]$ it will be interesting to see the way that, not only how he conducts himself, but how people reacted to, to him" (MA, 57.39), "he probably will go out and win without drugs, and then we will probably completely forget" (MA, 58.06), "If you are not performing you have no power, because [...] no one wants to be associated with a team that's not performing" (MA, 51.58), and "They are leaders when it comes to the theory industry and stuff. When things go wrong $[\ldots]$ it actually affects the economy." (MA, 61.48)

There was a large number (57) of examples of students demonstrating their ability to apply leadership principles from the case. Student exploration ranged from the sponsorship pressure on the athletes to the ethics of a key sponsor, Nike: "It's the athlete's own decision whether they want to dope or not. Obviously if they want to compete at the top level, they will feel pressured to take enhancing drugs, [...] it's not their choice, however; they are governed by pressure. All the sponsors have the desire obviously to obtain a gold at the Olympics" (MA, 41.46); "if you think about how much they have to gain from it, from having someone like Lance, as one of the key sponsored people, how long did they know? Did they know the whole time? [... Was this] The risk they were willing to take for such huge financial gain? Is that fair?" (MA, 04.12). They discussed Lance Armstrong's power and hero leadership: "he still has lots of power, even though he is a cheat. People still see [him] as a hero" (MA, 11.57); "if you are seen as a hero in the cycling fraternity (indecipherable) and all of a sudden you have beaten cancer, what does that do? It just gives you more power. More eminence." (MA, 11.15). They discussed the ethical alignment of Lance Armstrong as a leader: "I would not do it, because 
there is much more at stake than that. [...] he could still go to jail if he is found guilty; he was money laundering, he was doing everything (indecipherable) that gangsters ordinarily do on the street" (MA, 61.48); and what that meant to the student personally, "I am more inclined to admire the leadership of a guy who finished thirtieth in a Tour de France and he was clean" (NSA, 56.16).

Evaluation skills, although consisting of fewer examples (13) were illustrated well. They included weighing up the power of sponsors, doctors and the cycling machine "Lance had the power to penetrate the mind of a lot of fans, a lot of sponsors [...] and yet there was a greater power behind him $[, \ldots]$ people who were running his mind, so in a sense they are actually leading him" (MA, 19.03); evaluating Lance's performance against the topic material "linking back to the topic that it seems unethical. The reading characterises ethical leaders as honest, caring and principled individuals who make fair and balanced decisions. So he wasn't very honest at all. Caring; he wouldn't care about anything but himself" (MA, 19.03); and linking back to followership theory in considering Lance's broader audience "it just makes me think about followers, what followers desire, you know, in a guy like Lance Armstrong" (MA, 22.26).

The recordings showed evidence of group problem-solving (7 counts) in the interaction between the students, the free run of the conversation and that the students had and were able to take the time to develop their ideas fully, the respectful language and tone of the sessions. It was also shown in the transcripts with comments such as "We all got slightly different ideas but it comes back to the fundamentals of the case; that still everyone was on the same page" (MA, 29.13). There were also comments about the group work in the sessions, including "it was almost a feeling like equality or things like that it came out of the discussion" (NSA, 100.12) and "we could get the inside people's opinions, so more and more [ideas] could come out" (MA, 63.50). Additionally, one student explored why group discussion was necessary for them, saying "we want to converse quite freely and share those ideas without feeling fear" (MA, 63.38).

There were various important points - key learnings - in each case. I found 20 instances of important points evidenced in the transcripts. There were many which explored the use of Power and Influence, such as "he also abused relationships, and he eliminated people who also attempted come out with the truth. So he used his power and influence and money to keep people quiet, and to protect his name" (MA, 02.06). Students explored a range of other issues including betrayal, trust, cheating, bullying, exploitation and heroic leadership, including the potential complicity of Lance Armstrong's sponsors in cheating. Students also extended the potential complicity of sponsors into the growing commodification of sport: "sport it has become a commodity, resulting in keeping those who have power, to call the shots, over sports people [athletes], using them as pawns to get a return on investment for themselves" (MA, 27.41).

Leadership emotional insights (15) were illustrated in a number of ways. Firstly, by a participant being persuaded by the case evidence and finding their role model has lost value in their eyes "well, where does that leave me now? [...] I have idolised this guy for so long and then they uncovered that he's a drug cheat" (MA, 37.09). Secondly, by participants having the courage to take an act of leadership and to "ask each other questions, so each and every one of us can just take a leadership role, for five 
minutes or so"(MA, 66.42). Fourthly, in understanding that leadership is not necessarily good leadership, with a participant coming to the realisation that Lance still had power and influence: "it's not good power, it's not good influence, it's not a good perception of him, but he's still got it"(MA, 57.19). Lastly, in showing that lecturers too learn from practice: "that was one of the hardest things I have ever done. Just sit back here and NOT answer the question, not make a comment. And the comments that I would have made would have drawn you off what you guys are thinking"(MA, 68.42).

Synthesising and solving was demonstrated in a number of ways. Students compared Lance Armstrong's current situation to that of other fallen, and since recovered athletes, such as Tiger Woods, and wondered if the passage of time might change public perception, and compared other codes, including "cycling is obviously a key example now how the other sports are going. Like baseball [, it] is an example of allegations of people being caught" (MA, 31.35). There was speculation on what WADA or USADA could do with Lance Armstrong's inside knowledge, should he ever choose to reveal it, and what impact this might have on cycling. Students explored the ethics of wealthy Auckland secondary schools buying in talent from lower decile schools, exploring the offer from the athlete's point of view and its 'too good' nature: "you offer something [like that] to our kids, free education, good school, because of your footy, whatever, they're not going to turn that down" (MA, 49.29). They noted the commercial arrangement of schools making such offers, and the lack of pastoral care supplied to ensure athlete academic and emotional performance within the new culture.

Self-directed learning (9) can be seen from a number of comments made by participants on the value of discussion and the sharing of ideas, and comments relating to previous learning, reading and outside exploration. One participant said that they see good leadership, they could read about it and understand it intellectually, but still question how it related to them until they could apply it. A great summary statement was: "you had to do some self-reflection when you were sharing your values and beliefs and hearing, as you said, the values and beliefs of your colleagues"(MA, 67.07).

\section{The Case Itself}

In reviewing all the transcripts, there was commentary evidence that the students did not have a sense of connection to the Tennis New Zealand case. I felt this could skew my data, so I decided to interrogate the data by each case.

Nelson did the Tennis New Zealand case as the Approach A session; Auckland as the Approach B session. They reversed Approaches for the Lance Armstrong case. The incidence counts follow:

\begin{tabular}{|c|c|c|c|c|c|}
\hline Category & Code & $\begin{array}{r}\text { Tennis NZ } \\
\text { Approach } \\
\text { A Session } \\
\text { Counts } \\
\text { (Nelson) }\end{array}$ & $\begin{array}{l}\text { Tennis NZ } \\
\text { Approach } \\
\text { B Session } \\
\text { Counts } \\
\text { (Auckland) }\end{array}$ & $\begin{array}{r}\text { Lance } \\
\text { Armstrong } \\
\text { Approach } \\
\text { A Session } \\
\text { Counts } \\
\text { (Auckland) }\end{array}$ & $\begin{array}{r}\text { Lance } \\
\text { Armstrong } \\
\text { Approach } \\
\text { B Session } \\
\text { Counts } \\
\text { (Nelson) }\end{array}$ \\
\hline \multirow[t]{2}{*}{ Effectiveness } & $\begin{array}{l}\text { Applying new } \\
\text { knowledge }\end{array}$ & 1 & 2 & 10 & \\
\hline & Applying Principles & & & 57 & \\
\hline
\end{tabular}




\begin{tabular}{|c|c|c|c|c|c|}
\hline Category & Code & $\begin{array}{r}\text { Tennis NZ } \\
\text { Approach } \\
\text { A Session } \\
\text { Counts } \\
\text { (Nelson) }\end{array}$ & $\begin{array}{l}\text { Tennis NZ } \\
\text { Approach } \\
\text { B Session } \\
\text { Counts } \\
\text { (Auckland) }\end{array}$ & $\begin{array}{r}\text { Lance } \\
\text { Armstrong } \\
\text { Approach } \\
\text { A Session } \\
\text { Counts } \\
\text { (Auckland) }\end{array}$ & $\begin{array}{r}\text { Lance } \\
\text { Armstrong } \\
\text { Approach } \\
\text { B Session } \\
\text { Counts } \\
\text { (Nelson) }\end{array}$ \\
\hline & Evaluation skills & & 1 & 13 & \\
\hline & Group problem-solving & & 2 & 7 & \\
\hline & Important points & & & 20 & \\
\hline & Interpersonal skills & & 1 & 3 & \\
\hline & $\begin{array}{l}\text { Leadership emotional } \\
\text { insight }\end{array}$ & 2 & 5 & 13 & \\
\hline & Self-directed learning & & & 9 & \\
\hline & Student participation & & 10 & 6 & \\
\hline & Synthesising \& solving & & 6 & 17 & \\
\hline
\end{tabular}

By analysing the data by case, it is not so much the less engaging case which is highlighted, but the poor performance of the Nelson sessions. What was remarkable was that effectiveness was not illustrated in the Lance Armstrong Approach B session.

Additionally, in comparing the two Auckland Approaches, we can still see that the Tennis New Zealand case rated less effectively than the Lance Armstrong case. The use of the less engaging case will have somewhat skewed the data.

\section{Dominance}

My overwhelming impression of the difference between the Approach $A$ and Approach $B$ sessions was one of dominance. The Approach A sessions run in Auckland were student-led. The Approach B sessions felt almost lecturer-dominated at times, which appeared to then further encourage student passivity. I came to notice this more and more as I became familiar with the data (and my transcript coding results mentioned earlier this section bear this out).

We have examined the raw materials. We now turn our attention to the focus group and lecturer survey data, where reflection in some form has been taken.

\section{Retroductive Data}

The data in this section is the result of students and lecturers contemplating their classroom experiences. They have had time to digest and time to attach meaning - or to lose meaning - to the Approach A and Approach B sessions.

\section{Word Counts: Auckland Session Focus Groups}

I recorded the Auckland focus group sessions where I talked to the students and the lecturer about their recollections of both the Approach A and the Approach B sessions they participated in (see Appendix Four(a) for the questions and categories). From the focus group transcripts, like the 
Approach A and Approach B sessions, I evaluated the average word counts for the sessions, which were as follows:

TABLE 15: AVERAGE WORD COUNT BY SPEAKER TYPE (FOCUS GROUP SESSIONS AT AUCKLAND CAMPUSES)

\begin{tabular}{lr|r|r|r|r|} 
& $\begin{array}{r}\text { Manukau } \\
\text { Focus } \\
\text { Group }\end{array}$ & $\begin{array}{r}\text { North Shore } \\
\text { Focus } \\
\text { Group 1 }\end{array}$ & $\begin{array}{r}\text { North Shore } \\
\text { Focus } \\
\text { Group 2 }\end{array}$ & $\begin{array}{r}\text { North Shore } \\
\text { Focus } \\
\text { Group }\end{array}$ & $\begin{array}{r}\text { Overall } \\
\text { Focus } \\
\text { Group } \\
\text { Average }\end{array}$ \\
Lecturer & 11 & 17 & 18 & 18 & 15 \\
Students & 16 & 19 & 35 & 27 & 23 \\
\hline Sam & 14 & 19 & 13 & 16 & 15 \\
\hline
\end{tabular}

I was interested to see that my own word counts were fairly low in each session - probably because I have over twenty years' experience in career practice, so interviewing to ensure the participant's voice is the most clearly heard is a reasonably well-honed skill. This focus group data does not appear to tell any particular story, aside from the fact that all voices were heard fairly evenly, with more focus on student feedback.

When I ran the focus group session with the Nelson class, I think it was equally balanced, although I did not record this session. Instead I wrote up the focus group ideas, question by question, on the whiteboard as a mind map (our normal way of banking workshop ideas). I photographed each completed question. All the focus group participants confirmed that the whiteboard work was representative. Instead of writing a transcript of a sound recording, I wrote a transcript of the whiteboard images. I then coded the transcript, which was imported into my CAQDAS software.

\section{Focus Group Transcript Data}

Like the Approach A and Approach B session transcripts, I analysed the focus group transcripts using the CAQDAS software, QDA Miner Lite. Because the focus groups would seek reflections from the participants on both the Approach A and Approach B sessions, I also coded each student response or part within the focus group transcripts as "A" or "B", and "Lance Armstrong" or "Tennis NZ" so I could be sure which approach or case the participant was referring to.

I exported the focus group frequency counts for both the Approach A and Approach B sessions, and pivot-tabled the results in Excel. The results are as follows:

TABLE 16: SUMMARY OF CATEGORY AND CODE INCIDENCE COUNTS (ALL FOCUS GROUPS BY APPROACH A AND APPROACH B)

\begin{tabular}{|l|l|r|r|}
\hline \multirow{2}{*}{ Category } & Code & $\begin{array}{r}\text { Approach A } \\
\text { Focus Group } \\
\text { Counts }\end{array}$ & $\begin{array}{r}\text { Approach B } \\
\text { Focus Group } \\
\text { Counts }\end{array}$ \\
\hline & Applying new knowledge & 3 & 2 \\
\hline & Applying Principles & & 1 \\
\hline & Evaluation skills & 2 & 1 \\
\hline & Group problem-solving & 13 & 5 \\
\hline
\end{tabular}




\begin{tabular}{|c|c|c|c|}
\hline Category & Code & $\begin{array}{r}\text { Approach A } \\
\text { Focus Group } \\
\text { Counts }\end{array}$ & $\begin{array}{r}\text { Approach B } \\
\text { Focus Group } \\
\text { Counts }\end{array}$ \\
\hline & Important points & 4 & \\
\hline & Interpersonal skills & 5 & 1 \\
\hline & Leadership emotional insight & 17 & 4 \\
\hline & Self-directed learning & 3 & 3 \\
\hline & Student participation & 15 & 4 \\
\hline & Synthesising \& solving & 3 & 4 \\
\hline \multirow[t]{7}{*}{ Ineffectiveness } & In/Out Group & & \\
\hline & Lecturer-Dominated & 1 & 2 \\
\hline & Micro-managing & 1 & \\
\hline & No Preparation & 3 & 1 \\
\hline & No Theory & 6 & \\
\hline & Not connected & 5 & 9 \\
\hline & Passive & 1 & 3 \\
\hline \multirow[t]{8}{*}{ Teaching Method } & Capturing Ideas & 1 & \\
\hline & Case in Point positive & 4 & \\
\hline & Hybrid positive & & 1 \\
\hline & Length & 2 & \\
\hline & Pre-Digested & & \\
\hline & Small Group Safety & 2 & \\
\hline & Suggestion & 4 & \\
\hline & Video & & 1 \\
\hline
\end{tabular}

Again, like my pre-coding impressions of the Approach A session transcripts in Auckland, the focus group Approach A responses sounded very positive, warm and clearly envisioned on the recordings. This impression seems to be borne out by evidence, with Approach A effectiveness score counts being higher than those for Approach B. For example, the effectiveness category coded data counts showing a higher incidence of the students in the Approach A sessions demonstrating that they were applying evaluation skills ( 2 to 0 ), group problem-solving (13 to 5 ), that they were raising important points (4 to 0 ), that they demonstrated interpersonal skills (4 to 1 ), gained leadership emotional insights (17 to 4), and there was more student participation (15 to 6). Synthesising and solving had a higher Approach B than Approach A count (4 to 3). Applying new knowledge was fairly even at 3 incidences in Approach A to 2 in Approach B.

In the focus groups, the Auckland students made many comments about their enjoyment of the Approach A sessions, with their answers to questions coming very quickly, with warm tones of voice. They made comments on the discussion, their engagement, on generating the answers, and on how well they related to the session. Two comments were notable. Firstly that students could "actually initiate the conversation, it's how we learn; it also builds confidence as well within the class" (MF, 14.55). Secondly, a student who was initially very resistant to the Approach A delivery method, 
experienced a reversal during the experience. This student related their story and concluded "that's the most fun I've ever had in your class" (NSF2, 16.50).

The students also were very engaged with their peers, with a lot of collective noun use (everyone, we, everybody) and comments about the session being "completely student led" (NSF1, 07.45), engagement, the discussion and its length, depth and complexity "we probably discussed it for an hour and a bit, without Lecturer or Lecturer or anyone saying anything" (MF, 10.16). Students also made many mentions of the range of views explored, and the differences of opinion, the deeper understanding of each other that arose from this, and the collegiality that created. Discussion was free flowing and did not end with making a statement. One student explained that you shared what you wanted to say, "then you are questioned by others" (NSF1, 06.13).

The students also talked about the interpersonal interplay and shift in views that resulted from the discussions, including the emotional intensity which arose from time to time, and the care they began to take of each other in not becoming personal. One student reflected that "I maybe would have been better to have a different approach in terms of understanding or acknowledging more in-depth how people analyse certain emotions" (NSF2, 25.23).

The Auckland focus groups were keen that I understand that everyone in the group had spoken and that they felt that this contributed to a shifting of collective views: "once others started sharing their views [...] everyone's started to change a bit" (NSF1, 09.13) and "everybody's got different opinions, but all of a sudden it's like... it's developing you see. It's not very different after all, it's exactly the same thing, but we [were] just looking at it and processing it differently" (NSF1, 05.22).

Some additional views on leadership and development came out in two statements. One was that the Approach A session "opened my eyes to different points of view on leadership" (NSF1, 08.33). Another was "I was deeply open to discussion to try and develop my ideas more" (NSF2, 19.54). However, my initial concern about the possible lack of theory exploration was raised in the focus groups; (6 to 0 ), as was the issue of preparation not being completed (3 to 1 ).

I also found that the students did not seem to have a sense of connection to the Tennis New Zealand case material. Nelson delivered the Tennis New Zealand case as the Approach A session; Auckland delivered the Tennis New Zealand case as the Approach B session.

TABLE 17: SUMMARY OF EFFECTIVENESS CATEGORY AND CODE INCIDENCE COUNTS (CASE BY CITY FOCUS GROUP)

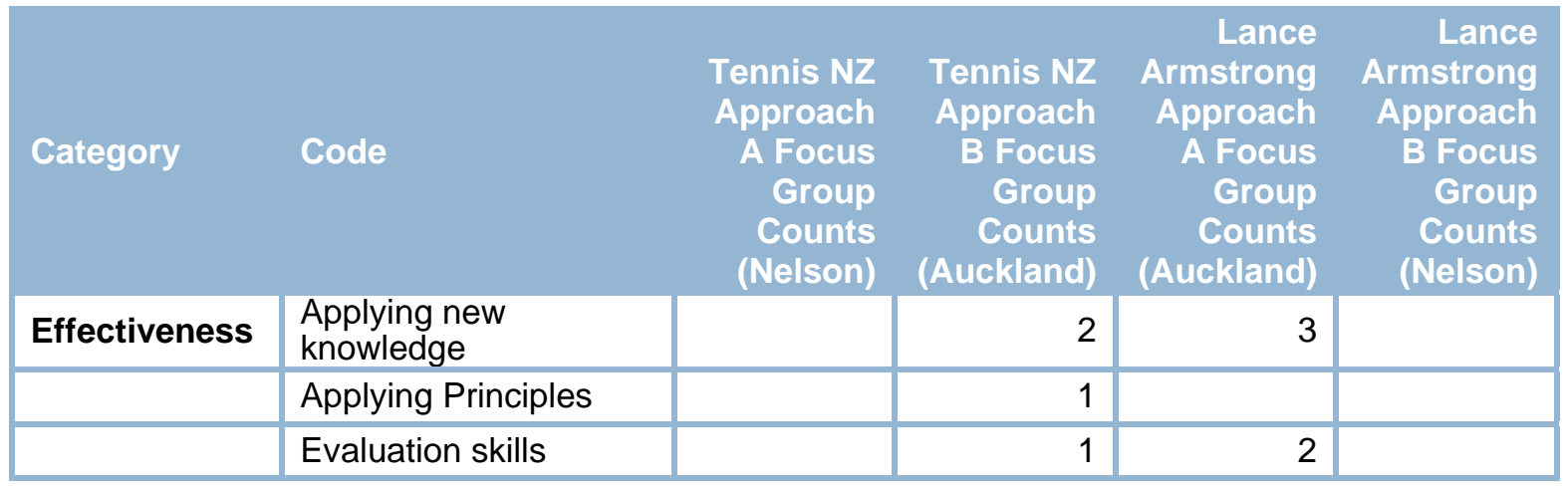




\begin{tabular}{|c|c|c|c|c|c|}
\hline Category & Code & $\begin{array}{r}\text { Tennis NZ } \\
\text { Approach } \\
\text { A Focus } \\
\text { Group } \\
\text { Counts } \\
\text { (Nelson) }\end{array}$ & $\begin{array}{r}\text { Tennis NZ } \\
\text { Approach } \\
\text { B Focus } \\
\text { Group } \\
\text { Counts } \\
\text { (Auckland) }\end{array}$ & $\begin{array}{r}\text { Lance } \\
\text { Armstrong } \\
\text { Approach } \\
\text { A Focus } \\
\text { Group } \\
\text { Counts } \\
\text { (Auckland) }\end{array}$ & $\begin{array}{r}\text { Lance } \\
\text { Armstrong } \\
\text { Approach } \\
\text { B Focus } \\
\text { Group } \\
\text { Counts } \\
\text { (Nelson) }\end{array}$ \\
\hline & Group problem-solving & & 4 & 13 & 1 \\
\hline & Important points & & & 4 & \\
\hline & Interpersonal skills & & 1 & 5 & \\
\hline & $\begin{array}{l}\text { Leadership emotional } \\
\text { insight }\end{array}$ & & 4 & 17 & \\
\hline & Self-directed learning & & & 3 & 3 \\
\hline & Student participation & & 2 & 15 & 2 \\
\hline & Synthesising \& solving & & 4 & 3 & \\
\hline
\end{tabular}

When I compared the coded data from the transcripts, it is clear that the Lance Armstrong case provoked good recall for the Auckland students. It was also mentioned with far more frequency by the Nelson students. This supports the findings from my transcript coding that (a) the Nelson sessions had not worked well, and that (b) the two cases which I had used were not evenly matched.

However, there is a timing issue here with regard to the Auckland focus groups. The Approach A and Approach B sessions had taken place on September 4/5 and August 27/28 respectively. The Auckland focus groups didn't take place until after the study break, on September 24 and 25. Considering the length of time that had elapsed between the Approach A session delivery and the focus group sessions, the students' ability to so clearly recall the case session is surprising.

However, I suspect this reflects a combination of three things: how student-led the Approach A session was, the difference in the delivery method, and the characteristics of the case itself. I do not feel that the students' ability to put themselves back into the room was due solely to the impactful nature of the case, as the Nelson focus group did not reflect the level of recall in their focus group data. The Nelson students remembered the Lance Armstrong case, but their recall of it was only slightly better than the Tennis New Zealand one, after a gap of two weeks on September 17.

The next set of reflective data I considered was the lecturer survey information which my volunteer lecturers had completed after each session they taught.

\section{Lecturer SurveyMonkey Coded Data}

As part of my research process, I created some survey instruments using SurveyMonkey for my lecturers to complete after delivering the Approach A and Approach B sessions. I then downloaded the SurveyMonkey data into Word documents. These documents were imported into QDA Miner Lite and coded using the already developed categories and codes. I exported the Approach A and Approach B frequency counts and pivot-tabled the results in Excel, as follows: 
TABLE 18: SUMMARY OF CATEGORY AND CODE INCIDENCE COUNTS (ALL LECTURER SURVEYS BY APPROACH A \&B)

\begin{tabular}{|c|c|c|c|}
\hline Category & Code & $\begin{array}{r}\text { Approach A } \\
\text { SurveyMonkey } \\
\text { Counts }\end{array}$ & $\begin{array}{r}\text { Approach B } \\
\text { SurveyMonkey } \\
\text { Counts }\end{array}$ \\
\hline \multirow[t]{10}{*}{ Effectiveness } & Applying new knowledge & & \\
\hline & Applying Principles & & \\
\hline & Evaluation skills & & \\
\hline & Group problem-solving & 1 & 1 \\
\hline & Important points & & \\
\hline & Interpersonal skills & 2 & \\
\hline & Leadership emotional insight & 1 & \\
\hline & Self-directed learning & 4 & \\
\hline & Student participation & 8 & 3 \\
\hline & Synthesising \& solving & 1 & \\
\hline \multirow[t]{7}{*}{ Ineffectiveness } & In/Out Group & 2 & \\
\hline & Lecturer-Dominated & & 2 \\
\hline & Micro-managing & 4 & \\
\hline & No Preparation & 3 & 3 \\
\hline & No Theory & 8 & \\
\hline & Not connected & 3 & \\
\hline & Passive & 2 & 2 \\
\hline \multirow[t]{8}{*}{ Teaching Method } & Capturing Ideas & & \\
\hline & Case in Point positive & & \\
\hline & Hybrid positive & 1 & 2 \\
\hline & Length & & \\
\hline & Pre-Digested & & 1 \\
\hline & Small Group Safety & 3 & \\
\hline & Suggestion & 5 & 3 \\
\hline & Video & & \\
\hline
\end{tabular}

On examining the tabled results, again I felt the Approach A data within the effectiveness cluster contained elements of effective teaching. However, there were also a number of incidences of ineffectiveness.

I was surprised by the evenness of the passivity counts and Hybrid case teaching counts. I decided to consider the lecturer Auckland feedback only, as the clarity and purpose of my Nelson data was less than ideal, and may have been skewing my results. The Auckland results were as follows:

TABLE 19: SUMMARY OF CATEGORY AND CODE INCIDENCE COUNTS (ALL AUCKLAND LECTURER SURVEYS BY APPROACH A AND APPROACH B)

\begin{tabular}{|l|l|l|r|}
\hline Category & Code & $\begin{array}{r}\text { Approach A } \\
\text { SurveyMonkey } \\
\text { Auckland Counts }\end{array}$ & $\begin{array}{r}\text { Approach B } \\
\text { SurveyMonkey } \\
\text { Auckland Counts }\end{array}$ \\
\hline Effectiveness & Applying new knowledge & & \\
\hline
\end{tabular}




\begin{tabular}{|c|c|c|c|}
\hline \multirow[t]{10}{*}{ Category } & Code & $\begin{array}{r}\text { Approach A } \\
\text { SurveyMonkey } \\
\text { Auckland Counts }\end{array}$ & $\begin{array}{r}\text { Approach B } \\
\text { SurveyMonkey } \\
\text { Auckland Counts }\end{array}$ \\
\hline & Applying Principles & & \\
\hline & Evaluation skills & & \\
\hline & Group problem-solving & 1 & 1 \\
\hline & Important points & & \\
\hline & Interpersonal skills & 2 & \\
\hline & Leadership emotional insight & 1 & \\
\hline & Self-directed learning & 4 & 2 \\
\hline & Student participation & 8 & \\
\hline & Synthesising \& solving & 1 & \\
\hline \multirow[t]{7}{*}{ Ineffectiveness } & In/Out Group & & \\
\hline & Lecturer-Dominated & & \\
\hline & Micro-managing & 4 & \\
\hline & No Preparation & 3 & 2 \\
\hline & No Theory & 8 & \\
\hline & Not connected & & \\
\hline & Passive & & 1 \\
\hline \multirow[t]{8}{*}{ Teaching Method } & Capturing Ideas & & \\
\hline & Case in Point positive & & \\
\hline & Hybrid positive & & \\
\hline & Length & & \\
\hline & Pre-Digested & & \\
\hline & Small Group Safety & 2 & \\
\hline & Suggestion & 5 & 3 \\
\hline & Video & & \\
\hline
\end{tabular}

This data appears a little more cogent: more in line with what the students themselves reported back, and more what I expected to see. However, taking the ineffectiveness and effectiveness codes together, it is difficult to assume that effective teaching has taken place from this data.

It appears that the lecturers too reflected the reservations which I was initially concerned about with this method: that of lack of drawing on the theory ( 8 to 0 ), the likelihood of students completing their required pre-reading and analyses before the class (3 to 2 ), and needing to build capacity in tackling materials this way (e.g., a student who ran a portion of the class in a micro-managing and dominating way; "XXX got up and he was basically me"; NSA, 99.56).

I have noted the issue of students doing the preparatory work being raised: however, the Lecturers reported that this was an issue regardless of the Approach taken.

\section{All| Data}

My research data of session and focus group recordings, the resulting session and focus group transcriptions and the lecturer surveys were processed as Word documents, which were then 
imported into QDA Miner Lite. I coded all files using both my already developed categories and my emergent codes. I exported the Approach A and Approach B frequency counts and pivot-tabled the results in Excel.

\section{Graphs of All Coded Data}

The summary of coding incidence - ie, all counts of the coding of session, focus group and lecturer survey data - by Approach A and B was reasonably high. All of the ten characteristics outlined by Harper, Lamb \& Buffington (2008) and Bridges \& Hallinger (1997) were evident.

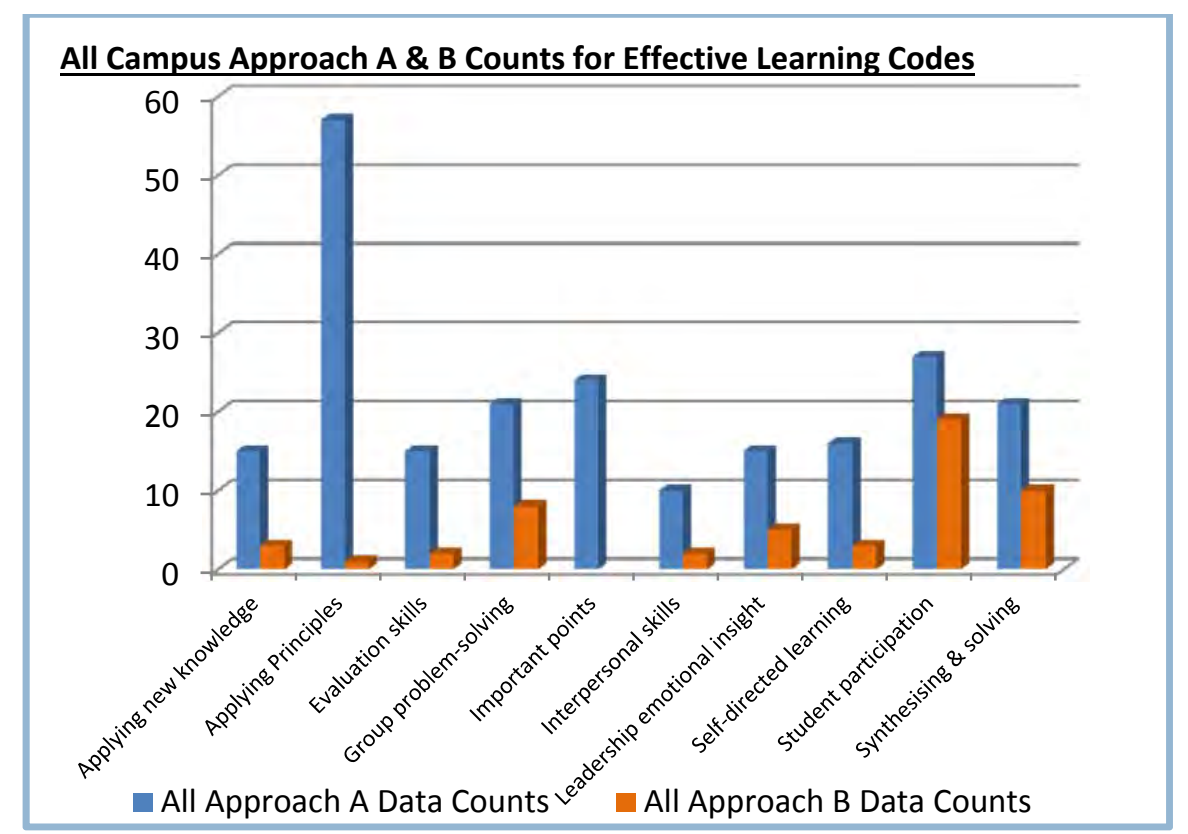

FIGURE 18: EFFECTIVE LEARNING CODE COUNTS (ALL CAMPUSES BY APPROACH A AND APPROACH B)

It was reasonably easy to see evidence of students applying principles in the Approach A sessions due to the length of time that they spoke and the ability that each individual had to develop their ideas. The same factors - the length of time that the students spoke for and the ability to develop their ideas - also made it easier for all participants to see evidence of group problem-solving, important points, student participation and synthesising and solving.

The emergent codes which I categorised as ineffective characteristics were interesting. In and out group issues (i.e., the sense that there was an 'us' and a 'them' in the room) only appeared in Nelson. The lecturer felt that the class was the 'in' group and he was in the 'out'.

The Lecturer dominated Approach A codes were from the Nelson Approach A session; all others were from Approach B. Micro-managing appeared in the Auckland Approach A session in which one student often spoke and was somewhat controlling. The 'no preparation' and 'no theory' only appeared in the Approach A sessions. The lack of connection to the case was almost entirely based around the Tennis New Zealand case; taught as both an Approach A and Approach B. Passivity was evident in the Approach B classes and in the Nelson sessions. 


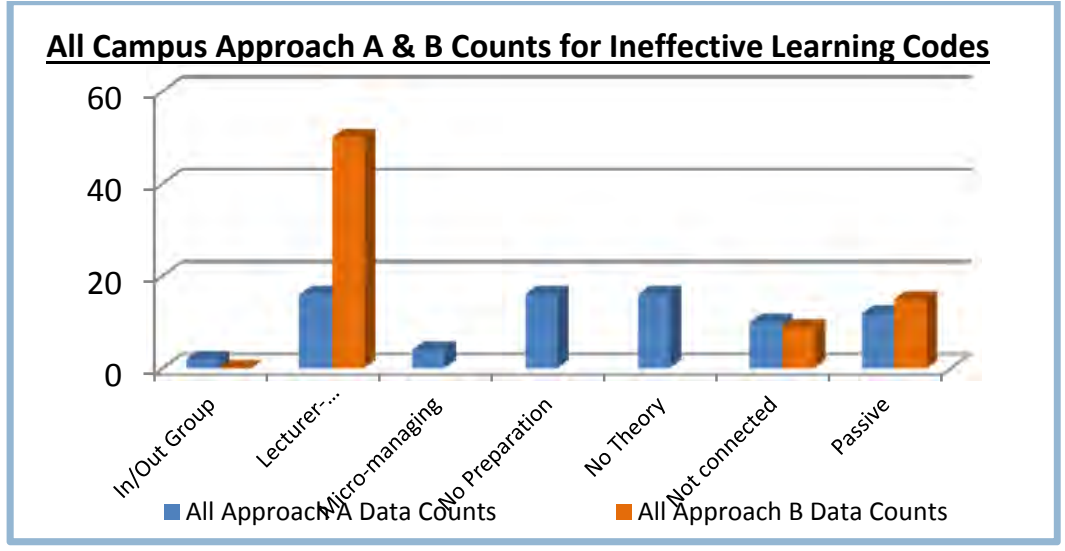

FIGURE 19: INEFFECTIVE LEARNING CODE COUNTS (ALL CAMPUSES BY APPROACH A AND APPROACH B)

\section{Dominance}

The Approach B and the Nelson Approach A sessions, focus groups and lecturer feedback appear to have been too lecturer-dominated. This was based on coding counts over all research data types. The Approach A data counts were more than three times less lecturer-dominated than the Approach B data (16 to 50); and when considering the Auckland Approach A data and 'everyone else' the incidence was 0 to 66 . The incidence of student passivity was roughly the same for both $A$ and $B$ data (12 and 15), but when considering the Auckland Approach A data and 'everyone else' the incidence shifted to 1 to 26 .

\section{The Cases Themselves}

While I found the Tennis New Zealand case fascinating, my students did not: 18 of the 19 comments illustrating lack of connection arose in the sessions, focus groups and lecturer feedback using the Tennis New Zealand case.

These included comments indicating a lack of understanding of tennis as a sport, such as "I don't think people understood what the case study was about" (NSF1, 02.44) to a lack of connection with the entire concept "I didn't even realise they were going through a restructure" (NSF2, 10.46; a tennisplayer), "we didn't know much about it"(NSF2, 09.34). One student related that perhaps New Zealand tennis still has more lessons to learn, as "you've only got to go to their website, there are not a lot of stories" (NSF2, 09.45). A lecturer noted that this "was an administration case, as opposed to a player case" (LSLA, referring to Tennis New Zealand). The difficulty I experienced in writing this case might be an indicator for future case writing projects: if it appears too hard to write, maybe it will be too hard to read.

The Tennis New Zealand case garnered negative feedback, with participants saying the case was "a bit ho-hum"(LSLA, but referring to TNZ), that there wasn't enough controversy or enough commonality to create engagement. Students made suggestions about using a hook through a central character, and giving that character a voice (NNF).

There were a number of very positive comments on the Lance Armstrong case, including comments about memorability. One student said in a focus group that the Lance Armstrong case was "easily the 
most interesting one - and it was like it wasn't a challenge. I didn't have to think back or anything, to answer the questions" (MF, 11.07). Students also enjoyed how the case was structured: "The Lance Armstrong case structure was easier; it was structured better" (NNF)", even though the structure is very similar to the Tennis New Zealand case.

\section{Participant Suggestions}

Students and lecturers suggested improvements (15) related to the sessions, teaching and the cases. These suggestions included improvements for the "Case in Point" sessions:

- One student suggested that outcomes are established before we start: "when we run them, as a class we should decide what we want to get out of the session before we start. So we just don't kind of dwell on the issues" (NSF1, 18.25)

- Someone is needed to record the key points in a session (which incidentally, happens at Harvard): "Maybe we should get up and start writing little bullet points on the board - to keep the flow of what we are talking about" (MA, 64.57)

- Case write-ups help embed the learning: "if you, like, write it up, and discussed and talk about it, [l...] understand that better" (MA, 65.34)

Some suggestions were designed to improve the case writing itself (these relating to the Tennis New Zealand case):

- There needs to be a protagonist: "Wanted more of a sense of connection - perhaps through a central character" (NNF)

- Character's voices need to be heard: "would have liked more conversation in the case" (NNF)

A number of the suggestions were specifically around getting greater clarity in questions. Some students suggested set questions to guide the participants, while lecturers suggested having quite specific questions to draw out theory.

A general comment was made by a lecturer, that they "Love the use of the case studies" (LSLA), and suggested that we establish a process to review good cases and to develop good case analysis processes in our students.

Comments around pre-digesting material, or having a more 'Hybrid'-style process, included:

- "if you went over this PowerPoint present[ation]- like this, lectured it beforehand and then we were able to talk about what you said in the lecture and then talked about it in this sort of situation, I probably would have learned a whole bunch more" (MA, 65.02)

- "you first read it, and like the readings are so big, and so many of them, it's like you can get lost in all the information. If you have a couple of key points to take away from the... like almost as if the readings were summarised" (MA, 65.44)

\section{Student Participation in the Sessions}

Student participation in the research was recorded by the lecturers after the sessions, as follows: 


\begin{tabular}{|c|c|c|c|c|c|c|}
\hline Campus & $\begin{array}{r}\text { Manukau } \\
\text { Approach } \\
\text { A }\end{array}$ & $\begin{array}{r}\text { Manukau } \\
\text { Approach } \\
\text { B }\end{array}$ & $\begin{array}{r}\text { Nelson } \\
\text { Approach } \\
\text { A }\end{array}$ & $\begin{array}{r}\text { Nelson } \\
\text { Approach } \\
\text { B }\end{array}$ & $\begin{array}{r}\text { North } \\
\text { Shore } \\
\text { Approach } \\
\text { A }\end{array}$ & $\begin{array}{r}\text { North } \\
\text { Shore } \\
\text { Approach } \\
\text { B }\end{array}$ \\
\hline Attended & 10 & 10 & 7 & 6 & $\begin{array}{r}18 \text { and } \\
12 \text { or } 13\end{array}$ & 25 \\
\hline Total & 30 & 30 & 12 & 12 & 70 & 70 \\
\hline
\end{tabular}

At the first Nelson class of my research session series, the Approach A content session, the full cohort was present. However, by the first recorded session, the numbers had halved, which was unusual for my class.

Lecturers noted in their survey feedback that numbers were lower than expected. For example, as attendance was "Not compulsory, students don't come" (LSTNZ), that the lecturer "Expected at least 16 - possibly 20" (LSLA, 16-20 is 'normal' for a tutorial) and had 13 in the class, or that the "class has a roll twice this size, but many are engaged in their respective sporting activities" (LSLA).

This was a busy time of the semester, with student's capstone 'Co-op' assignments deadlines looming and the study break just ahead. Students were very willing to sign up to participate in the research, but that did not translate to their involvement on the Approach recording days themselves.

Although I have no data to support my view, I wonder if many students simply determined that, as all the materials would be online, the learning they would take from the sessions was a 'nice to have', not a 'need to have'.

A final factor was that the Auckland students did not have to submit their case analysis (their write-up assignment) before their Approach A recorded session. As a result, they may not have undertaken their write-up before the session, so have been under-prepared. This had the potential to: (1) have affected the attendee numbers at Manukau and North Shore; and (2) have affected the theory being explored in the session due to the lack of exposure to the background materials.

\section{Chapter Summary}

In this chapter I set out to explore the data which I gathered to translate my planned "Case in Point" and 'Hybrid' case delivery method comparison into practice.

However, in my data, I found errors in my methods. One of my cases did not work as expected. Despite my best intentions in preparation, the cases were not seen by the students as being evenly engaging. Students provided me with useful feedback on what they found wrong with the Tennis New Zealand case - all of which is borne out by the literature in Chapter 3. On the other hand, the Lance Armstrong case was timely, engaging, memorable and on-topic.

Another error of method was in not ensuring mutual understanding with the volunteer lecturers who assisted in my research project. In taking opposite approaches to the A sessions, and with one lecturer mixing the $A$ and $B$ sessions, the resulting data was not as clear as it might have otherwise been. However, despite mistakes and misapprehensions, interesting research findings can arise. I 
have gathered some useful information on effective learning, ineffective teaching environments and teaching methods on which to base future teaching decisions, which I will discuss in the next chapter.

In having lived with this project for close on two years, and having reflected on the results of my primary research since last September, some strong impressions have formed.

A major impression of this chapter's work is how very easy it is for lecturers to - despite the best of intentions - dominate and limit the free flow of discussion and discovery. The Approach B sessions and the Nelson Approach A sessions were at times lecturer-dominated, with student word counts being low and length of time that students spoke for was shorter. This domination appeared to then further encourage student passivity, perhaps becoming an oppressive cycle. The Approach B and Nelson sessions showed fewer effective learning characteristics from students.

The counterpoint to this dominance issue was the Auckland Approach A sessions, which were largely student-led. Students spoke for significantly longer in the Auckland Approach A sessions than in any of the Approach B sessions or the Nelson Approach A sessions. The word count averages show that the average Auckland student appeared to take the time to more fully develop their ideas than in the more lecturer-led sessions. Each time the lecturers spoke in the Approach A sessions, they used fewer words, and they shared the leadership role with the students. By weight of the voices being heard in the room, the Auckland Approach A sessions appear on the surface to reflect a powersharing model, and to have taken more of a shared leadership approach.

In general, the Approach A Auckland sessions showed a markedly higher level of student engagement than the Approach $B$ sessions and the Nelson sessions. Evidence of effective learning characteristics was visible in the Auckland Approach A session coding, with eight of the ten effective learning characteristics outlined by Harper, Lamb \& Buffington (2008) and Bridges \& Hallinger (1997) being present. The two characteristics which were not so well displayed in the session data were interpersonal skills and student participation. Some of this similarity was due to excellent student participation shown at the beginning of the Approach B sessions in students sharing their leadership experiences from the first - unrecorded - session.

The Auckland students had much better recall after a month of the Approach A Lance Armstrong case sessions, which is due to in major part to the student-led nature of session and the difference in delivery method, and in minor part to the characteristics of the case. The Nelson students remembered after ten days the Lance Armstrong case, but their recall of it was only slightly better than the Tennis New Zealand one. Their delivery method had been similar in both instances, strongly lecturer-led.

The research findings are complete. In the coming chapter, we discuss how the materials I have gathered thus far will answer my research question: "Do students make sense of leadership cases differently when they are delivered using different methods?" 


\section{LINKING FINDINGS \& LITERATURE REVIEW}

I sought to answer the question: "Do students make sense of leadership cases differently when they are delivered using different methods?" Using a retroductive grounded theory research design, I translated my planned "Case in Point" and 'Hybrid' case delivery method comparison into practice, and analysed those findings in the previous chapter.

In this chapter, all the research undertaken thus far is brought together. I re-examine the beginning of this project. I will compare and reinterpret findings in light of the literature review which I undertook in Chapter 2 on case type, structure and selection, and in Chapter 3 on teaching delivery and effective learning. Like the leadership field, much has been written about cases; my own research list now encompasses almost 700 articles, journal articles, chapters and texts. My literature review has, as a result, been broad. As the threads of my thesis come together, some earlier areas of exploration, while remaining part of the pattern, will take only serve to support the stronger elements in the resulting delineation of leadership case studies.

\section{What Led Me to This Point}

In New Zealand, tertiary educators whom I have spoken with tend to use teaching cases as a tool to teach management subjects, particularly, in my experience, leadership. We tend to deliver this in a somewhat hybridised way which I term the 'Hybrid' approach. The "Case in Point" method of syndicate-based learning is not usually delivered here.

I am interested in active learning, and the more I read, the more I wanted to know why "Case in Point" sessions are run in the way they are, and if this method significantly increases leadership learning effectiveness. So I set out to attempt a comparison between the two methods.

I will commence my discussion with the teaching case.

\section{The Teaching Case Itself}

\section{Teaching Case Definition}

Firstly I wish to establish a definition of teaching cases. In the Chapter 2 literature review on this topic, I began compiling a personal working definition of teaching cases, which is:

Teaching cases are engaging and factual stories which reflect society's changing mores and fit the time they were written in. They support intensive discussion and detailed analysis, contain multi-layered problems seen from multiple perspectives, and are created to guide, teach, anchor theory and illuminate decisions. Created from scholarly, 
triangulated, generalisable, logically-structured research, they help to bridge the gap between theory and practice.

When I began this work I sought a definition of teaching cases. I was unable to find one that encompassed the aspects of research and case typology, detailed key components, provided guidance for use and explained what they were for. I consider that the definition above is a useful defining and starting point.

\section{Teaching Cases with Impact}

When we come to write a case, the overwhelming consensus from the literature is that cases should be factual (Ellet, 2007; Hansen, 1997; Harling \& Misser, 1998; Hativa, 2001; Remenyi, 2012; Wright, 1996; Vega, 2011; Yadav et al, 2007). We must give the protagonists their true voices, and let the reader make their own connotation. Leadership cases must equally be realistic two factors - the real discovery of facts, and opinion formulation involvement - form a "strong precursor to learning" (O'Connell, McCarthy \& Hall, 2004, p. 296, citing Corey, 1980).

Moreover, cases are based on past events. They cannot be 'real' while set in the future or the present (Vega, 2011). However, they can be set in the future as a storytelling mechanism.

Summarising what a case narrative and content requires, Bruner suggests the following six aspects: sequentiality, logic, creating negotiated meaning, where deviations are comprehensible, where there is dramatism (and so: 'trouble') with a good conclusion requiring legitimacy and a satisfactory ending (1990). Of these, 'trouble' is probably the key inclusion. Other critical ingredients (in decreasing importance) were that that the content was 'thought-provoking'; was well-written and told a good story; was generalisable and relevant; and had focus or purpose.

The cases which I used in this research were not seen by the students as being evenly engaging. The Lance Armstrong case apparently had 'trouble' (Bruner, 1990; "The Lance Armstrong case is really controversial"; NNF), legitimacy (Bruner, 1990; "easily the most interesting one - and it was like; it wasn't a challenge. I didn't have to think back or anything, to answer the questions"; MF, 11.07) and a satisfactory ending (Heidegger, as cited by Lewis, 2011, p. 206; "everyone was quite shocked at the lengths he went to, and like the things that weren't so obvious... Yeah, like the things that obviously people already knew, but the end they went into quite a bit of detail all the other things, on the negative side out of it all, and how he treated everyone. Yeah, like how much effort he put into cheating. It was crazy"; MF, 07.39). It contained the requirements of a good story, flowed for the students (i.e., well-written; "The Lance Armstrong case structure was easier; it was structured better" $\mathrm{NF})$.

The Tennis New Zealand case on the other hand did not contain compelling trouble ("The subject of the case was a bit ho-hum too, particularly for sports people. This was an administration case, as opposed to a player case"; LSLA), did not appear to contain legitimacy ("needed to feel more connection to the material and ideas"; NF), nor have vollendung ("to achieve a successful outcome the right case has to be provided, one which is likely to highly engage the students by means of some 
subject knowledge, but also as importantly, some point of view or opinion"; LSLA), nor be well-written ("needed to have more in common with the ideas, needed to be more engaging"; NF) nor a good story ("Wanted more of a sense of connection - perhaps through a central character" and "would have liked more conversation in the case"; NF).

Our students learn more effectively with cases containing the 'voice' of the key protagonists, with personalities, tone and feel consistent with the words and images portrayed in the case (Hansen, 1994; Wright, 1996). Cases with these components have impact.

\section{Teaching Case Structure}

Throughout my research process, I have consolidated a number of ideas on case structure.

\section{Case Format}

There are a number of delivery formats. Two key format elements of good cases is that they use the protagonist's voice where possible (Hansen, 1994; Naumes \& Naumes, 1999; Wright, 1996), and are written in the first person (Leenders, Mauffette-Leenders \& Erskine, 2001; Christensen \& Hansen, 1994).

Additional format aspects include standalone or series cases, exercise cases, first- or third person cases, raw, video or live cases. The Tennis New Zealand case did not contain the protagonists' voices, and was weaker for that. It is a good strategy to augment written cases with video or live subjects wherever possible; it increases the 'stickiness' of student learning (O'Connell et al, 2004). The students made mention of the lack of media richness in the materials available for the Tennis New Zealand case, and there was a specific comment about the engagement created with the Lance Armstrong video ("the video was good", NNF). However, the video in the Lance Armstrong case sessions certainly made an impact, as there were eight mentions of having watched the video clip in the Approach transcripts.

Aside from the lack of video material and protagonists' voices for Tennis New Zealand, there appeared to be no problem in general with the structure of the cases that I used for this project.

\section{Teaching Note}

An effective teaching note is a key part of a teaching case: the note provides much of the higher-level decision-making information necessary for prospective users to be able to evaluate whether a case will suit their needs or not. It should include a synopsis, a scoping statement about the intended audience, teaching objectives; questions \& answers; a suggested teaching plan; and some form of extension materials, which should include video (O'Connell et al, 2004); a bibliography (Curtin, 2010; Doroja, 2004; Manaeva, 2009); and may include an epilogue, extension materials, exhibits, or links.

A teaching note was supplied with the cases taught in this research in order for the lecturers to know what was in my mind, to help them guide the classroom sessions. While it did assist the lecturers to some degree, there are two issues. Firstly, the cases for this research were prepared prior to the finalising of my literature review, so I had not determined the need for a teaching plan to be included 
in the note. Had I included a teaching plan, the session delivery may have been more closely aligned. Secondly, the lecturer's familiarity with the material determines the usefulness of the note in many ways: while Nic John referred extensively to the teaching note in the Approach A case as he is less familiar with the topic; Dr. Kidman did not, as she is already expert.

\section{Structure Summary}

From now on, as well as the components I have discussed thus far, I will also ensure that I am writing teaching cases with impact. This includes my protagonists' voices; which definitely contain plenty of 'trouble'; which are good stories, well told; are timely; and which definitely have video and, whenever possible, live case components. When it comes to the teaching note, the teaching cases which I write will now also include a teaching guide.

To summarise my findings to date on case and teaching note structure, I have compiled an 'industry standard' of inclusions for teaching case construction:

\section{TABLE 20: PROPOSED INDUSTRY STANDARD FOR TEACHING CASE INCLUSIONS}

\begin{tabular}{|c|c|}
\hline The Case & The Teaching Note \\
\hline Structure: introduction, body, conclusion & Synopsis \\
\hline $\begin{array}{l}\text { Length: short (600-950 words) to Medium (2000 } \\
\text { words) }\end{array}$ & Scope (re the audience) \\
\hline Factual, presented without bias or judgement & Teaching objectives \\
\hline $\begin{array}{l}\text { With a carefully chosen image (so the reader can } \\
\text { 'inhabit' the case quickly) }\end{array}$ & Questions \& answers \\
\hline Containing 'trouble' & Suggested teaching guide or plan \\
\hline Containing protagonists' voices & Bibliography \\
\hline Timely & Extension materials if available \\
\hline Video or link to video & \\
\hline Live case components where possible & \\
\hline
\end{tabular}

I know the case type, learner outcomes, and how cases are put together. I now consider the decisions required for finding a teaching case.

\section{Finding a Teaching Case}

When seeking a teaching case, most lecturers will turn to a search engine, to case databases, to colleagues, to texts, or write a case themselves. Where we lack the time to research and write a case, we could apply Griffin's 'raw case' approach (2009) or we could search the databases.

I considered the steps that I take in searching for teaching materials, and put together a decision tree detailing these. In thinking about this, I considered that our starting off place is usually the topic area or theory, details of which are usually contained in the teaching note of cases. Thus we start by searching the topic and find some cases via their teaching note. 
Our next determining factor is likely to be fit with our audience, and/or fit with our teaching purpose. This too is teaching note information. All things being equal, and if we still have a few cases to select amongst, the next criteria will be the consideration of our teaching objectives. At any point, if we get a 'no' to our questions, we can consider whether we could tailor the case to have it better suit our needs.

The next consideration is the suitability of the case questions and answers for our needs. If these work for us, we can then consider the case length. While the overall document length may be listed in a case database, the case length itself is unlikely to be. At this point we will need to sight any cases that meet our needs.

Provided, like Goldilocks, the length is 'just right', we can then, at last, consider whether the case contains the appropriate modicum of trouble, is thought-provoking and is well written (with the implication that it is a good story). As I have found in my research, these 'need to haves' of trouble, provocativeness, and being a good story are key to effective student learning. We can only seek impact at this late stage, because without the other elements being satisfied, the teaching case is of no use to us. This is borne out by the failure of the Tennis New Zealand case, compared to the success of the Lance Armstrong case. Expediency has no place in case selection.

In summary, the key selection decisions that need to be made each time a user seeks a suitable teaching case can be flow charted as follows:

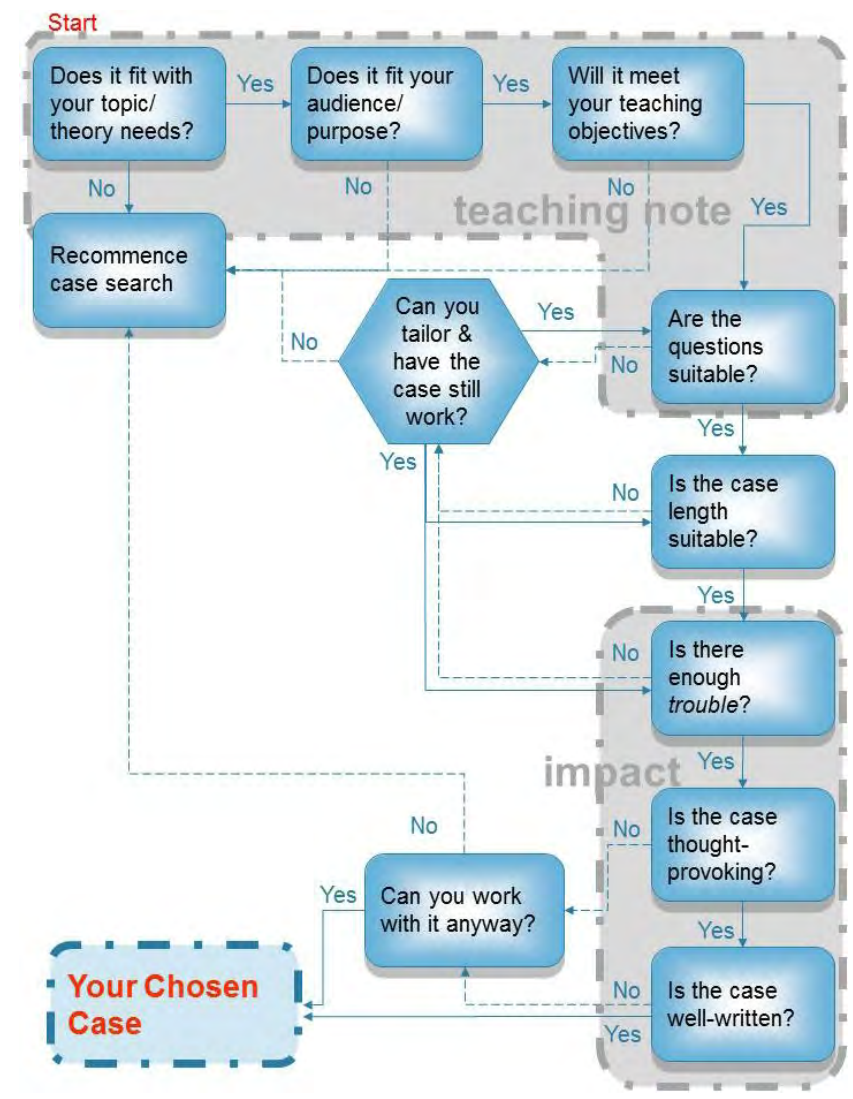


It becomes understandable that the really nice-to-have elements of case content, such having relevance, being generalisable and having a clear focus or purpose may not often be possible. So the lesser advocated items on the list of content requirements - such as good characterisation, empathy, a good story, realism, empathy-provoking, illustrative, absorbing, ending with a 'kicker', being a complete entity and being transformative - are even less likely to be satisfied... unless one writes one's own cases.

This research project has enabled me to clarify my case writing inputs and search. I now turn to determining a method to find the outputs.

\section{The Research}

Trying to establish useful methods was difficult. I was unable to find another researcher who had attempted this comparison previously. It seems that this type of comparison has not been commonly attempted.

Noted Public Policy and case lecturer Professor Laurence Lynn Jr (1999) cites Behn (1993), stating that the case researchers are not able to establish their 'rightness' or even the benefit of the insights provided by cases or the research; but the very asking of the questions is important. I sensed that I too was asking important questions; is the "Case in Point" method more effective for student learning? Should I be teaching this way? And if I should, where was the evidence?

Eventually I determined a research design of retroductive grounded theory (Kempster \& Parry, forthcoming 2014), running two sessions, one Approach A ("Case in Point", using a medium length case) one Approach B ('Hybrid', using a short case).

I was lucky enough to be able to run these sessions at three AUT campuses, on the same topics, using the same materials and teaching case, and using more or less the same teaching plan. I also purpose-built the cases to fit the task creating a medium and a short case from the same case research (see Appendix Six for the cases). I recorded Approach A and Approach B sessions. After each of the sessions was delivered, the lecturers completed a survey on how that session went.

Following that, I then held focus groups with the students and the lecturers to determine what their impressions were and to track how impressions may have changed from the earlier sessions. I recorded the non-Nelson campus focus groups. I transcribed all the session recordings and analysed them using a priori codes and emerging codes using CAQDAS software.

Having revisited how the research was approached, I next consider the results.

\section{Understandings from the Research}

My research method included retroductive grounded theory (Kempster \& Parry, forthcoming 2014, p. 83), meaning that I sought explanations through participant feedback of the causes for leadership learning in my research, and considered the context to determine which methods worked, when \& why. 


\section{The Voices in the Room}

This is a very dominant vein in some of the results; one of control and power.

In the classroom, as lecturers we can be seduced into playing the part of the expert, and our voice can dominate (Sinclair, 2007). My lasting impression of the sessions which I recorded is how easy it is for lecturers to - despite the best of intentions - dominate and limit the free flow of discovery and discussions. I am also deeply grateful to both Dr. Kidman and Nic John for their free-thinking in unwittingly creating a situation where I was able to so clearly see a lecturer-led, student-led spectrum.

As mentioned in my findings, the Approach A Auckland sessions showed a markedly higher level of student engagement when coded using the effectiveness characteristics identified by Harper, Lamb and Buffington (2008), and Bridges and Hallinger (1997), than both the Approach B sessions and the Nelson sessions. In the Approach A Auckland sessions, the students also spoke for a quarter as long again as the lecturers did, averaging at 33 words per response, and speaking for more than $80 \%$ of the session time. The students had the clearest voice in the room.

The Approach B and Nelson sessions appeared to show more passivity and fewer effective learning characteristics, far more lecturer dominance and shorter responses given by students. There was more silence in the Approach B and Nelson sessions, and the lecturers dominated the discussion (taking between 52 and $69 \%$ of total session time). There was less facilitated and shared leadership shown in these sessions.

The students were also more wary of each other (no doubt well modelled by their lecturers and already embedded in class culture). Discussion was centred around case issues, and at no time held any hint of personal attacks. There were some cautionary comments, made by students, including "The discussion started, you know, everybody started getting into it and it got... not heated [laughter] but everybody got quite into putting their views across" (NSF1, 07.12). In listening to the recordings, this 'heat' was not evident, and students sounded, in tone and language, respectful of each other and each other's ideas.

The students in the Auckland sessions also appeared to share power quite well, demonstrating facilitative and shared leadership; particularly in the Approach A sessions. There were a good range of contributors; and aside from the student who prepared material and 'lectured' at the start of one of the North Shore sessions, access to making comment and being heard without interruption appeared even. There were comments in the focus group feedback about the fact that everyone had contributed, including those who do not usually participate.

From my observation and post-research reflection, I consider that what lecturers do by having an overly dominant voice in the room is to inhibit free-flowing discussion, shut down creativity, decrease action-learning and increase passivity. I believe that having a free flow of discovery is a particularly important aspect for learning leadership, as leadership is learned well using an apprenticeshiporiented approach (Kempster, 2006; O'Connell, McCarthy \& Hall, 2004). 
Another consideration is student recall. The Auckland student's ability to put themselves back into the room in the Lance Armstrong case was surprising in the focus group data. With the study break having fallen between the Approach deliveries and the focus group sessions and a month having elapse, their recall of this case discussion was very clear. On balance, I consider this is due to the student-led nature of session and the difference in delivery method. The impactful characteristics of the case itself too have an effect, but are not a key contributor, as the Nelson students did not have this level of recall after a gap of only two weeks.

I next consider theory.

\section{Theoretical Underpinnings}

As part of our real-world rehearsal for leadership learning, we need repeating structures - theories which we can measure and evaluate performance against. Theories aid effective learning.

In the comments made in the Approach A sessions, in the focus groups and in the lecturer surveys, there were many comments about the lack theoretical input; a lack of academic value in the discussion at times; and a lack of specificity of the questions. As Auckland students had not necessarily completed their write-ups or readings, they had not made themselves conversant with the underlying theory; a barrier for both shared and facilitative leadership, but particularly for the latter (requiring 'informed choice'). Had the students completed their preparatory work, they would have been able to discuss the merits of various theories.

At Nelson, despite the students having covered the materials prior to the discussion session, student discussion was lecturer-dominated, resulting in student answers being very brief, often almost monosyllabic, with students not developing their ideas well. Good theory discussion was impeded.

Dr. Ljiljana Eraković from the University of Auckland's Business Faculty, teaches Year Three Strategic Management via the "Case in Point" method. She arranges each week's programme into one tutorial session followed later in the week by one case debrief session. Dr. Eraković related to me that she ensures students are conversant with the materials by using the tutorial as a student workshop and case discovery time, with students working together. At the end of the tutorial, her students sit a test to demonstrate their understanding of the class materials. Her delivery regime provides a vehicle for ensuring theory is covered, and demonstrates a mechanism - the test - for ensuring the work is done.

The teaching portion of our teaching case requires us to put aside dominance and to provide mechanisms for the students to engage with theories prior to the session. I next discuss the findings from the two Approaches.

\section{Approach A versus Approach B}

The two Approaches were less equal than I would have liked.

Due to the Nelson sessions being delivered the wrong way around, the lack of class connection with $\mathrm{Nic}$, and the lecturer-dominated delivery, the data from the Nelson Approach A and B sessions are skewed; limiting its usefulness. 
In addition, there are three areas which have contributed to the Approach A Auckland sessions appearing more impressive than they may actually be. They are: (a) the engaging nature of the Lance Armstrong case set against the 'boring' nature of the Tennis NZ one; (b) the Auckland students' assignment date allowing them to have not fully absorbed the materials before the session; and (d) the students' lack of familiarity with the Manukau lecturer.

Yet in my mind, these caveats do not overly negate the evidence I have gathered. They provide more of a set of cautionary flags. Those flags are:

- Lecturers wanting to deliver cases using the "Case in Point" method need training and mentoring to understand the delivery process and how it should work

- Cases should be written in the first person, speak with the character's voice, and contain 'trouble'. At the very least, relevant video should be supplied with the case

- Assessments must support the teaching process to encourage students to complete analyses and readings before "Case in Point" debrief classes

- Shared or facilitated leadership and power sharing class cultures must be built deliberately from the start of each semester.

Approach A - the "Case in Point" method - appears to provide deeper, richer leadership learning for students... if only students do the work before they come.

\section{The Case in Point Learning Process}

Having a mechanism to ensure that students complete the readings, the theory and some case analysis prior to the case debrief session would bolster the theoretical debrief content. The approach that Dr. Eraković takes in the tutorial session, with students having an assessment at the end, ensures students have familiarity with the material before arriving at the debrief.

Dr. Eraković uses a short quiz for this. However, my teaching philosophy reflects Dr. Kidman's in this respect: "show me where the learning takes place in an exam". To better fit my philosophy, I would instead look to making weekly write-up submission compulsory at the end of the tutorial session, to ensure that reading, theory-familiarisation and analysis are embedded prior to the case debrief.

Also I suspect that the students will need to build their resilience in working this collaborative, active learning shared leadership approach. I suspect they will need practice in working in an interdependent way. Transcript comments supporting this included a student who said "what I was finding hard is when everyone has different ideas and just putting them together. I think what I am finding hard is running everything together" (NSA, 96.10) and, discussing the first Approach A tutorial session, "because of how they socially construct [the Approach A session], they actually didn't take it [a leadership role], because they were going 'what do we need to do, I don't get it. What does she want?'" (NSF, 18.51).

Reducing confusion, providing certainty around how the method works and what the expectations and demand are in a measured way will help students transition to the "Case in Point" method will be important for effective learning. I would be inclined to plan a course in a staged way for learners not 
familiar with this method. For example, initially half the teaching hours could be delivered using the "Case in Point" method. Students would have time to get used to the new method, then, by the end of the first half of the course, the lecturer could migrate to teaching this way for the entire time.

The case teaching requires theories, training and mechanisms to ensure students do their preparation work, and a staged roll out that builds capacity. I now consider whether learning was effective using the "Case in Point" method.

\section{Effective Learning}

A key driver in my research has been to determine what constitutes effective learning. Harper, Lamb and Buffington (2008) found that effective case learning included: (1) applying principles; (2) identifying important points; (3) synthesising and solving; (4) student participation; (5) demonstrating evaluation skills; and (6) gaining interpersonal and management skills. I used these characteristics as codes in my research to seek where effective learning was taking place.

In addition I used the action-oriented effective leadership learning characteristics determined by Bridges and Hallinger (1997). These are: (1) applying new knowledge; (2) self-directed learning; (3) group problem-solving; and (4) leadership emotional insights.

The characteristics outlined by Harper, Lamb and Buffington (2008) and Bridges and Hallinger (1997) formed my ten a priori effective learning codes. Coding incidence was reasonably high in the Approach A versus the Approach B sessions, focus groups and lecturer surveys, on all ten characteristics. It was reasonably easy to see evidence of students applying principles in the Approach A sessions due to the length of time that they spoke and the ability each individual had to develop their ideas. The same factors - the length of time that the students spoke for and the ability to develop their ideas - also made it easier for all participants to see evidence of group problem-solving, important points, student participation and synthesising and solving.

There was less of a differential in student participation between the approaches. Some of this similarity was due to excellent student participation shown at the beginning of the Auckland Approach $B$ sessions in students sharing their leadership experiences from the previous week; reflecting facilitative leadership. However, I suspect that one of the key limiters to effective learning is a lecturerdominated session. Student answers become brief.

The feedback from the students about the Auckland Approach A sessions, both after the sessions themselves and in the focus groups, was very positive. The students had enjoyed themselves. I sensed a feeling of connection and engagement from the tone of the session and focus group recordings. Additionally, in the focus groups, they could still remember what they had discussed in the sessions; I could hear it in the immediate recall they had of the sessions, in how free-flowing their commentary was. Students said "I remember the case like it was almost in front of me now" (MF, 12.16), "it was brilliant, I loved it" (NSF1, 07.09), "that's the most fun I've ever had in your class" (NSF2, 16.50) and "I didn't have to think back or anything, to answer the questions" (MF, 11.07). The learning was 'sticky'. 


\section{Effective Leadership Learning}

There was evidence in the research of students, in the Approach A Auckland sessions, applying leadership principles to the case (57 incidences to 0 ). This was shown in the length of time that students in the Approach A sessions spoke, and how they developed their ideas more fully, than in the B sessions ( 25 words per contribution to 16 ; and $62 \%$ of the time speaking compared to $21 \%$ ). Despite the under-exploration of the theory itself, students also touched on many of the important leadership issues which had been seeded in the cases (20 to 1). They also related these case issues well to their own lives, providing others in the room with good insights and applying ethical and leadership values to many sports situations. They rehearsed potential future workplace leadership roles (Kempster, 2006; O'Connell, McCarthy \& Hall, 2004).

In the Nelson focus group, the students appeared to learn less well, needing prompting to remember both the cases and the leadership issues. In the Auckland focus groups, the students once more became passionate about the issues in the Lance Armstrong case, once more discussing the issues in the case, rather than how the case was delivered (redirect was required to keep them on task).

I consider that this provides evidence supporting that my students did "make sense of leadership cases differently when they [were] delivered using different methods". I found this difference particularly evident in the Auckland Approach A sessions, with the language used, the length of time students spoke for, the development of their answers, the connections that they made. These sessions appeared to me to be modelling a shared leadership model in action-learning.

Unfortunately, as already mentioned, the delivery method was not the only difference in these experiments. There were three main barriers. Firstly, the lecturers did not deliver both of their sessions in a largely similar way. Secondly, the cases used were not evenly engaging. Thirdly, the deadline for the Auckland student case analysis did not align with the timing of the Approach A session. It is likely that students had not completed their write-up before the session, so were underprepared. This is likely to have affected Approach A attendee numbers in Auckland; and to have reduced the amount and quality of the theory being explored in the sessions.

While I consider that the potential for the "Case in Point" delivery method as an effective learning tool, my experiments in this thesis were not resoundingly conclusive. Perhaps 'guardedly positive' is a more accurate conclusion.

Despite my guarded comment, I am personally convinced of the learning effectiveness of the "Case in Point" delivery method for leadership teaching cases.

\section{Chapter Summary}

In this chapter, I set out to compare and reinterpret my findings in light of expert views on case type, structure and selection, and on teaching delivery and effective learning. I have revisited where this research journey started, and what I set out to discover. 
Firstly, I have summarised what a teaching case is. This includes creating a working definition of teaching cases to use as a guide in preparing and using cases, and proposing a teaching case typology. I outlined key elements to provide impact. Our cases need to include the participants' voices, contain 'trouble', be good stories, be timely and have video or live case components. I outlined a possible 'industry standard' for case structure.

Secondly, I have outlined a process for selecting cases, a set of decisions which helps us to find a case that is fit for our purposes. This contains the elements of teaching note and impact characteristics necessary to source new cases.

Thirdly, I considered aspects of case teaching. We have revisited dominance and being student-led, the usefulness of theory in effective teaching, re-examined the limitations of my research process, highlighted the need for case delivery training, realised we need mechanisms to ensure students undertake their preparation, and a staged roll out that builds capacity and have guardedly concluded that the "Case in Point" delivery method as an effective learning tool.

In the next and final chapter, Conclusions, I consider whether or not students make sense of leadership teaching cases differently when they are delivered using different methods, what the limitations of my research was, and where what I have learned may lead in the future. 


\section{Sensing Differently}

The question I set out to answer was "Do students make sense of leadership cases differently when they are delivered using different methods?" With the proviso of my delivery methods and the cases not having been entirely equal, I consider that I have enough evidence to suggest that students do make sense of leadership cases differently, when they are delivered using different methods.

The evidence to support this includes the presence, in the Auckland Approach A sessions, that effective learning was taking place, due to a fairly strong presence of effectiveness characteristics in the data. Used to code the transcripts, those effective learning codes were: applying new knowledge; applying principles; showing evaluation skills; group problem-solving; finding important points; demonstrating interpersonal skills; gaining leadership emotional insight; self-directed learning; student participation; and synthesising \& solving (Harper, Lamb \& Buffington, 2008; Bridges \& Hallinger, 1997).

Further evidence can be found in the quality of the ideas developed and presented by the students: the sense they made of the material and the sessions. Bloom's Taxonomy Levels 3 (Applying), 4 (Analysing) and 5 (Evaluating) were illustrated in the Approach A Auckland sessions, with students applying leadership principles, fully developing their own ideas, taking acts of leadership to speak, facilitating the way for others to speak, taking a leadership role in the room, drawing out of many of the important leadership issues within the cases, relating the case issues to themselves and reflecting, and applying ethical and leadership values to sports situations. They rehearsed potential future workplace leadership roles.

The Auckland focus group data illustrated Bloom's Taxonomy Level 1, 'Remembering' via the ease and vividness of the students' recall of the Lance Armstrong case (MF, NSF1, NSF2). My research methods and my research experience do not provide me with the depth or consistency of material to determine whether this recall is due to the student-led nature of session or the difference in delivery method.

The clarity of the Auckland student recall is, in minor part, due to the impactful nature of the Lance Armstrong case. However, the Nelson focus group data would indicate this is a minor factor, as Nelson students' recall, after only two weeks, is much more even - and far less engaged - with regard to both cases. Nelson's delivery method had been similar in both instances, being strongly lecturer-led.

Collectively, the key differences that I have noted relate to the 'richness of student response'. This richness is made up of a combination of things. This includes length of student responses; the 
development of student ideas during that response time; of being able to more fully expand on their ideas by the lack of lecturer-imposed time constraints; an increased willingness of students to respond; aspects of shared leadership and shared power in the classroom; and the ability to put themselves back in the space to access the results, ideas and outcomes of the discussion.

As a result, Approach A, the "Case in Point" method of teaching, appears to be a more effective delivery method for leadership learning than Approach $B$, the 'Hybrid' method.

I have some reservations. I sense that teaching this way could be difficult and requires the alignment of many factors. Success in applying the "Case in Point" method will depend strongly on the expertise of the lecturers, building the resilience, competence and capacity of the learners, developing the appropriate level of quality in the teaching materials and the will of all participants in the process.

To provide better learning for my students, I realise that I need to change my delivery. Planning and implementing this then, will be my next project.

\section{Limitations}

There were a number of limitations, due in large part to my lack of experience as a researcher.

Despite having prepared a pair of what I thought to be evenly matched cases with which to conduct this research, student engagement proved not to be equal (incurring 18 of 19 comments about lack of engagement in my findings). This will have influenced the clarity of my results to some degree. I have now reinforced the views of experts with my own findings, and will in future construct cases which are written in the first person, speak with the character's voice, and contain 'trouble'. I will also find relevant video for my future cases.

Explaining does not equal understanding. The lecturers who undertook these research sessions so kindly for me did not have the same understanding as I did, of what I was asking for. This has highlighted to me the need for lecturer training in delivering the "Case in Point" method. For example, the lecturers did not call on students to report back on group findings in the Approach A sessions, so it was harder for me to determine whether students had actually worked well in groups during the sessions (although feedback in the focus groups did provide confirmation of this). With this in mind, in any future research endeavours, I would hold some practical training workshops and undertake some teaching observations to ensure all participants understand the delivery process and how it should work in practice. This harks back to Phillips and Olson's findings for effective learning, of using 'effective teachers' as mentors and conducting teaching observations (2013).

It was also difficult for the Manukau and Nelson student groups to have different lecturers for the sessions which they participated in, creating a lack of rapport in the sessions, which will have affected results to a degree. Future research of this type could be better if the class lecturers can lead, and the research is led and analysed by another. If this were not possible, ensuring all lecturers are equally trained and have the same understanding of the delivery method would assist somewhat. 
The difficulty of aligning requirements across campuses provided a further limitation. There were two issues relating to this. Firstly the mis-alignment of the Auckland student case analysis assignment deadline so that it fell after the Approach A session. I am now more aware of providing mechanisms to ensure that students complete their pre-class preparation for "Case in Point" debrief classes. In addition, I will also be more careful to check in future cross-campus research endeavours, that assessment due dates support the teaching process. Secondly, the difference in the cross-campus timing of the focus groups, due to the difference of the Auckland study break and the Nelson one meant a two week difference in the timing of the focus group sessions. This did not impact the findings - in fact, I think this circumstance provided better data - but this was an error in planning. It was by accident, not design.

\section{Future Research}

In my extensive literature review, I was not able to find previous research comparing "Case in Point" and 'Hybrid' style teaching case delivery. My research has errors which other, more experienced researchers may not have made. It would be enlightening to see how other researchers would approach and explore this comparison, and I would welcome other, expert results.

In order to help to govern my own overly dominant voice in the room, I am now, with my students' permission, recording my class sessions and will - once the demands of this work is complete analyse them to determine how much time is given to the students' voice. Using the transcription process skills gained from this research, I will be noting the speaker change times to give me some data on my own dominance. This element of self-reflection using class recordings (Phillips \& Olson, 2013) will enable me to become more aware of my own pattern, and allow me to deliberately create more free-flowing student-led discussion, increase creativity, increase action-learning and decrease passivity. This will assist my own transformation into a "Case in Point" style instructor. This data collection and analysis process may lead to future research projects.

After conferring with my Leadership teaching colleagues at AUT in Auckland and Bay of Plenty Polytechnic, I hope to persuade them of the need for change in our delivery method, based on the results of my research. I aim to transform my teaching delivery in Semester 1 of 2015, and hope that this transformation can become a cross-institutional, collaborative project. This process may well provide further research.

The information I have gathered and compiled on the structure and writing of teaching cases may also lead to future research. It would also be interesting to undertake some research into the stance of journals and publications on their requirement for teaching notes.

Lastly, the cases which I have already written will need to be amended in accord with the further thinking I have done on an 'industry standard' teaching case content and structure. This work may provide additional materials for future publication. 
Abell, Derek (1997). What Makes a Good Case? ECCHO Newsletter Autumn/Fall 1997 (pp. 1-5). Retrieved 23 July 2012 from http://www2.econ.iastate.edu/classes/econ362/hallam/CaseStudies/WhatMakesAGoodCase.pdf

Adler, R., Whiting, R., \& Wynn-Williams, K. (2004). Student-led and teacher-led case presentations: empirical evidence about learning styles in an accounting course. Accounting Education, June 2004, Volume 13, Issue 2 (pp. 213-229)

Allen, Beverly Lundy; Morton, Lois Wright \& Li, Tianyu (2003). Shared Leadership. USA: Iowa State University. Retrieved 19 January 2009 from http://www.soc.iastate.edu/extension/pub/tech/RDI125.pdf

Alliger, G. M., \& Tannenbaum, S. I. (August 1995). A meta-analysis on the relations among training criteria. In M. Teachout (Chair), Meta-analytic investigations of training effectiveness. Symposium conducted at the annual convention of the American Psychological Association, New York, USA.

Alliger, G. M., Tannenbaum, S. I., Bennett, W. Jr., Traver, H., \& Shotland, A. (1997). A metaanalysis of the relations among training criteria. Personnel Psychology, Summer 1997, Volume 50, issue 2 (pp. 341-358).

Amrein-Beardsley, A., \& Haladyna, T. (2012). Validating a theory-based survey to evaluate teaching effectiveness in higher education. Journal on Excellence in College Teaching, Volume 23, issue 1 (pp. 17-42)

Andersson, Kristina; Hussénius, Anita \& Gustafsson, Christina (2009). Gender theory as a tool for analyzing science teaching. Teaching and Teacher Education, February 2009, Volume 25, Issue 2 (pp. 336-343)

Ardalan, Kavous (2006). The philosophical foundation of the lecture-versus-case controversy: Its implications for faculty teaching, research, and service. International Journal of Social Economics, 2006, Volume 33 Issue 3 (pp. 261-281)

Argyris, Chris (1980). Some limitations of the case method: experiences in a management development program. Academy of Management Review, 1980, Volume 5, issue 2 (pp. 291-298)

Armandi, Barry, Oppedisano, Jeannette, \& Sherman, Herbert (2003). Leadership theory and practice: a "case" in point. Management Decision, 2003, Volume 41, Issue 10, (pp. 1076-1088). Retrieved from http://search. proquest.com/docview/212079036?accountid=40261 Arumugam, Dr. M. (2011). Relevance of Case Study Methodology In Management Education. The International Journal, Volume 1, issue 5, Sep 2011 (pp. 226-231). Retrieved 1 June 2012 from 
Atkins, Madeleine \& Brown, Dr. George A (1988). Effective Teaching in Higher Education. UK: Routledge (Methuen \& Co Ltd)

Austin, James E. (1993). Teaching Notes: Communicating the Teacher's Wisdom. USA: Harvard Business School Press, 793105-PDF-ENG (pp. 1-11)

Ballantine, Joan A., Duff, Angus \& Larres, Patricia McCourt (2008). Accounting and business students' approaches to learning: A longitudinal study. Journal of Accounting Education, December 2008, Volume 26, Issue 4 (pp. 188-201)

Barrett, Dr. Helen (2005). Researching Electronic Portfolios and Learner Engagement: The REFLECT Initiative. IRA's Journal of Adolescent and Adult Literacy, March 2007, Volume 60, issue, 6 (pp. 436-449)

Bassey, Michael (2003). Case Study Research in Joanna Swann \& John Pratt (2003) Educational Research in Practice: Making sense of methodology. USA: Continuum International Publishing. (Chapter 8, pp. 111-123)

Bassey, Michael (1999). Case study research in educational settings. UK: Open University Press Bauer, Ronald C. (1955). Cases in College Administration. USA: Bureau of Publications, Teachers College Press

Becker, Bronwyn; Dawson, Patrick; Devine, Karen; Hannum, Carla; Hill, Steve; Leydens, Jon; Matuskevich, Debbie; Traver, Carol; \& Palmquist, Mike (2005). Case Studies. USA: Writing@CSU. Colorado State University Department of English. Retrieved 13 July 2012 from

http://writing.colostate.edu/guides/research/casestudy/index.cfm

Blank, Steven C. (1985). Effectiveness of Role Playing, Case Studies, and Simulation Games in Teaching Agricultural Economics. Western Journal of Agricultural Economics, July 1985, Volume 10 , issue 1 (pp. 55-62)

Blunden, Andy (November 2009). Critical Realism and Reality. Retrieved 17 Sept 2012 from http://home. mira.net/ andy/works/bhaskar.htm

Blunt, Rick (2001). Knowledge Management in the New Economy, Appendix 2: Adult Learning Models (pp. 107-111). USA: iUniverse Inc

Bolman, Lee \& Deal, Terrence E. (2008). Reframing Organizations: Artistry, Choice and Leadership (Fourth Edition). USA: Jossey-Bass

Bonoma, Thomas V. \& Kosnik, Thomas J. (1989). Learning by the Case Method in Marketing. USA: Harvard Business School Publishing Corporation Ltd. Reprint Number 590008-PDF-ENG (pp. 1-10) Booth, Charles; Bowie, Stuart; Jordan, Judith \& Rippin, Ann (2000). The Use of the Case Method in Large and Diverse Undergraduate Business Programmes: Problems and Issues. The International Journal of Management Education, 2000, Volume 1, Issue 1 (pp. 62-75) 
Boud, David, \& Feletti, Grahame (1997). The challenge of problem-based learning (2nd Edition).

UK: Kogan Page

Brookfield, Stephen D. (1991). Developing Critical Thinkers: Challenging Adults to Explore Alternative Ways of Thinking and Acting. USA: Jossey-Bass

Bruner, Jerome Seymour (2006). In Search of Pedagogy Volume I: The Selected Works of Jerome S. Bruner. USA: Routledge

Bruner, Jerome Seymour (1990). Acts of Meaning. USA: Harvard University Press

Bruner, Jerome Seymour (1977). The Process of Education. USA: Harvard University Press

Bruner, Robert F. (2001). How and Why to Begin Teaching with Cases. USA: Darden Business

Publishing, University of Virginia. Retrieved 19 November 2012 from

http://ssrn.com/abstract=162928

Bruner, Robert F. (2000). Designing a case method teaching plan. USA: Darden Business

Publishing, University of Virginia. Retrieved 19 November 2012 from

http://archive.ite.journal.informs.org/oldsite/Vol1No2/Grossman/brunerb/resources_plan.htm

Bruner, Robert F. (1999a). Advice to Writers of New Cases. USA: Darden Business Publishing,

University of Virginia. Retrieved 19 November 2012 from http://ssrn.com/abstract=152153

Bruner, Robert F. (1999b). The Power of Student Teams. USA: Darden Business Publishing,

University of Virginia. Retrieved 19 November 2012 from http://ssrn.com/abstract=191071

Bruner, Robert F. \& Foerster, Stephen R. (2004). Writing a Great Case 101. USA: Darden Business

Publishing, University of Virginia. Retrieved 19 November 2012 from

http://ssrn.com/abstract=495542 or http://dx.doi.org/10.2139/ssrn. 495542

Bryman, Alan (1989). Research Methods and Organization Studies. UK: Unwin Hyman Ltd

Bryman, Alan \& Bell, Emma (2010). Business Research Methods (Second Edition). UK: Oxford University Press

Buchbinder, Sharon B.; Alt, Patricia M.; Eskow, Karen; Forbes, William; Hester, Eva: Struck, Miriam; \& Taylor, Dianne (2005). Creating Learning Prisms with an Interdisciplinary Case Study Workshop. Innovative Higher Education, Summer 2005, Volume 29, issue 4 (pp. 257-274)

Burns, Robert (1855). The Complete Works of Robbie Burns: "Epistle from Esopus to Maria". USA: Phillips, Sampson \& Company

Butcher, John; Corfield, Rohini; \& Rose-Adams, John (2012). Contextualised approaches to widening participation: a comparative case study of two UK universities. Widening Participation and Lifelong Learning, Volume 13, Special Issue, January 2012. Retrieved 21 March 2012 from 
Cameron, Ann-Frances; Trudel, Marie-Claude; Titah, Ryad \& Léger, Pierre-Majorique (2012). The Live Teaching Case: A New IS Method and its Application. Canada: HEC Montréal. Journal of Information Technology Education, 2012, Volume 11. Retrieved 19 August 2013 from http://www.jite.org/documents/Vol11/JITEv11p027-042Cameron1064.pdf

Carlson, John A. \& Schodt, David W. (1995). Beyond the lecture: Case teaching and the learning of economic theory. Journal of Economic Education. Winter 1995, Volume 26 Issue 1 (pp. 17-29)

Carroll, Stephen J. Jr., Paine, Frank T., \& Ivancevich, John J. (1972). The Relative Effectiveness of Training Methods - expert opinion and research. Personnel Psychology, Autumn September 1972, Volume 25, Issue 3 (pp. 495-509)

Caulley, Darrell N. \& Dowdy, Irene (1979). Evaluation case histories as a parallel to legal case histories. Evaluation \& Program Planning, 10 (pp. 359-372). Retrieved 16 July 2012 from http://www.eric.ed.gov/PDFS/ED207989.pdf

Charan, Ram (1976). Classroom Techniques in Teaching by the Case Method. Academy of Management Review. July 1976, Volume 1, Issue 3 (pp. 116-123)

Christensen, C. R. \& Hansen, A. J. (1987). Teaching and the Case Method: Texts, cases, and readings. USA: Harvard Business School Press

Clawson, James G. (1997). Adult Learning Theory. USA: Darden Business Publishing, University of Virginia. UVA-PHA-0047

Collins English Dictionary (1994). Definition of case study (Third Edition). UK: HarperCollins Publishers

Corey, E. Raymond (1996). Writing Cases and Teaching Notes. USA: Harvard Business School Press. Ref 9-399-077

Corey, E. Raymond (1980). Case Method Teaching. USA: Harvard Business School Press. Ref 9581-058

Corelli, Marie (1905). The Spirit of Work in The Daily Mail (Editors) The Queens Christmas Carol: An anthology of poems, stories, essays, drawings and music by British authors, artists and composers. UK: Ballantyne Press

Cox, Dr. Sharon (2009). Teaching \& Learning Guides: Case Studies for Active Learning. UK: Birmingham City University. Retrieved 31 March 2014 from

http://www.heacademy.ac.uk/assets/hlst/documents/resources/ssg cox active learning.pdf

Cresswell, John W. (2009). Research Design: Qualitative, quantitative and mixed methods approaches ( $3^{\text {rd }}$ Edition). India: Sage Publications Ltd

Cresswell, John W. (1994). Research Design: Qualitative and quantitative approaches. USA: Sage Publications Ltd 
Cufaude, Jeffrey (2004). The Art of Facilitative Leadership: Maximizing others' contributions.

Systems Thinker, December 2004-January 2005, Volume 15, issue 10 (pp. 1-5) Retrieved 26 June 2014 from http://asae.cms-plus.com/files/FileDownloads/HandOuts/SmallPrograms/Pre-

\section{Reading\%20December\%20Facilitation.pdf}

Curtin Library \& Information Service (2010). APA Referencing. Victoria, Australia: Curtin University of Technology

Daft, Richard L. \& Pirola-Merlo, Andrew (2009). The Leadership Experience (Asia-Pacific Version 1). Australia: Cengage

De Vaus, David A. (2001). Research Design in Social Design. USA: Sage Publications, Inc Dhanaraj, Professor Charles (2010). Writing a Teaching Note. USA: Kelley School of Business, University of Indiana and Visiting Professor, Indian School of Business: \& Case Centre (formerly $\mathrm{ECCH}$ ). Retrieved 1 November 2012 from

http://www.youtube.com/watch?v= uZNPMXxilnc\&feature=player embedded

Doroja, Gerry S. (2004). Literature Review and Referencing. Malaysia: Xavier University. Retrieved 25 April 2011 from http://courseweb.xu.edu.ph/courses/ics100/materials/ics100-

\section{Literature\%20Review.ppt}

Dorado, Phil (2007). The 60 Second Leader: Everything you need to know about leadership, in 60 second bites. UK: Capstone Publishing Ltd

DuBrin, Andrew J. (2013). Leadership: Research findings, practice and skills. USA: Cengage Learning

Duch, Barbara J.; Groh, Susan E., \& Allen, Deborah E. (2001).Why problem-based learning?. In B. J. Duch, S. E. Groh, \& D. E. Allen (Eds.), The power of problem-based learning: A case study of institutional change in undergraduate education. USA: Stylus Publishing LLC

Dul, Jan \& Hak, Tony (2008). Case Study Methodology in Business Research. UK: Elsevier Ltd Dunne, Richard \& Wragg, Ted (1994). Effective Teaching. UK: Routledge

Easterby-Smith, Mark; Thorpe, Richard; \& Lowe, Andy (1999). Management Research: an introduction. UK: Sage Publications Ltd

Eisenhardt, Kathleen M. (1989). Building Theories From Case Study Research. Academy of Management. The Academy of Management Review, 1989, Volume 14, issue 4 (pp. 532-550). Retrieved 16 June 2011 from ABI/INFORM Global. (Document ID: 141446)

Engbers, Trent A. (2006). Student Leadership Programming Model Revisited. Journal of Leadership Education, Winter 2006, Volume 5, Issue 3 (pp. 1-14)

Ennis, Robert H. (1993). Critical Thinking Assessment. Theory into Practice, 1993, Volume 32, Issue 3 (pp. 179 -186) 
Ertmer, Peggy A., \& Stepich, Donald A. (2002). Initiating and maintaining meaningful case discussions: Maximizing the potential of case-based instruction. Journal on Excellence in College Teaching, Volume 13, issue 2/3 (pp. 5-18)

Farhoomand, Ali (2004). Writing Teaching Cases: A Quick Reference Guide. Communications of the Association for Information Systems, Volume 13, 2004 (pp. 103-107). Retrieved 31 May 2012 from http://www.emeraldinsight.com/products/new/pdf/quick ref.pdf

Fisher, Charles F. (1972). The Use and Effectiveness of the Case Study Method in the Inservice Training of College and University Administrators. USA: American Council on Education (ED078734)

Fisher, Charles F. (1977). The Evaluation and Development of College and University Administrators, Part 2. ERIC/Higher Education Research Currents, June 1977 (ED139363)

Fisher, Charles F. (1977). The Evaluation and Development of College and University Administrators, Part 1. ERIC/Higher Education Research Currents, March 1977 (ED136707) Flyvbjerg, Bent (2011). Case Study in Norman K. Denzin and Yvonna S. Lincoln (eds) The Sage Handbook of Qualitative Research (4th Edition). USA: Sage Publications Inc (Chapter 17, pp. 301316)

Flyvbjerg, Bent (2004). Five misunderstandings about case-study research in Clive Seale, Giampietro Gobo, Jaber F. Gubriuam and David Silverman (Eds) Qualitative Research Practice. UK \& USA: Sage Publications (pp. 420-434)

Flower, Joe (1995). A conversation with Ronald Heifetz: Leadership without Easy Answers. The Healthcare Forum Journal, July-August 1995, Volume 38, issue 4 (pp. 30-36)

Foran, John (2001). The Case Method and the Interactive Classroom. The NEA Higher Education Journal, Thought \& Action, Summer 2001 (pp. 41-50)

Forehand, Mary (2010). Bloom's Taxonomy: From Emerging Perspectives on Learning, Teaching and Technology. USA: University of Georgia. Retrieved 26 November 2012 from

http://www.roe11.k12.il.us/GES\%20Stuff/Day\%204/Process/Blooms/Mary\%20Forehand\%20discuss ion-Bloom\%27s\%20Taxonomy.pdf

Forest, James J. F. (2006). Chapter 18: Teaching and Learning in Higher Education in James J.F. Forest \& Philip G. Altbach (eds) International Handbook of Higher Education. USA: Springer (pp. 347-375)

Forman, Janis \& Rymer, Jone (1999a). The Genre System of the Harvard Case Method. Journal of Business and Technical Communication, October 1999, Volume 13, issue 4 (pp. 373-400)

Forman, Janis, \& Rymer, Jone (1999b). Defining the Genre of the Case Write-Up. Journal of Business Communication, April 1999, Volume 36, issue 2 (pp. 103-133) 
FreeDictionary (2012) Byzantine Empire. Retrieved 17 September 2012 from

http://encyclopedia2.thefreedictionary.com/Byzantine+Empire

French, J. R. P., \& Raven, B. (1959). The bases of social power. In D. Cartwright (Ed.), Studies in Social Power. USA: University of Michigan, Institute for Social Research (pp. 150-167)

Fulmer, Robert M (1997). The evolving paradigm of leadership. Organizational Dynamics, Spring 997, Volume 25, issue 4 (pp. 59-72)

Fulmer, William E. (1992). Using cases in management development programmes. International Journal of Training \& Development, Volume 11, issue 3 (pp. 33-37)

Gardner, Howard E., in collaboration with E Laskin. (1995) Leading Minds: An Anatomy Of Leadership. USA: Reed Business Information, Inc

Garvin, David A. (2003). Making the Case: Professional education for the world of practice. Retrieved 30 May 2014 from http://harvardmagazine.com/2003/09/making-the-case-html

Gilgun, Jane F. (2011). Yes They Are: The Generalizability of Case Studies. Current Issues in Qualitative Research, Volume 2, Number 4, May 2011 (pp. 1-2)

Gill, T. Grandon (2011). Informing with the Case Method: a guide to research, writing \& facilitation. USA: Informing Science Press

Gill, T. Grandon (2010). Informing Business: Research and Education on a Rugged Landscape. USA: Informing Science Press

Golich, Vicki L., Boyer, Mark, Franko, Patrice \& Lamy, Steve (2000). The ABCs of Case Teaching. Pew Case Studies in International Affairs, Georgetown University. Retrieved 23 July 2012 from http://www.cl.cam.ac.uk/ dq209/others/case-method-teaching.pdf

Gorman, Michael E.; Mehalik, Matt M., \& Werhane, Patricia H. (2000). Ethical and Environmental Challenges to Engineering. USA: Prentice Hall

Graham, Andrew (2009). Writing Cases for Public Administration Teaching and the Transfer of Knowledge about Public Administration Practice. Canada: Institute of Public Administration of Canada (IPAC) Case Study Hub. Retrieved 19 August 2013 from

http://ipac.ca/documents/Writing Cases for Public Administration T.pdf

Green, Melanie C. (2004). Storytelling in Teaching. Observer. The Association for Psychological Science, April 2004, Volume 17, Number 4 (pp. 1-7)

Greenstein, Marilyn Magee \& Hall, James A. (1996). Using student-generated cases to teach accounting information systems. Journal of Accounting Education, Winter 1996, Volume 14, Issue 4 (pp. 493-514) 
Griffin, Meghan (2009). The Narrative Case Study Meets Hypertext: Case Studies in the Digital Age. MERLOT Journal of Online Learning and Teaching, Volume 5, issue 4, December 2009 (pp. 703-708). Retrieved 24 July 2012 from

Grünbaum, Niels N. (2007). Identification of ambiguity in the case study research typology: what is a unit of analysis? Qualitative Market Research: An International Journal, 2007, Volume 10, Issue 1 (pp. 78-97)

Gudmundsdottir, Sigrun (1991). The narrative nature of pedagogical content knowledge. Paper presented at the Annual Meeting of the American Educational Research Association, Chicago, Illinois, USA, 3-7 April 1991 (pp. 1-10)

Hamschmidt, Jost (Ed.) (2007). Case Studies in Sustainability, Management and Strategy: The oikos collection. Sheffield, UK: Greenleaf Publishing

Hansen, Abby J. (1997). Writing Cases for Teaching: Observations of a Practitioner. The Phi Delta Kappan, March 1997, Volume 78, issue 5 (pp. 398-403)

Harling, Kenneth \& Misser, Emmy (1998). Case writing: An art and A science. International Food and Agribusiness Management Review, 1998, Volume 1, issue 1 (pp. 119-138)

Harper, Jeffrey, Lamb, Steven W., \& Buffington, James R.I. (2008). Effective Use of Case Studies in the MIS Capstone Course through Semi-Formal Collaborative Teaching. Journal of Information Systems Education, 2008, Volume 19, Issue 4 (pp. 411-418)

Hativa, Nira (2001). Teaching For Effective Learning in Higher Education. The Netherlands: Springer Netherlands

Heath, John (2006). Teaching and writing case studies: a practical guide. UK: European Case Clearing House (now the Case Centre)

Heifetz, Ronald A.; Grashow, Alexander \& Linksy, Marty (2009). The Practice of Adaptive Leadership: Tools and Tactics for Changing Your Organization and the World. USA: Harvard Business School Publishing Corporation Ltd

Heifetz, Ronald A. (1994). Leadership without Easy Answers. USA: Harvard University Press. Hegan, Krista (2011). Reflection on Learning through Case Writing. NZ: Otago Management Graduate Review, Volume 9, 2011 (pp. 37-43)

Herreid, Clyde Freeman (2005). Using Case Studies to Teach Science. USA: ActionBioScience. Retrieved 8 May 2012 from http://www.actionbioscience.org/education/herreid.html

Herreid, Clyde Freeman (1998). Sorting Potatoes for Miss Bonner: Bringing Order to Case-Study Methodology through a Classification Scheme. USA: National Science Teachers Association (Reprinted with permission from Journal of College Science Teaching, Vol. 27, No. 4, February 1998). 
Herreid, Clyde Freeman (1994). Case studies in science - A novel method of science education. Journal of College Science Teaching, Volume 23, issue 4 (pp. 221-229)

Hesse-Biber, Sharlene Nagy \& Leavy, Patricia (2011). The Practice of Qualitative Research (Second Edition). USA: SAGE Publications, Inc

Hitchner, Stephen Jr. (1977). Preparation of Teaching Notes. USA: Harvard Business School Press \& Kennedy School of Government Case Program. Ref N14-77-189.0

Hutchings, Pat (1993). Windows on Practice: Cases about Teaching and Learning quick view. Change, Nov-Dec 1993, Volume 25, issue 6 (pp. 14-21)

Hycner, Richard H. (1985). Some guidelines for the phenomenological analysis of interview data. Human Studies, 1985, Volume 8, issue 3 (pp 279-303)

lowa State University (2010). Making the Case for the Live Case Study. School of Business Prospectus, Spring 2010, Volume 26, Issue 1 (pp. 18-22). Retrieved 19 August 2013 from http://www. business.lastate.edu/files/main/Prospectus/2010/spring/making the case.pdf

Jackson, Brad \& Parry, Ken (2008). A very short, fairly interesting and reasonably cheap book about studying leadership. London: Sage

Johnson, Glenn, Ross (1990). First Steps to Excellence in College Teaching (2nd Edition). USA: Magna Publications. Chapter 7 (pp. 43-47)

Kempster, Steve \& Parry, Ken (2014). Chapter 5: Critical Realism and Grounded Theory in Joe O'Mahoney and Steve Vincent (Eds) Studying Organizations Using Critical Realism: A Practical Guide. UK: Oxford University Press

Kenney, Sally J. (2001). Using the master's tools to dismantle the master's house: can we harness the virtues of case teaching? Journal of Policy Analysis and Management, volume 20, issue 2, 2001 (pp. 346-350)

Kimmel, Paul A. (1995). Framework for incorporating critical thinking into accounting education. Journal of Accounting Education, Summer 1995, Volume 13, issue 3 (pp. 299-318)

Kirkpatrick, Donald L \& Kirkpatrick, James D (2006). Evaluating Training Programs: The Four Levels (Third Edition). USA: Berrett-Koehler Publishers, Inc.

Kinchin, Ian M. (2013). Visualising knowledge structures to highlight the articulation between theory and method in higher education research. International Perspectives on Higher Education Research, 2013, Volume 9 (pp. 199-218).

Kleinfeld, Judith (1988). Learning To Think Like a Teacher: The Study of Cases. USA: Alaska University Center for Cross-Cultural Studies. Retrieved 31 May 2012 from http://eric.ed.gov/PDFS/ED308039.pdf 
Knowles, Malcolm S.; Holton, Elwood F. III \& Swanson, Richard A. (2005). The Adult Learner (Sixth Edition). USA: Elsevier.

Knowles, Malcolm S. (1980). The Modern Practice of Adult Education: From pedagogy to andragogy. USA: Prentice Hall

Knowles, Malcolm S. (1977). Adult Learning Processes: Pedagogy and Andragogy. Religious Education, 1977, Volume 72, issue 2 (pp. 202-211)

Kolb, David A. (1984). Experiential Learning: Experience as the source of learning and development. USA: Prentice Hall, Inc

Krain, Matthew (2010). The Effects of Different Types of Case Learning on Student Engagement. International Studies Perspectives, 2010, Volume 11, issue 3 (pp. 290-307)

Krauss, Steven Eric (2005). Research Paradigms and Meaning Making: A Primer. The Qualitative Report, December 2005, Volume 10, issue 4 (pp. 758-770)

Kreber, Carolin (2001). Learning Experientially through Case Studies? A Conceptual Analysis. Teaching in Higher Education, 2001, Volume 6, Issue 2 (pp. 217-228)

Krom, Cynthia L. \& Williams, Satina V. (2011). Tell me a story: Using creative writing in introductory accounting courses to enhance and assess student learning. Journal of Accounting Education, December 2011, Volume 29, Issue 4 (pp. 234-249)

Kuntz, Susa \& Hessler, Arthur (1998). Bridging the Gap between Theory and Practice: Fostering Active Learning through the Case Method. Paper presented at the Annual Meeting of the Association of American Colleges and Universities (AAC\&U) 84th Annual Meeting, Washington, DC USA, 15-17 January 1998 (ERIC ID ED420626)

Kvale, Stienar (2007). Doing Interviews (The Sage Qualitative Research Kit). USA: Sage Publications Ltd.

Lapierre, Laurent \& Cardinal, Jacqueline (2003). Guidelines for Writing Teaching Notes. Canada: Centre for Case Studies, HEC Montréal. Retrieved 31 October 2012 from

http://www2.hec.ca/en/casecentre/case/quide redaction np a.pdf

Layne, Leslie (2012). Defining Effective Teaching. Journal on Excellence in College Teaching, Volume 23, issue 1 (pp. 43-68)

Lee, Moses (2010). Note on How to Write a Teaching Note. USA: William Davidson Institute at the Ross School of Business, University of Michigan. Reference Number 1-429-016. Retrieved 31 October 2012 from http://64.9.214.97/docfiles/pdf/cases/preview/howtoteachnote.pdf

Leenders, Michiel R.; Mauffette-Leenders, Louise A. \& Erskine, James A. (2001). Writing Cases (Fourth Edition). USA: The University of Western Ontario 
Leenders, Michiel R. \& Erskine, James A. (1989). Case Research: The Case Writing Process (3rd Edition). USA: The University of Western Ontario

Liang, Neng \& Wang, Jiaqian (2004). Implicit Mental Models in Teaching Cases: An Empirical Study of Popular MBA Cases in the United States and China. Academy of Management Learning \& Education, 2004, Volume 3, issue 4 (pp. 397-413)

Lundberg, Craig C.; Rainsford, Peter; Shay, Jeff P. \& Young, Cheri A. (2001). Case Writing Reconsidered. Journal of Management Education, August 2001, Volume 25, issue 4 (pp. 450-463) Lundberg, Craig C. \& Winn, Joan (2005). The Great Case-Teaching-Notes Debate. Journal of Management Education, April 2005, Volume 29, issue 2 (pp. 268-283)

Lundeberg, Mary A. \& Yadav, Aman (2006a). Assessment of Case Study Teaching: Where Do We Go from Here? Part I. Journal of College Science Teaching, March-April 2006, Volume 35, issue 5 (pp. 10-13)

Lundeberg, Mary A. \& Yadav, Aman (2006b). Assessment of Case Study Teaching: Where Do We Go from Here? Part II. Journal of College Science Teaching, May-June 2006, Volume 35, issue 6 (pp. 8-13)

Lundeberg, Mary A., Levin, Barbara B. \& Harrington, Helen L. (1999). Who learns what from cases and how: The research base for teaching and learning with cases. USA: Lawrence Erlbaum Associates

Lynn, Laurence E. Jr (1999). Teaching and learning with cases: A guidebook. USA: Chatham House

Lyons, Paul (2004). Management Skill Development and Case-Based Modelling. Academy of Management Proceedings; 2004 (p. A1-A6)

Magner, Colleen (2008). Contextual leadership development: a South African perspective.

European Business Review, 2008, Volume 20, Issue 2 (pp. 128-141)

Manaeva, Lena (2009). Citing Sources: Author-Date Style of Referencing. USA: Graduate School of Management, St. Petersburg State University. Retrieved 25 April 2011 from

http://www.gsom.spbu.ru/files/en/upload/library/citing.pdf

Mari, Carlo (2010). Teaching and the Case Method: Text, Cases, and Readings (Review). Academy of Management Learning \& Education, Dec 2010, Volume 9, Issue 4 (pp. 729-732)

Marcketti, Sara B.; Arendt, Susan W. \& Shelley, Mack C. II (2011). Leadership in action: student leadership development in an event management course. Leadership \& Organization Development Journal, 2011, Volume 32 Issue 2 (pp. 170-189)

Mason, Mark (2008). Critical Thinking and Learning. USA: Blackwell Publishing 
Mauffette-Leenders, Louise A, Leenders, Michiel R, \& Erskine, James A. (2001). Learning with Cases (4th Edition). Canada: Richard Ivey School of Business, University of Western Ontario Mayo, Elton (1945). The Social Problems of an Industrial Civilization. USA: Division of Research, Harvard Business School Press

McBride, Allan B. (1996). Creating a Critical Thinking Learning Environment: Teaching Statistics to Social Science Undergraduates. Political Science and Politics, September 1996, Volume 29, issue 3 (pp. 517-521).

McDade, Sharon A. (1995). Case study pedagogy to advance critical thinking. Teaching of Psychology. Feb 1995, Volume 22, issue 1 (pp. 9-10)

McKeachie, W. J. (1994). Teaching tips: A guidebook for the beginning college teacher ( $9^{\text {th }}$ edition). USA: D. C. Heath \& Company

McNair, Malcolm P. (Ed) (1954). The Case Method at the Harvard Business School. USA: Harvard Business School Press

McNamara, David (2002). Classroom Pedagogy and Primary Practice (Second Edition). UK: Routledge

McQueen, Robert J. (1995). Case Method Teaching in Strategic Management: Using and Creating New Zealand Case Resources. NZ: University of Waikato. Proceedings of the 3rd Annual New Zealand Strategic Management Educators Conference (pp. 185-191)

Mejía, Dr. Andrés (2009). On why there is generalisation in research on single cases. Presented at the annual conference of the Philosophy of Education Society of Great Britain (PESGB), Oxford, April 2009. Retrieved 21 March 2012 from

http://wwwprof.uniandes.edu.co/ imejia/PDF/generalisation in research on single cases.pdf

Merriam, Sharan B. (1998). Qualitative Research and Case Study Applications in Education. USA: Jossey-Bass Inc

Merriam, Sharan B. (1988). Case Study Research in Education: A qualitative approach. USA: Jossey-Bass Inc

Merriam, Sharan B.; Caffarella, Rosemary S. \& Baumgartner, Lisa M. (2007). Learning in Adulthood: A Comprehensive Guide. USA: John Wiley \& Sons, Inc (pp. 421-438). Chapter 16: Reflections on Learning in Adulthood Merseth. Katherine K. (1996). Cases and Case Methods in teacher education. In John P. Sikula (Ed) Handbook of Research on Teacher Education (2nd edition). USA: MacMillan Reference Books (Chapter 31, pp. 722-744)

Millott, Dawn (2003). Writing Case Studies: A Manual. USA: Saskatoon Public Schools, Abridged from International Records Management Trust. Retrieved 31 May 2012 from

http://olc.spsd.sk.ca/de/pd/instr/strats/casestd/casestds.pdf 
Mintzes, Joel, \& Quinn, Heather J. (2007). Knowledge restructuring in biology: Testing a punctuated model of conceptual change. International Journal of Science and Mathematics Education, June 2007, Volume 5, issue 2 (pp. 281-306)

Moore, Thomas L. (2004). Facilitative Leadership: One Approach to Empowering Staff and Other Stakeholders. Library Trends, Summer 2004, Volume 53, issue 1 (pp. 230-237)

Morgan, Gareth (1997). Images of Organization (2nd edition). USA: Sage

Morra, Linda G. \& Friedlander, Amy C. (2009). Case Study Evaluations. World Bank Operations Evaluations Department. Retrieved 16 July 2012 from

http://www.asocam.org/biblioteca/MVI 318.pdf

Moxley, Russell S. (2000). Leadership and Spirit. USA: Jossey-Bass.

NationMaster (n.d.a). Definition of Expository Writing. Retrieved 24 November 2012 from http://www.statemaster.com/encyclopedia/Expository-writing

NationMaster (n.d.b). Definition of Narrative. Retrieved 24 November 2012 from

http://www. statemaster.com/encyclopedia/Narrative

Naumes, William \& Naumes, Margaret J. (1999). The Art \& Craft of Case Writing. USA: Sage Publications Ltd

Ó Cinnéide, Barra (2006). Developing and testing student oriented case studies: The production process and classroom/examination experiences with "entertaining" topics. Journal of European Industrial Training, 2006, Volume 30 Issue 5 (pp. 349-364)

Ó Cinnéide, Barra (1998). Proposed Enhancement of the Contribution of the Teaching Note to the Case Writing Process. Journal of European Industrial Training, 1998, Volume 22, issue 1 (pp. 2832)

Ó Cinnéide, Barra (1997). The role and effectiveness of case studies: student performance in case study vs "theory" examinations. Journal of European Industrial Training, 1997, Volume 21 Issue 1 (pp. 3-13)

O'Connell, David J.; McCarthy, John F. \& Hall, Douglas T. (2004). Print, Video, or the Ceo: The Impact of Media in Teaching Leadership with the Case Method. Journal of Management Education, June 2004, Volume 28, Issue 4 (pp. 294-318)

OED (2014a). Oxford Dictionary Definition: curiosity. UK: Oxford Dictionaries. Retrieved 31 March 2014 from http://www.oxforddictionaries.com/definition/english/curiosity

OED (2014b). Oxford Dictionary Definition: theory. UK: Oxford Dictionaries. Retrieved 31 March 2014 from http://www. oxforddictionaries.com/definition/english/theory

OED (2009). Oxford Dictionary of English (Second Edition, E-book 2010): Definition of Rich. UK: Oxford University Press 
OED (2008). Concise Oxford English Dictionary Definition: obiter dicta. UK: Oxford University Press. Retrieved 16 July 2012 from http://www.wordreference.com/definition/obiter\%20dictum O'Shannassy, Tim, Kemp, Sharon, \& Booth, Chris (2010). Case studies in MBA strategic management curriculum development from Australian universities. Journal of Management and Organization, 2010, Volume 16 Issue 3 (pp. 467-480)

Papatheodorou, Theodora \& Moyles, Janet (2009). Learning Together in the Early Years: Exploring Relational Pedagogy. UK: Routledge

Parks, Sharon Daloz (2005). Toward a More Adequate Myth: The Art of Leadership. USA: Harvard Business School Publishing Corporation Ltd

Parrado, Salvador (2008). Some Notes on Case Study Methodology for Action COST project. Belgium: UNED. Retrieved 5 October 2012 from http://soc.kuleuven.be/io/cost/act/20080905 FinalSP Case Study for COST final.doc

Pearce, Craig L., \& Conger, Jay A. (2003). All those years ago: The historical underpinnings of shared leadership. In C. L. Pearce, \& J. A. Conger (Eds.), Shared leadership: Reframing the hows and whys of leadership. USA: Sage (pp. 1-18)

Phillips, Vicki \& Olson, Lynn (2013). Ensuring effective instruction: how do I improve teaching using multiple measures? USA: ASCD \& the Bill and Melinda Gates Foundation

Polito, Tony; Berry, Rik \& Watson, Kevin (2001). Historical Origins of Leadership Content within Business School Curriculum. USA: Unpublished Monograph. Retrieved 30 October 2012 from http://www.tonypolito.com/wri mba.doc

Polyanyi, Michael (1966). The Tacit Dimension. USA: Doubleday \& Company Inc Ponterotto, Joseph G. (2005). Qualitative Research in Counseling Psychology: A Primer on Research Paradigms and Philosophy of Science. Journal of Counseling Psychology, 2005, Volume 52, issue 2 (pp. 126-136)

Prat, Nicholas (2012). Teaching Information Systems With Cases: An exploratory study. The Journal of Computer Information Systems, Spring 2012, Volume 52, issue 3 (pp. 71-81).

Precht, Richard David (2011). Who Am I? And if So, How Many? A Journey Through Your Mind (English edition translated by Frisch, Shelley from the 2007 first edition). UK: Constable Rangan, V Kasturi (1995). Choreographing a Case Class. USA: Harvard Business School Press. Ref 9-595-074

Rasco, J. Félix Angulo (2008). Case Method Framework: The Case Method as a Method to Educate Teachers. European Commission: CaMOT (Case Method of Technology for Practical Use of Training Teachers) \& the Directorate General for Education \& Culture. Retrieved 19 November 2012 from http://grupolace.uca.es/camot/files/CaseMethodFramework.pdf 
Remenyi, Dan (2012). Case Study Research: A quick guide. UK: Academic Publications International

Robbins, Stephen P. (1991). Management (3rd Edition). USA: Prentice Hall

Roberts, Kenneth E. (2007). New technology plays a vital role in the growth of the case method in Europe. The CASE Journal: ECCHO, Issue 37 (pp. 25-26). Retrieved 3 September 2012 from

\section{http://www.ecch.com/files/downloads/ECCHO/ECCHO37.pdf}

Roberts, Kenneth E. (2006a). Case development in the 1960s. The CASE Journal: ECCHO, Issue 35 (pp. 25-26). Retrieved 3 September 2012 from

\section{http://www.ecch.com/files/downloads/ECCHO/ECCHO35.pdf}

Roberts, Kenneth E. (2006b). 1970s: The case method strengthens in Europe. The CASE Journal: ECCHO, Issue 36 (pp. 25-26). Retrieved 3 September 2012 from

\section{http://www.ecch.com/files/downloads/ECCHO/ECCHO36.pdf}

Roberts, Kenneth E. (2005a). Case development in Europe - An historical perspective, part 3. The CASE Journal: ECCHO, Issue 33 (pp. 6-7). Retrieved 3 September 2012 from

\section{http://www.ecch.com/files/downloads/ECCHO/ECCHO33.pdf}

Roberts, Kenneth E. (2005b). Case development 1945-1960. The CASE Journal: ECCHO, Issue 34 (pp. 25-26). Retrieved 3 September 2012 from

\section{http://www.ecch.com/files/downloads/ECCHO/ECCHO34.pdf}

Roberts, Kenneth E. (2004). Case development in Europe - An historical perspective, part 2. The CASE Journal: ECCHO, Issue 32 (pp. 6-8). Retrieved 3 September 2012 from

\section{http://www.ecch.com/files/downloads/ECCHO/ECCHO32.pdf}

Roberts, Kenneth E. (2003). Case development in Europe - An historical perspective, part 1. The CASE Journal: ECCHO, Issue 31 (pp. 6-8). Retrieved 3 September 2012 from

\section{http://www.ecch.com/files/downloads/ECCHO/ECCHO31.pdf}

Roberts, Kenneth E. (1997). An Introduction to Case Teaching. ECCH: The Case for Learning Paper Series. Ref 397-029-6

Rotch, William, Opitz, Casey, Newton, Dan, Frey, Sherwood, Sihler, Bill, Vandell, Bob, \& Bruner, Bobbie (1989). Case Writing. USA: Darden Business Publishing, University of Virginia. Ref UVA-G0364

Saldaña, Johnny (2009). The Coding Manual for Qualitative Researchers. USA: Sage Savage, Jonathan (2005). Sound2Picture: developing compositional pedagogies from the sound designer's world. Music Education Research, Vol. 7, No. 3, November 2005 (pp. 331-348). Retrieved 21 March 2012 from http://isavage.org.uk/wp-content/uploads/2011/03/s2p DRAFT.pdf 
Seawright, Jason \& Gerring, John (2008). Case Selection Techniques in Case Study Research: A Menu of Qualitative and Quantitative Options. Political Research Quarterly, 2008, Volume 61, Issue 2 (pp. 294-308)

Schank, Roger C. \& Abelson, Robert. P. (1995). Knowledge and memory: The real story. In R. S. Wyer, Jr. (Ed.), Advances in Social Cognition. USA: Lawrence Erlbaum Associates (pp. 1-85)

Schwarz, Roger (2002). The Skilled Facilitator: A comprehensive resource for consultants, facilitators, managers, trainers and coaches (revised edition). USA: Jossey-Bass

Shapiro, Benson P. (2009). Hints for Case Teaching. USA: Harvard Business School Publishing Corporation Ltd. Reference 9-585-012

Shugan, Steven M. (2006). Editorial: Save Research: Abandon the Case Method of Teaching. Marketing Science, 2006, Volume 25, issue 2 (pp. 109-115)

Sockalingam, Nachamma \& Schmidt, Henk G. (2011). Characteristics of Problems for ProblemBased Learning: The Students' Perspective. Interdisciplinary Journal of Problem-based Learning, Spring 2011, Volume 5, issue 1, Article 3 (pp. 6-33)

Somekh, Bridget \& Zeichner, Ken (2008). Action research for educational reform: remodelling action research theories and practices in local contexts. Educational Action Research, Vol. 17, No. 1, March 2009 (pp. 5-21)

Stanger-Hall, Kathrin F. (2012). Multiple-Choice Exams: An Obstacle for Higher-Level Thinking in Introductory Science Classes. CBE-Life Sciences Education, Fall 2012, Volume 11, issue 3 (pp. 294-306). Retrieved 21 November 2012 from http://www. lifescied. org/content/11/3/294. full

Stedman, Nicole L. P.; Rutherford, Tracy A. \& Roberts, T. Grady (2006). Does Providing Feedback to Student Reflections Impact the Development of Their Leadership Competence? Journal of Leadership Education, Winter 2006, Volume 5, Issue 3 (pp. 177-189)

Strach, Pavel \& Everett, André M. (2008). Transforming research case studies into teaching cases. Qualitative Research in Organizations and Management, 2008, Volume 3, issue 3 (pp. 199-214). Retrieved June 16, 2011, from ABI/INFORM Global. (Document ID: 1596450031).

Stake, Robert E. (1995). The Art of Case Study Research. USA: Sage Publications Ltd Stanford Encyclopedia of Philosophy (2007). John Stuart Mill. Retrieved 3 September 2012 from http://plato.stanford.edu/entries/mill//

Stenhouse, Lawrence A. (1978). Case Study and Case Records: Towards a contemporary history of education. British Educational Research Journal, Volume 4, Issue 2 (pp. 21-39)

Strange, Jill M. \& Mumford, Michael D. (2005). The origins of vision: Effects of reflection, models, and analysis. Leadership Quarterly, February 2005, Volume 16, issue 1 (pp. 121-148) 
Swiercz, Paul Michael, PhD. (2000). SWIF Learning: A Guide to Student Written- Instructor Facilitated Case Writing. USA: The George Washington University. Retrieved 23 July 2012 from http://www.wacra.org/Student\%20Case\%20Writing\%20Guide\%20-\%20SWIF\%20Manual.pdf

Swiercz, Paul Michael \& Ross, Kathleen T. (2003). Rational, Human, Political, and Symbolic Text in Harvard Business School Cases: A Study of Structure and Content. Journal of Management Education, August 2003, Volume 27, issue 4 (pp. 407-430).

Swift, Graeme (1983). Waterland. UK: William Heinemann

Ross, Kathleen T. (1998). Rational, Human, Political, and Symbolic Text in Harvard Business School Cases: A Study of Structure and Content. USA: George Washington University, unpublished Doctoral Thesis.

Tannenbaum, Robert \& Schmidt, Warren H. (May-June 1973). How to Choose a Leadership Pattern. Harvard Business Review, Volume 51, issue 3 (pp. 162-180).

The University of Huddersfield (2011). Comparative reviews of software. Retrieved 2 February 2014 from http://onlineqda.hud.ac.uk/Intro CAQDAS/reviews-of-sw.php

The University of Surrey (n.d.). Choosing an Appropriate CAQDAS Package. Retrieved 2 February 2014 from http://www.surrey.ac.uk/sociology/research/researchcentres/caqdas/support/choosing/

Thomas, Gary (2011). How to do your Case Study: A Guide for Students and Researchers. USA: Sage Publications

Thomas, Theda; Davis, Tim \& Kazlauskas, Alanah (2007). Embedding Critical Thinking in IS Curricula. Journal of Information Technology Education, Volume 6, 2007 issue (pp. 327-346)

Ticehurst, G. W. \& Veal, A. J. (2000). Business Research Methods: A Managerial Approach. Australia: Pearson Education Australia

Towl, Andrew R. (1969). To Study Administration by Cases. USA: Harvard University Graduate School of Business Administration

Tranfield, David \& Starkey, Ken (1998). The Nature, Social Organisation and Promotion of Management Research: towards policy. British Journal of Management, December 1998, Volume 9 , issue 4 (pp. 341-353)

Tuckman, Bruce W. (1965). Developmental Sequence in Small Groups. American Psychological Association Psychological Bulletin, Volume 63, issue 6 (pp. 384-399)

Van Maanen, John (2011). Tales of the Field: on writing ethnography. USA: University of Chicago Press

Veal, A. J. (2005). Business Research Methods: A Managerial Approach (2nd edition). Australia: Pearson Education 
Vega, Professor Gina (2012). How important is a teaching note? What should be in a teaching note? USA: Bertolon School of Business, Salem State University \& Case Centre (formerly ECCH). Retrieved 1 November 2012 from http://www.youtube.com/watch?v=WL-

\section{ogPACENU\&feature=player embedded}

Vedpuriswar, A. V. (2001). Developing Cases. India: IBS Knowledge Center. Retrieved 23 July 2012 from http://www.vedpuriswar.org/articles/Case\%20Method/Developing\%20Cases.doc

Vissak, T. (2010). Recommendations for Using the Case Study Method in International Business Research. The Qualitative Report, 15(2), 370-388. Retrieved June 16, 2011, from Research Library. (Document ID: 2022026031).

Voigt, Christian \& Swatman, Paula M.C. (2005). Instigating Interaction in Electronic Case-Based Learning. Australia: School of CIS, University of South Australia

Wall, Mark (2006). The case study method and management learning: making the most of a strong story-telling tradition in emergency services management education. The Australian Journal of Emergency Management, Vol. 21 No. 2, May 2006. Retrieved 21 March 2012 from

http://www.em.gov.au/Documents/Case\%20study\%20method\%20and\%20management\%20learnin g.pdf

Walsh, Ivan (2006). How to Write a Case Study. USA: Microsoft Word Tips and Tricks. Retrieved 29 July 2010 from http://microsoftwordtips.wordpress.com/2006/12/09/how-to-write-a-case-study/

Wassermann, Selma (1993). Getting down to cases: learning to teach with case studies. USA: Teachers College Press

Wassermann, Selma (1992). A Case for Social Studies. The Phi Delta Kappan, June 1992, Volume 73, issue 10 (pp. 793-801)

Weatherford, Larry (2008). Teaching Notes. USA: Darden Business Publishing, University of Virginia. (pp. 1-12). Ref UVA-PHA-0034

Weil, Sidney; Oyelere, Peter \& Rainsbury, Elizabeth (2004). The usefulness of case studies in developing core competencies in a professional accounting programme: a New Zealand study. Accounting Education: An International Journal, June 2004, Volume 13, Issue 2 (pp. 139-169) Weimer, Maryellen PhD (November 2010). Deep Learning vs. Surface Learning: Getting Students to Understand the Difference. USA: Author. Retrieved 20 November 2012 from http://www.facultyfocus.com/articles/teaching-professor-blog/deep-learning-vs-surface-learninggetting-students-to-understand-the-difference/

Weimer, Maryellen, PhD (7 February 2013). Defining Teaching Effectiveness. USA: Faculty Focus. Retrieved 13 February 2013 from http://www.facultyfocus.com/articles/teaching-professor- 
Wilier, Lynda R. (1995). Working 9 To 5: The Use of Film/Video Analysis as an Adaptation of the Case Study Method in Teaching Organizational Behaviour. International Journal of Organizational Analysis, 1995, Volume 3, Issue 2 (pp. 198-204)

Willig, Carla (2008). Introducing qualitative research in psychology: Adventures in theory \& method. UK: Open University Press

Winston Kenneth I. (2000). Teaching ethics by the case method. Journal of Policy Analysis and Management, Winter 2000, Volume 19, issue 1 (pp. 153-160). ProQuest ID: 222363289

Wolcott, Harry F. (1975). Feedback Influences on Fieldwork; or A Funny Thing Happened on the Way to the Beer Garden. In Urban Man in Southern Africa, Clive Kileff and Wade Pendleton (Eds). Zimbabwe: Mambo Press

Wolter, Bjorn H. K.; Lundeberg, Mary A.; Kang, Hosun \& Herreid, Clyde Freeman (2011). Students' Perceptions of Using Personal Response Systems ("Clickers") With Cases in Science. Journal of College Science Teaching, March-April 2011, Volume 40, Issue 4 (pp. 14-19)

Wrage, Stephen B. (1994). Best Case Analysis: What Makes a Good Case and Where to Find the One You Need. International Studies Notes, April/Spring 1994, Volume 19, issue 2 (pp. 12 pages). (UA ID: 413752)

Wright, Phillip (1996). Simulating reality: the role of the case incident in higher education. Education and Training, 1996, Volume 38, issue 6 (pp. 20-24).

Yemen, Gerry (2012). What Kind of Business Case Studies Are We Writing? USA: Darden Business Publishing, University of Virginia. UVA-PHA-0064

Yemen, Gerry (2010). On Writing Teaching Notes Well. USA: Darden Business Publishing, University of Virginia. Ref UVA-PHA-0062

Yemen, Gerry (2008). On Writing Cases Well. USA: Darden Business Publishing, University of Virginia. Ref UVA-PHA-0058

Yin, Robert K. (2004). Case Study Methods in Judith L. Green, Gregory Camilli, Patricia B. Elmor, Complementary Methods for Research in Education (3rd Edition). USA: American Educational Research Association

Yin, Robert K. (2009). Case Study Research: design and methods (4 $4^{\text {th }}$ Edition). USA: Sage Publications, Inc

Yukl, Gary (2006). Leadership in Organizations (6th Edition). USA: Pearson Education Inc. 


\section{Appendices}

\section{Appendix One (a): Field Research Case Study Types}

Sourced from Thomas (2011) and the other authors listed below.

\begin{tabular}{|c|c|c|c|c|c|c|c|c|c|c|c|c|c|c|c|c|}
\hline $\begin{array}{l}\text { Research Case } \\
\text { Types }\end{array}$ & 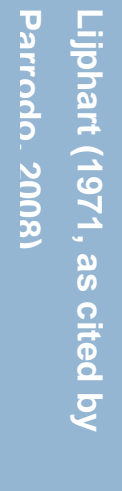 & 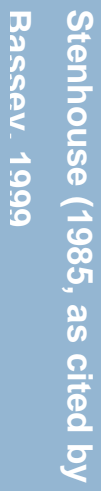 & 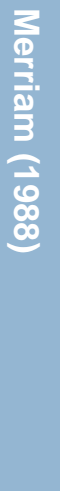 & 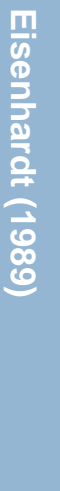 & 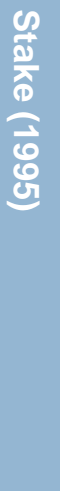 & 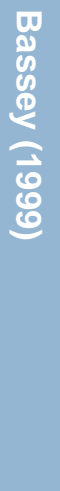 & 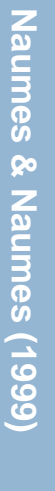 & 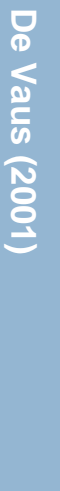 & 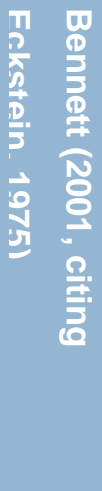 & 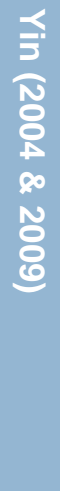 & 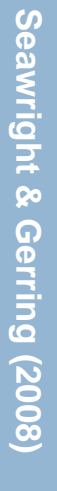 & 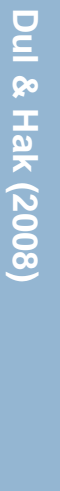 & $\begin{array}{l}3 \\
8 \\
0\end{array}$ & 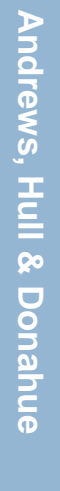 & 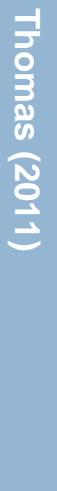 & 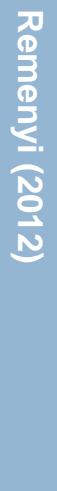 \\
\hline Interpretative & $x$ & & $x$ & & & & & & & & & & & & & \\
\hline Theory-testing & $x$ & $x$ & & $x$ & & $x$ & & $x$ & $x$ & & & $x$ & & & & \\
\hline Theory-building & $x$ & $x$ & & $x$ & & $x$ & & & $x$ & & & $x$ & & & & \\
\hline Plausibility probes & $x$ & & & & & & & & $x$ & & & & & & & \\
\hline Outlier & $x$ & & & & & & & & & $x$ & $x$ & & & & $x$ & \\
\hline Descriptive & $x$ & $x$ & $x$ & $x$ & & $x$ & & $x$ & $x$ & $\mathrm{x}$ & & & & $x$ & & $x$ \\
\hline Evaluative & & $x$ & $x$ & & & $x$ & $x$ & & & & & & & & & $\mathrm{x}$ \\
\hline Practice-oriented & & $x$ & & & & & & & $x$ & & & $x$ & & & & \\
\hline Intrinsic & & & & & $x$ & & & & & & & & & & & \\
\hline Instrumental & & & & & $\mathrm{x}$ & & & & & & & & & & & \\
\hline Series or single & & & & & $\mathrm{x}$ & & & $x$ & & $x$ & & & & & & $x$ \\
\hline Decision-making & & & & & & & $x$ & & & & & & & & & \\
\hline Holistic, embedded & & & & & & & & $x$ & & & & & & & & \\
\hline $\begin{array}{l}\text { Retrospective or } \\
\text { prospective }\end{array}$ & & & & & & & & $x$ & & & & & & & & \\
\hline Longitudinal & & & & & & & & & $\mathrm{x}$ & $x$ & & & & & & \\
\hline Critical & & & & & & & & & & $x$ & & & & & & \\
\hline Typical & & & & & & & & & & $x$ & $x$ & & & & $x$ & \\
\hline
\end{tabular}




\begin{tabular}{|c|c|c|c|c|c|c|c|c|c|c|c|c|c|c|c|c|c|c|}
\hline $\begin{array}{l}\text { Research Case } \\
\text { Types }\end{array}$ & 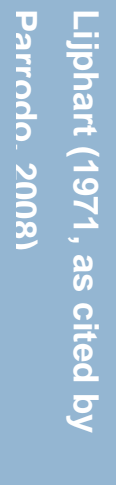 & 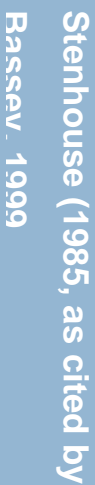 & 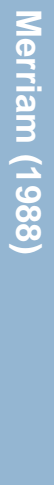 & 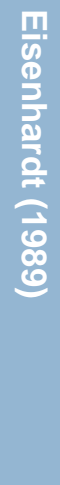 & 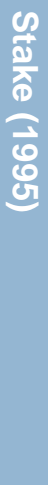 & 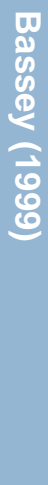 & 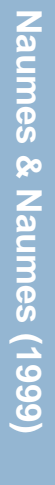 & 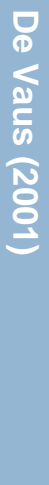 & $\begin{array}{l}\pi \\
\frac{2}{x} \\
\frac{0}{0} \\
\vec{D} \\
\frac{3}{3} \\
\overrightarrow{0} \\
\overrightarrow{0} \\
\frac{\pi}{2}\end{array}$ & 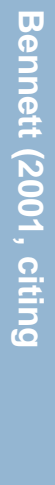 & 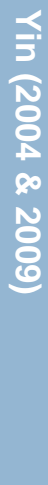 & 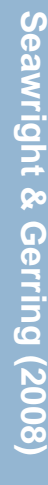 & d & & & & 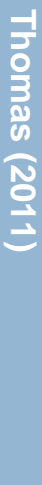 & 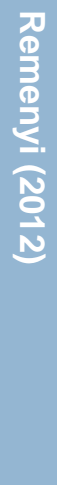 \\
\hline Influential & & & & & & & & & & & $\mathrm{x}$ & $x$ & & & & & & \\
\hline Observer & & & & & & & & & & & & & & & & & & \\
\hline Problem & & & & & & & & & & & & & & & & & & \\
\hline Scenario & & & & & & & & & & & & & & & & & & \\
\hline Local knowledge & & & & & & & & & & & & & & & & & $\mathrm{x}$ & \\
\hline Individual field case & & & & & & & & & & & & & & & & & & $\mathrm{x}$ \\
\hline
\end{tabular}


Appendix One (b): Teaching Case Study Types

\begin{tabular}{|c|c|c|c|c|c|c|c|c|c|c|c|c|c|c|c|c|}
\hline $\begin{array}{l}\text { Teaching } \\
\text { Case Types }\end{array}$ & 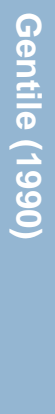 & 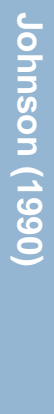 & 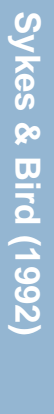 & 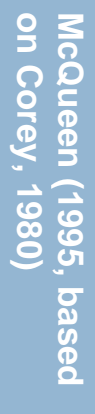 & 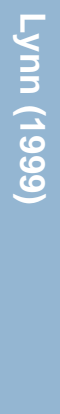 & 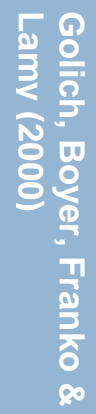 & 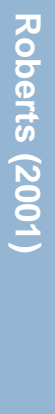 & 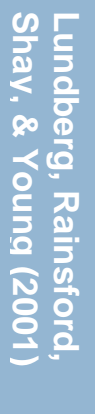 & 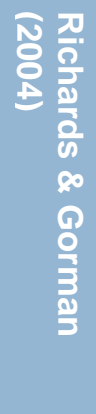 & 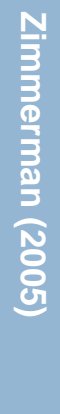 & 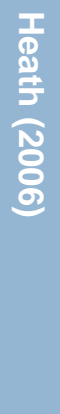 & 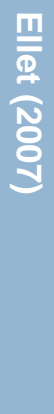 & 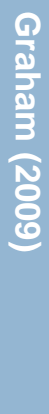 & $\begin{array}{l}\text { 올 } \\
\text { 졸 } \\
\text { 을 }\end{array}$ & 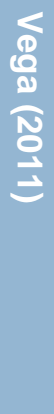 & 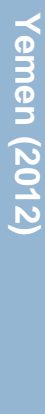 \\
\hline $\begin{array}{l}\text { Compare/ } \\
\text { Contrast/ } \\
\text { Deviant }\end{array}$ & $x$ & & & $x$ & & & & $x$ & & & & $x$ & & $x$ & & \\
\hline Evaluation & $X$ & & & $x$ & & & & & & & & $x$ & & $x$ & $\mathrm{X}$ & \\
\hline Series & $X$ & & $x$ & & & & & $x$ & & & & & & & & \\
\hline $\begin{array}{l}\text { Decision- } \\
\text { making }\end{array}$ & $x$ & & & & $x$ & $X$ & & & $x$ & & $x$ & $x$ & & $x$ & $X$ & \\
\hline Practice & $x$ & & & $x$ & $\mathrm{x}$ & & & $x$ & & & $x$ & & & $x$ & & \\
\hline Role Playing & & $x$ & & & & & & $x$ & & $x$ & & & & & & \\
\hline Field & & $x$ & & & & & $x$ & & & & & & & & & $x$ \\
\hline Discussion & & $x$ & & & & & & & & & & & & $x$ & $x$ & \\
\hline Lab & & $X$ & $x$ & & & & & & & & & & & & & \\
\hline $\begin{array}{l}\text { Descriptive / } \\
\text { Illustrative }\end{array}$ & & & $x$ & & $x$ & $x$ & & $x$ & $x$ & $x$ & $x$ & $x$ & & $x$ & $x$ & $x$ \\
\hline Short & & & $x$ & & & & & $x$ & & $x$ & $x$ & & & & & \\
\hline Multi-media & & & $x$ & & & & & & $x$ & & & & & & & \\
\hline $\begin{array}{l}\text { Problem- } \\
\text { oriented }\end{array}$ & & & & $x$ & $x$ & & & & & & $x$ & $x$ & $x$ & & & \\
\hline Discovery & & & & $x$ & & & & $x$ & & & & & & & & \\
\hline Policy-making & & & & & $X$ & & & & & & & & & & & \\
\hline Arm chair & & & & & & & $x$ & & & $x$ & & & & & & $\mathrm{X}$ \\
\hline Best Practice & & & & & & & & & $x$ & & & & & & & \\
\hline Mouse-trap & & & & & & & & & & & & $x$ & & & & \\
\hline Rules & & & & & & & & & & & & $x$ & & & & \\
\hline
\end{tabular}




\begin{tabular}{|c|c|c|c|c|c|c|c|c|c|c|c|c|c|c|c|c|}
\hline $\begin{array}{l}\text { Teaching } \\
\text { Case Types }\end{array}$ & 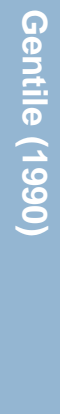 & 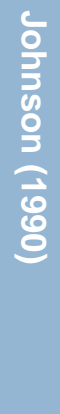 & 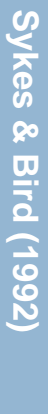 & 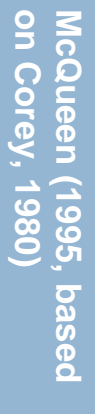 & 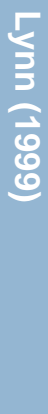 & 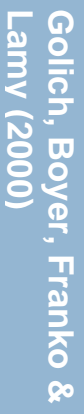 & 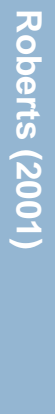 & 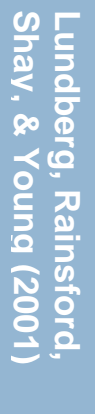 & 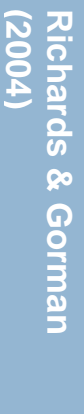 & 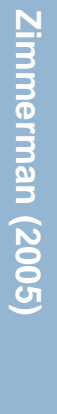 & 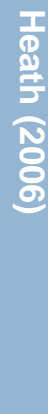 & 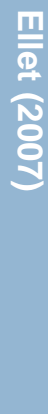 & $\begin{array}{l}\frac{\text { Q }}{3} \\
\frac{3}{3} \\
\text { 을 } \\
8 \\
8\end{array}$ & 욜 & 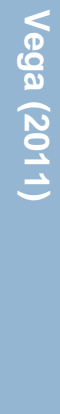 & 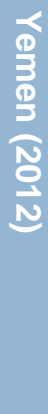 \\
\hline $\begin{array}{l}\text { Data (i.e., Raw } \\
\text { cases) }\end{array}$ & & & & & & & & $X$ & & & & & & & & \\
\hline Event & & & & & & & & & & & & & $x$ & & & \\
\hline Full Scenario & & & & & & & & & & & & & $x$ & & & \\
\hline $\begin{array}{l}\text { Complex } \\
\text { Scenario }\end{array}$ & & & & & & & & & & & & & $x$ & & & \\
\hline Meta-case & & & & & & & & & & & & & $x$ & & & \\
\hline
\end{tabular}


Appendix One (c): Tabled Authors' Areas of Topic Expertise

\begin{tabular}{|c|c|}
\hline Author cited (year) & Professional areas, positions \& roles (where known) \\
\hline Abell (1997) & Professor of Marketing \& Management, at Harvard, Lausanne \& Zurich \\
\hline $\begin{array}{l}\text { Allen (1981, citing Bennett \& } \\
\text { Chakravarthy, 1978) }\end{array}$ & Professor of Management, University of Rhode Island \\
\hline $\begin{array}{l}\text { Andrews, Hull \& Donahue } \\
\text { (2009) }\end{array}$ & $\begin{array}{l}\text { US Air Force Research Laboratory; US Air Force Research Laboratory; Boeing } \\
\text { Company }\end{array}$ \\
\hline Austin (1993) & $\begin{array}{l}\text { Eliot I. Snider and Family Professor Emeritus of Business Administration, } \\
\text { Harvard }\end{array}$ \\
\hline Bassey (1999) & Emeritus Professor of Education, Nottingham Trent University \\
\hline $\begin{array}{l}\text { Bennett (2001, citing Eckstein, } \\
\text { 1975) }\end{array}$ & Professor, Research \& Public Policy, Georgetown University \\
\hline Bruner \& Foerster (2004) & $\begin{array}{l}\text { Distinguished Professor of Business Administration (Finance, Management \& } \\
\text { Innovation), Darden; Professor of Finance, Darden }\end{array}$ \\
\hline Corey (1996) & Malcolm P. McNair Professor of Marketing, Harvard \\
\hline De Vaus (2001) & Associate Professor of Sociology at La Trobe University \\
\hline Dhanaraj (2010) & $\begin{array}{l}\text { Kelley School of Business, University of Indiana; Visiting Professor, Indian } \\
\text { School of Business }\end{array}$ \\
\hline Dul \& Hak (2008) & $\begin{array}{l}\text { Professor of Technology \& Human Factors, RSM Erasmus University; Associate } \\
\text { Professor of Research Methodology, RSM Erasmus University }\end{array}$ \\
\hline Eisenhardt (1989) & $\begin{array}{l}\text { Assistant Professor, Department of Industrial Engineering \& Engineering } \\
\text { Management, Stanford University }\end{array}$ \\
\hline Ellet (2007) & Lecturer in International Business, Harvard \\
\hline Erskine \& Leenders (1989) & $\begin{array}{l}\text { Professor of Marketing \& Professor of Operations Management, Richard Ivey } \\
\text { School of Business at the University of Western Ontario }\end{array}$ \\
\hline Fisher (1972) & $\begin{array}{l}\text { American Council on Education, Washington DC \& Institute for College \& } \\
\text { University Administrators }\end{array}$ \\
\hline Gentile (1990) & Leadership guru \& Senior Research Scholar, Babson College \\
\hline Gill (2011) & Professor in Management Information Systems, University of South Florida \\
\hline $\begin{array}{l}\text { Golich, Boyer, Franko \& Lamy } \\
\text { (2000) }\end{array}$ & $\begin{array}{l}\text { Professor Political Science California State University; Professor Political } \\
\text { Science University of Connecticut; Associate Professor Economics, Colby } \\
\text { College; Associate Professor International Relations, University of Southern } \\
\text { California }\end{array}$ \\
\hline Graham (2009) & Professor of Public Policy, Queens University \& Case Editor for Institute of Public \\
\hline
\end{tabular}




\begin{tabular}{|c|c|}
\hline Author cited (year) & Professional areas, positions \& roles (where known) \\
\hline & Administration of Canada \\
\hline Hamschmidt (2007) & $\begin{array}{l}\text { Professor of NGO Management, Sustainability, Entrepreneurship \& Strategy, } \\
\text { University of St Gallen Switzerland }\end{array}$ \\
\hline Hansen (1997) & English \& Teaching, Harvard \& consulting \\
\hline Harling \& Misser (1998) & $\begin{array}{l}\text { School of Business \& and Economics, Wilfrid Laurier University; The Writing } \\
\text { Centre, Wilfrid Laurier University }\end{array}$ \\
\hline Heath (2006) & Professor Strategic Management, University of Leicester \\
\hline Herreid (2005) & $\begin{array}{l}\text { SUNY Distinguished Teaching Professor, Department of Biological Sciences, } \\
\text { State University of New York (Buffalo) \& Director, National Center for Case } \\
\text { Study Teaching in Science }\end{array}$ \\
\hline Hitchner (1977) & Professor of Public Policy, Kennedy School of Government, Harvard \\
\hline Johnson (1990) & Professor Emeritus Educational Curriculum \& Instruction, Texas A\&M University \\
\hline Lapierre \& Cardinal (2003) & $\begin{array}{l}\text { Distinguished Professor of Business Administration (Finance, Management \& } \\
\text { Innovation), Darden; Professor of Finance, Darden }\end{array}$ \\
\hline Lee (2010) & Adjunct Assistant Professor Entrepreneurship, University of Michigan \\
\hline $\begin{array}{l}\text { Lijphart (1971, as cited by } \\
\text { Parrodo, 2008) }\end{array}$ & Research Professor Emeritus of Political Science, University of Leiden \\
\hline $\begin{array}{l}\text { Lundberg, Rainsford, Shay, \& } \\
\text { Young (2001) }\end{array}$ & $\begin{array}{l}\text { Professor of Human Resource Management, Cornell University; Professor of } \\
\text { Tourism Management, Professor of Entrepreneurship \& Leadership, University of } \\
\text { Denver; University of Montana; Professor of Hotel Administration, University of } \\
\text { Nevada, Las Vegas }\end{array}$ \\
\hline Lynn (1999) & Professor of Public Policy \& Management, University of Chicago \\
\hline $\begin{array}{l}\text { McQueen (1995, based on } \\
\text { Corey, 1980) }\end{array}$ & Department of Management Systems, Waikato University \\
\hline Merriam (1988) & Professor of Adult Education, University of Georgia \\
\hline Merseth (1991) & $\begin{array}{l}\text { Director, Comprehensive Teacher Education Institute, University of California, } \\
\text { Riverside }\end{array}$ \\
\hline Millott (2003) & Online Learning Centre, Saskatoon Area Schools Canada \\
\hline Naumes \& Naumes (1999) & $\begin{array}{l}\text { Associate Professor of Strategic Management, University of New Hampshire; } \\
\text { Senior Lecturer in Management, University of New Hampshire }\end{array}$ \\
\hline Ó Cinnéide (1998) & Professor Emeritus Entrepreneurship \& Marketing, University of Limerick \\
\hline Remenyi (2012) & $\begin{array}{l}\text { Visiting Professor of Research Methodology, School of Systems \& Data Studies, } \\
\text { Trinity University }\end{array}$ \\
\hline
\end{tabular}




\begin{tabular}{|c|c|}
\hline Author cited (year) & Professional areas, positions \& roles (where known) \\
\hline Richards \& Gorman (2004) & Engineering, University of Virginia; Engineering, University of Virginia \\
\hline Roberts (2001) & Principal Lecturer in Business Policy, North Staffordshire Polytechnic UK \\
\hline Robyn (1986) & Assistant Professor of Public Policy, Kennedy School of Government, Harvard \\
\hline Rotch (1991) & Professor of Business Administration, Darden \\
\hline Seawright \& Gerring (2008) & $\begin{array}{l}\text { Assistant Professor of Political Science Northwestern University; Professor of } \\
\text { Methodology \& Comparative Politics, Boston University }\end{array}$ \\
\hline Stake (1995) & Professor or Education, University of Illinois \\
\hline $\begin{array}{l}\text { Stenhouse (1985, as cited by } \\
\text { Bassey, 1999) }\end{array}$ & Director, Centre for Applied Research in Education, University of East Anglia \\
\hline Sykes \& Bird (1992) & $\begin{array}{l}\text { Associate Professor of Educational Administration, Michigan State University; } \\
\text { Associate Professor of Teacher Education, Michigan State University \& Senior } \\
\text { Researcher, NCRTL. }\end{array}$ \\
\hline Thomas (2011) & Professor of Education, University of Birmingham UK \\
\hline Vega (2011) & $\begin{array}{l}\text { Professor of Entrepreneurship, Salem State University, author \& trainer for } \\
\text { Cranford University's Case Centre }\end{array}$ \\
\hline Wassermann (1992) & Professor Emerita, Faculty of Education, Simon Fraser University Canada \\
\hline Weatherford (2008) & Associate Professor Business \& Logistics, University of Wyoming \\
\hline Wrage (1994) & United States Naval Academy \\
\hline Wright (1996) & Associate Professor, Faculty of Administration, University of New Brunswick \\
\hline Yemen (2012) & Senior Researcher \& Case Writer, Darden \\
\hline Yin (2004 \& 2009) & $\begin{array}{l}\text { Distinguished scholar-in-residence, psychology, at American University's School } \\
\text { of International Service }\end{array}$ \\
\hline Zimmerman (2005) & Professor Department of Arts, Science \& Business, Ohio State University \\
\hline
\end{tabular}




\section{Appendix Two (a): Research Project Plan | July 2012 to June}

Following is my high-level plan for my Master Thesis project:

\begin{tabular}{|c|c|c|c|c|}
\hline Item & Details & $\begin{array}{l}\text { Planned } \\
\text { Date }\end{array}$ & Comments & $\begin{array}{l}\text { Actual } \\
\text { Date }\end{array}$ \\
\hline $\begin{array}{l}\text { Preliminary } \\
\text { research }\end{array}$ & $\begin{array}{l}\text { Background reading \& } \\
\text { gathering materials }\end{array}$ & $\begin{array}{l}\text { Jun - Aug } \\
2012\end{array}$ & Completed on schedule & $\begin{array}{l}\text { Aug } \\
2012\end{array}$ \\
\hline $\begin{array}{l}\text { Proposal } \\
\text { development }\end{array}$ & $\begin{array}{l}\text { Documenting project } \\
\text { starting position }\end{array}$ & $\begin{array}{l}\text { Aug - Sep } \\
2012\end{array}$ & $\begin{array}{l}\text { Research Proposal approved } \\
\text { early }\end{array}$ & $\begin{array}{l}17 \text { Sep } \\
2012\end{array}$ \\
\hline $\begin{array}{l}\text { Thesis } \\
\text { structuring \& } \\
\text { Literature Review }\end{array}$ & $\begin{array}{l}\text { As per the Fantasy Table of } \\
\text { Contents structure }\end{array}$ & $\begin{array}{l}\text { Oct - Dec } \\
2012\end{array}$ & $\begin{array}{l}90 \% \text { complete (will need further } \\
\text { refining once research is } \\
\text { complete) }\end{array}$ & $\begin{array}{l}\text { March } \\
2013\end{array}$ \\
\hline $\begin{array}{l}\text { Methodology } \\
\text { development }\end{array}$ & $\begin{array}{l}\text { Continued methodology } \\
\text { research }\end{array}$ & $\begin{array}{l}\text { Dec - Feb } \\
2013\end{array}$ & $\begin{array}{l}\text { Structurally complete (will need } \\
\text { further refining once research is } \\
\text { complete) }\end{array}$ & $\begin{array}{l}\text { June } \\
2013\end{array}$ \\
\hline Pilot testing & $\begin{array}{l}\text { Using NMIT MGT636 class } \\
\text { for method etc } \\
\text { Refining process }\end{array}$ & $\begin{array}{l}\text { Mar - Jun } \\
2013\end{array}$ & $\begin{array}{l}\text { Students enjoyed the process, } \\
\text { found the workload difficult, so } \\
\text { have swapped some assignment } \\
\text { credit to ensure a student } \\
\text { WIIFM, which Lynn will mark }\end{array}$ & $\begin{array}{l}\text { May } \\
2013\end{array}$ \\
\hline Ethics approval & $\begin{array}{l}\text { Ethics documentation, Gain } \\
\text { ethics approval }\end{array}$ & $\begin{array}{l}\text { Feb - } \\
\text { Mar } 2013\end{array}$ & Approved 7 August & $\begin{array}{l}\text { August } \\
2013\end{array}$ \\
\hline $\begin{array}{l}\text { Case materials } \\
\text { development }\end{array}$ & $\begin{array}{l}\text { Ethics documentation, Gain } \\
\text { ethics approval }\end{array}$ & July 2013 & $\begin{array}{l}\text { Completed one medium case \& } \\
\text { one short case for each sub- } \\
\text { topic. Completed early August } \\
\text { ready for teaching in late August. }\end{array}$ & $\begin{array}{l}\text { August } \\
2013\end{array}$ \\
\hline $\begin{array}{l}\text { Case teaching } \\
\text { research \& } \\
\text { Surveys }\end{array}$ & $\begin{array}{l}\text { Develop questionnaires } \\
\text { Run case research, Student } \\
\text { \& Lecturer Surveys }\end{array}$ & $\begin{array}{l}\text { Jul - Oct } \\
2013\end{array}$ & $\begin{array}{l}\text { Questionnaires developed } \\
\text { (June). All remainder on track }\end{array}$ & $\begin{array}{l}\text { August } \\
2013\end{array}$ \\
\hline $\begin{array}{l}\text { Findings \& data } \\
\text { analysis }\end{array}$ & $\begin{array}{l}\text { Refining, additional } \\
\text { modelling \& research }\end{array}$ & $\begin{array}{l}\text { Oct - Mar } \\
2014\end{array}$ & $\begin{array}{l}\text { Data collected. Focus groups } \\
\text { went as expected. Transcription } \\
\text { completed. Data analysed. }\end{array}$ & $\begin{array}{l}\text { Mar } \\
2014\end{array}$ \\
\hline Thesis writing & $\begin{array}{l}\text { Refining, additional } \\
\text { modelling \& research }\end{array}$ & $\begin{array}{l}\text { Jan - Mar } \\
2014\end{array}$ & Fair draft to Brad by 01 April & $\begin{array}{l}\text { April } \\
2014\end{array}$ \\
\hline Thesis editing & $\begin{array}{l}\text { Case materials written pre- } \\
\text { thesis, reviewed post-thesis }\end{array}$ & $\begin{array}{l}\text { Feb - Jun } \\
2014\end{array}$ & & $\begin{array}{l}\text { June } \\
2014\end{array}$ \\
\hline
\end{tabular}




\begin{tabular}{|c|c|c|c|c|}
\hline & & Planned & & Actual \\
\hline Item & Details & Date & Comments & Date \\
\hline \multirow[t]{2}{*}{$\begin{array}{l}\text { Thesis } \\
\text { completed }\end{array}$} & $\begin{array}{l}\text { Call for other cases, if } \\
\text { required, specifying format } \\
\text { (as per research } \\
\text { outcomes), for a case study } \\
\text { publication }\end{array}$ & Jun 2014 & & \\
\hline & $\begin{array}{l}\text { Case study collection ready } \\
\text { for potential publication. }\end{array}$ & $\begin{array}{l}\text { Decembe } \\
\text { r } 2014\end{array}$ & & \\
\hline
\end{tabular}




\section{Appendix Two (b): CAQDAS Research Categories \& Code Definitions}

\begin{tabular}{|c|c|c|}
\hline Category & Code & For marking evidence of: \\
\hline \multirow[t]{10}{*}{ Effectiveness } & Applying principles & Students applying core principles contained in the case \\
\hline & Important points & Identifying key case transitions, issues or theory \\
\hline & Synthesising \& solving & Demonstrating solutions, applications and new approaches \\
\hline & Student participation & Involvement, engagement and connection \\
\hline & Evaluation skills & Rational evidence-based judgement \& thinking skills \\
\hline & Interpersonal skills & $\begin{array}{l}\text { Showing consideration of others and good communication } \\
\text { skills }\end{array}$ \\
\hline & $\begin{array}{l}\text { Applying new } \\
\text { knowledge }\end{array}$ & $\begin{array}{l}\text { Demonstrating forward-thinking, applying insights to new } \\
\text { situations, thinking "what does this mean for me" }\end{array}$ \\
\hline & Self-directed learning & Showing initiative and action-oriented learning \\
\hline & Group problem-solving & Illustrating group work, discussion, team-PBL solutions \\
\hline & $\begin{array}{l}\text { Leadership emotional } \\
\text { insight }\end{array}$ & Unique leadership theory or self-leadership insights \\
\hline \multirow[t]{7}{*}{ Ineffectiveness } & In group/out group & Where the group has split into 'us' and 'them' \\
\hline & Lecturer-dominated & Heavily lecturer-led areas of a session \\
\hline & Micro-managing & $\begin{array}{l}\text { Excessive control, instructions or dominance from any } \\
\text { person }\end{array}$ \\
\hline & No preparation & Lack of expected or required class preparation \\
\hline & No theory & Expected theory not explored, and explicitly noted \\
\hline & Not connected & Participants explicitly disengaged from the case \\
\hline & Passive & $\begin{array}{l}\text { Case leader having to work hard to get responses, student } \\
\text { slowness in answering, monosyllabic or reluctant responses }\end{array}$ \\
\hline \multirow[t]{8}{*}{ Teaching Method } & Capturing ideas & Proposing ideas or teaching techniques for the session \\
\hline & Case in Point positive & $\begin{array}{l}\text { Positive comments specifically related to Case in Point case } \\
\text { method }\end{array}$ \\
\hline & Hybrid positive & $\begin{array}{l}\text { Positive comments specifically related to Hybrid case } \\
\text { method }\end{array}$ \\
\hline & Length & Comments about case length for that delivery \\
\hline & Pre-digested & $\begin{array}{l}\text { Students requesting more chunking, synthesising or 'pre- } \\
\text { digestion' of material by lecturers }\end{array}$ \\
\hline & Small group safety & $\begin{array}{l}\text { Where students have felt able and empowered to speak } \\
\text { because of the size and intimacy of the group }\end{array}$ \\
\hline & Suggestion & Any suggestions for session improvements \\
\hline & Video & What video adds \\
\hline
\end{tabular}

\section{Further Research Coding Considerations:}

In considering which categories to use, I also considered for some time using Sockalingam and Schmidt's eleven student-rated characteristics of effective learning (2011, Lead to learning issues; Trigger interest; Be of suitable format; Stimulate critical reasoning; Promote self-directed learning; Be of suitable clarity; Be of appropriate difficulty; Enable application or use; Relate to prior knowledge; Stimulate elaboration; Promote teamwork). However, some 
aspects of Sockalingam and Schmidt's characteristics are already covered by Harper, Lamb and Buffington, or by Bridges and Hallinger (such as "Promote self-directed learning" and "Self-directed learning"; "Promote teamwork" being largely synonymous with "Group problemsolving"; "Enable application or use" largely similar to "Applying principles"; and "Stimulate critical reasoning" being partly similar to both "Evaluation skills" and "Synthesising \& solving"). Additionally, I was unable to identify incidences of "Be of suitable format", "Be of suitable clarity", "Be of appropriate difficulty". It was also difficult to determine which aspects might be "related to prior knowledge" and which might "stimulated elaboration". I felt I had an approximately $50 \%$ hit rate with these characteristics within my data; I did not consider this to be significant enough, or that it added enough value, to use it. As a result, I decided to stick with the ten characteristics already selected from Harper, Lamb and Buffington (2008), Bridges and Hallinger (1997). 


\section{Appendix Three (a): Ethics Application Approval Letter}

\section{Office of the Vice-Chancellor}

Research Integrity Unit

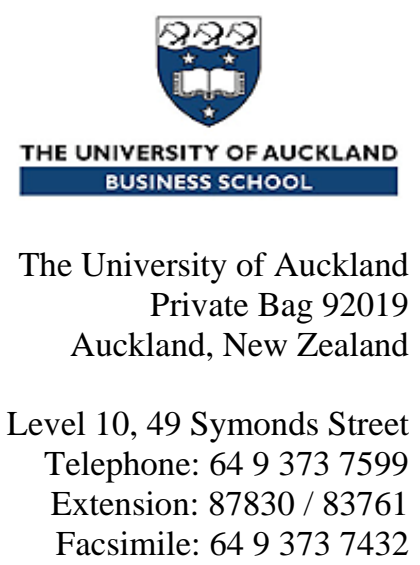

\section{UNI VERSITY OF AUCKLAND HUMAN PARTICI PANTS ETHI CS COMMITTEE}

07-Aug-2013

\section{MEMORANDUM TO:}

Prof Bradley Jackson

Management \& Intl Business

\section{Re: Application for Ethics Approval (Our Ref. 10056)}

The Committee considered your application for ethics approval for your project entitled Assessing sense-making strategies of students learning leadership from case studies.

Ethics approval was given for a period of three years with the following comment(s):

Please consider removing the word 'exclusively' from all PIS and CF in sentences relating to data: "I understand that the data gathered will be used exclusively for the completion of Sam's Master's thesis..." as data may be used at a future date for example, conference and or comparative research etc.

The expiry date for this approval is 07-Aug-2016.

If the project changes significantly you are required to resubmit a new application to UAHPEC for further consideration.

In order that an up-to-date record can be maintained, you are requested to notify UAHPEC once your project is completed.

The Chair and the members of UAHPEC would be happy to discuss general matters relating to ethics approvals if you wish to do so. Contact should be made through the UAHPEC ethics adminisatrators at humanethics@auckland.ac.nz in the first instance.

All communication with the UAHPEC regarding this application should include this reference number: 10056. 
(This is a computer generated letter. No signature required.)

Secretary

University of Auckland Human Participants Ethics Committee

c.c. Head of Department / School, Management \& Intl Business

Additional information:

1. Should you need to make any changes to the project, write to the Committee giving full details including revised documentation.

2. Should you require an extension, write to the Committee before the expiry date giving full details along with revised documentation. An extension can be granted for up to three years, after which time you must make a new application.

3. At the end of three years, or if the project is completed before the expiry, you are requested to advise the Committee of its completion.

4. Do not forget to fill in the 'approval wording' on the Participant Information Sheets and Consent Forms, giving the dates of approval and the reference number, before you send them out to your participants.

5. Send a copy of this approval letter to the Manager - Funding Processes, Research Office if you have obtained funding other than from UniServices. For UniServices contract, send a copy of the approval letter to: Contract Manager, UniServices.

6. Please note that the Committee may from time to time conduct audits of approved projects to ensure that the research has been carried out according to the approval that was given. 


\title{
Sheet
}

DEPARTMENT OF MANAGEMENT AND

INTERNATIONAL BUSINESS

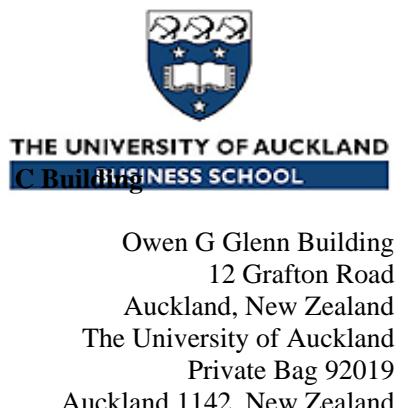

\section{LEADERSHIP CASE DELIVERY RESEARCH: PARTICIPANT INFORMATION SHEET}

\author{
AUT LEADERSHIP STUDENTS
}

As a Master of Management student in the Department of Management and International Business at the University of Auckland, I would like to invite you to participate in my thesis research examining whether students make sense of leadership cases differently when cases are delivered using different teaching methods.

Your participation in this process is entirely voluntary. The data gathered will be used for the completion of my Master's thesis and any publications that may emerge from this. My research in summary will involve:

- The sound recording of two 1 hour and 45 minute AUT Sports Leadership workshop sessions, during normal class time, involving the consenting leadership class participants, led by a senior lecturer.

- Once both the Approach A and Approach B sessions have taken place, a sound recorded 30 minute focus group with the leadership class participants and the senior lecturer will take place during normal class time. The interview will debrief your perceptions of leadership case delivery methods as well as your personal reflections of what you felt worked well.

- Later possible email follow-up from me, regarding any further reflections you may have on the themes that arise from my analysis of the research data.

As part of your course assessment work, you will complete a one page case analysis, prior to the Approach A session, which will be marked solely by Dr. Lynn Kidman. I will have no influence on the marks given for this assignment.

All the information collected during the course of the research will remain confidential. I will not use real names in the study. However, due to the group nature of the recording, total anonymity cannot be guaranteed.

Should you decide not to participate in my research project, all the materials for these sub-topics will be available online to be accessed at a time that suits you. Additionally, once the recorded sessions have been completed, I will post a summary of the case discussions online to ensure that you are not disadvantaged in any way.

Your participation or non-participation will not affect your grades for this course, nor in any way affect your future employability as a result of your involvement or non-involvement. 
The data will be used to write my thesis and any publications that arise from this research.

You may withdraw from the study at any time, but you cannot withdraw your data. You may withdraw from the study at any time up until the workshop session recording takes place. With your consent, I would like to record the workshops via sound recording equipment. You may also decide at any point of the session to leave the room, without providing a reason, and decide to no longer participate in the research.

Additionally, despite having participated in the workshop session(s), you may decide to withdraw from the research before the focus group takes place. The focus group sessions will also be sound recorded. You may also decide at any point of the focus group to leave the room, without providing a reason, and decide to no longer participate in the research.

I will personally transcribe the audio soundtrack, solely for the purpose of my research. I will not disclose any information to any outside party. The transcribed data will be transferred onto a removable harddrive, pass-worded and safely stored. While the research is underway, only my supervisor and I will have access to the transcripts. Once complete, only I will have access to it. The transcript data will be securely stored for ten years for the purpose of developing the research for further publication. After this period of time the data will be destroyed.

Once preliminary analysis of the data has taken place, I may wish to contact you via email to gain follow-up reflective evidence, before the end of the semester. If you have provided your email address on the consent form and signed it, you are giving me permission to contact you directly. If at any time you decide that you no longer wish to participate further in my research project, please contact me, and I will remove your details from my participants' contact list.

A summarised thesis will be available to all participants. Don't hesitate to contact me if you have any questions about my research; my contact details, and those of my supervisor, are below.

Thank you for considering my research request.

Yours sincerely

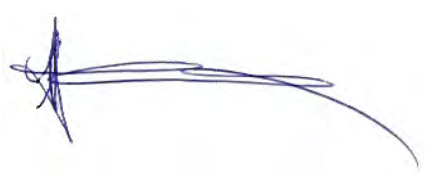

Sam Young (sam.young@nmit.ac.nz orsyou939@aucklanduni.ac.nz)

Ph 035469175 ext 367 or 0272447154

Supervisor: Professor Brad Jackson (b.jackson@auckland.ac.nz)

Ph 093737599 ext 83267

Head of Department, Management \& International Business: Professor Nigel Haworth

(n.haworth@auckland.ac.nz)

Ph 093737599 ext 85235

For any concerns regarding ethical issues you may contact the Chair, The University of Auckland Human Participants Ethics Committee, The University of Auckland, Research Office, Private Bag 92019, Auckland 1142. Ph 093737599 ext 87830/83761. Email humanethics@auckland.ac.nz

APPROVED BY THE UNIVERSITY OF AUCKLAND HUMAN PARTICIPANTS ETHICS COMMITTEE ON 07-Aug-2013 for (3) years, Reference Number 10056 


\section{LEADERSHIP CASE DELIVERY RESEARCH: PARTICIPANT CONSENT FORM}

\section{AUT LEADERSHIP STUDENTS}

I consent to participating in the thesis research undertaken by Sam Young in her Master of Management thesis in the Department Management and International Business at the University of Auckland, examining whether students make sense of leadership cases differently when cases are delivered using different teaching methods.

I have read the Participant Information Sheet, have understood the nature of the research and why I have been selected. I have had the opportunity to ask questions and to have them answered to my satisfaction.

My participation in this process is entirely voluntary. I understand that the data gathered will be used for the completion of Sam's Master's thesis and any publications that may emerge from this. I understand that her research will involve:

- The sound recording of two 1 hour and 45 minute AUT Sports Leadership workshop sessions during normal class time, involving the consenting leadership class participants, led by a senior lecturer.

- Once both the Approach A and Approach B sessions have taken place, a sound recorded 30 minute focus group with the leadership class participants with a senior lecturer present will take place during normal class time. The interview will debrief my perceptions of leadership case delivery methods and my personal reflections of what I felt worked well.

- Later possible email follow-up from Sam, regarding any further reflections I may have on the themes that arise from her analysis of the research data.

As part of my course assessment work, I understand that I will need to complete a one page case analysis, prior to the Approach A session. This will be marked solely by Dr. Lynn Kidman. I understand that Sam will have no influence on the marks given for this assignment.

I understand that all the information collected during the course of the research will remain confidential. Sam guarantees that her study will not use my real name. However, I do realise that due to the group nature of the recording, my total anonymity cannot be guaranteed.

I understand that should I decide not to participate in Sam's research project, I can instead access all the materials for these sessions online, and that a summary of the case discussions will be made available to me by Sam once her recorded sessions have been completed. 
I understand that my participation or non-participation will not affect my grades for this course, nor in any way affect my future employability as a result of my involvement or non-involvement.

I understand that the data collected will be used to write Sam's thesis and any publications that arise from her research.

I understand that I may withdraw from Sam's study at any time up until the workshop session recording takes place. I understand that I am giving my consent for Sam to record the workshops using sound recording. I understand that, once the recording has started in the session, I can cease to participate, without providing a reason, by leaving the room.

I understand that, despite having participated in the workshop session(s), I may withdraw from the focus group before it takes place. I understand that the focus group session will be sound recorded. I understand that, once the focus group has started the only way I can cease to participate is to leave the room. I understand that, if I decide to withdraw from the research at any point, I will not be able to withdraw my data.

I understand that I will not be able to edit any of the recordings or the resulting transcripts. I understand that Sam will personally transcribe the audio soundtracks, solely for the purpose of her research. She will not disclose any information to any outside party. The transcribed data will be transferred onto a removable harddrive, pass-worded and safely stored. While the research is underway, only Sam's supervisor and Sam herself will have access to the transcripts. Once complete, only Sam will have access to it. I understand that the transcript data will be securely stored for ten years for the purpose of developing the research for further publication. After this period of time the data will be destroyed.

I understand that, once preliminary analysis of the data has taken place, Sam may wish to contact me via email to gain follow-up reflective evidence before the end of the semester. I have provided my email address below so that she can contact me directly. I understand if, at any time I no longer wish to participate in this research, I can contact Sam directly and she will remove me from her participant's contact list.

I understand that, should I be interested, Sam will also email me a summarised copy of her thesis once complete.

I agree to take part in this research.

- I understand that I am free to withdraw participation at any time up until the end of Semester 2, 2013.

- I understand I cannot withdraw any data, should I agree to participate.

- I agree / do not agree to be audiotaped.

- I wish / do not wish to receive the summary of findings.

- I agree to not disclose anything discussed in the focus group.

- I understand that data will be kept for ten years, after which it will be destroyed.

Name:

Signature:
Date:

Email:

APPROVED BY THE UNIVERSITY OF AUCKLAND HUMAN PARTICIPANTS ETHICS COMMITTEE ON 07-Aug-2013 for (3) years, Reference Number 10056 

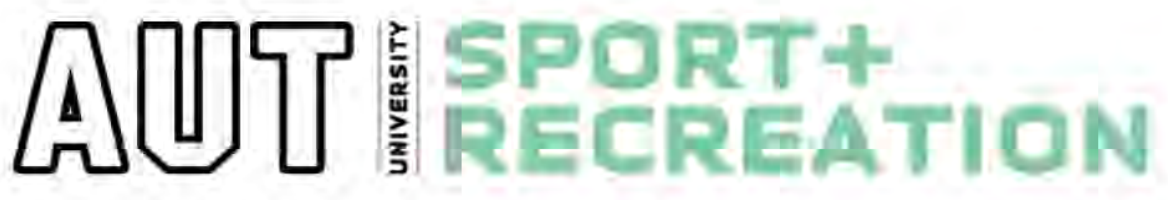

To whom it may concern,

As a sports coaching and leadership lecturer at AUT, I strongly support Sam Young's proposed research project into case study delivery methods, planned to take place in September 2013.

Our students come from a broad range of backgrounds and learning styles, also with a breath of ages - from school leavers to retirees - and stages. Because of the diversity in our classrooms, we seek to vary our delivery methods as much as possible. At the School of Sport and Recreation we focus on quality teaching and learning and Sam's project will provide us with evidence of a particular delivery model and its effect on student leaming.

Our job as lecturers is to create an environment whereby learning takes place for our students. Sam's research project offers an opportunity to improve our understanding of how students make sense of case study learning in a way that is active, enhances engagement and improves our own understanding of our profession.

Within the leadership class, case studies are a large part of the paper. As we have large numbers at AUT, I have found it difficult to find a way to get the most out of students when using case studies. Therefore, it will be interesting to deliver known materials in a different way. Additionally, I feel that the results of Sam's case approach comparison will assist our school in making decisions about how best to help our students leam, and to be open to new ways of delivering our classes.

Sam is an amazing, passionate reflector and planner of leadership. She has been prominent in the development of our leadership paper at the School of Sport and Recreation. I am very confident that Sam's Masters will provide insight to many lecturers and teachers of Leadership internationally. In saying that, she has been able to think through how this research project will work in as objective a manner as possible. She is a careful and thorough researcher, and I have every confidence that this project will be undertaken with care, respect and transparency for the participants, analysis and outcomes.

1 am looking forward to our continuing relationship with developing the best for the students and participating in Sam's project during this coming semester.

Yours sincerely

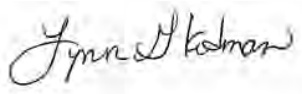

Lynn Kidman, PhD

Auckland University of Technology

Private Bag 92006

Auckland New Zealand 1020

Ph: +64 (0)9 9219999 Ext. 6678 or

at AUTM Ext. 5197 


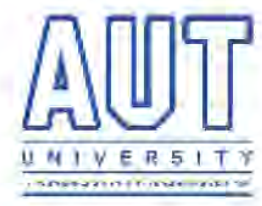

31 March 2014

\section{To whom it may concern,}

Sam Young has taught on AUT University's Bachelor of Sport and Recreation programme, delivered at Nelson's NMIT Campus, since 2007.

Her proposed research project into case study delivery methods, planned to take place in September 2013, has the endorsement of Dr Lynn Kidman. Lynn is the course co-ordinator at AUT University for the Sports Leadership paper, and works closely with Sam.

Both Lynn and Sam will keep me informed of the research project. They are both very competent and aware of how to work in the best interests of our students.

With Lynn's strong support, I have no hesitation in supporting and endorsing Sam's research.

This research outcome will be of great interest for us at AUT University. Obtaining a better understand of how our students make sense of case study learning, in a way that is active, enhances engagement. In turn this will improve teaching and learning approaches that can only assist our team.

I therefore look forward to seeing the results of Sam's research project.

Yours sincerely,

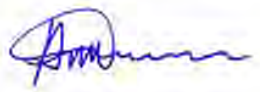

Henry Duncan, PhD

Head of Schoo

Sport and Recreation

Private Bag 92006 Auckland 1020 New Zealand www. aut.ac.nz

Telephone 64-9 921-9999 Ext 7839

School of Sport and Recreation 
AUT Bachelor of Sport \& Recreation

J Block

Hardy Street

NELSON

Phone: (03) 5469175 ext 692

Email: Claire.Dallison@nmit.ac.nz

Letter in Support of Sam Young's Research Ethics Application

To whom it may concem,

Sam Young has been teaching year three management papers on the joint venture Bachelor degree programme between AUT and NMIT since 2007. She is a wellrespected lecturer who is passionate about fostering student learning.

As the leader of the AUT Sport and Recreation programme at NMIT, I strongly support Sam Young's proposed semester 2 research project, in comparing two case study delivery methods with our year three AUT Sports Leadership students.

While the any student group will range in learning styles, our sport and recreation students tend to be more kinaesthetic leamers. A teaching delivery style based around lecturing will not engage them. We currently use a blended approach of workshop and lecture. However, it is possible that case-centred teaching method may more actively engage students and provide a more meaningful way for them to apply their learning.

To support students learning, we need to seek new methods of delivery. Sam's research project offers our Sport and Recreation team the opportunity to better understand how our students make sense of case study learning, and the results should assist our team's teaching and learning strategies and decisions.

Sam is an academic who creates learning partnerships with her colleagues and her students. She is a reflective practitioner who researches carefully, and methodically, with care for the respect and autonomy of the individual. She is enthusiastic in creating positive and open learning environments. Sam brings these qualities to all aspects of her work.

It will be wonderful to play a small part in Sam's project, and I will be fascinated to see the outcomes of her research, both for the Sport and Recreation team, and for our students.

Yours sincerely

Claíre Dallíson

Claire Dallison

AUT Bachelor of Sport \& Recreation, Nelson Programme Leader 


\section{June 2013}

To whom it may concern,

As a teacher of management papers in the Applied Business School at NMIT, I strongly support Sam Young's proposed research project into case study delivery methods, planned to take place in September 2013

I have taught alongside Sam at NMIT for the last four years, and during this time we have had numerous discussions about teaching pedagogies and practices. Her focus has always been on the improvement of teaching and learning to deliver students better outcomes for students.

The students at NMIT come from a broad range of backgrounds and learning styles, also with a breath of ages - from school leavers to retirees - and learning and development stages. Because of the diversity in our classrooms, we seek to vary our delivery methods as much as possible, and most importantly try and create 'real world' learning opportunities for them. Case study teaching is a key component of this type of learning.

Consequently Sam's research project holds considerable interest for us by helping us improve our understanding of how students make sense of case study learning in a way that is active, enhances engagement and improves our own understanding of teaching and leaming.

As a proponent of 'flipped' teaching methodology. I regularly use cases in my teaching, and will be very interested to see first-hand the themes that arise from the two methods that Sam proposes testing. I believe the results of Sam's case approach comparison will assist myself and the wider teaching population in making decisions about how best to help our students leam.

Sam has invested a great deal of energy and thought into her Masters to date, and has been open and objective in working through the development of her research project. She is a passionate, considered and diligent researcher, and I have every confidence that this project will be undertaken with care, respect and transparency for the participants, analysis and outcomes.

I am looking forward to working more closely with Sam and participating in her project during this coming semester.

Yours sincerely<smiles>CCCCCC</smiles>

Nic John

Academic Staff Member 


\section{Appendix Four (a): Research Questions: Lecturer Survey}

Location online: This survey is also currently viewable at

https://www.surveymonkey.com/s/X3KJ9YM.

\section{Survey Screen One}

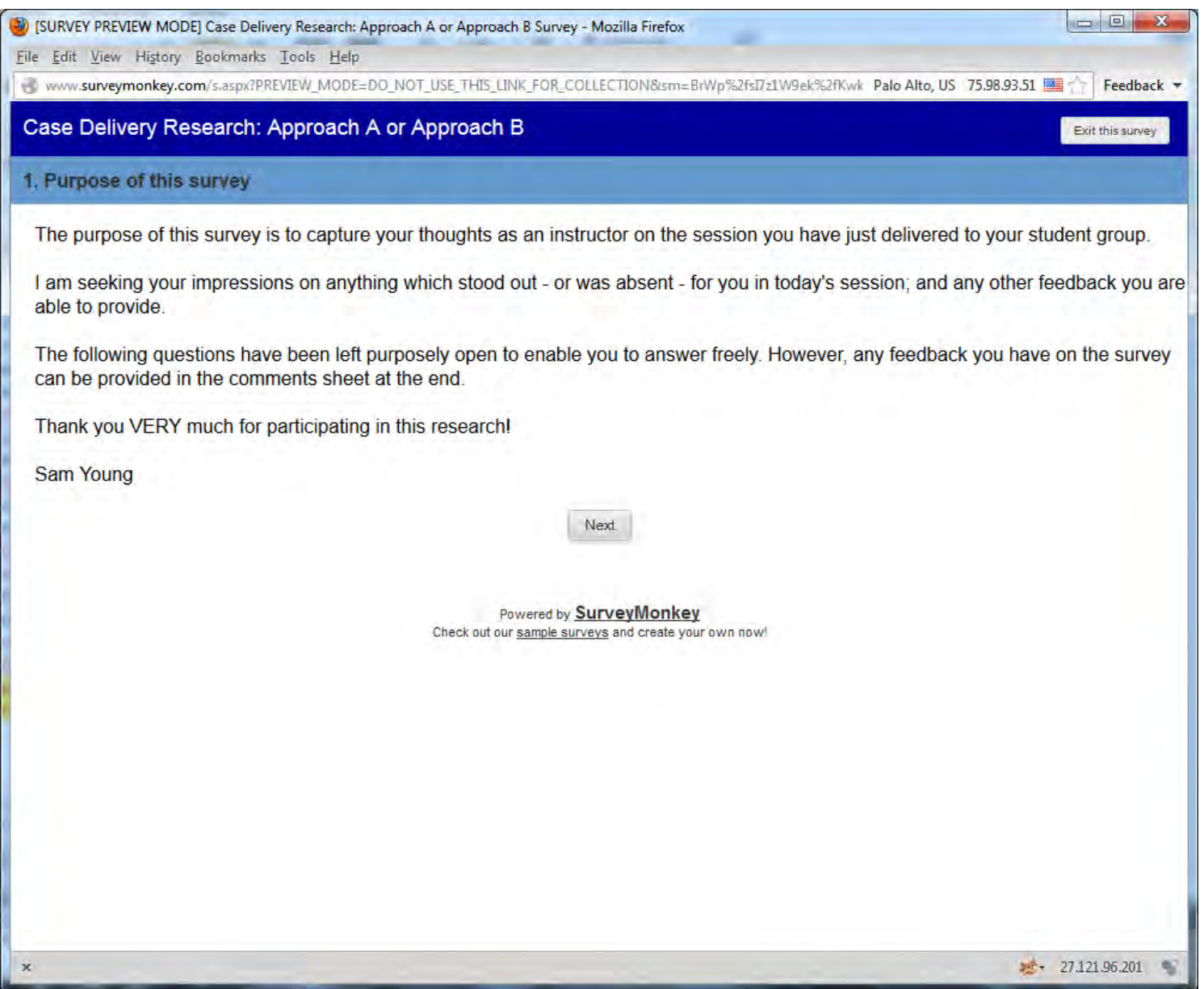




\section{Survey Screen Two}

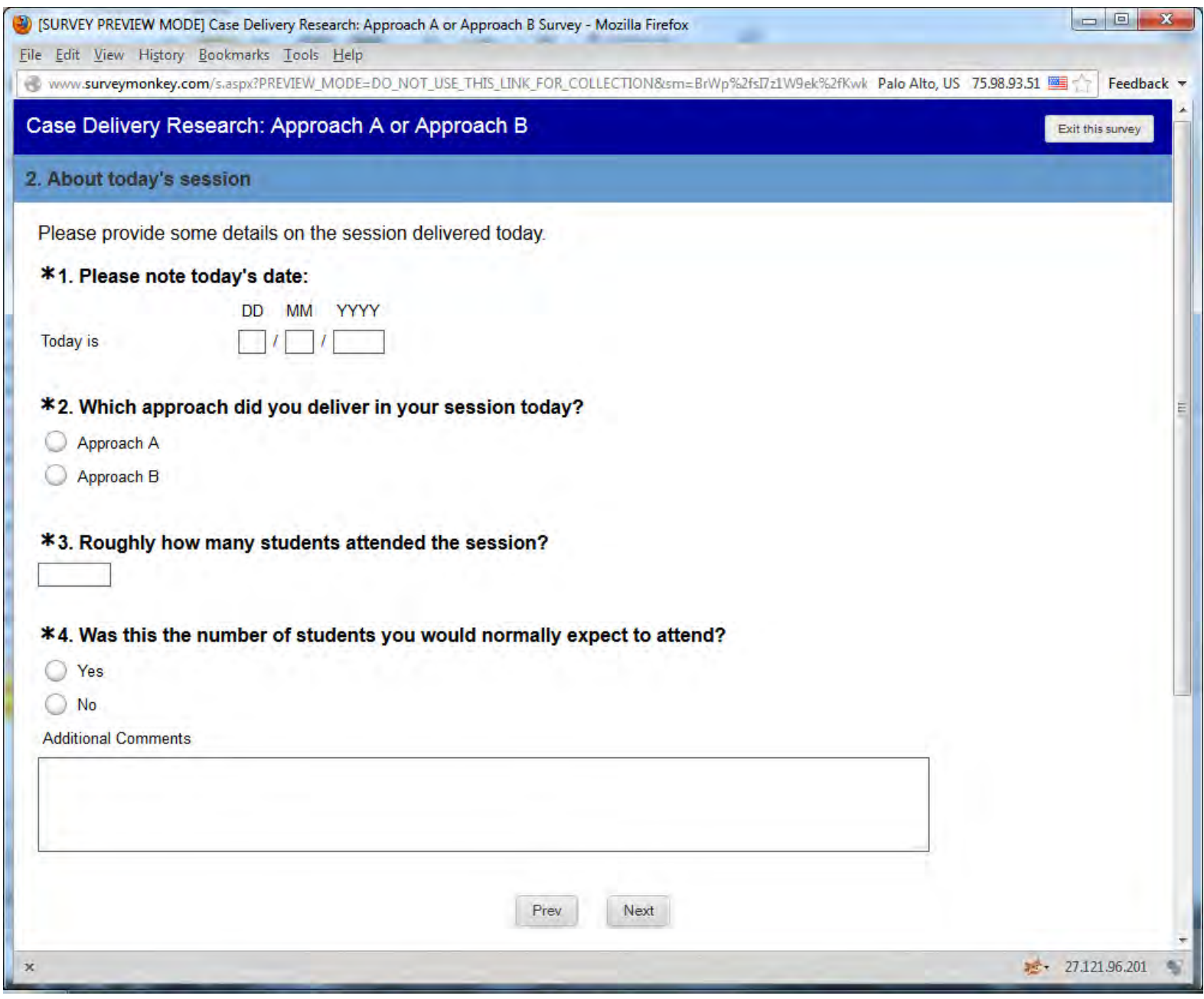




\section{Survey Screen Three}

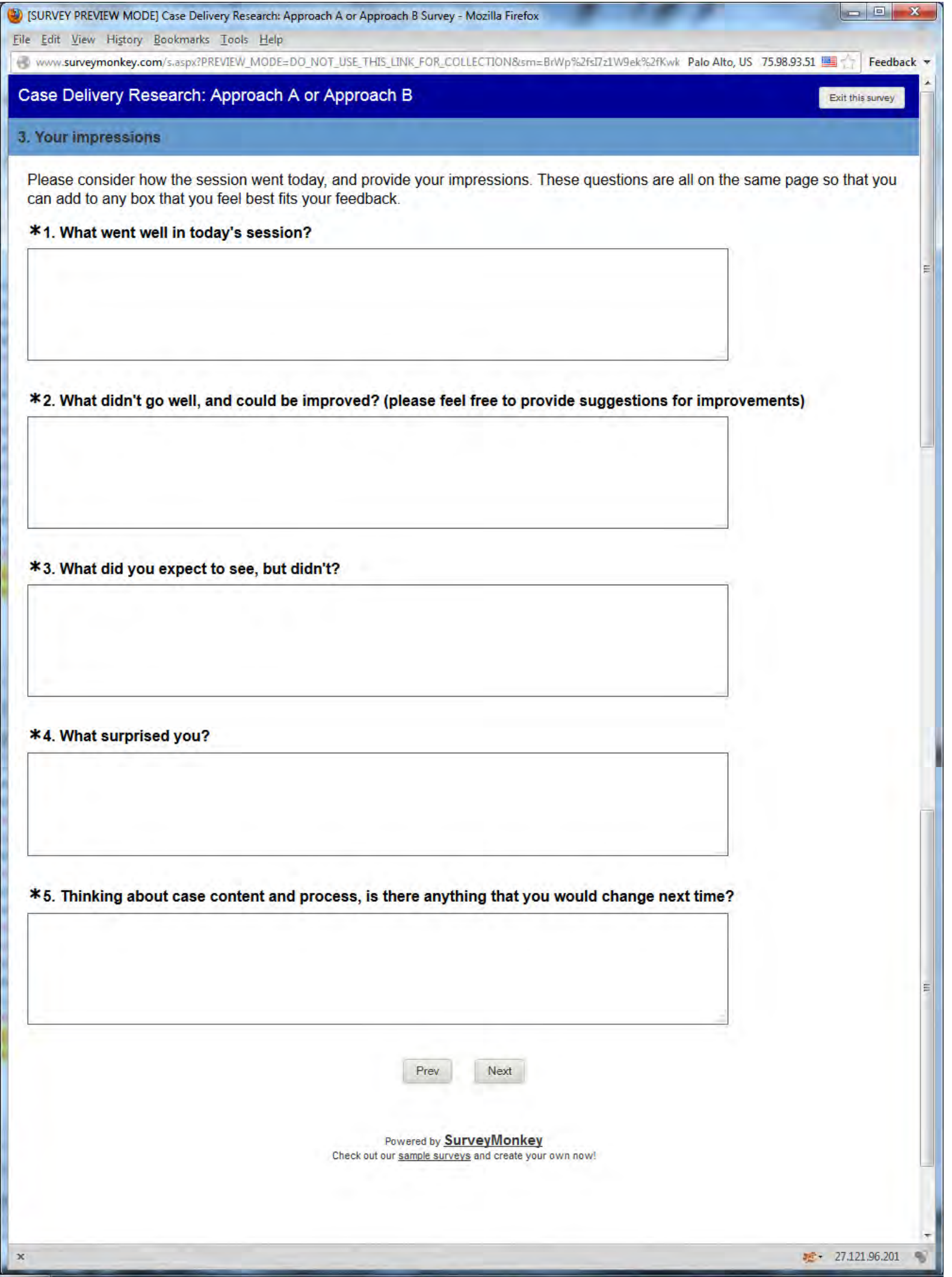




\section{Survey Screen Four}

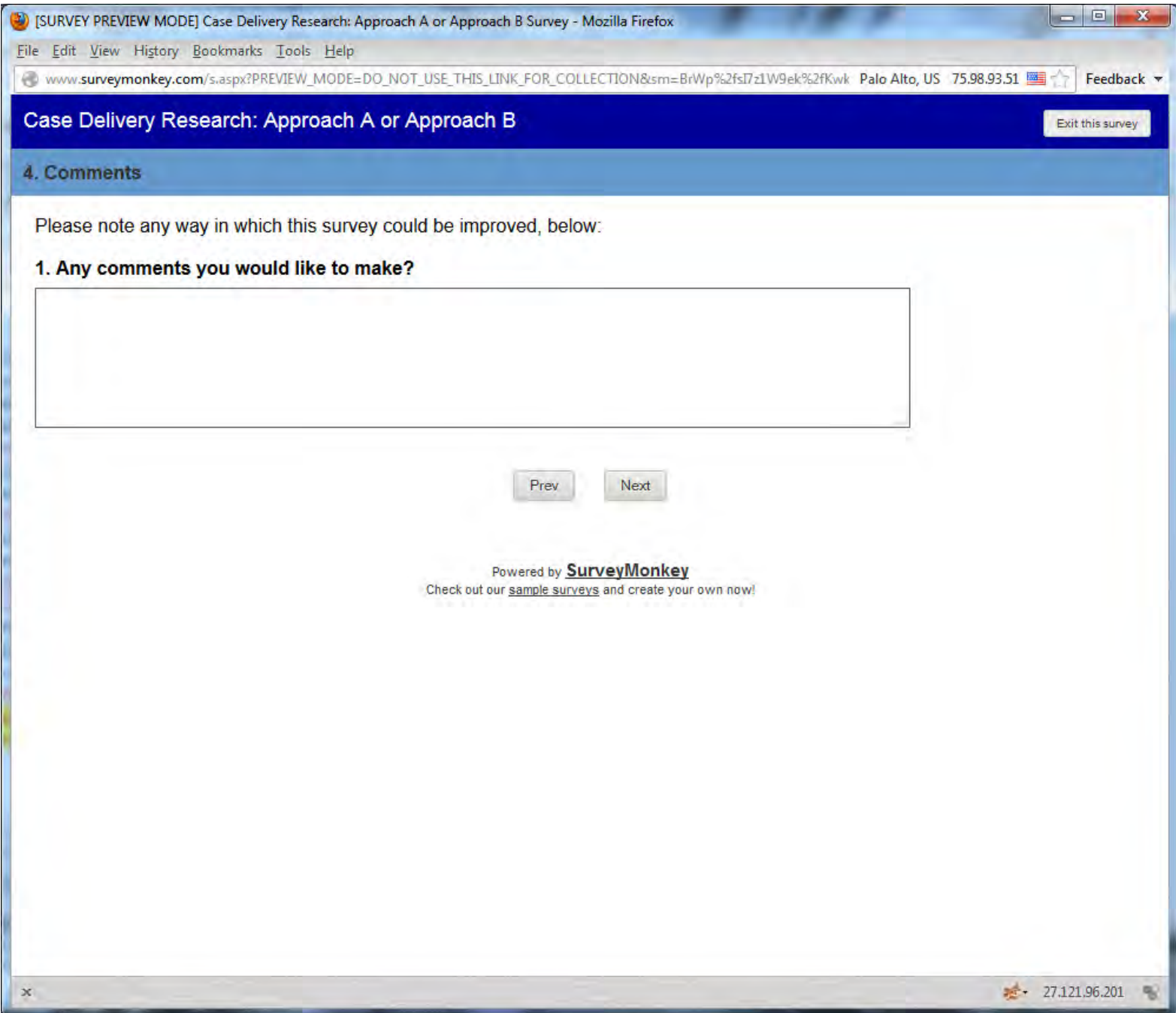




\section{Appendix Four (b): Student Focus Group Questions}

All instructors will have prompted their students to reflect on the two sessions which they attended.

1. Considering the voice recorded Shared Leadership session you attended, on reflection, is there anything that you felt went particularly well?

2. Was there anything that you feel could have been improved in that session?

3. If you think about the things that you expected to have happen in a session like that, was there anything that didn't happen in the recorded Shared Leadership session?

4. Were there any surprises for you in thinking about this session, or hearing the comments of the other students around you?

5. Do you think you learned well from this method? Why?

6. Considering the voice recorded Power \& Ethics session you attended, on reflection, is there anything that you felt went particularly well?

7. Was there anything that you feel could have been improved in that session?

8. If you think about the things that you expected to have happen in a session like that, was there anything that didn't happen in the recorded Power \& Ethics session?

9. Were there any surprises for you in thinking about this session, or hearing the comments of the other students around you?

10. Do you think you learned well from this method? Why?

11. Considering both the Shared Leadership session and the Power \& Ethics sessions, on reflection, do you have a preference for either method? Why?

NB: if preferring one method over the other, ask:

a. Is there any one thing in particular that attracts you to this way of teaching and learning?

b. Do you feel that your learning is improved with this approach? How, do you think?

c. What is it about the other method that reduces its appeal? Why?

d. Did you feel that the entire class learned more from this Approach that the other? What evidence or impressions lead you to feel this way?

If answering "no preference, ask:

a. Did you feel that the other students learned more from one Approach that the other? What evidence or impressions lead you to feel this way?

12. Is there anything else that you can contribute? 
The following lesson plans were provided to each of the lecturers undertaking the Approach A and B sessions:

\section{Nic John Lesson Plan: Approach A, Session 1 Shared Leadership}

Group NMIT Nelson Campus, T302

Date 30 August 2013

Objectives Students will:

1. Continue to determine what makes an effective leader

2. Continue to evaluate and further explore our own model of leadership.

\begin{tabular}{|c|c|c|c|}
\hline Time & Content & Method & Resources \\
\hline 1.75 & $\begin{array}{l}\text { Effectively a tutorial; } \\
\text { expectation is that students } \\
\text { are self-directed, but lecturers } \\
\text { may prompt with questions or } \\
\text { suggest ideas for student } \\
\text { research. } \\
\text { Students use the time to: } \\
\text { - Read the materials } \\
\text { - Watch the clip at } \\
\text { http://www.youtube.com/w } \\
\text { atch?v=KQDmX5nVbVw } \\
\text { - Discuss students' } \\
\text { individual case analysis } \\
\text { (i.e., sharing case } \\
\text { analyses \& finding } \\
\text { common paths) in small } \\
\text { groups } \\
\text { - Ask clarification questions } \\
\text { on materials }\end{array}$ & $\begin{array}{l}\text { Small group } \\
\text { discussion } \\
\text { Student input } \\
\text { only } \\
\text { Students } \\
\text { encouraged to } \\
\text { use the white } \\
\text { boards } \\
\text { Watch the } \\
\text { YouTube clip, } \\
\text { but don't have } \\
\text { any input into } \\
\text { student } \\
\text { discussion. }\end{array}$ & $\begin{array}{l}\text { Readings: } \\
\text { Ferkins \& Shilbury - Developing board } \\
\text { strategic capability in sport } \\
\text { organisations - TNZ, 2010.pdf } \\
\text { Hoye - Leadership Within Australian } \\
\text { Voluntary Sport Organization } \\
\text { Boards.pdf } \\
\text { Case: } \\
\text { 02d case study - Tennis New Zealand } \\
\text { unify, lead and strengthen, 2013.pdf }\end{array}$ \\
\hline
\end{tabular}

Nic John Lesson Plan: Approach A, Session 2 Shared Leadership

Group NMIT Nelson Campus, T302

Date 3 Sept 2013

Objectives Students will:

1. Continue to determine what makes an effective leader

2. Continue to evaluate and further explore our own model of leadership.

\begin{tabular}{|c|c|c|c|}
\hline Time & Content & Method & Resources \\
\hline 1.75 & $\begin{array}{l}\text { Sound recorded. } \\
\text { Class discussion, lecturer } \\
\text { facilitated } \\
\text { Using the questions in the }\end{array}$ & $\begin{array}{l}\text { PowerPoint } \\
\text { Small group } \\
\text { discussion } \\
\text { Class }\end{array}$ & $\begin{array}{l}\text { PowerPoint notes for lecturer: } \\
\text { 02d Shared Leadership.ppt } \\
\text { Case Teaching Note: } \\
\text { Young - Tennis New Zealand Full }\end{array}$ \\
\hline
\end{tabular}




\begin{tabular}{|c|c|c|c|}
\hline Time & Content & Method & Resources \\
\hline & case's teaching note & $\begin{array}{l}\text { Discussion \& } \\
\text { questioning }\end{array}$ & 2013, v1-7.doc \\
\hline
\end{tabular}

\section{Nic John Lesson Plan: Approach B, Session 1 Power \& Ethics}

Group NMIT Nelson Campus, T302

Date 6 Sept 2013

Objectives Students will:

1. Continue to determine what makes an effective leader

2. Continue to evaluate and further explore our own model of leadership.

\begin{tabular}{|c|c|c|c|}
\hline Time & Content & Method & Resources \\
\hline 1.75 & $\begin{array}{l}\text { Please sound record this } \\
\text { session } \\
\text { Go through the PowerPoint, } \\
\text { combination of } \\
\text { lecture/workshop as usual } \\
\text { Keys: } \\
\text { Frames of reference (9-10) } \\
\text { Sources of Power (12-14) } \\
\text { Ethical vs unethical (16) } \\
3 \text { Levels of personal moral } \\
\text { development (18) }\end{array}$ & $\begin{array}{l}\text { PowerPoint } \\
\text { Small group } \\
\text { discussion } \\
\text { Class } \\
\text { Discussion \& } \\
\text { questioning }\end{array}$ & $\begin{array}{l}\text { Readings: } \\
\text { Brown \& Trevino - Ethical Leadership, } \\
\text { 2006.pdf } \\
\text { Yukl - Leadership in Organisations } \\
\text { Chp 6, 2002.pdf OR Daft \& Pirola- } \\
\text { Merlo - The Leadership Experience, } \\
\text { Chapter 11, 2009.pdf } \\
\text { Case: } \\
\text { 02e Case Study - Lance Armstrong } \\
\text { Everyone's doing it, 2013.pdf } \\
\text { 02e Case Study - The Underarm } \\
\text { Incident.pdf }\end{array}$ \\
\hline
\end{tabular}

Group NMIT Nelson Campus, T302

Date 9 Sept 2013

Objectives Students will:

1. Continue to determine what makes an effective leader

2. Continue to evaluate and further explore our own model of leadership.

\begin{tabular}{|c|c|c|c|}
\hline Time & Content & Method & Resources \\
\hline 1.75 & $\begin{array}{l}\text { No recording - can finish } \\
\text { early! } \\
\text { Go through the PowerPoint, } \\
\text { combination of } \\
\text { lecture/workshop as usual } \\
\text { Key: Ethical Action Guidelines } \\
\text { to use Power \& Politics (23) }\end{array}$ & $\begin{array}{l}\text { Class } \\
\text { Discussion \& } \\
\text { questioning }\end{array}$ & $\begin{array}{l}\text { Readings: } \\
\text { Brown \& Trevino - Ethical Leadership, } \\
\text { 2006.pdf } \\
\text { Yukl - Leadership in Organisations } \\
\text { Chp 6, 2002.pdf OR Daft \& Pirola- } \\
\text { Merlo - The Leadership Experience, } \\
\text { Chapter 11, 2009.pdf } \\
\text { Case: } \\
\text { 02e Case Study - Lance Armstrong } \\
\text { Everyone's doing it, 2013.pdf } \\
\text { 02e Case Study - The Underarm } \\
\text { Incident.pdf }\end{array}$ \\
\hline
\end{tabular}


Group AUT Manukau (M) / North Shore Campus (NS)

Date 26 Aug 2013 (NS)

27 Aug 2013 (M)

Objectives Students will:

1. Continue to determine what makes an effective leader

2. Continue to evaluate and further explore our own model of leadership.

\begin{tabular}{|c|c|c|c|}
\hline Time & Content & Method & Resources \\
\hline 1.75 & $\begin{array}{l}\text { North Shore not recording } \\
\text { Manukau will record up to } \\
\text { the Tennis NZ case } \\
\text { Go through the PowerPoint, } \\
\text { combination of } \\
\text { lecture/workshop as usual }\end{array}$ & $\begin{array}{l}\text { PowerPoint } \\
\text { Small group } \\
\text { discussion } \\
\text { Class } \\
\text { Discussion \& } \\
\text { questioning }\end{array}$ & $\begin{array}{l}\text { 02d Shared Leadership.ppt } \\
\text { Readings: } \\
\text { Ferkins \& Shilbury - Developing board } \\
\text { strategic capability in sport } \\
\text { organisations - TNZ, 2010.pdf } \\
\text { Hoye - Leadership Within Australian } \\
\text { Voluntary Sport Organization } \\
\text { Boards.pdf } \\
\text { Cases: } \\
\text { 02d case study - Tennis New Zealand } \\
\text { unify, lead and strengthen, 2013.pdf } \\
\text { 02d Case Study - MyFC by the } \\
\text { people, for the people, 2010.pdf }\end{array}$ \\
\hline
\end{tabular}

Lynn Kidman Lesson Plan: Approach B, Session 2 Shared Leadership

Group AUT Manukau (M) / North Shore Campus (NS)

Date 27 Aug $2013(\mathrm{M})$

28 Aug 2013 (NS)

Objectives Students will:

1. Continue to determine what makes an effective leader

2. Continue to evaluate and further explore our own model of leadership.

\begin{tabular}{|c|c|c|c|}
\hline Time & Content & Method & Resources \\
\hline 1.75 & $\begin{array}{l}\text { North Shore recording } \\
\text { No recording for Manukau } \\
\text { Go through the PowerPoint, } \\
\text { combination of } \\
\text { lecture/workshop as usual }\end{array}$ & $\begin{array}{l}\text { PowerPoint } \\
\text { Small group } \\
\text { discussion } \\
\text { Class } \\
\text { Discussion \& } \\
\text { questioning }\end{array}$ & $\begin{array}{l}\text { 02d Shared Leadership.ppt } \\
\text { Readings: } \\
\text { Ferkins \& Shilbury - Developing board } \\
\text { strategic capability in sport } \\
\text { organisations - TNZ, 2010.pdf } \\
\text { Hoye - Leadership Within Australian } \\
\text { Voluntary Sport Organization } \\
\text { Boards.pdf } \\
\text { Cases: } \\
\text { 02d Case Study - MyFC by the } \\
\text { people, for the people, 2010.pdf } \\
\text { 02d case study - Tennis New Zealand }\end{array}$ \\
\hline
\end{tabular}




\begin{tabular}{|l|l|l|l|}
\hline \multicolumn{1}{|c|}{ Time Content } & \multicolumn{1}{|l}{ Method } & \multicolumn{1}{l}{ Resources } \\
\hline & & & unify, lead and strengthen, 2013.pdf \\
\hline
\end{tabular}

\section{Lynn Kidman Lesson Plan: Approach A, Session 1 Power \& Ethics}

Group AUT Manukau (M) / North Shore Campus (NS)

Date 3 Sep 2013 (NS)

4 Sep $2013(M)$

Objectives Students will:

1. Continue to determine what makes an effective leader

2. Continue to evaluate and further explore our own model of leadership.

\begin{tabular}{|c|c|c|c|}
\hline Time & Content & Method & Resources \\
\hline 1.75 & $\begin{array}{l}\text { No recording } \\
\text { Effectively a tutorial; } \\
\text { expectation is that students } \\
\text { are self-directed, but lecturers } \\
\text { may prompt with questions or } \\
\text { suggest ideas for student } \\
\text { research. } \\
\text { Students use the time to: } \\
\text { - Read the materials } \\
\text { - Watch the clip at } \\
\text { http://www.youtube.com/w } \\
\text { atch?V=KQDmX5nVbVw } \\
\text { Discuss students' } \\
\text { individual case analysis } \\
\text { (i.e., sharing case } \\
\text { analyses \& finding } \\
\text { common paths) in small } \\
\text { groups } \\
\text { Ask clarification questions } \\
\text { on materials }\end{array}$ & $\begin{array}{l}\text { Small group } \\
\text { discussion } \\
\text { Student input } \\
\text { only } \\
\text { Students } \\
\text { encouraged to } \\
\text { use the white } \\
\text { boards } \\
\text { Watch the } \\
\text { YouTube clip, } \\
\text { but don't have } \\
\text { any input into } \\
\text { student } \\
\text { discussion }\end{array}$ & $\begin{array}{l}\text { Online Links: } \\
\text { - } \quad \text { http://www.screenr.com/W4qs } \\
\text { - } \quad \text { http://www.screenr.com/flqs } \\
\text { - } \quad \text { http://www.screenr.com/ylqs } \\
\text { - } \quad \text { http://www.screenr.com/Kdfs } \\
\text { - } \quad \text { http://wwww.screenr.com/4dfs } \\
\text { - } \quad \text { http://www.screenr.com/wmfs } \\
\text { - } \quad \text { http://www.screenr.com/sRfs } \\
\text { - } \quad \text { http://www.screenr.com/HRfs } \\
\text { Readings: } \\
\text { Brown \& Trevino - Ethical Leadership, } \\
\text { 2006.pdf } \\
\text { Yukl - Leadership in Organisations } \\
\text { Chp 6, 2002.pdf OR } \\
\text { Daft \& Pirola-Merlo - The Leadership } \\
\text { Experience, Chapter 11, 2009.pdf } \\
\text { Case: } \\
\text { 02e Case Study - Lance Armstrong } \\
\text { Everyone's doing it, 2013.pdf }\end{array}$ \\
\hline
\end{tabular}

\section{Lynn Kidman Lesson Plan: Approach A, Session 2 Power \& Ethics}

Group AUT Manukau (M) / North Shore Campus (NS)

Date 4 Sep $2013(M)$ 5 Sep 2013 (NS)

Objectives Students will:

1. Continue to determine what makes an effective leader

2. Continue to evaluate and further explore our own model of leadership.

\begin{tabular}{|c|c|c|c|}
\hline Time & Content & Method & Resources \\
\hline 1.75 & $\begin{array}{l}\text { Sound recorded. } \\
\text { Class discussion, lecturer } \\
\text { facilitated } \\
\text { Using the questions in the } \\
\text { case's teaching note }\end{array}$ & $\begin{array}{l}\text { Class } \\
\text { Discussion \& } \\
\text { questioning }\end{array}$ & $\begin{array}{l}\text { PowerPoint notes for lecturer: } \\
\text { 02e Power \& Ethics in Leadership.ppt } \\
\text { Teaching Note for lecturer: } \\
\text { Young - Lance Armstrong Full 2013, }\end{array}$ \\
\hline
\end{tabular}




\begin{tabular}{|l|l|l|l}
\hline & v1-5.doc \\
\hline
\end{tabular}




\section{Appendix Five (b): Instructor Briefing Pack - Background}

\section{Materials}

The following materials were also provided to each of the lecturers to clearly illustrate the difference between the Approach A ("Case in Point") and Approach B sessions:

- Copy of Chapter 2: How do we begin (pp. 19-43) from Parks, Sharon Daloz (2005). Leadership Can Be Taught. USA: Harvard Business School Press. Explaining how a "Case in Point" session runs organically, depending on where the students lead the exploration

- Link to Harvard Business School (2009). Inside the Case Method Part 1. Retrieved from https://www.youtube.com/watch?v=Y4j25Pj4JyQ detailing Harvard's "Case in Point" method

- Link to Harvard Business School (2009). Inside the Case Method Part 2. Retrieved from https://www.youtube.com/watch?v=JJ7aVrtTbgo detailing Harvard's "Case in Point" method

- Copy of my draft literature review detailing the differences thus far between the "Case in Point" (Approach A) method and the hybrid method currently taught (Approach B)

- Copy of Chapter 1: What is the Case Method Paradigm? (pp. 1-25) from Gill, Grandon (2011). Informing with the Case Method. USA: Informing Science Press. This compares the hybrid and the "Case in Point" method, illustrating differences.

In addition, I provided Nic with a class bio (Degree: AUT B.Sport \& Recreation; age range 20-30, average 23; Men 54\%, Women 46\%; Ethnicity - NZ/Pakeha 93\%, NZ Maori 7\%, Pasifika 0\%, Internationals $0 \%$ ), plus a list of the student's names and photos, and an assessment of cohort capability. 
Appendix Six (a): Medium Teaching Case - Lance Armstrong

\section{Lance Armstrong - Everybody's doing it}

A case study about a leader's ethics and use of power

2013

by Sam Young 


\section{Lance Armstrong - Everybody's doing it}

\section{A case study about leadership}

"My name is Lance Armstrong. I am a cancer survivor. I'm a father of five. And yes, I won the Tour de France seven times"1

From 1999 to 2005, Lance Amstrong annually won road cycling's most public event: the Tour de France, Competed for, over three weeks in 23 stages, the Tour weaves through 2,500 miles of plains, hills and mountains and is a test of endurance, strategy, technology, skill, stamina and teamwork ${ }^{2}$.

However, the race has been tarnished by questionable practices; the most prevalent being the taking of banned substances by cyclists. Drugs programmes are overseen globally by the World Anti-Doping Agency (WADA) and specifically for US athletes by the quasigovernmental United States Anti-Doping Agency (USADA).

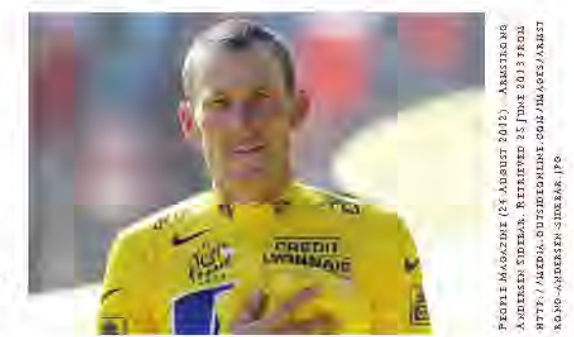

Testing at races is delegated to cycling's international governing body, Union Cycliste Internationale (UCI) , with test issues being passed on to national cycling bodies (such as USA Cycling). All these organisations should work cohesively together, but in reality, they all have different aims, rules and regulations, Athletes can seek the gaps.

Up until 1994, Lance Armstrong won steadily, but not outstandingly. That year, Lance started working with Dr Michele Ferrari. In 1995, Lance started winning, rising to seventh in the world and gaining a place with the French team Cofidis. In 1996 he was diagnosed with testicular cancer, which had metastasised to his abdomen, lungs, lymph nodes and brain. With aggressive surgery and chemotherapy, Lance was in full remission by February $1997^{6}$,

Lance made his post-cancer cycling comeback in $1998^{6}$. Sponsored by Nike, the US Postal Service (USPS), Discovery Channel, RadioShack, Anheuser-Busch, Oakley, Nissan, Trek-Bicycle Corp, Johnson Health Tech, SRAM Corporation, FRS, Easton-Bell Sports, Honey Stinger and 24-Hour Fitness Gyms, Lance built a team strong in cycle technology, sports gear, nutrition and capital?

As well as for USPS/Discovery, Lance was indirectly riding for his cancer charity, Livestrong ${ }^{8}$, which gave him great publicity. He and Livestrong were indivisible; he was not merely a rider, he was a cancer survivor. He credited his fitness and willpower with his 'beating' cancer, which appeared to convey greater cult status. Some propose that this evangelism is a not-uncommon side effect of a successful cancer remission ${ }^{10}$.

This symbiotic relationship between Lance and Livestrong created an extremely strong sense of loyalty from his followers. He was seen as a risk-taker, with some degree of 'inside' knowledge gained via his illness and recovery ${ }^{11}$.

Lance said "we had one goal and one ambition and that was to win the greatest bike race in the world and not just to win it once, but to keep winning it" ${ }^{12}$. The team of medicine men that Lance put together to ensure this included his old friend Michele Ferrari; from 1997 to 1999 and 2004 onwards, Pedro Celaya; and from 1999, Luis

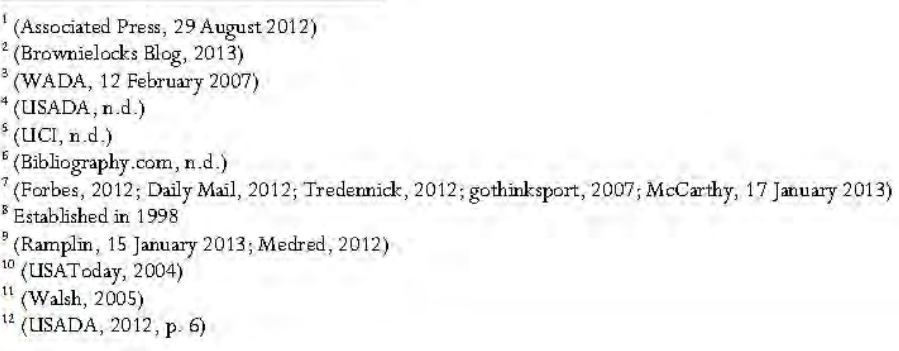




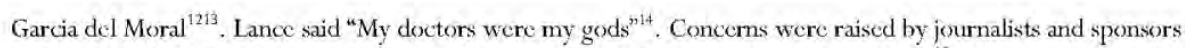
about the medical tcam's reputations, but were brushed aside, or contact became covert ${ }^{13}$.

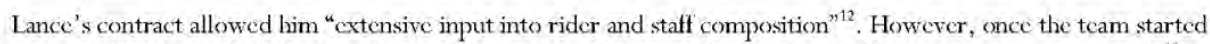
winning, he effectively had carte blanche. Many reported on Lance's coercion, bullying and strong-arm tactics ${ }^{13}$. He was "the boss man of the Tour", establishing his own regime in the peloton. Any racers who challenged him "would be run down by an Armstrong teammate or, for certain violators, by Lance himself"15. A young French cyclist, Clristophe Bassons, did not dope and broadcast widely that riders couldn't finish in the top ten without PEDs ${ }^{16}$. Lance bullied Bassons, calling him "Mr Clean", publicising Christophe's comments in press interviews, organising the pack to shun him, and forcing him to retire from the tour ${ }^{17}$. In Spain 2002, Armstrong red-carpeted a teammate telling the rider he had to follow the team doctor's doping program if he wanted to continue riding for the team ${ }^{18}$. The rider said "Lance called the shots on the team" and "what Lance said went" ${ }^{\text {"18 }}$. Scott Mercier chose to keave competitive cycling in 1997 when the choiec-dope or go-was placed before him as a team member ${ }^{4 t}$. Lance injected limself with $\mathrm{EPO}^{19}$ in front of team mate Jonathan Vaughters saying "' $[\mathrm{n}]$ ow that you are doing EPO too, you can't go write a book about it" ${ }^{13}$. Lance's cx-wife, Kristin, ferricd and prepared drugs for the team ${ }^{13}$.

When sports writer David Walsh said that Lance's results were too good to be true, Lance went to great lengths to undermine the credibility of the four-times UK journalist of the year winner, avoiding answering, ignoring questions asked by David at press conferences, not returning calls, labelling him the "the little $\mathrm{L}^{* * * * * * *}$ troll" and sending David to 'Coventry ${ }^{2023}$. Other journalists wouldn't associate publicly with David as they feared being denied interviews with Lance and his team ${ }^{17}$. After she left the USPS team, ex-employec Emma O'Reilly spoke out about the doping she had witnessed. She was then repeatedly publicly humiliated by Lance with accusations of prostitution and alcoholism ${ }^{23}$. Betsy Andreu also whistle-blew, going so lar as to lodge an altidavit in $2006^{10}$ to witnessing Lance tell his cancer specialist what PEDs he was taking when he was first diagnosed with cancer in 1996. Lance's retaliation was to label ber "bitter" and a "crazed b****". He shunned both Betsy and her cyclist husband, Гrankie; with the pull Lance had in cyeling, this effectively ended Гrankic's carcer ${ }^{23}$. Betsy's has stated many times that it is her belict that Lance's PED consumption was the cause of his cancer.

Both Betsy and Emma, along with former rider Stephen Swart, provided David with material for the book cowritten with Pierre Ballester in $2004^{23}$. Lance brushed off the book's accusations, dismissing them by saying that David had no evidence and that "extraordinary accusations must be followed up with extraordinary proof" Lance's actions belied his words, however, as he sued David in the UK where libel laws are stringent, and settled out of court - for $£ 300,000$. David was from this point effectively out of cycling's inner circle.

There may be a more venal reason for the defamation action. SCA Promotions Inc had promised Lance a US $5 \mathrm{~m}$ bonus if Lance was clean in his Tour campaign; David's book indicated that Lance had not been clean ${ }^{10}$. SCA threatened to sue Lance ${ }^{10}$; it is not a great stretch that Lance sued David to ensure that he (Lance) got his bonus.

There was a code of silence - called the "omerta" - amongst the Tour elite. No one spoke about doping, or about Lance ${ }^{12}$. Lance was good friends with the UCI President, and had made two significant donations to UCI, which, when taken with the rumours of doping, and no $\mathrm{UCI}$ action, made Lance appear untouchable ${ }^{21}$. David Walsh has commented that many good investigative journalists left the Tour, as the doping culture became more overt ${ }^{21}$.

USADA said that "the US Postal Service Pro Cycling Team ran the most sophisticated, professionalized and successtul doping program that sport has ever seen ${ }^{, 22}$. For example, in 1998, when a UCI drug tester appeared unexpectedly at the team's hotel, Dr Pedro Celaya managed to smuggle in a litre of saline to Lance's room, administering it before Lance could be tested. However, in 1999, Pedro was replaced - for not being "aggressive cnough" - with Luis Garcia del Moral, Luis had a spreadshect containing the team doping plan, detailing "This is when you use growth hormonc, this is when to start EPO ${ }^{23}$. That year, the team avoided most of the carly season events so as to

${ }^{13}$ (USADA, 2012)

${ }_{14}^{14}$ (Armstrong, 2000, p, 119)

${ }^{15}$ (Saporito, 16 January 2013)

${ }_{16}^{16}$ performance-enhancing drugs (PEDs)

${ }^{17}$ (Walsh, 22 October 2012; Willsher, 13 October 2012)

${ }^{18}$ (Macur, 10 October 2012)

${ }_{19}^{19}$ Bamed substance, erythropoietin

${ }^{20}$ Reminiscent of Prime Minister Rob Muldoon's treatment of journalist Tom Scott in New Zealand in the $1970 \mathrm{~s}$ and $80 \mathrm{~s}$

${ }^{21}$ (Walsh, 26 August 2012a)

${ }^{22}$ (USADA, 10 October 2012)

${ }^{23}$ (Walsh, 14 October 2012) 
avoid most of the testing. Additionally, the team's strategy was to undertake training in remote locations, without test requirements to notify UCI or USADA. The same year, Lance tested positive for corticosteroids, but UCI was fobbed off with a retroactive cortisone cream prescription. Lance and two of his teammates had blood drawn in Spain, then reinfused in France during the 2000 Tour. Later that year in Spain, having taken testosterone, he scratched a race to avoid testing, having been tipped off by team mate George Hincapic ${ }^{23}$. Medical 'advice' like this doesn't come cheap though, as Lance paid Michele more than USDS $1 \mathrm{~m}$ via a Swiss bank account between 1996 and $2006^{24}$. And the medicine men found the gaps.

EPO tests were non-existent in 1999, but in 2005 a French laboratory had Lance's 1999 Tour B samples tested for EPO. The French sports magazine, L'Equipe, obtained copies and published the six positive tests in their magazine. Unfortunately, because testing had used much of the remaining B samples, it was not replicable. Lance brushed off the results, implying it was persecution because the French were jealous of US Cycling's superiority ${ }^{11}$. His much touted view that this was "just French sour-grapes" was taken as gospel and repeated by US publications ${ }^{23}$.

Lance retired from professional cycling after his 2005 Tour win. Howerer, in September 2008, he announced a come-back, and that he would compete in the 2009 Tour de Irance, where he placed third ${ }^{6}$.

In late 2008, the USADA started investigating drug supply-lines around another US cyclist, Kayle Leogrande. They successfully banned him on evidence, despite him not having had a positive drugs test. By 2010 , they were put in touch with US cyclist, Floyd Landis, Lance's team mate, who had discussions with USADA. At the end of April of 2010 Floyd wrote an email detailing discussions thus far. However, at the same time as the USADA initial interviews, the California US Attorney's Office was investigating Lance with regard to "doping related crimes like drug trafficking, fraud and moncy laundering" ${ }^{25}$. USADA postponed their enquiries pending the outcome. The two year federal investigation was closed in February 2012, with no elcar case to answer.

With the UIS federal case having collapsed, the USADA felt morally free to recommence their 2010 investigation, and "picked up the torch"26. Throughout USADA's investigation, many of Lance's USPS / Discovery Channel Pro Cycling team mates, friends and employecs confirmed that, for more than a decade, doping took place; and therefore, Lance's wins were achieved fraudulently ${ }^{13}$. Over a dozen - including George Hincapic, Frankie Andreu, Tyler Hamilton, Jonathan Vaughters, Christian Vande Velde, Betsy Andreu and Emma O'Reilly - provided affadavits about PEDs including EPO, testosterone, human growth hormone and cortisone ${ }^{13}$.

After initially denying the possibility of habitual doping by Lance in May of 2011, UCI listened to F'oyd Landis and Tyler Hamilton in 2012. Floyd and Tyler provided their 2010 USADA cridence to UCI, and themselves admitted doping 27 . Howerer, UCI then appeared to sit on the evidence 28 .

When the USADA investigation was reaching completion, USADA requested meetings with Lance about their findings. Lance and his legal team prevaricated, postponed and finally simply didn't attend ${ }^{13}$. As a result, Lance was charged in absentia. In an August 2012 letter to the Doping Journal, Lance said "I am a retired cyclist, yet USADA has lodged charges over 17 years old despite its own 8-year limitation", and "there is zero physical evidence to support his [Travis Tygart, CEO of USADA] outlandish and heinous claims" ${ }^{\text {"29 }}$.

USADA charged Lance in June of 2012, producing their 'reasoned decision', banning Lance from US sport for life and stripping him of his seven Tour de Trance wins ${ }^{30}$. They passed their decision on to WADA, US Cycling and UCI. WADA immediately ratified USADA's detcrminations ${ }^{28}$. As UCI had not appealed USADA's ruling within 21 days, the documents were sent to UCI on 10 October. On 22 October, under intense global scrutiny, and IOC pressure $^{31}$, UCI upheld the USADA's ruling ${ }^{27}$. There may have been some additional pressure to this uphold this ruling to keep the centennial Tour de France, due to take place in 2013, free from distracting controversy.

Lance said "that athletes can be convicted today without positive A and B samples [...] perverts the system" and that the "only physical evidence here [that USADA has] is the hundreds of controls I have passed with flying colors"

${ }^{24}$ (The Telegraph, 12 October 2012)

${ }^{25}$ (CBCTheNational, 2013)

${ }^{26}$ (Walsh, 26 August 2012b)

${ }^{27}$ (UCI, 2012)

${ }^{28}$ (Gibson, 29 January 2013

${ }^{29}$ (Armstrong, 2012)

${ }^{30}$ (Daily Lance, 22 October 2013 )

${ }^{31}$ The International Olympic Committee had the ability to withdraw cycling from the 2016 Olympics if Lance's ban was not upheld (Myles, 2013; Magnay, 5 December 2012; Stephens, 23 October 2012) 
However, in February 2013, when asked by Oprah Winfrey in a 'tell all' interview "In all seven of your Tour de France victories, did you ever take banned substances or blood dope?" Lance replied "Yes"

By the time of the Oprah interview, Lance has resigned from all directorships, sold lis shares back to SRAM Corporation, had his name taken from the Lance Armstrong 'Livestrong' Foundation which he founded. The soccer team, Sporting Kansas City, removed his charity's name from their stadium: no more "Livestrong Sporting Park ${ }^{133}$. All of Lance's sponsors, with the sole exception of Johnson Health Tech which continues its Livestrong relationship, had cancelled their contracts ${ }^{34}$, dropping Lance's annual income an estimated $\$ 50 \mathrm{~m} \mathrm{pa}^{35}$.

But the bad news docsn't end there for Lance. The Sunday Times are now suing Lance for $1 \mathrm{~m}$ plus, based on their 2006 settlement of $£ 300,000$ for David's book, for what is now demonstrably a false accusation ${ }^{36}$. Additionally, the US Government is suing Lance's team, Tailwind Sports, for the $\$ 40 \mathrm{~m}$ paid in sponsorship by the US Postal Scrvice from 1998 to 2004 ${ }^{37}$. Further, SCA Promotions Inc paid Lance S1 $2 \mathrm{~m}$ in bonuses based on clean wins; now there are seven self-declared 'dirty' wins, SCA's lawyer Jeffrey Tillotson has indicated if the money doesn't come back, SCA will sue ${ }^{38}$. But wait - there's more: the US federal investigation into drug trafficking, money laundering and fraud could also be reopened now that Lance has admitted doping.

Michele Ferrari was prosecuted and struck off for doping in 2004; Pedro Celaya is currently under investigation and Luis Garcia del Moral was given a lifetime ban from all sport in $2013^{13} 39^{4041}$. Lance's team manager and coach are also in the gum ${ }^{13}$.

Many athletes rationalise doping via the "false consensus effect"; that everyone uses druys, so, in order to remain competitive, they must do se as well ${ }^{42}{ }^{43}$. Additionally, athletes appear to fecl that the anti-doping programmes and tests are incffective, and that perhaps punishments are not severe enough. "Dale", a professional cyclist, reported that a 140-strong race only had fifty or so turn up on the day. Apparently there was to be a last-minute doping control and he "realized that some guys and teams would only show up to races where they knew the ambulance [doping control] would not be there" ${ }^{\text {n+3 }}$. There is also no out of scason testing, so cyclists know they can avoid a test by avoiding the race; and keep an unblemished test record. Howerer, this strategy depends on obtaining reliable testing information ahead of time. It is possible that Lance had intelligence from within UCI, exploiting the gaps.

It has been reported that many of the cyclists were reluctant to whistle-blow because they didn't trust UCI, USADA, or WADA to take appropriate - or indeed any - action. They felt that the lack of prosecutions was condoning the drugs culture that they felt was obviously pervasive in cycling ${ }^{284}$.

Many in cycling felt doping and avoiding testing is "justifiable practice" and was an "occupational necessity" ${ }^{43}$. As Lance says, "I didn't invent the culturc, but I didn't try to stop the culture, and that's my mistake, and that's what I have to be sorry for, and [...] the sport is now paying the price ${ }^{\text {n32 }}$.

\section{Discussion Qucstions}

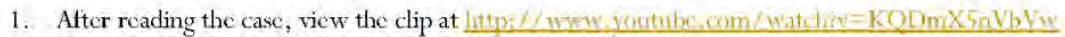
(CBCTheNational, 16 January 2013). What do you fecl are the key issues in this case?

2. What attributes does Lance display?

${ }^{32}$ (BBC, 18 January 2013a)

${ }^{33}$ (Goldman, 18 January 2013)

${ }^{34}$ (Dailyrecord, 21 December 2013; Goldman, 18 January 2013; McCarthy, 17 January 2013; Tredennick, 23 October 2012; Daily Mail, 18 October 2012, Forbes, 2012)

${ }^{35}$ (Daily Mail, 2012)

${ }^{36}$ (TheRecord, 24 December 2012)

${ }^{37}$ (Dye, 2013)

${ }^{36}$ (CNN, 18 January 2013)

${ }^{39}$ (Walsh, 2001)

${ }^{40}$ (Davies, 2012; Magnay, 18 February 2013)

${ }^{41}$ (Austin, 12 October 2012)

${ }^{42}$ (Morente-Sánchez \& Zabala, 2011; The Guardian, 17 June 2013)

${ }^{43}$ (Sefiha, 2012)

${ }^{44}$ (Walsh, 3 February 2013; Associated Press, 3 December 2012; Associated Press, 24 April 2013; Fuller, 2012) 


\section{TEACHING NOTES}

\section{Case Synopsis}

This is the true story of Lance Armstrong, his win at all costs attitude, the subversion of his ethics and misuse of power.

From 1999 to 2005, Lance Armstrong won the Tour de France seven times with his team, US Postal Scrvice Pro Cycling.

Allegations of doping, drug trafficking, fraud, money laundcring and bullying tactics were levelled against him, but none of the accusations stuck, until a USADA prosecution of rider Kayle Leogrande was successful: without a positive drugs test.

The USADA then banned Lance for life, without a positive drugs test, and in absentia. Their ban was upheld by WADA, and cventually, UCI.

This case looks at the leader's use of influence, dependency, socialised power motivation, morality ethical leadership and ethics in international cycling.

\section{Use of This Case}

This case is designed for undergraduates studying leadership, to better understand the concepts of leadership ethics and the leader's use of power.

\section{Case Objectives}

Students will examine leadership ethics and ethical decisionmaking.

Students will learn how leaders use, and can abuse, power.

\section{DISCUSSION QUESTIONS \& ANSWERS}

After reading the case, view the clip at

http://www.youtube,com/watch?v=KODmX5nVbVw. (CBCTheNational, 16 January 2013). What do you feel are the key issues in this case?

Students should identify the following key issues:

\section{Power and Influence}

Power is an intangible force in organisations that provides us with the ability to "influence other people to bring about desired outcomes" (Daft \& Pirola-Merlo, 2009, pp. 380-381). Pfeffer (1992, p. 12, also Yukl, 2006) states that power is the "capacity to bring about certain intended consequences in the behaviour of others". DuBrin (2013, p. 241) feels power is the capacity to influence others.

Which brings us neatly to influence, the catalyst required for power to work. Daft and Pirola-Merlo describe influence as "the effect a person's actions have on [...] others" (2009, p. 381). DuBrin (2013, p. 241) feels that influence is "the ability to affect the behaviour of others in a particular direction", noting that influence increases in importance when we don't have formal authority.

That formal authority was defined by French and Raven as 'position power', and is made up of three components: 'reward' power to recognise your staff and remove negative consequences, 'legitimate' power as the holder of the title to legitimately require performance, and 'cocrcive' power to punish those who work for you if they don't carry out your demands. All three of these types of power are conferred to a greater or lesser degree in an organisational position (1959). Yukl 
comments that position power-derived influence is "necessary to control rebels who try to disrupt" the organisation's activitics (2006, p. 443).

However, informal authority is equally important. It was defined by French and Raven as 'person power', and is made up of two components: 'expert' power given to us by value of our expertise, and 'referent' power gained from whom we know, the forcefulness of our own personality, persuasiveness and level of charisma (1959).

In the case of Lance Armstrong, he not only had position power - "extensive input into rider and staft composition" (USADA, 2012, p. 6), but also person power through the "omerta" (USADA, 2012), by being considered the "boss man of the Tour" (Saporito, 16 January 2013), through being able to cut down those who criticised him (Walsh, 26 August 2012a) and the influence-perceived or real-he held over UCI through his friendship of the President and the donations he had made (Walsh, 26 August 2012a). Further, Lance had a great deal of position power-derived influence, and was able to prescribe behaviours in his role as team leader, often forcing ethically-uncomfortable choices on his team mates.

Lance had both position and personal power over those around him, as time went on, his status as a multiple Tour winner also gave him position power over other racers. For those who were on his team, the combination of both types of power also gave Lance a huge amount of influence within the team itself.

Additionally, Judi Marshall (1984) provides some alternative dimensions of power: power 'over' others, power 'through/with' others, and the "the powers of communities $[\ldots]$ to recruit and reward in likeimagc, to include and exclude, to assign resources, and to define agendas or frameworks of meaning" (Marshall, 1995 , p. 58). Lance had power over his team, and over many followers who were in awe of him; he had power through and with those who decided to be 'on-side', and he accessed the power of community through the "omerta" (USADA, 2012; Walsh, 26 August 2012a; Saporito, 16 January 2013).

\section{Dependency}

Along with influence, dependence is also a power magnificr: a magnifier of access to information, people and resources. Sometimes called resource power, dependence occurs where individuals, teams and organisations acquire power when they can provide essential or diflicult to obtain resources (Smith \& Grenier, 1982).

Lance's team members and the media were highly dependent on Lance for their livelihoods; the team for obtaining wins, and the benefits which came with that; the media for unrestricted access to the winners' stories (Walsh, 26 August 2012a; Walsh, 14 October 2012; Walsh, 22 October 2012; Willsher, 13 October 2012).

\section{Socialised power motivation}

Power motivation is explored by Magec and Lagner (2008), where a leader is able to take actions or make decisions which affect the lives of their followers. This is not positive or negative until we take into account the profession and leadership style where power is used; for example, positive in helping professions such as career counselling, or negative through depraved behaviours in politics.

Jackson \& Parry (2008, p. 18) talk about a socialised power motivation that is critical to leadership, where good leaders gain personal satisfaction from influencing their team for the benefit of the team and the tcam members, not for the leader's personal benetit. Pro-social behaviour may result from a greater sense of responsibility on the part of the leader, from strong inhibitions against over the top behaviour, or from the gender of the leader (Magee and Lagner suggest women may be more socialised than men, 2008). 
Lance's behaviours appear to be self-oriented, displaying little socialised power motivation. His actions appear to be for his own benefit; he appears to have indulged in over the top behaviour; he does not appear to have thought about what was in the best interests of his team members as individuals (USADA, 2012; Saporito, 16 January 2013; Walsh, 26 August 2012a; Walsh, 14 October 2012; Walsh, 22 October 2012; Willsher, 13 October 2012; USADA, 10 October 2012; Macur, 10 October 2012).

\section{Ethical Use of Power}

When considering whether an action is ethical or not, Cavanaugh, Mobert and Velasquez developed a model; Ethical Action Guidelines for Power and Politics $(1981$, p. 368) as amended by Robbins (1998, p, 422), and cited by Daft \& Pirola-Merlo (2009, p. 397),
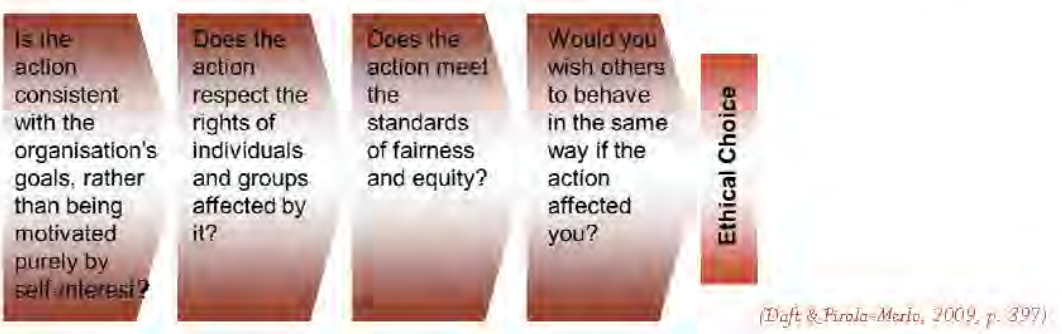

Designed to serve as a guide to whether an intended act is ethical, these four questions should be asked one after the other, If any questions are able to be answered with a yes, then the action is unethical. Leaders need to be aware of the ethical responsibilities that possessing power brings, and ensure they use power to order to help, not to harm others (Daft \& Pirola-Merlo, 2009).

Asking the first question, "Is the action consistent with the organisation's goals, rather than being motivated purely by self-interest" of the US Postal Service Pro Cycling team, then Lance's actions are probably ethical ("we had one goal and one ambition and that was to win the greatest bike race in the world and not just to win it once, but to keep winning it", USADA, 2012, p. 6). The team won, and better met their goals. Asking the second question, "Does the action respect the rights of individuals and groups affected by it?", the answer is less clear. It depends which actions, and how you would regard the word 'affected'. It is a competition, so in theory, any competitor will be affected, thus rendering the question moot. However, the third question, "Does the action meet the standards of fairness and equity", is a clear no. Lance and the US Postal Service Pro Cycling team's conduct didn't meet the requirements of their code, the competition, nor professional sporting standards (USADA, 2012; UCI, 2012). To the fourth question, "Would you wish others to behave in the same way if the action affected you?" Lance would probably answer "Of course".

Lance's use of power was unethical.

\section{What attrlbutes does Lance display?}

\section{Frame of Reference}

Bohlman and Deal's leader frame of reference shows the shaping factors in how a leader sees the world (1991, diagram from Daft \& Pirola-Merlo, 2009, 377). These frames demonstrate how we gather information, make decisions \& exercise our power. 


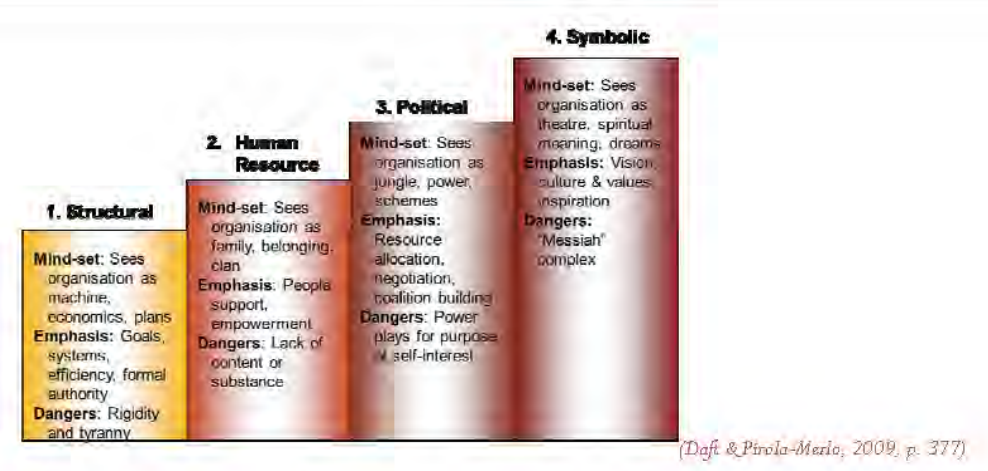

The Structural frame of reference is process-oriented, and aligned to the Morgan's 'organisation as a machine' metaphor (1997). The Human Resource frame is aligned to 'cultures', people and empowerment; and the Political frame to a combination of 'political systems' and 'instruments of domination', being chaotic and often self-oriented. The Symbolic frame doesn't align well to Morgan's metaphors, but is somewhat aligned to Kohlberg's idea of the fifth and sixth moral development stage (1976), that of post-conventional (principled) development, as well as being aspirational and aligned to Maslow's self-actualisation stage of his Hierarchy of Needs model (1943).

In reviewing stages, Lance appears to largely use the political frame of reference. He schemes to try to 'beat' the doping system, with his medical allies (USADA, 2012); he allocates the resources -drugs, doctors and training programmes (USADA, 2012); he builds coalitions as the 'Boss' within the peloton (Saporito, 16 January 2013); and he negotiates in order to achieve his own personal goals, as opposed to the goals of the team (Walsh, 22 October 2012; Willsher, 13 October 2012; Macur, 10 October 2012; USADA, 2012). He also appears to have been pulled into the dangers of this frame via his extended use of power plays in his own best interests (such as the victimisation of David Walsh, Betsy Andreu and Emma O'Reilly; Walsh, 22 October 2012; Willsher, 13 October 2012; Macur, 10 October 2012; USADA, 2012).

Ethical versus Unethical Leadership

Zanderer (1991) investigates the value of leadership integrity which Daft \& Pirola-Merlo present in a table of ethical versus unethical leadership actions $(2009$, p. 164):

\begin{tabular}{|l|l|}
\hline Ethical Leadership & Unethical Leadership \\
\hline Possesses humility & Is arrogant and self-serving \\
Maintains concern for the greater good & Excessively promotes self-interest \\
Is honest and straightforward & Practices deception \\
Fulfils commitments & Breaches agreements \\
Strives for fairness & Deals unfairly \\
Takes responsibility & Shifts blame to others \\
Shows respect for each individual & Diminishes others' dignity \\
Encourages \& develops others & Neglects follower development \\
Serves others & Withholds help and support \\
Shows courage to stand up for what is right & Lacks courage to confront unjust acts \\
\hline
\end{tabular}


Ethical leadership is humble, has a socialised power motivation, is transparent and open, does what they say they will do, is fair, responsible, respectful, cncouraging, cmpowering and courageous (Daft \& PirolaMcrlo, 2009),

Lance appears to have been focused on himself, sclf-aggrandising, cheated, not delivered on his promises, applicd unfair pressure, had an external locus of control, used his followers for his own cnds, cut followers when they could no longer contribute to his own outcomes, lacked the courage to acknowledge his own shortcomings and acted unjustly (USADA, 2012; Walsh, 26 August 2012a; Walsh, 14 Octobcr 2012; Walsh, 22 October 2012; Willsher, 13 October 2012; USADA, 10 October 2012; Macur, 10 October 2012). He has displayed the characteristics of an unethical leader.

\section{Ethical Leadership}

Leaders who seck justice, honesty and 'right' in their leadership practice are ethical leaders (Brown \& Treviño, 2006). They are "fair and principled decision-makers", and a "moral person" with "altruistic motivation" (Brown \& Treviño, 2006, p. 597).

Ethical leadership is influenced by situational factors such as role modelling and ethical context, moderating influences such as moral intensity, ability to self-monitor, inhibition, moral utilisation, the 'big five' personality factors, locus of control, low Machiavellianism, a good ability to reason morally and a low noed for power (Brown \& Treviño, 2006).

Lance has an extcrnal locus of control (blamed others for his own misfortunc), was highly Machiavellian, could not reason morally, was very extrovert, was not cmotionally intelligent so was unable to selfmonitor, was agrecable only while it suited him, has a poer ethical context, and not a lot of interest in his followers outcomes. Lance more closely typifice an unethical leader than an ethical leader. Lance has proven himself by his actions to be an unprincipled decision-maker, a likely immoral person, and to be lacking altruistic motivation (Walsh, 22 October 2012; Willsher, 13 October 2012; Macur, 10 October 2012; USADA, 2012).

\section{How do you think this situation could have been prevented?}

Ethical Use of Power

Use of the Ethical Action Guidelines for Power and Politics as developed by Cavanaugh, Mobert and Velasquez (1981, p. 368) as amended by Robbins (1998, p, 422), and cited by Daft \& Pirola-Merlo (2009, p. 397) by each of the participants in order to determine whether their individual actions were ethical or not would have prevented the situation from arising.

Should this action have been taken by cach cyclist, medical person and team member, this situation could never have arisen. In addition, if Lance himself had asked himself these questions, he would not have put any pressure on any of his team mates or stafl to have taken uncthical actions.

\section{Frame of Reference}

A more balanced development and use of frames of reference, other than political, would have significantly reduced Lance's exposure to the danger of power plays, by having expanded lis perception of his likely influence on his followers and the likely outcomes of taking a single approach ("the boss man of the Tour", racers who challenged him "would be run down by an Armstrong teammate or, for certain violators, by Lance himself"; USADA, 2012; Saporito, 16 January 2013).

If Lance had been focused on the human resource frame, for example, then the people within the team as individuals, his relationship with them, and their personal development would have meant more to him. In this frame he would have led through empowerment, support \& encouraging open communication. His 
messages would have been about value, and servant leadership, as opposed to domination and

manipulation,

\section{Moral Leadership}

Moral leadership is about leading the way in practices that are 'right', fair, ethical and empowering of your followers (Daft \& Pirola-Merlo, 2009), It is ensuring a leader's influence is applied to 'just' ends.

Kohlberg's (1976) stages of moral development can be summarised as pre-conventional, where our acts are aligned to societal expectations in order to avoid punishment; as conventional, where we act as others expect us to as participants in a just society; and post-conventional, where we act as we think best, in the best interests of society.

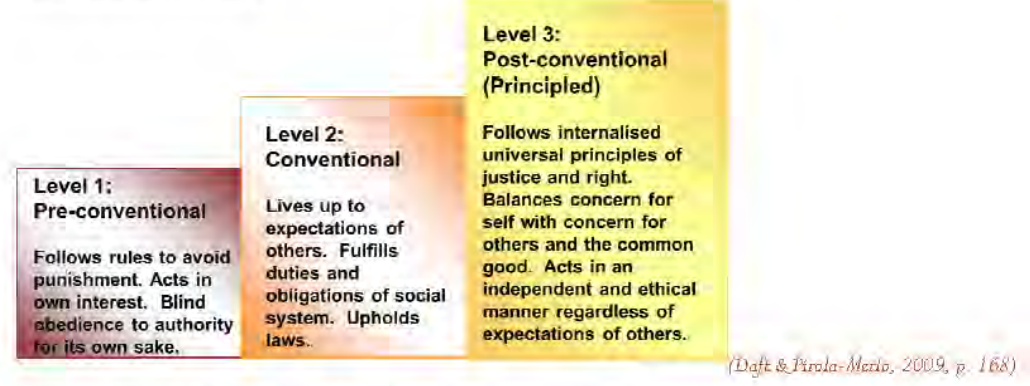

At most we could align Lance's words with pre-conventional morality. We could not align his actions with even this level (USADA, 2012). If Lance had thought through any of Kohlberg's stages of moral development (1976), he would have been far less likely to have perpetrated fraud or deceit,

\section{Stewardship}

The stewardship style of leadership is where leaders are accountable both to the followers and to the organisation, in a way that supports both the needs of the followers and the organisation, It is not about control, taking care of or trying to define meaning and purpose for the followers (Daft \& Pirola-Merlo, 2009). There are four stewardship principles:

1. Partnership - all partners are responsible for defining organisational vision and purpose, and for sharing power and decision-making.

2. Doing - power, decision-making, authority and control are devolved to reside with those who are closest to the customer, and everyone is doing the work, No one is paid solely to manage.

3. Reward-alignment - rewards are tied to success and so redistribute wealth; exceptional contributions equal exceptional recompense.

4. Teams lead - teams create and define goals, maintain controls, create a nurturing environment and the marketplace. Leaders guide and facilitate the teams without controlling.

Had Lance used a stewardship approach, he would not have pressurised those around him to have cheated (USADA, 2012; Saporito, 16 January 2013). However, the group themselves could well have decided to have cheated together, but the culture and nature of the deceit would have been quite different.

\section{Servant Leadership}

Servant leadership is where leaders transcend their own self-interest in order to serve the needs of their followers. A servant leader focuses on supporting their followers to grow and develop, providing opportunities for the entire organisation and all those within it to gain as people and materially (Greenleaf, 1998), 
There is a heavy emphasis on empowerment; shared authority, decision-making and participation; and creating a 'community of trust'. Servant leaders consciously use their gifts in a socialised way to help others and the organisation; they do not seck power. They listen, and ask questions, and facilitate organisational needs. They are trustworthy, so inspirc trust, and continuc to build trust through bonesty, delivery and openness. Servant leaders are Theory Y leaders; they respect and actively work towards the growth and development of their people (Grecnleat, 1998; McGregor, 1960).

Had Lance taken a servant leadership approach, he would have listened more than he spoke, would have avoided his own trappings of power, would not have been 'the boss' in the peloton, would not have created out groups with those who no longer wanted to cheat and have not pressurised those around him to have cheated (USADA, 2012; Saporito, 16 January 2013). However, the group themselves could well have decided to have cheated together, but, again, the culture and nature of the deceit would have been quite different.

Ethical Leadership

Leaders who seek justice, honesty and 'right' in their leadership practice are ethical leaders (Brown \& Treviño, 2006).

Ethical leadership is influenced by situational factors such as role modelling and ethical context, moderating intluences such as moral intensity, ability to self-monitor, inhibition, moral utilisation, the 'big five' personality factors, locus of control, low Machiavellianism, a good ability to reason morally and a low need for power (Brown \& Treviño, 2006).

Lance has an external locus of control (blamed others for his own misfortune), was highly Machiavellian, could not reason morally, was very extrovert, was not emotionally intelligent so was unable to selfmonitor, was agrecable only while it suited him, has a poor ethical context, and not a lot of interest in his followers outcomes. Lance more closely typifies an unethical leader than an ethical leader.

\section{If you had been in Lance's team, what would you have done? Why?}

Anticipate some students will go along with Lance's actions, some will not, depending on whether they display instrumental or end values, and their own locus of control. Talk them through the differences (Daft \& Pirola-Merlo, 2009):

- Instrumental values: Beliefs about the behaviours which are appropriate to apply in reaching their goals, such as honesty, courage; HOW we get to our goals

- End values; Belicts about the kind of goals which are worth pursuing, such as a comfortable life, good health; that the ends justify the means.

- Locus of control: whether they place primary responsibility for what happens to themselves within themselves or on outside forces. 


\section{BIBLIOGRAPHY}

Armstrong, Lance (2012). USADA's unconstitutional witch hunt. Doping Journal, 2012, Volume 9, article 5. Retrieved 24 Junc 2013 from hettp://depingiournal.org/9/5/

Armstrong, Lance (2000). It's Not About the Bike: My journey back to life. USA: Yellow Jersey

Associated Press (23 October 2012). Mired in Armstrong doping scandal, UCI claims 'moral authority' to lead

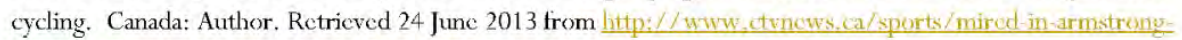

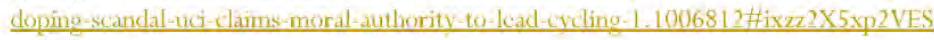

Associated Press (24 April 2013). Get drug testing out of UCl's hands, says LeMond. South Africa: Business Day

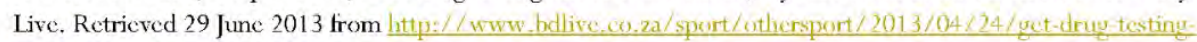
sut-of-ucis-hands-savs-lomond

Associated Press (29 August 2012). Lance Armstrong says he's champ. USA: ESPN. Retrieved 25 Junc 2013 from

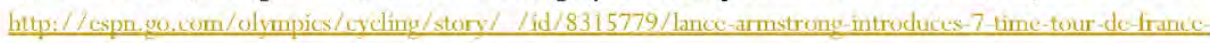
champ

Associated Press (3 December 2012). LeMond says UCI's McQuaid must stand down. Retrieved 29 Junc 2013

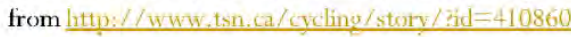

Austin, Simon (12 October 2012). Lance Armstrong case creates an unlikely hero. UK: BBC Sport. Retrieved 26 Junc 2013 from $\lfloor$ tetys:/ w ww. bibe.ces.uk/sport/0/eveling/19930514

BBC (18 January 2013a). Lance Armstrong \& Oprah Winfrey: interview transcript. UK: BBC Sport. Retrieved 24 Junc 2013 from latip://www. bbcico. uk/sport/()/cycling/21065539

BBC (18 January 2013b). Lance Armstrong's apology questioned by WADA president. UK: BBC Sport. Retrieved

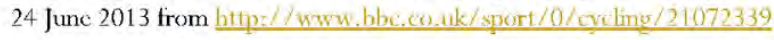

Bibliography.com (n.d.) Lance Armstrong. Retrieved 26 June 2013 from

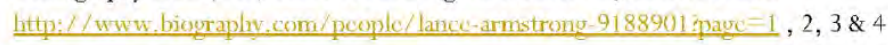

Bolman, Lee G. \& Deal, Terence E. (1991). Reframing Organizations: Artistry, Choice and Leadership. USA: Josscy-Bass

Brown, Michacl E \& Treviño, Linda K (2006). Ethical Lcadership: A review and future directions. The Lcadership Quarterly, December 2006, Volume 17, issuc 6 (pp. 595-616)

Browniclocks Blog (2013). Tour De France History, Winners \& Cartoon Fun by Browniclocks. Retrieved 25 June 2013 from Lttp: / www , browniclodes.com/tourdefrance. htom

Cavanaugh, Gerald F, Mobert, Dennis J \& Velasquez, Manuel (1981). The Ethics of Organizational Politics. Academy of Management Review, July 1981, Volume 6, issue 3 (pp. 363-374)

CBCTheNational (16 January 2013). Lance Armstrong: After the Apology. Retrieved 25 Junc 2013 from hetp: / www. voutubicom/ watchiv=KODmX5nVbVw

CNN (18 January 2013). SCA Lawyer: Client wants money back. USA: CNN. Retrieved 28 June 2013 from bitp://articte Wn com/view/2013/02/07/Dallas insurer SCA Promotions sues to recover 12M Tour de 1. $\underline{\mathrm{r} / \# / \text { video }}$ 
CNN (24 June 2013). Lance Armstrong's Legacy. Retrieved 26 June 2013 from

htp: //edition.cin.com/rideo/data/2.0/video/sports/2013/06/24/davics-lance-armstronj-creling$\underline{\text { logacy. onm.html }}$

Daft, Richard L. \& Pirola-Merlo, Andrew (2009). The Leadership Experience (Asia Pacific Version 1). Australia: Cengage Learning

Daily Lance (22 October 2012). World Awaits UCI Ruling on Armstrong Doping Case. Retrieved 29 June 2013

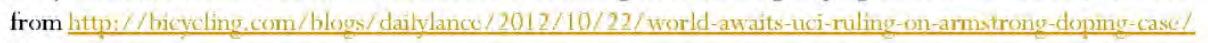

Daily Mail (18 October 2012). Shamed Lance Armstrong will lose AT LEAST \$50m over the next five years as SIX more sponsors cut ties with disgraced cyclist. Retrieved 25 June 2013 from

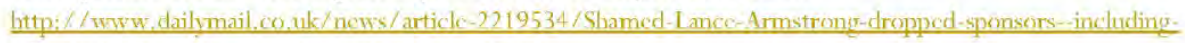
bike-deal-Nike-claims-cyclist-misled-decade. html

Dailyrecord (21 December 2013). Nissan withdraw cycling team sponsorship in the wake of Lance Armstrong scandal. Retrieved 25 June 2013 from http://www dailyrecord.co, uk/sport/other-sports/cycling/nissanwithdraw-cyeling-tcam-sponsorship-1500620

Davies, Edward (2012). Antidoping agency savages Lance Armstrong's doctors. British Medical Journal, October 2012, Volume 345, issue 7879 (p. 6)

Dimeo, Paul (26 October 2012). The Lance Armstrong case: Implications for Anti-doping policy. Global Policy Journal online. Retrieved 25 June 2013 from hitts://www globalpelicvioumal.com/blog/26/10/2012/lance armstrong-case-implications-anti-doping-policy

DuBrin, Andrew J. (2013). Leadership: Rescarch findings, practice and skills. USA: Cengage Learning

Dye, Jessica (23 April 2013). Lance Armstrong sued by government over sponsor money. Retrieved 25 June 2013 from Lttp: / / sports, yahoo.com/news/lance-armstrong-sued-gevernment-over-sponsor-money-021242659spt.html

Forbes (2012). Lance Armstrong's Dropped Sponsors. Retrieved 25 June 2013 from hitp: / / www forbes, com/puctures/ttject5ejek/nike-2/

French, J. R. P., \& Raven, B. (1959). The bases of social power. In D. Cartwright (Ed.), Studies in social power (pp. 150-167). USA: University of Michigan, Institute for Social Rescarch

Fuller, Jaimic (4 November 2012). The UCI. Why our hand has been forced into taking legal action. Retrieved 29 June 2013 from http:// watercoaler.skins net/blog/2012/11/04/the-uci-why-our-hand-has-been-forced-intotakine-loval-action/

Gibson, Owen (29 January 2013). Wada 'dismayed' by UCI's handling of Lance Armstrong fallout. UK: The Guardian. Retrieved 25 July 2013 from hltp://www guardian co.uk/sport/2013/jan/29/wada-uci-armstronjaltair

Goldman, Stuart (18 January 2013). Johnson Health Tech Still Supports Livestrong. Retrieved 25 June 2013 from http://chibindiastrv.com/manufacturers/ johmson-health-tech-still-supports-livestrong

gothinksport (2007). Our Partner LiveStrong. Retricved 25 June 2013 from http://www gothinksport.com/partners.htmi

Greenleaf, Robert (1998). The Power of Scrvant Leadership. San Francisco, USA: Berrett-Kochler

Jackson, Brad \& Parry, Ken (2008). A very short, fairly interesting and reasonably cheap book about studying leadership. London: Sage 
Kohlberg, Lawrence (1976). Moral Stages and Moralization: The Cognitive-Developmental Approach. In T. Lickona (Ed.), Moral development and behavior: Theory, rescarch, and social issucs (pp.31-53). USA: Holt, Rinchart \& Winston

Macur, Juliet (10 October 2012). Details of Doping Scheme Paint Armstrong as Leader. USA: NYTimes. Retrieved 26 June 2013 from http:// www nytimes.com/2012/10/11/sports/cycling/agency-details-dopingcase against-lance-armstrong html pagewanted $=$ all

Macur, Julict (4 January 2013). In Reversal, Armstrong Is Said to Weigh Admitting Drug Use. USA: NYTimes. Retrieved 26 June 2013 from hiths:/ www nytimes com/2013/01/05/spests/cycling/lance-armstrong-said-toWeigli-admission-ol-dopine. htom

Magnay, Jacquelin (5 December 2012). IOC forced to delay decision on Lance Armstrong. UK: The Telegraph. Retrieved 29 June 2013 from

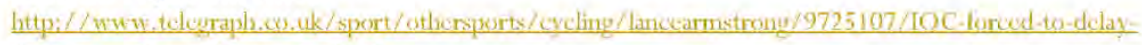
decision-m-Lance-Armstrong himi

Marshall, Judi (1995). Gender and Management: A critical review of rescarch. British Journal of Management, 1995, Volume 6, issue 1 (pp. 53-62)

Marshall, Judi. (1984). Women Managers: Travellers in a Male World. Chichester, UK: Wiley

Maslow, Abraham (1943). A Theory of Human Motivation. Psychological Review 50(4) (pp. 370-396). Retricved

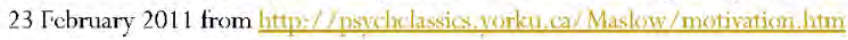

McCarthy, Michacl (17 January 2013). How Will Sponsors React to Lance Armstrong Confessional? Retrieved 25 June 2013 from http://adage.com/article/news/sponsors-react-lance-armstrong-confessional/239242/

McGregor, Douglas (1960). The Human Side of Enterprise. New York, USA: McGraw Hill International

Magee, Joe C. \& Langner, Carric A. (2008). How Personalized and Socialized Power Motivation Facilitate Antisocial and Prosocial Decision-Making. Journal of Research in Personality, December 2008, Volume 42, Issue 6 (pp. 1547-1559).

Medred, Craig (7 September 2012). No cheater's 'free pass' for Lance Armstrong just because he beat cancer. USA:

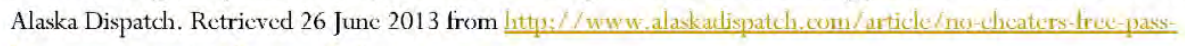
lance-armstromo-just-bocainse-ho-beat-cancer

Morente Sánchez, Jaime \& Zabala, Mikel (2013). Doping in Sport: A Review of Elite Athletes' Attitudes, Beliefs, and Knowledge. Sports Medicine, Nonth 2013, Volume 43, issue 6 (pp. 395 -411)

Morgan, Gareth (1997). Images of Organisation. USA: Sage

Myles, Robert (16 January 2013). Lance Armstrong scandal could see cycling dropped from Olympics. USA:

Digital Journal. Retrieved 28 June 2013 from $\underline{\text { ittp: } / / \text { divitaliournal.com/article } 341442}$

People Magazine (24 August 2012). Armstrong Andersen Sidebar. Retrieved 25 June 2013 from hitp://media coutsideonline.cem/imajes/armstronj-andersen-sidebar.ipg

Pfeffer, Jeffrey (1992). Managing With Power: Politics and Influence in Organizations, USA: Harvard Business School Press

Ramplin, Kimbo (18 January 2013). The Big Texan's Telenovela, Pt II. Retricved 25 June 2013 from hetp: / thereferral. wordpross.com/tag/floyd-landis/ 
Rapp, Timothy (14 January 2013). Timeline of Lance Armstrong's Career and Eventual Downfall. USA: The Blcacher Report. Retricved 3 July 2013 from http://bleacherreport.com/articles/1484496-timelinc-of-lancearmstrongs-carcer-and-cerentual-downtall

Saporito, Bill (16 January 2013). Viewpoint: Why Lance Armstrong Couldn't Stop Himself (and Still Can't): A writer's experience with a tarnished icon. USA: Time Magazine. Retrieved 26 June 2013 from http: / / kecpinuscore blogs time.com/2013/01/16/vicwpoint-why-lance-armstreng-couldint stop - himself-andstill-cant/

Schwartz, Nicholas (15 January 2013). The Definitive Timeline Of Lance Armstrong's Apparently Doped-Up Carcer: The rise and fall of America's greatest cyclist. USA: BuzzFeed. Retrieved 3 July 2013 from http:/ / www buzzfoed.com/nicholasschwartz/a-dedinitive-timeline-ol-lance-armstrongs-carcer

Sctiha, Ophir (2012). Bike racing, neutralization, and the social construction of performance-enhancing drug use. Contemporary Drug Problems, Summer 2012, Volume 39, issue 2 (pp. 213-245)

Smith, Howard L., \& Grenier, Mary (1982). Sources of Organizational Power for Women: Overcoming Structural Obstacles. Sex Roles, Volume 8, number 7, 1982. Retrieved 5 June 2007 from

hetp:/ / www.springerlink.com/eontent/k504751041728628/fulltext.pdf

Stephens, Thomas (23 October 2012). Press criticise UCI in Armstrong affair. Retrieved 29 June 2013 from http://www.swissinto. Ch/eng/swiss news/Press criticisc UCI in Armstrong affair.html?cid=33789842

The Guardian (17 June 2013). UCI's public relations job retards its anti-doping function - cycling inquiry.

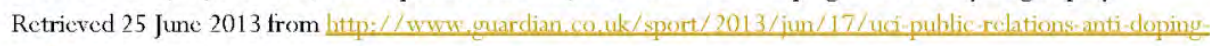
cycling

The Telegraph (24 August 2012). Lance Armstrong timeline - triumph and controversy. UK: The Telegraph. Retrieved 3 July 2013 from

http://www telegraply.ces. ulk/sport/othersperts/cveling/ancearmstrong/9496350/Lance-Armstrong-timelinetriumph-and-controfersy. htm

The Telegraph (12 October 2012). What Lance Armstrong's medical staff said in USADA doping inquiry. UK: The Telegraph. Retrieved 26 June 2013 from hith: / / www.teleoraph.co.uk/sport/othersports/cveling/lanccarmstrone/9603400/What-the-Lance. Armstrongs-medical-staft-said-in-UISADA-doping-inquirv. hitml

TheRecord (24 December 2012). UK's Sunday Times suing Lance Armstrong, secking return of libel settlement payment and costs. Retrieved 25 June 2013 from http: //www, therecord.com/sports-story/2618678-uk-ssunday-times-suing-lance-armstronj-sceking-return-ol-libel-settl/

Tredennick, Andrew (23 October 2013). Lance Armstrong Has Lost His Last Sponsor. Australia: Business Insider. Retrieved 25 June 2013 from http://au, businessinsider.com/lance-armstrong-has-lost-his-last-sponsor-2012-10

UCI (2012). Decision of the UCI regarding the case United States Anti-Doping Agency (USADA) versus Lance Armstrong. Retrieved 25 Junc 2013 from

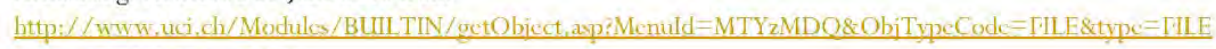
$\underline{\text { \&id }=\text { ODF } 5 \text { MiT \& } \& \text { anoId }=1}$

UCI (n.d.). Union Cycliste Internationale Mission Statement, About UCI UCI Structure. Retrieved 26 June 2013

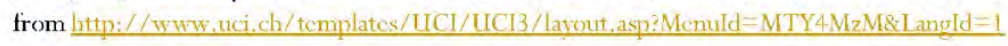

USADA (2012). Report on Proceedings Under the World Anti-Doping Code and the USADA Protocol: Reasoned Decision of USADA on Disqualification and Ineligibility. Retrieved 25 June 2013 from

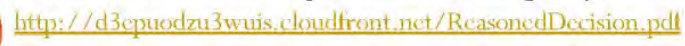




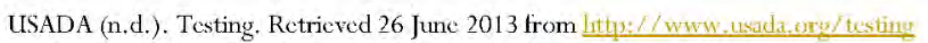

USAToday (23 September 2004). Company withholding S5M bonus from Armstrong. USA: USAToday. Retrieved

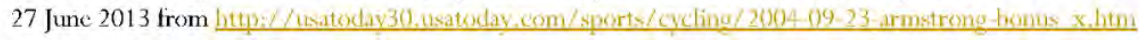

WADA (12 February 2007). Q\&A: The World Anti-Doping Agency. Retrieved 26 June 2013 from Litts://wwrw wada-ama.org/rtacontent/document/OA The World Anti-Doping Avency.pdil

Walsh, David (14 October 2012). THE WOMEN WHO STOOD UP TO THE BULLY: The courage of Betsy Andreu and Emma O'Reilly has finally exposed Armstrong's lies. UK: Sunday Times, p. 8

Walsh, David (15 July 2001). Questions of belicf that refuse to go away. UK: Sunday Times, p. 10

Walsh, David (22 October 2012). Covering Lance Armstrong was a wild ride, but the truth came out. USA: Sports Illustrated. Retrieved 26 June 2013 from

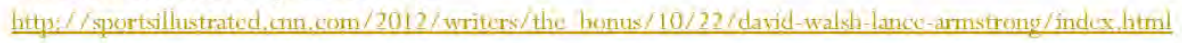

Walsh, David (26 August 2012a). David Walsh's 13-year investigation into Lance Armstrong. UK: Sunday Times, p. 16

Walsh, David (26 August 2012b), BROKEN ON THE WHEEL OF TRUTH: Lance Armstrong is the most successful Tour de France champion. And his greatest victory was hiding his offences. UK: Sunday Times, p. 8

Walsh, David (28 August 2005). New drugs allegations mean Lanoc Armstrong again faces the question: Champor cheat? UK: Sunday Times, p. 21

Willsher, Kim (13 October 2013). Mr Clean Christophe Bassons 'not bitter' towards Lance Armstrong. UK: The

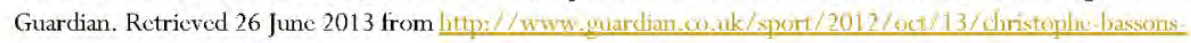
not-bifter-lance-armstrong

Wilson, Rebecca (19 January 2013). Rebecca Wilson says there is only one place in the world left for Lance Armstrong - inside a prison cell. UK: The Daily Telegraph. Retrieved 25 June 2013 from

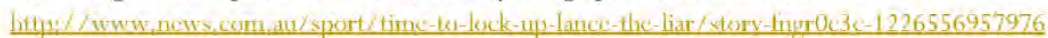

Wilson, Stephen (17 January 2013). AP Sources: IOC Strips Amstrong of Olympic Medal. USA: NBCSports. Retricved 28 June 2013 from hitu://nbesports.msnbecom/id/50493013/1ns/sports-cyeling/

Wolff, Alexander \& Epstein, David (22 October 2012). A Massive Fraud Now Morc Fully Exposed. Retrieved 25 June 2013 from Litps://sportsillustrated.enn.com/vault/article/magazinu/MAG1206183/1/index.him

Yukl, Gary (2006). Leadership in Organizations (6th Edition). USA: Pearson Education Inc. 


\section{APPENDICES}

Events Timeline 45

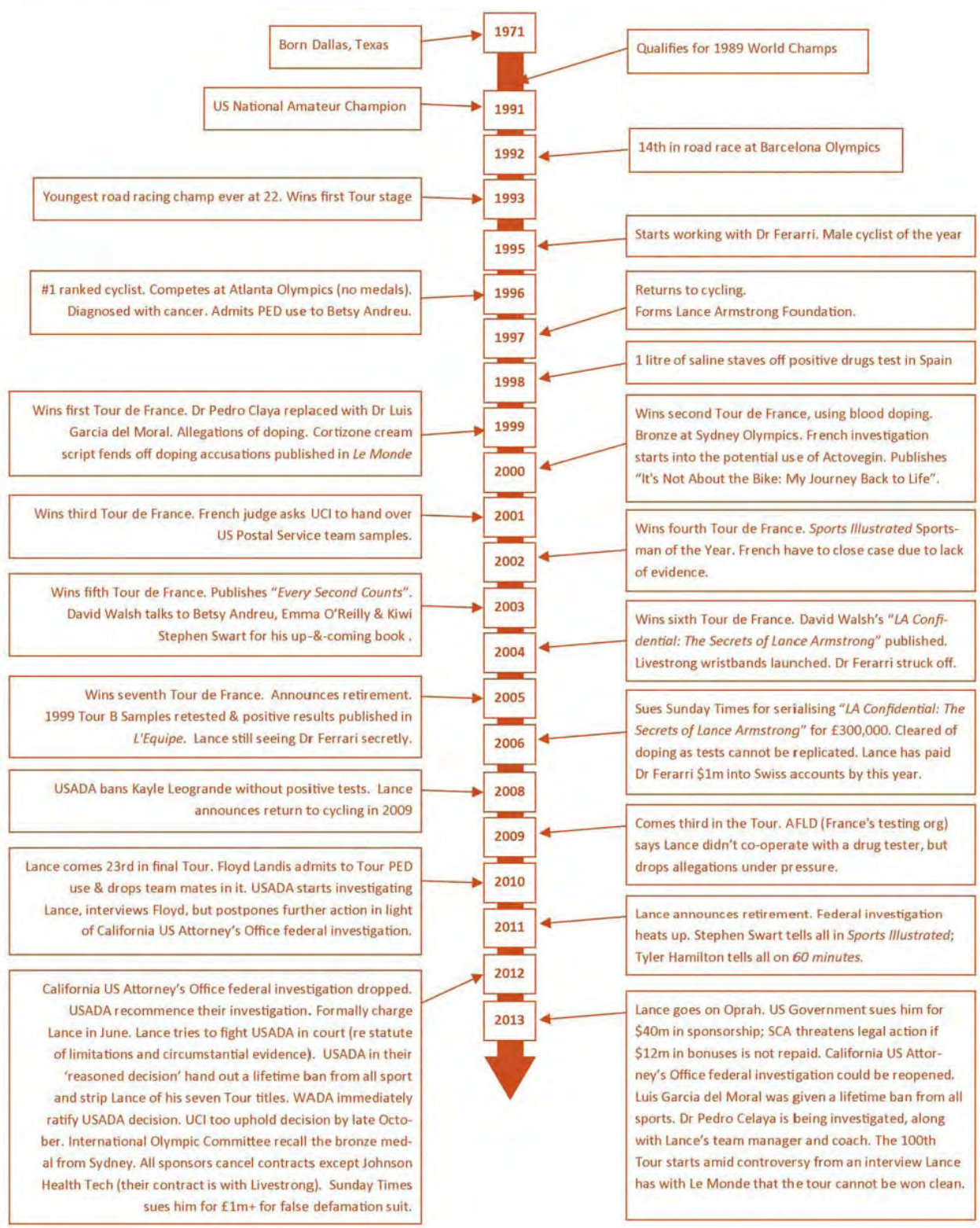


Appendix Six (b): Medium Teaching Case - Tennis New Zealand

\section{Tennis New Zealand - unify, lead and strengthen}

A case study about shared leadership

2013

by Sam Young 


\title{
Tennis New Zealand - unify, lead \& strengthen
}

\author{
A case study about leadership
}

How do you co-ordinate a "together, yet separate" organisation made up of 477 affiliated member clubs with different constitutions, aims and structures, 66 unaffiliated clubs, six 'special interest' affiliates, 25 regional divisions, 28 subdivisions and a 25 member board? 1

Sports in New Zealand are funded through Sport New Zealand (SNZ). SNZ provides funding and expertise through national sports and recreation organisations (NSOs \& NROs) $)^{2}$. Effectively, the NSOs are the national representatives for their respective sports, responsible for sports governance and national operation ${ }^{3}$.

The ethes of NSOs is grounded in their history as independent voluntecr executive committees which ran on the smell of an oily rag in the service of their members, with their own constitutions and aims ${ }^{3}$. In

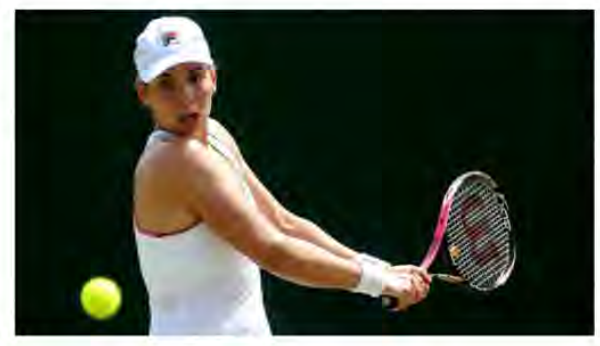

New Zealand, similar to Canada and Australia, NSOs are "responsible for maintaining the rules and organisation"1 of their sporting codes, working on all levels - international, national, regional and club - and nowadays with paid administration and management.

Tennis New Zealand, or TNZ, is New Zealand's NSO for tennis. TNZ is responsible for administration and management, and is proud of being one of the International Tennis Federation founding members. With nearly 500 member clubs and 44,000 individual members, TNZ's activities include national grading, selection and management of representative teams and players, national and international tournament organising and hosting, arranging junior player international tours, supporting our emerging players on the world tours and Grasshoppers, a games-based primary school tennis introductory course ${ }^{4}$.

More than 317,000 New Zealanders play tennis, making it NZ's second most popular adult participation sport after goll $f^{5}$. TNZ advocates for all tennis players in New Zealand, including clite Kiwi players such as Marina Erakovic ${ }^{4}$. Today, TNZ is a lean, mean organisation with good communication flows back to grassroots tennis. But it wasn't always that way.

In the mid-2000s, TNZ had 477 affiliated member clubs, 66 unaffiliated clubs, six 'special interest' affiliates, 25 regional divisions, 28 sub-divisions and a 25 member board: "together, yet separate" due to the differences in their constitutions, aims and structures ${ }^{1}$. TNZ had less than $14 \%$ of the tennis-playing population as registered members, which was troubling them 6 . 'Head Office' had a culture of imposing decisions and direction on the regions. The 25 regions, each of whom had differing agendas and priorities, would take what they felt was important back to the multiple clubs in their region?

Tennis was experiencing a downturn in performance, From the 1990s on, players competing internationally struggled to get into the world top 100, where once tennis in New Zealand had had players in the top $20^{3}$.

TNZ's turnover was in deficit in the early $2000 \mathrm{~s}$ to a fairly stellar loss of $\$ 400 \mathrm{k}$ in 2006 (on a turnover of just over $\mathrm{S} 1.4 \mathrm{~m}$ ). TNZ undertook a 'health check' survey on the state of New Zcaland tennis in 2004, which revealed declining participation, fewer inter-club competitions, declining voluntecr numbers, those already mentioned

${ }^{1}$ (Ferkins \& Shilbury, 2010, p. 236)

${ }^{2}$ (SNZ, n.d.)

${ }^{3}$ (Ferkins \& Shilbury, 2010)

${ }^{4}$ (TNZ, 2011)

${ }^{5}$ (TNZ, 2008)

${ }^{6} 43,792 / 317,200=13.8 \%($ Ferkins \& Shilbury, 2010, p. 241)

(Ferkins, 2007) 
financial losses, declining maintenance programmes and maintenance funding. In 1985 there were 63,500 members; in 1990 54,000; and by 2005, 43,792 ${ }^{3}$. A $31 \%$ bleed in membership over 20 years (without allowing for a same period $21 \% \mathrm{NZ}$ population growth, which would result in an adjusted TNZ member loss of $38 \%{ }^{8}$ ). Over two thirds of tennis clubs memberships totalled fewer than $100^{3}$.

Members were quoted in a health-check survey as saying that TNZ was "unwieldy", "ungovernable" and that there was a national-regional "disconnect" . The clubs felt that Head Oftice was not listening to them. The regions felt that neither the clubs nor Head Office were listening to them. Head Office was frustrated that no one was doing as they were told, and no one would say why. All participants felt disenfranchised ${ }^{7}$. TNZ had seven paid staff and a board which was largely appointed for three year periods, with little opportunity for those outside the board to impact decisiom-making, strategy or direction, emphasising the regions' fecling of disconnection ${ }^{3}$.

There were no clear pathways for communication, strategy, planning, finance, funding, decisions, ideas, innovation, control or reporting. It was too hard to get the 25 regions to agrec, and to keep 25 organisational heads on task and able to see the bigger picture. Individual agendas got in the way ${ }^{7}$.

This aspect of individual agendas and uneven allocation of resources appears to have resulted in power being unevenly spread. More powerful regions had the ability to sequester larger amounts of scaree resources for their own agendas, not necessarily aligned nor prioritised by $\mathrm{TNZ}^{?}$.

Tennis is a sport with a long history, with each club having a unique heritage. None wanted to lose their identity, all wanted to contribute, but all had differing views on how that should be done.

TNZ knew they had to change - the health-check survey report clearly indicated so, and "provided the catalyst" to seck some pretty major strategic change ${ }^{3}$. They knew they needed a major structural change regarding the number of regional entities and national-regional relationships, and needed a regional governing structure designed that would allow them a greater ability for the national board to enact its strategic prioritics?

What happened next was surprising. In 2005, a New Zealand doctoral researcher at Unitech's Department of Sport, Lesley Ferkins, approached Tennis New Zealand to explore what they could do together to improve TNZ's governing capability. In the course of her preliminary investigation, Dr Ferkins developed a proposal to consider board strategie capability which specifically targeted the redesign of TNZ's governance structure, in a collaborative partnership with the organisation ${ }^{3}$.

Dr Ferkins explored how boards might develop their strategic capability, using a literature review and developing cases from other sports organisations she was working with; by analysing TNZ's context, interviewing particjpants and identifying common themes arising from her interviews; creating some interventions to meet the issues; and having TNZ consider, contextualise and apply those ideas. TNZ and Dr Ferkins monitored progress and reflected on the results, then modified existing - or created new - interventions, and actioned them. This was followed by more reflection and a further round of evaluation and interventions. This iterative process ensured where both partics learned from each other and explored potential solutions in an equal partnership ${ }^{3}$.

Dr Ferkins, through her detailed interview process, found that individual beard members identificd yovernance structure, having a skills-based versus a representative board and board composition as issues necding workableand acceptable - solutions. Overall, TNZ's board collectively felt that the key issue was the governanee structure of the organisation ${ }^{3}$.

Several major areas of concern were identified. Firstly, the organisation was significantly fragmented - with nearly 500 separate clubs, directions and leaders; plus a greater multiplicity of geals, funding approaches, constitutions, directors, reporting requirements and constituents. All these parts were not working together, but were often effectively working against each other, to service the different objectives and agendas of the individual clubs and those within them. Magnifying this situation was the layer between the clubs and the national body: the 25 regional entities. Because of their regional relationships (or lack of them), TNZ as an NSO was unable to effectively achieve its strategic goals, and unable to merge national and regional interests ${ }^{3}$.

Worse, these issues had all been identified in internal reports, which had labelled TNZ "ungovernable" and having "no agreed agenda for the sport", findings drawn from over twelve years of documentation flagging dysfinction 10 .

${ }^{8} 19853.3 \mathrm{~m}, 2006,4.2 \mathrm{~m}$ used as base (StatsNZ, 2013)

${ }^{9}$ (Ferkins \& Shilbury, 2010 p. 241)

${ }^{10}$ (Ferkins \& Shilbury, 2010 p. 242) 
There appeared to be no higher, cohesive purpose for the regions, clubs or voluntecrs to co-eperate with the national body, effectively fragmenting the organisation ${ }^{3}$.

Dr Ferkins found that the board contained directors with good strategic thinking skills; collectively they had great sports and macro-environmental knowledge; they had conducted good strategie design, analysis and articulation; they ran their meetings strategically; but they were effectively being road-blocked when trying to enact their strategic prioritics ${ }^{3}$.

TNZ board's strategic priorities - once they were set - could not be delivered to the regions effectively ${ }^{11}$. There were too many entities, too many agendas, ineffective structures, and too much power in some areas of the organisation, then able to hold the rest of the organisation to ransom. Additionally, the regions felt that the NSO was imposing, telling, and controlling. They felt discnfranchised and there was a climate of "misunderstanding, suspicion and fear"12. TNZ as an NSO was effectively 'hamstrung' and unable to effect change ${ }^{3}$.

Interestingly, from a regional viewpoint, there was a perception that TNZ as the national sports organisation misunderstood the nuance of 'ownership' of the sport, and that the regions did not have a fair say despite fecling they were the legitimate 'owner'"

The ability of a national board to effect strategic change depends on its relationships with its stakcholders, and in particular, its regional entities. If there is good understanding, clear communication and shared goals, the process is smooth. Howerer, without that knowledge, clarity and jointly agreed outcomes, it is chaos that will result, not change.

The Maiden Committec, chaired by Sir Colin Maiden, was established to investigate TNZ's governance issues and work as a project committee with Dr Ferkins, who was appointed as the researcher. The ability of Dr Ferkins to take an academically independent position was a critical clement of the trust built with TNZ and the Maiden Committec; to suggest and not prescribe; to evaluate on evidence without agenda; and to bring academic expertise in sport governance. She was able to research and provide TNZ with corporate, non-protit and sport gevernance knowledge, to detail governing structures and change paths, and provide cases which she had developed on Squash NZ and NZ Soccer'. Over a period of four months, the Maiden Committec considered the structure, components and 'lessons learnt' of nine other sporting organisations in New Zealand and Australia ${ }^{3}$.

Those lessons learned from other regional sports organisations were that getting a sound regional structure for sport was a critical and common issue; and to have fewer organisations overall. Some sports focused on building regional sports capabilities while others wanted to scrap current structures and create centralised entities. The change path was daunting, with far-rcaching ramitications - and generally required a mind-set shift from an authoritarian and paternalistic (command and control) approach to a service-oriented partnership ${ }^{3}$.

Dr Ferkins examined the idea of both structural and behavioural change. In considering the type of change TNZ needed, Dr Ferkins looked closely at the use and siting of power and influence, both inherent in the oryanisation's positions, and that residing in people: in the directors and staff themselves. She also investigated solutions to ensure that the board was representative of the national, regional and specialist membership groups, and, as there was resistance to a representational structure in the current board, encouraging theoretical debate to tease out what drove that sense of resistance ${ }^{37}$.

Creating debate was a key driver to the organisation's ability to sustain the change path. Working together through their differences, the national and regional stakeholders began to develop a "greater level of awareness and appreciation of their respective roles", voicing fears and suspicion that had been allowed to go unexplored for too long $^{13}$. They also faced the realities of their declining sport where in-fighting would only hasten the decline, Through what became real dialogue, the disparate parts of the 'business' got to know each other, trust each other, understand each other's points of view and to debate with each other as equals for the good of the sport. They created a pan-organisational climate of seeking the middle-ground, power-sharing and jointly creating paths, processes, outcomes and geals ${ }^{3}$. TNZ's collective focus through this process shifted from control to negotiation and collaboration ${ }^{7}$

${ }^{11}$ (Ferkins \& Shilbury, 2012, p. 123)

${ }^{12}$ (Ferkins \& Shilbury, 2010, p. 248)

${ }^{13}$ (Ferkins, 2007, p. 24) 
Dr Ferkins provided background information to help the Maiden Committec think though organisational structures, including what other sports had done. From this contextualising information, the Maiden Committec Chair developed and presented eleven recommendations, essentially encompassing the lessons learned from other sports organisations to the committec, for debate. He prefaced this with "I think we have to move forward in the interests of tennis - it's a great sport and we've just got to do better. We just can't stay where we are otherwise we will continue to decline". Pressure from Sport New Zealand (then SPARC) for sports to get "their act together" also provided impetus for TNZ ${ }^{14}$. The Maiden Committee recommendations included reducing the number of stakeholder organisations from 25 to six 'regional' organisations, and having six directors on the board in addition to the CEO. Regional representatives on the board were in favour of the recommendations, although there were issues flagged around who ultimately orned TNZ. The Maiden Committee passed their recommendations onto the regions and the TNZ board ${ }^{3}$.

Their next step was to recommend and draft changes to the organisation's and stakeholders' regional organisations constitutions and MOUs ${ }^{15}$ - rephrasing 'control' statements as 'enhance' and 'develop' - to allow for their new proposed structure of six regions, while taking care to reinforce the continuance of regional autonomy. They proposed a shift to a half appointed and half elected 'bybrid' board, with the election process fostering the sense of a regional mandate being carried onte the TNZ board ${ }^{7}$. The skill-set of the board directorships changed by requiring directors to be expert in strategic thinking and in considering "the greater good of the sport" ${ }^{\text {"16 }}$. TNZ members unanimously approved this structure at an August 2006 Special General Mecting.

Dr Ferkins surveyed a number of particjpants in the change process, and received some valuable feedback including impressions, likely challenges, critique and perception-shifts. Regions felt that the new constitution was workable as it fostered regional autonomy and didn't give their power away to the NSO, while flagging the need for a three year review in order to keep on course ${ }^{3}$. Regional views also allowed that TNZ needed to govern, but, while that there was still some level of mistrust, the 'us' and 'them' was becoming 'we'. TNZ's board collectively agreed on the level of their involvement in strategy within the broader organisation, and communicated that widely ${ }^{7}$. A respondent said "You can't come in and dominate. We need to have a collaborative approach to integrating the strategy into the programmes and to draw on the expertise within the regions ${ }^{12}$.

This was highlighted by another respondent, who said that TNZ's "ability to deliver strategies across the sport is not about words in a constitution. It's through relationships" ${ }^{\text {"17 }}$. While deliberately at first, the internal culture of TNZ has continued to shift from an adversarial top-down telling approach to an engaged, dialoguc-rich atmosphere of $\mathrm{co}$ operative inquiry and a federated network of answers. Buzzwords in the organisation include 'collaboration', ' $\mathrm{co-}$ ownership' and 'empowerment". The regions and the NSO are equal partners in ensuring the heal thy future of the sport in this country.

TNZ is now working towards a stronger sense of collective interdependence between the different sectors of the organisation, a clear idea of what each of their roles needed to be for the success of tennis as a whole, an understanding of their internal 'power dynamics' and a much clearer sense of their regional constitutional "ownership"? To cmbed this in the organisation, TNZ created a new vision: "New Zcaland is a tennis nation" and a new purpose; to "Unity, lead and strengthen tennis in New Zcaland"18. Their shared goal is clear; their collective and collegial path toward it more certain.

\section{Discussion Questions}

1. What do you feel the key issues were for the leadership of Tennis New Zealand?

2. What do you feel is TNZ's new leadership style?

3. What issues might TNZ face under a change of CEO or Board Chair?

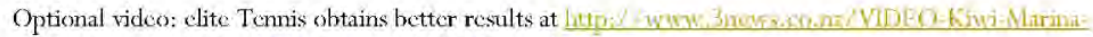

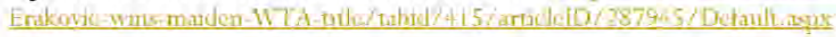

\footnotetext{
${ }^{14}$ (Ferkins \& Shilbury, 2010, p. 247)

${ }^{15}$ Memorandum of Understanding - documenting and formalising understandings and agreements between organisations

${ }^{16}$ (Ferkins, 2007, p. 28)

${ }^{17}$ (Ferkins \& Shilbury, 2010, p. 249)

${ }^{18}$ (TNZ, 2011)
} 


\section{TEACHING NOTES}

\section{Case Synopsis}

What happens when a

National Sports

Organisation tries to impose governance on a group of 25 rebcllious regions and six very diverse national affiliate organisations, comprising of 477 clubs, with declining membership (despite being the secondmost participated-in sport in the country), poor financial returns and decreasing national and international player rankings and performance? Dysfunction, mistrust, fragmentation and fear.

This is the true story of the evolution of Tennis New Zcaland (TNZ) which moved from a hicrarchical command and control head office with subordinatc branches to an egalitarian, shared leadership network partnership under the guidance of Dr Leslcy Ferkins.

This case looks at the shared lcadership model, as it has been successfully implemented throughout the Tennis NSO and RSOs which make up TNZ.

\section{Use of This Case}

This case is designed for undergraduates studying leadership, to better understand the concepts of shared leadership.

\section{Case Objectives}

Students will examine shared leadership and the issues with implementing and maintaining a shared leadership style.

\section{DISCUSSION QUESTIONS \& ANSWERS}

\section{What do you feel the key issues were for the leadership of Tennis New Zealand?}

Students should identify the following key issues:

\section{Lack of Trust}

Hosmer defined trust from an individual standpoint as "the result of 'right', 'just', and 'fair' behaviour - that is, morally correct decisions and actions based upon the ethical principles of analysis - that recognizes and protects the rights and interests of others within society" and from an organisational viewpoint as "the expectation by one person, group or firm of ethically justifiable behaviour - that is, morally correct decisions and actions based upon ethical principles of analysis - on the part of the other person, group, or firm in a joint endcavor or cconomic exchange" (1995, p. 399).

Trust is a key component of leadership, "critical to the success of leaders and essential for the followers" (Martin, 1998, p. 48). Without trust from the participants in the leadership process, there will be no "real changes and outcomes that reflect [leader and follower] shared purposes" (Rost, 1990, p. 102, as cited by Daft \& Pirola-Mcrlo, 2009, p. 4).

The regional sports organisations, or independent regional entitics ('branches') of Tennis New Zcaland, didn't trust the national sports organisation to represent the will of the 'owners' (Ferkins, 2007; Ferkins \& Shilbury, 2010). Without trust, leadership is paralysed, and ineffective.

Failure of Leadership

It is gencrally accepted that good leadership is more critical in sports organisations than in business, because sports organisations are more cohesive (Carron \& 
Chelladurai, 1981); there are more complex interpersonal dynamics (Bloom, Schinke, \& Salmela, 1998; Martens, 1990); poor communication has more far-rcaching effects; a more adaptable leadership style \& strong perception skills are required to select appropriate approaches; a high stress tolerance, a good ability to rebound from adversity, and the necessity to be constantly secking out the new is required; and because an intensive use of psychology is essential (Crust \& Lawrence, 2006).

Henry and Lee (2004, p. 26) discuss the "failure of coordination between sporting and other relevant bodics; a failure of governments to regulate or control potentially harmful activities; and a failure to establish decision-making, or to control procedures, which are fairly, transparently and efliciently implemented" as being key issues in sports leadership, as it relates to governance. Their networked governance model draws on a "complex web of interrelationships between stakeholders" (p. 28) where stakeholder groups effect change and use power depending on alliances, need and environmental pressure, much more suited to the fast paced change occurring in the professional sports sector. Further, Henry and Lee propose seven principles necessary for leadership in sports governance: transparency, accountability, democracy, responsibility, equity, and these two old management retainers: effectiveness and efficiency (2004).

TNZ, in working from a top-down, command and control model (Ferkins, 2007), was attempting to operate with old tools in a new environment. Additionally, TNZ was unable to operate using any of the seven principles proposed by Henry and Lee (2004) for good sports governance.

Jackson and Parry point out that leadership "is a process that goes on between all people and that all people can be involved in leadership, almost in spite of their formal position" (2008, p. 83). A leadership act takes place when, in the words of Marie Corelli, "Scize this very minute. Whatever you can do, or drcam you can begin it; Boldness has genius, power, magic in it" (misattributing Goethe, 1905, p. 31). In a leadership vacuum, we can chose to take leadership action, even though we are not the 'olficial' or acknowledged leader. Phil Dourado tells us that acts of leadership can be taken anywhere, at any time, by any person in an organisation (2007), and that "a vibrant organization is full of acts of leadership" (2007, p. 164). Great results "depend [...] on the capacities of individuals (who may be located in a wide variety of positions)" (Dourado, 2007, p. 165, citing Flowers, 2005), and this capacity is even more critical in the largely voluntary sports sector.

Further, if leadership acts within an organisation are continually met with negativity or resistance, the actors themselves will wear down. Others will see the fruitlessness of taking action, and chose not to take leadership action themselves.

Tennis New Zealand, due to its fragmented constituents and diverse construction, made it extremely difficult to sec acts of leadership at a national level (Ferkins \& Shilbury, 2010; Ferkins, 2007). With no clear leaders, few rewards for acts of leadership, resistance to change and negativity, the lack of visibility of leadership acts reduced the likelihood of TNZ members making acts of leadership.

\section{Feeling a Lack of Ownership and Control}

Unique aspects of sports and sporting organisations include sports have many diverse stakeholders needs which need to be met, without the clarity of actual ownership; the strong sense of emotional connection and passion that stakeholders engender towards their teams, clubs and codes; balancing business needs with competition, the authenticity of the contest and uncertain outcome; strong 'brand' loyalty from sports consumers; vicarious identification and cultural aftiliation with code 'heroes'; high levels of optimism; and a conservative approach to the adoption of new technology while bolding onto traditions which may no longer meet code needs (Hoye, Smith, Westerbeck, Stewart \& Nicholson, 2006).

The tennis' regional sports organisations and regional tennis clubs felt that they should be the 'owners' of tennis in New Zealand, but that the suspected differing agendas of the NSO threatened or challenged that ownership. Due to the lack of frank and honest discussion between the NSO, RSOs and clubs, elements of 
"misunderstanding, suspicion and fear" had grown and had cffectively blocked communication and shared purpose (Ferkins \& Shilbury, 2010, p. 148). TNZ was not communicating with the grass roots members of its organisation, not making it clear that they understood mombers' passion for their sport and their clubs. TNZ appeared unaware of the conservative nature of sportspeople, whereby for change to be effective, it would need to be planned carcfully and communicated well, showing stakcholders clearly where cach action would benefit members and the sport as a whole.

\section{Lack of Dialogue}

Daft \& Pirola-Merlo define dialogue as active sharing \& listening where participants explore common ground without preconceptions or agenda, growing to understand cach other frecly through shared ideas and together finding a common world view (2009). Discussion, on the other hand, is where your point of view is proposed or imposed as the best option, you persuade everyone clse to your view, and opposing opinions are beaten down. The two approaches can be compared as inquiry, mutuality and unity versus advocacy, persuasion and winning.

When taking a dialogue approach, the resuling unity and mutual understanding provides long-term solutions for organisations. Discussion, on the other hand, tends to result a short-term, quick fixes.

Daft \& Pirola-Merlo's model of dialogue and discussion (2009, p. 278) illustrates the differences between these two ideas.

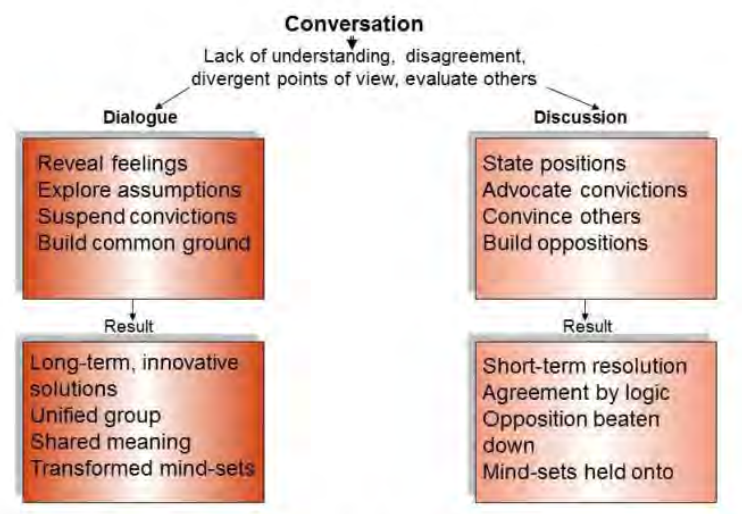

Because dialogue is characterised by group unity, brainstorming ideas to meet each person's needs, working for shared meaning, commitment to looking for the meaning behind the words of others, openness, secking mutual purposes, and transformed mindsets, it fits very well with the concept of shared lcadcrship.

The regions felt that the board had hidden agendas, and were fearful of losing control of 'their' organisation. Parties took up entrenched positions over issues (Ferkins \& Shilbury, 2010; Ferkins, 2007). Before the change process, and intervention of Dr Ferkins, TNZ had a climate of discussion not a culture of dialoguc.

\section{Lack of Power}

Power is an intangible force in organisations that provides us with the ability to "influence other people to bring about desired outcomes" (Daft \& Pirola-Mcrlo, 2009, pp. 380-381). Pfeffer (1992, p. 12, also Yukl, 2006) states that power is the "capacity to bring about certain intended consequences in the behaviour of others". 
TNZ's clubs and regions felt discmpowered and disenfranchised by their national sports organisation; TNZ as 'Head Office' felt powerless to cnact their strategic role by the opposition in the regions (Ferkins \& Shilbury, 2010; Ferkins, 2007).

\section{Having to Please Multiple Stakeholders}

Sport and sporting organisations answer to many diverse stakeholders who feel a strong emotional connection to 'their' code, without the clarity of actual ownership. Business needs must be balanced with competition, along with the authenticity of the contest and cultural expectations (Hoye, Smith, Westerbeck, Stewart \& Nicholson, 2006). While there are often few layers within sports organisations individually, the collective web of sports organisations complicate clear communication, alignment of purpose and wise use of scarce resource to a degree not seen in business (Hoye \& Cuskelly, 2007). Henry and Lee networked governance model draws on this "complex web of interrelationships between stakcholders" (2004, p. 28), acknowledging it, so that stakcholder groups can use it to effect change and use power depending on alliances, need and environmental pressure.

Further, funding is often from tagged sources such as government, gambling or sponsorship arrangements which belps to ensure that sport remains short of resources, thus feels short of choices.

\section{Enormous Expectations}

Sport in New Zealand brings with it cnormous expectations. Our government views - and finds - sports to build on our sporting tradition, and to drive economic development and societal well-being (Hoye, Smith, Westerbeck, Stewart \& Nicholson, 2006; HPSNZ, 2013). Kiwi athletes anticipate, by dint of talent, hard work and training, being able to compete with the best in the world (HPSNZ, 2013). The voluntecs who run the clubs expect some level of voice and ownership in the organisations they give their time to, despite feeling they are "being treated badly with little or no respect from sport organisations" (SPARC, 2007; SPARC, 2006, p. 7). Audiences expect to have access to view sport, and treat sport as a social good (Nicholson, 2007). All participants tend to be more 'brand' loyal than the average consumer (Hoye, Smith, Westerbeck, Stcwart \& Nicholson, 2006).

These expectations then make the performance downturn of TNZ even more of a disappointment for all stakeholders, and helped to provide the critical impetus for change at TNZ.

\section{What do you feel is TNZ's new leadership style?}

\section{Transformational Leadership}

Transtormational leadership is characterised by the ability to bring about significant change in followers and the organisation, and the influence relationships this style uses to create a transformation in follower and leader attitudes, motivations and behaviours. Transformational leaders influence and inspire the follower group using an intangible shared vision, supported by values and ideas which provide meaning and clarity to the group's shared goals. Followers get to be leaders, to develop and self-actualise; leaders get to inspire and paint a vivid 'future vision' (Jackson \& Parry, 2011; Daft, 2009).

Transactional leadership on the other hand, is a style that relies on exchange; where rewards are given in return for compliance and performance (Daft, 2009).

TNZ is definitely trying to transition the governance leadership of the organisation from a transactional style of leadership, based on exchange, to a more transformational style; one based on a clear future vision, values and ideas which to provide greater meaning, clarity and better aligned goals. 


\section{Ethical Leadership}

Intcgrity, honesty, being professional, being dependablc, trustworthy, leading by example and communicating what is accountable organisational behaviour are becoming features of ethical lcadership. Ethical leaders do not have a personal need for power; they rather divert it for the benefit of others (Brown \& Trevino, 2006). TNZ does not surround themselves with personal hype and publicity; as an organisation, the distrust charismatic traits. As opposed to focusing on profit, they are creating a socially good, and are attempting to cmbed a culture of development and sharing towards all participants.

However, this leadership style does not allow for acts of leaderslip, which the next option docs make room for.

\section{Shared Leadership}

Pearce \& Conger define shared leadership as "A dynamic, interactive influence process amongst individuals in groups for which the objective is to lead one another to the achievement of group or organisational goals or both" (2003, p. 1). Allcn, Morton and Li define it as "the co-creation of an environment by a group of individuals, organizations, and communitics with the intent to accomplish a common vision and collaborative goals" (2003, p, 4),

The components of shared leadership are detined by Moxley (2000) as balance of power (ic equal partners); shared purpose; shared responsibility; mutual respect; commitment (both in tough times and good times).

For the partncrship model to work, you need an egalitarian balance of power, and to use their personal power (our own "gifts and skills, our competence and our expertise") to co-create win:win outcomes. Equally, no one within the group can use cocréve power or the power of their position. Those within the organisation must be equal partners, empowering each other. Creating a true balance of power is likely the hardest aspect of a shared leadcrship model (Moxley, 2000, p. 96; Frerkins, 2007).

The element of shared purpose must be lived by every member of the leadership group, with individual's divergent opinions and agendas subsumed for the group goal. Shared leadership has room for different tactics, debate and working through conflict, but the purpose remains the same. The partners honour the opinions of all, but the shared commitment to the group's intended outcome is always clearly in view and being aimed for by all (Moxley, 2000).

Responsibility and accountability for partnership work is also essential. This cannot be an "us and them" model; "it can only be us. There is no waiting for someone else to act" (Moxlcy, 2000, p. 76). Interestingly, Moxlcy also suggests that shared leadership needs to separate authority and accountability, regardless of position, so that cvery role in the organisation is where the 'buck stops' (Moxley, 2000).

Moxley also specifies decp respect for the" inherent worth and value" people as an essential element of shared leadership (2000, p. 76); cmbracing diversity, and assuming that all participants bring unique gifts, skills and cnergies. Respect also requires dignity, respect and truly valuing each individual.

Moxley's tinal requirement is partnering in the nitty-gritty, with all participants work together, interdependently, to make sense of demanding, complex, real and concrete problems. Sharing in the tough times when change is mission-critical can be easier than creating shared outcomes when life is easy, where egos and agendas bloom. With a shared leadership model, no one will save you but yourself; there is no manager who will decide and tell the team what to do (Moxlcy, 2000).

When Moxley's requirements are met, rclationships transform into a partnership, inspiring a fecl and tone of increased vitality and energy; eren spirituality (2000). 
Characteristics of shared leadership (Nemcrowicz \& Rosi, 1997, p. 16) as compared to universalistic (trait and great man) lcadership show a clear difference in philosophical approach. Shared leadership aligns well with sports organisations where there is a more societal agenda and voluntecrs are driven by generosity, their love of sport, creating a sense of social connection, and paying back (appreciation) (SPARC, 2006):

\begin{tabular}{|l|l|l|}
\hline Characteristics & \multicolumn{1}{|l|}{ Universalistic Leadership } & Quality of people's interactions \\
\hline Authority base & Formal position & Pcople working well together \\
\hline Evaluated by & Leader solving problems & $\begin{array}{l}\text { All work to enhance processes. } \\
\text { Shared responsibility \& fulfilment }\end{array}$ \\
\hline Responsibility & Leaders provide solutions \& answers & $\begin{array}{l}\text { Interdependence. All are active } \\
\text { participants in the leadership process }\end{array}$ \\
\hline Power / Equality & $\begin{array}{l}\text { Distinct differences between leaders } \\
\text { \& followers }\end{array}$ & $\begin{array}{l}\text { Comms arc key, focusing on } \\
\text { dialoguc }\end{array}$ \\
\hline Communication & Often formal & $\begin{array}{l}\text { Valuc democracy, honesty \& shared } \\
\text { cthics. Scek common good. }\end{array}$ \\
\hline Processes & $\begin{array}{l}\text { Often rely on secrecy, deception \& } \\
\text { Payolfs. }\end{array}$ &
\end{tabular}

Sports' collective ideals (SPARC, 2006) fit well with Nemerowicz \& Rosi's shared leadership characteristics; those aspects of interaction, working together, interdependence, communication and sceking the common good (1997, p. 16).

TNZ was initially a far more 'command and control' oriented culture. The shift to a shared leadership model will provide many dallenges, but is a model far better suited to a sports organisation largely run by voluntecrs, where participation in decision making is also of prime importanoc (Inglis, 1997).

\section{Involvement in Decision-making}

The "Continuum of involvement in decision making" was expanded by Dr Ferkins from the three "Levels of Part-time Board Member Involvement in Strategy" proposed by Pettigrew and McNulty (1999). Similar to Tamnenbaum and Schmidt's "Continuum of leadership behaviour" (1973), the Continuum of Involvement outlines how much organisations involve participants in decision-making; ranging from arbitrary directing to total participation.

Dr Ferkins defined 'being told' as being where the board "accepts or rejects proposals presented by management" (Ferkins, 2007, p. 19), and aligned this with Pettigrew \& McNulty's Level 1(1999). Level 2 was where the board was consulted with and "helps shape ideas regarding strategy" (p. 19) under "being asked'; and Level 3 where the board's "influence is continuous and helps create an environment for strategic debate and influences the way management devclops strategy" (p. 19) aligned with 'shaping design'. Dr Ferkins then suggests two additional levels, with (4) 'co-leading design' aligned with Tannenbaum and Schmidt's Leadcrship Continuum at "Manager permits subordinates to function within limits defined by superior" (1973, p. 164), where the beard "co-leads the development of a strategie plan in full collaboration with management" (p. 19), followed lastly by (5) 'Driving design' where the board "collaborates with management to design board processes that utilise, monitor and sustain the strategic prioritics" (p. 19). Sec below, Ferkins, 2007, after Pettigrew \& McNulty, 1999: 


\section{Continuum of Involvement}

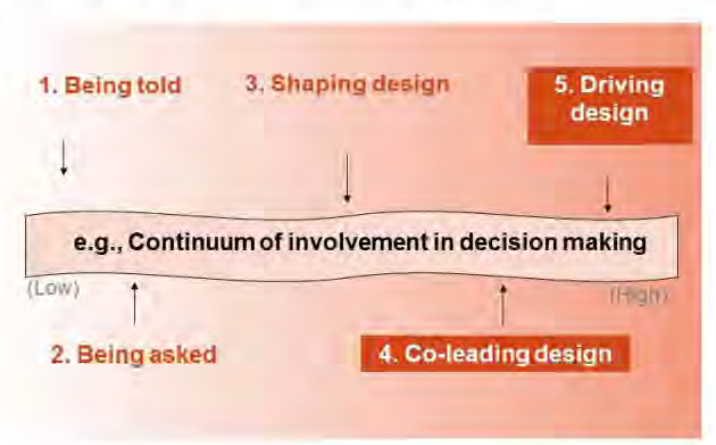

This model then fits very well with the idea of shared leadership.

TNZ initially operated at the 'Being told' end of the spectrum, which was not achieving the organisation's goals, nor meeting the needs of the regional members, the clubs or the sport as a whole.

They are now aware that they are aiming towards the 'Driving design' end of the spectrum where the board "collaborates with management to design board processes that utilise, monitor and sustain the strategic priorities" end of the continuum (Ferkins, 2007, p, 19); where the skills, motivations, expectations and rewards for all participants are very much different.

\section{Netwarked Model}

Where traditional business governance models are more hierarchical, top-down, controlling and driven by exchange with salaried management and paid employees, sports administration must rely far more on the genuine goodwill and the passion of the participants. Sport governance tends to be more open, more diverse and far more alliance-driven. Almost everyone involved in sporting endeavour will have an engaged opinion - though often diverse - as to whether the operation is being run well or poorly, and be interested in taking action to correct it.

The networked governance model of Henry and Lee (2004) draws the idea that sports operates using a "complex web of interrelationships between stakeholders" (p. 28) where stakeholder groups effect change and use power depending on alliances, need and environmental pressure. This model is suited to the fast paced change occurring in the professional sports sector, it is flexible, adaptive and a model that enables sports organisations to respond quickly to shifts in the external environment.

The networked model works in several ways. Firstly, by being clear about the purpose, nature and direction of each organisation within the loose alliances that are formed. Secondly, by being directly accountable to the stakeholders and for the decisions that they make with regard to risk, finance and to the spirit of the sport. Thirdly, in acting as representatives when making decisions, and ensuring their members also are representative of the organisational demographics. Fourthly, by taking responsibility as stewards for the longevity, sustainability and community of the sport. Fifthly, in treating all aspects of the organisation with fairness, parity and equity. Sixthly, and finally, in ensuring that the sports organisation is both effective and efficient (Henry \& Lee, 2004).

Considering Henry and Lee's seven requirements, TNZ was: (1) unclear about their purpose, nature and direction of each member of the alliance; (2) unable to be accountable due to that lack of clarity; (3) was not acting as representatives when decision-making; (4) was unable to act as sports stewards; (5) was 
unable to provide fairness, parity and equity; $(6 \& 7)$ was therefore ineffective and efficient (Ferkins, 2007; Ferkins \& Shilbury, 2010).

'TNZ in seeking potential solutions for reworking the organisation's structure adopted, in Dr Ferkins' opinion, Henry and Lee's networked governance model ("Systemic governance of sport: football - a web of interaction between stakeholders" 2004, p. 30) overlaying the shared leadership aspects of powersharing, participation in decision-making, partnering, co-ownership and collaboration to create their umique Networked model of governance (Ferkins, 2007).

\section{The Networked Model}

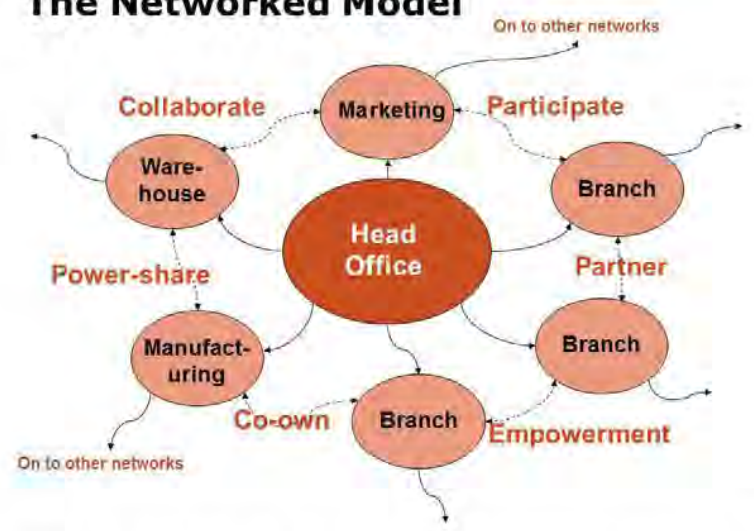

TNZ shifted from an (A) hierarchical, top-down governance model to a (B) flatter, egalitarian shared leadership model, where true representative shared leadership is sought and rewarded (Ferkins \& Shilbury, 2010, p. 251)

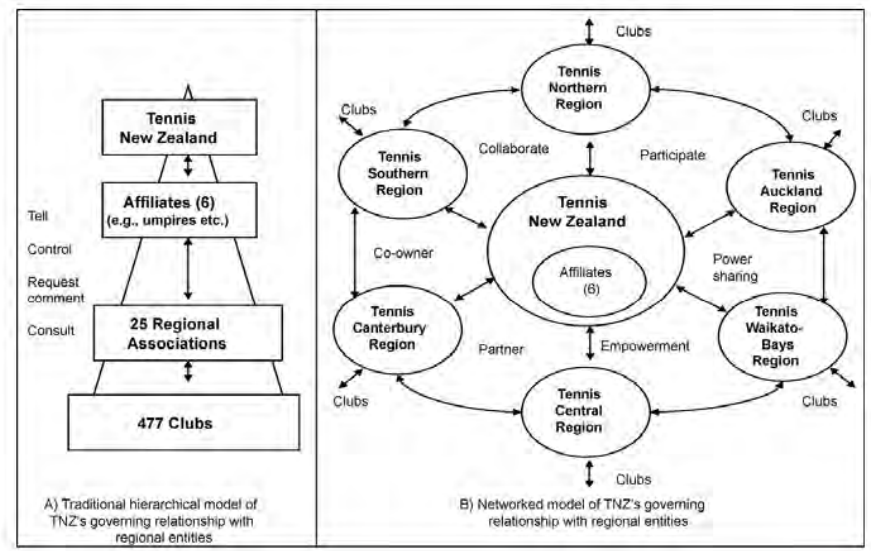

\section{What issues might TNZ face under a change of CEO or Board Chair?}

\section{Fear of team leadership}

Jackson and Parry (2011) note that people are intrinsically suspicious of team leadership, not wanting to participate in a model which may be 'shared' in name, but not in nature, rewards or responsibility. New personnel, particularly in paid positions, may find their distrust of the shared leadership model creates barriers which effectively halt the effectiveness of TNZ model. 
Risk of cultural shift

Jackson and Parry (2011) flag the sustainability of distributed leadership models over time. With personnel, policy, reward, external environment and strategic changes, the initial purpose for shared leadership may change so much that the underpinning principles are dispersed or no longer relevant. Further, Jackson and Parry suggest that hierarchical models still have benctits to contribute, and that leader-centric models, with refinement, may serve as a "healthy democratic counterbalance" (2011, p. 111).

\section{Challenge to the leader's ego}

Ferkins (2007) raises the issue of shared leadership being a challenge to the appointed organisational leadership; both the CEO and the Chair of the Board. When a CEO is appointed to a position, it is expected that the power, authority and responsibility for decisions, results, purpose, culture and goalachievement falls into the one 'accountable' set of hands.

A more traditional CEO coming on board may find working in a truly shared leadership model, where the separation of authority and accountability (Moxley, 2000) might find the new leader struggling to understand where they fit, how to appropriately use power, and how their results will be measured.

\section{Logistical Challenges}

Ferkins (2007) raises the issue of shared leadership having logistical challenges in creating a shared leadership model, and in keeping a shared leadership model functioning healthily over time.

Creating the necessary shared leadership environment where there is a balance of power, a shared purpose, shared responsibility, building mutual respect and commitment (Moxley, 2000) is a difficult transition from an organisation such as TNZ where there was suspicion, mistrust, silos, segregation and no clear communications channels (Ferkins, 2007). A great deal of effort must be invested in enabling free dialogue and building the interpersonal networks that the model relies on.

In addition, the time and enduring effort that it takes to ensure that the group stay engaged in rich dialogue, continues to build trust, respect, and commitment will provide their own logistical challenges when there are so many other claims on individual's time and energy.

Power \& Status

Jackson and Parry (2011, p. 104) suggest that "decp power structures" visible in organisations through car parks, company cars, office spaces and furniture, access to key personnel, actions, language, mannerisms and rewards can reinforce our leadership assumptions, stereotypes and prejudices. Those coming into a shared leadership organisation may seck to remake it in line with their own expectations. Shared leadership models provoke legitimate concerns over concentrations of power, and highlight the roles and influence of followers.

Additionally, someone who is used to wielding position or coercive power could destroy the trust inherently necessary for shared leadership (Moxley, 2000).

\section{What rewards does a shared leadership style bring?}

Transformational style

Shared leadership is a transformational lcadership style with a shared process (Jackson \& Parry, 2011), which inspires carcful communication, and a lot of listening. The idea of collective leadership was initially proposed by Burns in 1978, the initiator of the transformational leadership meta-theory, which Burns 
expanded on in 1996, exploring the idea of "webs of potential collective leadership" (p. 1). This concept fits well with the networked model of Henry and Lee (2004).

\section{Changes/decisions/actions become embedded}

With shared leadership, when the group agrecs, there is no wasted effort in fighting the change, It is adopted and actioned. Because of the wide-spread agreement and adoption, one or two changes in leadership group personnel will not result in a unilateral change in strategy or direction. Thus change can be embedded. Additionally, groups tend to make better decisions and negotiate complexity better than individuals - one of the many rcasons for governance boards, committees, organisations and teams (Elkin, Jackson and Inkson, 2004, as cited by Jackson \& Parry, 2011; Jackson \& Parry, 2011).

\section{Enables leadership succession}

Shared leadership enables succession in two ways. Firstly, leaders create more leaders through the proces: of empowerment (Kouzes \& Posner, 1998, as cited by Jackson \& Parry, 2011). There is a rough proverb that to see where a leader has been, look for more leaders. Sccondly, with a shared leadership model, everyone is more able to step into cach other's role as a direct result of the collaborative characteristics outlined by Moxley (2000) of having a shared purpose, shared responsibility and commitment.

\section{Allows other forms of leadership to be considered}

The aspects of equal partnership, shared purpose and shared responsibility also allows other forms of leadership to be considered (Moxley, 2000). Because the organisation is focused on what is best for the organisation and egos are put aside for organisational good, the partners are able to step back and consider what other forms of leadership that may better deliver what is truly best for the organisation.

\section{Creates a culture of respect}

The culture of respeet created in a shared leadership model becomes endemic through the organisation (Moxley, 2000). A shared leadership team's interactions and dialogue is of high quality; they work well together, all aiming to enhance processes; they share responsibility, are active participants in the leadership process and acknowledge their interdependence; they possess values of democracy, honesty and shared ethics, secking the common good. This leads inevitably to mutual respect and trust (Nemerowicz \& Rosi, 1997).

\section{Enables different \& creative mental models to flourish}

Due to the shared leadership characteristics as outlined by Nemerowicz and Rosi (1997) Moxley (2000) it too is inevitable that in such a supportive and appreciative atmosphere, different and creative mental models, such as "post-herojic or anti-heroic normative modes" are encouraged to flourish, and to add value to the culturc and creativity of the organisation (Jackson \& Parry, 2011, p. 111).

\section{Allows and fosters diversity}

Again, with regard to the shared leadership characteristics earlier detailed by Nemerowicz and Rosi (1997) Moxley (2000), diversity too is a natural side-effect.

\section{Allows for flexibility}

The structure of a shared leadership model allows for more flexibility when making complex decisions in today's fast changing environment, "characterized by speed, ambiguity and complexity" (Jackson \& Parry, 2011, p. 105).

\section{Allows for ownership}

Again, with regard to the shared leadership characteristics earlier detailed by Nemerowicz and Rosi (1997) Moxley (2000), the interdependence between the regions, the clubs and TNZ allowed "greater clarification of the power dynamics and issues of "ownership"' (Ferkins, 2007, p. 24). 


\section{How do Acts of Leadership fit with Shared Leadership?}

First have the group watch Phil Dourado's True Leader Tales clip (2007) at

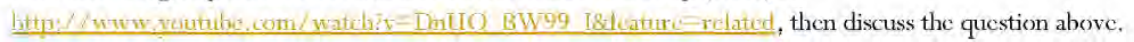

Jackson and Parry point out that leadcrship "is a process that goes on between all people and that all people can be involved in leadership, almost in spite of their formal position" (2008, p. 83). A leadership act takes place when, in the words of Marie Corclli, "Seize this very minute. Whatever you can do, or dream you can begin it; Boldness has genius, power, magic in it" (misattributing Gocthe, 1905, p. 31). In a leadership vacuum, we can chose to take leadership action, even though we are not the 'official' or acknowledged leader. Phil Dourado tells us that acts of leadership can be taken anywhere, at any time, by any person in an organisation (2007), and that "a vibrant organization is full of acts of leadership" (2007, p. 164). Great results "depend [...] on the capacities of individuals (who may be located in a wide variety of positions)" (Dourado, 2007, p. 165, citing Flowers, 2005), and this capacity is even more critical in the largcly voluntary sports sector.

The components of shared leadership are detined by Moxley (2000) as balance of power (ic equal partners); shared purpose; shared responsibility; mutual respect; commitment (both in tough times and good times). The shared leaderslip model also relies on having authority derived from high quality participant interactions, which can be measured by the teams and networks working well together. Responsibility is shown by the participants consistently enhancing work processes with rich, open communication and dialoguc. There is true shared responsibility, which leads to fulfilment. All participants understand their interdependence; they are active in the leadership process, they value democracy, honesty and have shared ethics (Nemerowicz \& Rosi, 1997). Trust must underpin cach transaction (Martin, 1998; Hosmer, 1995). Each understands that the 'buck stops' at their desks; exactly the requircments for acts of leadership throughout the organisation (Moxley, 2000; Dourado, 2007).

\section{Where have you seen shared leadership?}

Ask students to discuss examples of where they have secn shared leadership, and draw out the characteristics which worked, and the barricrs they found.

Look for commonalitics and themes between the examples, particularly if there is a strong "higher purpose' in the organisations where this has been tried (such as sports, hobbies and organisations with some type of spiritual focus). 


\section{BIBLIOGRAPHY}

Allen, Beverlyn Lundy, Morton, Lois Wright \& Li, Tianyu (2003). Shared Leadership. USA: Iowa State University.

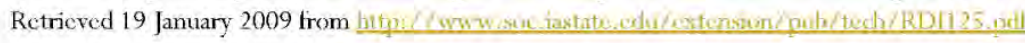

Avolio, Bruce J.; Walumbwa, Fred O. \& Weber, Todd J. (2009). Leadership: Current Theories, Research, and Future Directions. Annual Review of Psychology, January 2009, Volume 60, issue 1 (pp. 421-449)

Carron, Albert V. \& Chelladurai, Dr Packianathan (1981). Cohesiveness as a Factor in Sport Performance. International Review for the Sociology of Sport, June 1981, Volume 16, jssue 2 (pp. 21-43)

Bloom, Gordon A., Schinke, Robert J., \& Salmela, John H. (1997). The development of perceived communication skills by elite basketball coaches and athletes. Coaching and Sport Science Journal, Volume 2 issue 3 (pp, 3-10)

Brown, Michacl E. \& Treviño, Linda K. (2006). Ethical Leadership: A review and future directions, The Leadership Quarterly, December 2006, Volume 17, issue 6 (pp. 595-616)

Burns, John Macgregor (1996). Empowerment for change: A conceptual working paper. USA: Kellogg Leadership Studies Project, University of Maryland

Corclli, Marie (1905). The Spirit of Work in The Daily Mail (Editors) The Queens Christmas Carol: An anthology of poems, stories, essays, drawings and music by British authors, artists and composers. UK: Ballantyne Press

Crust, Lee \& Lawrence, Ian (2006). A Review of Leadership in Sport: Implications for Football Management. Athletic Insight, December 2006, Volume 8, issue 4 (pp. 28-48)

Daft, Richard L. \& Pirola-Merlo, Andrew (2009). The Leadership Experience (Asia-Pacific Version 1). Australia: Cengage

Dorado, Phil (2007). The 60 Second Leader: Everything you need to know about leadership, in 60 second bites. UK: Capstone Publishing Ltd

Ferkins, Lesley (2007), Sport Governance: Developing strategic capability in national sport organisations. Australia: Deakin University, umpublished doctoral dissertation

Ferkins, Lesley; McDonald, Gael \& Shilbury, David (2010). A model for improving board performance: The case of a national sport organisation. Journal of Management and Organization, September 2010, Volume 16, issue 4 (pp. 601-621)

Ferkins, Lesley; McDonald, Gael \& Shilbury, David (2005). The Role of the Board in Building Strategic Capability: Towards an Integrated Model of Sport Governance Rescarch. Sport Management Review, November 2005, Volume 8, issue 3 (pp. 195-225)

Ferkins, Lesley \& Shilbury, Datid (2012). Boards Bcing Strategic: It's a Balancing Act. Retrieved 4 July 2013 from

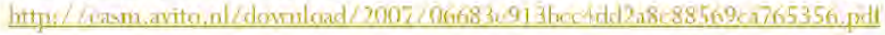

Ferkins, Lesley \& Shilbury, David (2012). Good Boards Are Strategic: what does that mean for Sport Governance. Journal of Sport Management (2012) issue 26 (pp. 67-80)

Ferkins, Lesley \& Shilbury, David (2010). Developing board strategic capability in sport organisations: the national regional governing relationship. Sport Management Review, Volume 13, no. 3, (pp. 235-254)

Ferkins, Lesley, Shilbury, David \& McDonald. Gacl (2009). Board Involvement in Strategy: Advancing the Governance of Sport Oryanizations. Journal of Sport Management, May 2009, Volume 23, issue 3 (pp. 245-277) 
Ferkins, Lesley; Shilbury, David \& Smythe, Liz (2013). Sport governance encounters: Insights from lived experiences. Sport Management Review, August 2013, Volume 16, issue 3 (pp. 349-363)

Getty Images (2 January 2013). Marina Erakovic. Retrieved 15 July 2013 From

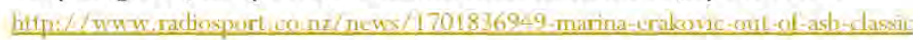

Henry, Ian, \& Lee, Ping Chao (2004). Governance and ethics in sport, in J. Beech \& S. Chadwick (Eds.), The Business of Sport Management. UK: Pcarson Education (pp. 25-41)

Hosmer, LaRue Tone (1995). Trust: The Connecting Link between Organizational Theory and Philosophical Ethics. The Academy of Management Review, April 1995, Volume 20, issue 2 (pp. 379-403)

Hoyc, Russell \& Cuskelly, Graham (2007). Sport Governance. UK: Elsevier

Hoyc, Russell; Smith, Aaron; Westerbeck, Hans; Stewart, Bob; Nicholson, Matthew \& Smith, Aaron (2006). Sport Management; Principles and Applications. UK: Elsevier

HPSNZ (2013). Strategic Plan. NZ: High Performance Sport New Zealand. Retrieved 10 August 2013 from

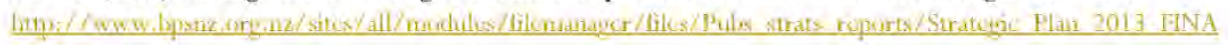
$\underline{\text { I pelli }}$

Jackson, Brad \& Parry, Ken (2011). A very short, fairly interesting and reasonably cheap book about studying leadership (second edition). UK: Sage

Jackson, Brad \& Parry, Ken (2008). A very short, fairly interesting and reasonably cheap book about studying leadership. UK: Sage

Manz, Charles C.; Pearce, Craig L.; Mott, Jetl W.; Henson, Zac; \& Sims Henry P. Jr. (2013). Don't take the lead...share the lead: Surprising leadership lessons from big time college sports. Organizational Dynamics, January-March 2013, Volume 42, Issue 1 (pp, 54-60)

Martens, R. (1990). Successful Coaching, USA: Leisure Press

Martin, Mirta M. (1998). Trust Leadership. The Journal of Leadership Studics, 1998, Volume 5, issue 3 (pp. 4149)

Moxley, Russell S. (2000). Leadership and Spirit. USA: Jossey-Bass.

Nemerowicz, Gloria \& Rosi, Eugene (1997). Education for Leadership and Social Responsibility, London, UK: Falmer Press.

Pearce, Craig L.; Conger, Jay A. \& Locke, Edwin A. (2008). Shared leadership theory. The Leadership Quarterly, October 2008, Volume 19, Issue 5 (pp. 622-628)

Pearce, Craig L.; Conger, Jay A. \& Locke, Edwin A. (2007). Shared leadership theory. The Leadership Quarterly, June 2007, Volume 18, Issuc 3 (pp, 281-288)

Pearce, Craig L., \& Conger, Jay A. (2003). All those years ago: The historical underpinnings of shared leadership. In C. L. Pearce, \& J. A. Conger (Eds.), Shared leadership: Reframing the hows and whys of leadership. USA: Sage (pp. 1-18)

Pearce, Craig L.; Manz, Charles C. \& Sims, Henry P. Jr. (2009). Where Do We Go From Here? Is Shared Leadership the Key to Tcam Success? Organizational Dynamics, July-Scptember 2009, Volume 38, Issuc 3 (pp. 234-238) 
Pearce, Craig L.; Manz, Charles C. \& Sims, Henry P. Jr. (2008). The roles of vertical and shared leadership in the enactment of executive corruption: Implications for rescarch and practice. The Leadership Quarterly, June 2008, Volume 19, Issue 3 (pp. 353-359)

Pearce, Craig L. \& Manz, Charles C. (2005). The New Silver Bullets of Leadership: The Importance of Self- and Shared Leadership in Knowledge Work. Organizational Dynamics, July-September 2009, Volume 34, Issue 4 (pp. $130-140)$

Pettigrew, Andrew \& McNulty, Terry (1999). Strategist on the Board. Organization Studies, 1999, Volume 20, issuc 1 (pp. 47-74)

Raynes, Chris (2012).Promato Club Membership Manager Demonstration. NZ: Topspin Systems Ltd. Retrieved 4 July 2013 from http: / / www. canterburutonnis,conz/wp-contont/uploards/2012/05/Promate-Domo-TNZ-May$2012 \cdot \mathrm{pdi}$

Raynes, Chris (2012).Promato Fact Sheet. NZ: Topspin Systems Ltd. Retrieved 4 July 2013 from

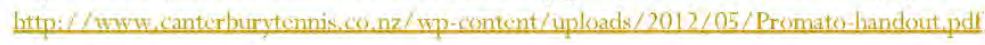

Rowe, Katic; Ferkins, Lesley; Shilbury, David, \& Hinckson, Erica (2013). Sport development and physical activity promotion: An integrated model to enhance collaboration and understanding. Sport Management Revicw, August 2013, Volume 16, issue 3 (pp. 364-377).

Shilbury, David \& Ferkins, Lesley (2011). Professionalisation, sport governance and strategic capability. Managing Leisure, 2011, Volume 16, issuc 2 (pp. 235-254).

SNZ (n.d.). Our Partners, New Zealand: Sport New Zealand. Retrieved 15 July 2013 from

bttp: / / www.sportnz.org-nz/en-nz/our-partners/

SNZ (2008). Participation in Sport and Recreation (from 2007/08 Active NZ Survey). NZ: Author. Retricved 15 July 2013 from http: / Hww. actixenzsurvey,org, nz/Results/2007-08-Active-NZ-Surfey/National-

Report/Participation-in-Sport-and/Recreation/

SPARC (2007). Voluntecrs: the heart of sport. NZ: Sport New Zealand. Retrieved 10 August 2013 from hitp: / / www. sportnz, ory.nz/Documents/sport \%20dovelopment/Voluntecrs-beart-of-sport-cxperjencesmotixations. pill

SPARC (2006). Finding and keeping voluntecrs: What the rescarch tells us. Retrieved 10 August 2013 from

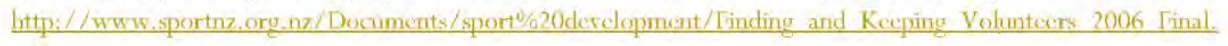
lidil

StatsNZ (2013). Interactive population pyramid for New Zealand. NZ Government: Statistics New Zealand.

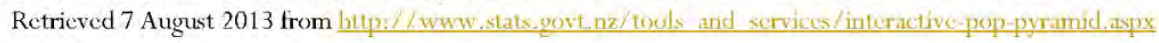

Tannenbaum, Robert \& Schmidt, Warren H. (1973). How to Choose a Leadership Pattern. Harvard Business Review, May-June 1973, Volume 15, issue 3 (pp. 162-180)

TNZ (21 May 2012). Tennis New Zealand Roadshow Review. Retrieved 4 July 2013 from

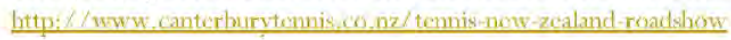

TNZ (2012).Proposed New Affiliation Fec Model. Retrieved 4 July 2013 from

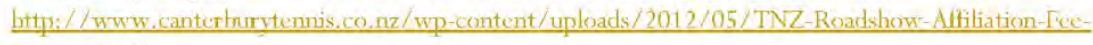
Proposal.judt

TNZ (2011). About Tennis NZ. NZ: Author. Retrieved 17 August 2011 from http: / www tomisnz.com/Article aspx?ID $=508$ 


\title{
Armstrong
}

\section{Lance Armstrong - Everybody's doing it}

\author{
A case study about leadership
}

- My name is Lance Armstrong. I am a cancer survivor. I'm a father of five. And yes, I won the Tour de France seven times" 1

From 1999 to 2005, Lance Amstrong annually won road cycling's most public event: the Tour de France. Competed for, over three weeks in 23 stages, the Tour weaves through 2,500 miles of plains, hills and mountains and is a test of endurance, strategy, technology, skill, stamina and teamwork ${ }^{2}$.

However, the race has been tarnished by questionable practices; the most prevalent being the taking of banned substances by cyclists. Drugs programmes are overseen globally by the World Anti-Doping Agency (WADA) and specifically for US athletes by the quasigovernmental United States Anti-Doping Agency (USADA) .

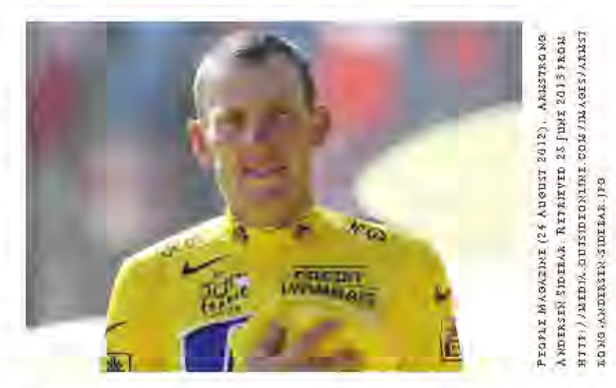
Testing at races is delegated to cycling's international governing body, Union Cycliste Internationale (UCI), with test issues being passed on to national cycling bodies (such as USA Cycling), All these organisations should work cohesively together, but in reality, they all have different aims, rules and regulations. Athletes can seek the gaps.

Up until 1994, Lance Armstrong won steadily, but not outstandingly. That year, Lance started working with $\mathrm{Dr}$ Michele Ferrari, and started winning, rising to seventh in the world. In 1996 he was diagnosed with metastasised cancer, but with aggressive surgery and chemotherapy he was in full remission early in $1997^{6}$.

Lance made his post-cancer cycling comeback in $1998^{6}$, Sponsored by Nike, the US Postal Service (USPS) and others, Lance built a team strong in cycle technology, sports gear, nutrition and capital ${ }^{7}$. As well as for USPS/Discovery, Lance also indirectly rode for his cancer charity, Livestrong ${ }^{8}$, which gave him cult status as a cancer survivor who 'beat' cancer ${ }^{90}$, engendering very strong follower loyalty. He was seen as a risk-taker, with some degree of 'inside' knowledge gained via his illness and recovery ${ }^{11}$.

Lance said "we had one goal and one ambition and that was to win the greatest bike race in the world and not just to win it once, but to keep winning it ${ }^{\text {"12 }}$. The team of medicine men that Lance put together to ensure this included his old friend Michele Ferrari; from 1997 to 1999 and 2004 onwards, Pedro Celaya; and from 1999, Luis Garcia del Moral ${ }^{1213}$. Lance said "My doctors were my gods"14. Concerns raised by journalists and sponsors about his medical team's reputations were brushed aside, or contact became covert ${ }^{13}$.

Lance's contract allowed him "extensive input into rider and staff composition"12. However, once the team started winning, he effectively had carte blanche. Many reported on Lance's coercion, bullying and strong-arm tactics ${ }^{13}$. He was "the boss man of the Tour", establishing his own regime in the peloton. Any racers who challenged him "would be run down by an Armstrong teammate or, for certain violators, by Lance himself"15. A young French cyclist, Christophe Bassons, did not dope and broadcast widely that riders couldn't finish in the top ten without $\mathrm{PEDs}^{16}$, Lance bullied Bassons, eventually forcing him to retire from the tour ${ }^{17}, \operatorname{In}$ Spain 2002, Armstrong red-

${ }^{1}$ (Associated Press, 29 August 2012)

${ }^{2}$ (Browmielocks Blog, 2013)

${ }^{3}$ (WADA, 12 February 2007)

(USADA, n.d)

$s\left(\mathrm{UCI}_{3}\right.$ n.d.)

${ }^{6}$ (Bibliography com, n.d

7(Forbes, 2012; Daily Mail, 2012; Tredenmick, 2012; gothinksport, 2007; McCarthy, 17 January 2013)

Established in 1998

Established in 1998
${ }^{9}$ (Ramplin, 15 Jamuary

${ }_{10}$ (USAToday, 2004)

"(Walsh, 2005)

${ }^{12}$ (USADA, 2012, p. 6 )

${ }^{13}$ (USADA, 2012)

${ }^{14}$ (Amstrong, 2000, pi 119)

is (Saporito, 16 Jamiary 2013)

${ }^{16}$ performance-Enhancing drugs (PEDs) 
carpeted a teammate telling the rider he had to follow the team doctor's doping programme to continue riding for the team ${ }^{18}$. The rider said "Lance called the shots on the team" and "what Lance said went" ${ }^{18}$. Scott Mercier chose to leave competitive cycling in 1997 when the choice-dope or go - was placed before him as a team member ${ }^{19}$. Lance injected limself with $\mathrm{EPO}^{20}$ in front of team mate Jomathan Vaughters saying "“ $[\mathrm{n}]$ ow that you are doing $\mathrm{EPO}$ too, you can't go write a book about it" ${ }^{13}$. Lance's cx-wife, Kristin, ferried and prepared drugs for the team ${ }^{13}$.

Sports writer David Walsh repeatedly raised the issue of doping, and was ostracised by Lance to the point where other journalists wouldn't associate publicly with David as they feared being denied interviews with Lance ${ }^{17} 2123$. Lance sued David for $₫ 300,000$ following David's 2004 book on doping, containing evidence from former team employec Emma O'Reilly about the doping she had witnessed, and from USPS team-mate Frankic Andreu's wife, Betsy. Emma was repeatedly publicly humiliated by Lanoc with accusations of prostitution and alcoloolism ${ }^{23}$. Lance labelled Betsy "bitter" and a "crazed b****" and effectively ended Irankic's cycling carecr ${ }^{1023}$. Betsy's belicf is that Lance's PED consumption was the cause of his cancer.

There was a code of silence - called the "omerta" - amongst the Tour clite. No one spoke about doping, or about Lance $^{12}$. Lance was good friends with the UCI President, and had made two significant donations to UCI, which, when taken with the rumours of doping, and no UCI action, made Lance appear untouchable ${ }^{22}$.

The medicine men found the gaps. When UCI drug testers appeared unexpectedly at the team's hotel, Dr Pedro Celaya managed to smuggle in a litre of saline to Lance's room, administering it before Lance could be tested. Luis Garcia del Moral who kept a spreadshect containing the team deping plan ${ }^{23}$. The team avoided many carly season crents to avoid testing, and undertook training in remote locations, not having to notify UCI or USADA. When Lance tested positive for corticosteroids, the UCI was fobbed off with a retroactive cortisone cream prescription. Lance and two of his teammates had blood drawn in Spain, then reinfused in France during the Tour. Medical 'advice' like this docsn't come cheap: Lance paid Michele Ferrari more than USDS $1 \mathrm{~m}$ between 1996 and $2006^{24}$.

While rumours abounded, there was little proof. USADA started investigating Lance after successfully prosecuting Kayle Leogrande without a positive drugs test, but postponed enquiries due to the US Attorney's Office investigation of Lance's "doping related crimes like drug trafficking, fraud and money laundering" When the federal investigation collapsed, USADA recommenced their investigation ${ }^{26}$ with many of Lance's USPS / Discovery Channel Pro Cycling team mates, friends and employecs providing affadavits that, for more than a decade, doping including EPO, testosteronc, human growth hormonc, cortisone and blood doping took place ${ }^{13}$.

Nearing investigation completion, USADA requested meetings with Lance. Lance and his legal team prevaricated, postponed and finally simply didn't attend ${ }^{13}$, so Lance was charged in absentia. His response was "there is zero physical evidence to support his [Travis Tygart, CEO of USADA] outlandish and heinous claims" ${ }^{127}$. USADA banned Lance from US sport for life and stripped lim of his seven Tour de France wins, passing their decision on to WADA, US Cycling and UCI, who eventually ratified USADA's determinations ${ }^{28} 29$.

Lance said "that athletes can be convicted today without positive A and B samples [... perverts the system" and that the "only physical evidence here [that USADA has] is the hundreds of controls I have passed with flying colors"? However, in February 2013, when asked by Oprah Winfrey in a 'tell all' interview "In all seven of your Tour de France victories, did you exer take banned substances or blood dope?" Lance replied "Yes"

\section{Discussion Questions}

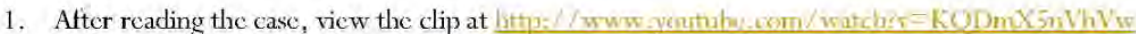
(CBCTheNational, 16 January 2013). What do you fecl are the key issues in this case?

2. What attributes does Lance display?

${ }_{17}^{17}$ (Walsh, 22 October 2012; Willsher, 13 October 2012)

18 (Macur, 10 October 2012)

${ }_{19}^{19}$ (Austin, 12 October 2012)

${ }^{20}$ Banned substance, erythropoietin

${ }^{21}$ Reminiscent of Prime Minister Rob Muldoon's treatment of journalist Tom Scott in New Zealand in the 1970s and 80s

${ }^{22}$ (Walsh, 26 August 2012a)

${ }^{23}$ (Walsh, 14 October 2012)

${ }_{24}$ (The Telegraph, 12 October 2012)

${ }^{25}$ (CBCTheNational, 2013)

${ }^{26}$ (Walsh, 26 August 2012b)

${ }^{27}$ (Armstrang, 2012)

${ }^{28}$ (Gibson, 29 January 2013; Daily Lance, 22 October 2013)

${ }_{29}$ (UCl, 2012)

${ }^{30}$ (BBC, 18 January 2013a) 


\title{
Tennis New Zealand - unify, lead \& strengthen
}

\author{
A case study about leadership
}

How do you co-ordinate a "together, yet separate" organisation made up of 477 affiliated member clubs with different constitutions, aims and structures, 66 unaffiliated clubs, six 'special interest' affiliates, 25 regional divisions, 28 subdivisions and a 25 member board? 1

Sports in New Zealand are funded through Sport New Zealand (SNZ). SNZ provides funding and expertise through national sports and recreation organisations (NSOs \& NROs) $)^{2}$. Effectively, the NSOs are the national representatives for their respective sports, responsible for sports governance and national operation ${ }^{3}$.

The ethos of NSOs is grounded in their history as independent volunteer executive committees which ran on the smell of an oily rag in the service of their members, with their own constitutions and aims. In

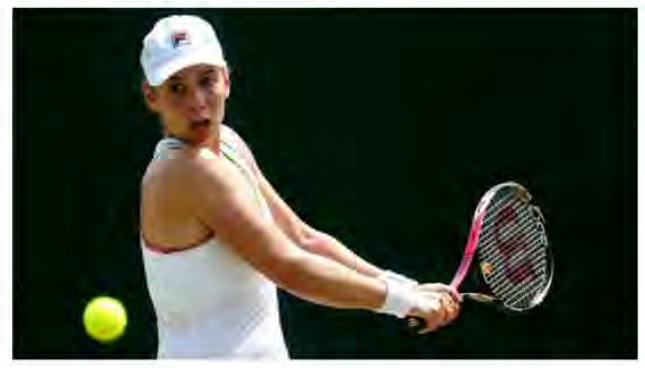
New Zealand, similar to Canada and Australia, NSOs are "responsible for maintaining the rules and organisation"1 of their sporting codes, working on all levels - international, national, regional and club - and nowadays with paid administration and management.

Tennis New Zealand, or TNZ, is New Zealand's NSO for tennis. TNZ is responsible for administration and management, and is proud of being one of the International Tennis Federation founding members. With nearly 500 member clubs and 44,000 individual members, TNZ's activities include national grading, selection and management of representative teams and players, national and international tournament organising and hosting, arranging junior player international tours, supporting our emerging players on the world tours and Grasshoppers, a games-based primary school tennis introductory course ${ }^{4}$.

More than 317,000 New Zealanders play tennis, making it NZ's second most popular adult participation sport after goll ${ }^{5}$. TNZ advocates for all tennis players in New Zealand, including clite Kiwi players such as Marina Erakovic ${ }^{4}$. Today, TNZ is a lean, mean organisation with good communication flows back to grassroots tennis. But it wasn't always that way,

From the 1990s on, tennis experienced a downturn in performance. Players competing internationally struggled to get into the world top 100 , where once tennis in $\mathrm{New} Z$ Zealand had had players in the top $20^{3}$. TNZ's 25 regions were "together, yet separate" duc to the differences in constitutions, aims and structures ${ }^{1}$. 'Head Office' had a culture of imposing decisions and direction on the regions; cach region did what they felt was important ${ }^{6}$.

From the early 2000s, TNZ's turnover was in deficit, rising to a fairly stellar loss of $\$ 400 \mathrm{k}$ in 2006 on a turnover of just over $\$ 1.4 \mathrm{~m}$. A TNZ 'health check' survey in 2004 further revealed declining participation, volunteer numbers, maintenance programmes and funding, and fewer inter-club competitions. Membership decreased $38 \%$ over the 20 years, 1985 to $2005^{7}$. Over $66 \%$ of tennis clubs numbered fewer than 100 members $^{3}$.

Health-check survey participants reported that TNZ was "unwicldy", "ungovernable", had "no agreed agenda for the sport" and that there was a national-regional "disconnect". They appeared to lack a higher purpose to help the

${ }^{1}$ (Ferkins \& Shilbury, 2010, p. 236)

2 (SNZ, n.d.)

${ }^{3}$ (Ferkins \& Shilbury, 2010)

${ }^{4}(\mathrm{TNZ}, 2011)$

${ }^{5}(\mathrm{TNZ}, 2008)$

${ }^{6}$ (Ferkins, 2007)

${ }^{7}$ TNZ 198563500 members; 1990 54000; 2005 43792. Same period NZ population growth of $21 \%-19853.3 \mathrm{~m}, 2006$, $4.2 \mathrm{~m}$ (base) (Ferkins \& Shilbury, 2010; StatsNZ, 2013) 
regions, clubs or volunteers to co-operate with the national body ${ }^{3}$. The clubs felt that Head Office was not listening to them. The regions felt that neither the clubs nor Head Office were listening to them. Head Office was frustrated that no one was doing as they were told, and no one would say why. All participants felt discnfranchised ${ }^{6}$.

There were no clear pathways for communication, strategy, planning, finance, funding, decisions, ideas, innovation, control or reporting. It was too hard to get the 25 regions to agrec, and to keep 25 organisational heads on task and secing the bigger picture. Individual agendas got in the way ${ }^{6}$. Those individual agendas and uneren allocation of resources resulted in power being unevenly spread. More powerful regions had the ability to sequester larger amounts of scarce resources for their own agendas, not necessarily aligned nor prioritised by $\mathrm{TNZ}^{6}$.

What happened next was surprising. In 2005, a New Zealand doctoral rescarcher at Unitech's Department of Sport, Lesley Ferkins, approached Tennis New Zealand to explore what they could do together to improve TNZ's governance. Dr Ferkins looked at how successfiul NSO boards had developed strategic capability, analysed TNZ's context, interviewed participants and identified common themes arising and had TNZ consider, contextualise and apply those ideas. Both parties learned from each other and explored potential solutions in an equal partnership ${ }^{3}$.

They found TNZ was significantly fragmented; all those separate clubs, directions and leaders; plus a greater multiplicity of goals, fimding approaches, constitutions, directors, reporting requirements and constituents effectively working against each other ${ }^{3}$. While the TNZ board contained directors with good strategie thinking skills, grcat sports and macro-environmental knowledge, conducting good strategic design, analysis and articulation; they were effectively being road-blocked when trying to enact their strategic priorities to the regions ${ }^{3}$.

The regions felt that the NSO was imposing, telling, and controlling. They felt disenfranchised and there was a climate of "misunderstanding, suspicion and fear". The regions felt that TNZ misunderstood the idea of sports 'ownership', and that the regions did not have a fair say despite fecling they were the legitimate 'owner'.

TNZ started working together with national and regional stakcholders to develop a "greater level of awareness and appreciation of their respective roles", voicing fears and suspicion that had been allowed to go unexplored for too long ${ }^{9}$. They also faced the realities of their declining sport where in-fighting would only hasten the decline. Through what became real dialogue, the disparate parts of the 'business' got to know each other, trust each other, understand each other's points of view and to debate with each other as equals for the good of the sport. They created a pan-organisational climate of secking the middle-ground, power-sharing and jointly creating paths, processes, outcomes and goals ${ }^{3}$. TNZ's collective focus shifted from control to negotiation and collaboration ${ }^{6}$.

Pressure from Sport New Zealand to get "theír act together" also provided impetus for TNZ ${ }^{10}$. Changes were made to the regional structures, decreasing the regions to six, and changing their constitutions and MOU ${ }^{11}-$ rephrasing 'control' statements as 'enhance' and 'develop' - to allow for a six member representative board charged with "the greater good of the sport", reinforcing the new six regions' autonomy ${ }^{123}$.

The 'us' and 'them' became 'we'. The internal culture of TNZ has continued to shift from an adversarial top-down telling approach to an engaged atmosphere of co-operative inquiry and a federated network of answers.

TNZ is now working towards a stronger sense of collective interdependenee between the different sectors of the organisation, a clear idea of what each of their roles needed to be for the suecess of tennis as a whole, an understanding of their internal 'power dynamies' and a much clearer sense of their regional constitutional "ownership". To embed this in the organisation, TNZ created a new vision: "New Zealand is a tennis nation" and a new purpose: to "Unify, lead and strengthen tennis in New Zealand"13. Their shared goal is clear; their collective path toward it more certain.

\section{Discussion Questions}

1. What do you feel the key issues were for the leadership of Tennis New Zealand?

2. What do you feel is TNZ's new leadership style?

3. What issues might TNZ face under a change of CEO or Board Chair?

\footnotetext{
${ }^{8}$ (Ferkins \& Shilbury, 2010, p. 248)

${ }^{9}$ (Ferkins, 2007, p. 24)

${ }^{10}$ (Ferkins \& Shilbury, 2010, p. 247)

${ }^{11}$ Memorandum of Understanding - documenting and formalising understandings and agreements between organisations

${ }^{12}$ (Ferkins, 2007, p. 28)

${ }^{13}(\mathrm{TNZ}, 2011)$
} 